
WEAR PARTICLES FORMATION IN COLD ROLLING

Melkamu Awoke Mekicha 



\title{
WEAR PARTICLES FORMATION IN COLD ROLLING
}

\section{DISSERTATION}

\author{
to obtain \\ the degree of doctor at the Universiteit Twente, \\ on the authority of the rector magnificus, \\ Prof. dr. ir. A. Veldkamp, \\ on account of the decision of the Doctorate Board \\ to be publicly defended \\ on Wednesday 3 March 2021 at 12.45 hours
}

by

\section{Melkamu Awoke Mekicha}

born on the 7th of April, 1988

in Gojjam, Ethiopia 
This dissertation has been approved by:

\section{Supervisors}

Prof. dr. ir. M.B. de Rooij

Prof. dr. ir. D.J. Schipper

\section{Co-supervisor}

Dr. D.T.A. Matthews

This research was carried out under project number F41.1.14551 in the framework of the Partnership Program of the Materials innovation institute M2i (www.m2i.nl) and the Foundation of Fundamental Research on Matter (FOM) (www.fom.nl), which is part of the Netherlands Organization for Scientific Research (www.nwo.nl).

ISBN: 978-90-365-5136-6

DOI: $10.3990 / 1.9789036551366$

(c) 2021 Melkamu Awoke Mekicha, The Netherlands. All rights reserved. No parts of this thesis may be reproduced, stored in a retrieval system or transmitted in any form or by any means without permission of the author. Alle rechten voorbehouden. Niets uit deze uitgave mag worden vermenigvuldigd, in enige vorm of op enige wijze, zonder voorafgaande schriftelijke toestemming van de auteur. 


\section{Graduation Committee:}

Chairman/secretary:

Prof.dr.ir. H.F.J.M. Koopman

University of Twente

Supervisors:

Prof.dr.ir. M.B. de Rooij

University of Twente

Prof.dr.ir. D.J. Schipper

University of Twente

Co-supervisor:

Dr. D.T.A. Matthews

University of Twente

Committee Members:

Prof.dr.ir. A.H. van den Boogaard

University of Twente

Prof. C. Gachot

Vienna University of Technology

Prof. dr. ir. D. Fauconnier

Ghent university

Dr.ir. T.C. Bor

University of Twente 



\section{Summary}

The surface cleanliness of a cold rolled sheet metal is a very important parameter for product performance in many sectors, such as automotive and packaging industries. Wear particles, generated during cold rolling, contaminate the surface and reduce the surface quality of a cold rolled sheet. Furthermore, wear particles can negatively influence downstream processes such as annealing, galvanizing and deep drawing. A detailed understanding of the microscale mechanisms at the roll-strip interface, relevant for wear particles generation, is crucial to enable control and predictability over the surface quality of a cold rolled metal sheet.

The primary aim of this thesis is to develop a physically based multi-scale wear model for the prediction of wear particle generation. This model development is underpinned by fundamental insights into the relevant interfacial mechanisms during cold strip rolling influencing wear particles generation. The final outcome is a multiscale wear model, developed to estimate the severity of wear particles formation in cold rolling processes operating in the boundary lubrication regime. The wear model is developed through several steps involving modelling the roll-strip contact at the macroscale and modelling the microscale wear behavior of a single roll asperity sliding through a sheet metal.

A contact model is developed based on existing models in the literature to understand how the real contact area ratio and the nature of the roll-strip contact changes as a function of relevant process parameters, as this affects the interfacial phenomena and thus the wear mechanism of the tribological system. In the contact model, the real contact area ratio is calculated and the micro contacts are identified. The effects of several rolling parameters such as thickness reduction, strip/roll roughness, and rolling speed on the real contact area ratio are investigated in the model. The accuracy of the developed contact model was experimentally verified by performing rolling experiments on a two-high pilot mill.

The wear behavior of an individual roll asperity sliding against a flat soft strip is investigated experimentally using scratch experiments and numerically using the material point method (MPM). The effect of asperity sharpness, interface shear strength and surface chemistry on wear particles generation are investigated by employing these methods. Also, a study of wear particle removal criterion is carried out, based on critical equivalent plastic strain, in the MPM simulations by using the degree of wear of the scratch experiments as a benchmark. In addition, the effect of hard chrome plating the rolls on wear particles formation is investigated in a single asperity contact to understand the fundamental mechanisms behind the positive effects of chrome plating on strip cleanliness.

Finally, the multi-scale wear model is developed by mapping the macroscale contact model with the single asperity wear model. This is realized by idealizing each micro-contact in the contact model by an ellipticalparaboloid. The wear model is validated by conducting cold rolling experiments with varying process parameters on a pilot scale rolling mill. Moreover, the influence of rolling parameters on wear particles formation is studied in the rolling experiments. The developed wear model covers the main physical phenomena related to wear particle generation and it can be included in industrial rolling models as both a predictive and retrospective analysis tool. 


\section{Samenvatting}

De oppervlaktebandreinheid van een koudgewalste staalplaat bepaalt in belangrijke mate de productkwaliteit in veel sectoren zoals de automobielindustrie en de verpakkingsindustrie. Slijtagedeeltjes die tijdens het koudwalsen gegenereerd worden blijven achter op het oppervlak en verslechteren de oppervlaktekwaliteit van de koudgewalste band. Bovendien kunnen deze slijtagedeeltjes een negatieve invloed hebben in opvolgende processtappen zoals het gloeien, verzinken en ook tijdens het persen of dieptrekken. Een gedetailleerd begrip van de relevante slijtagemechanismes, die plaatsvinden op microschaal, is cruciaal om de oppervlaktekwaliteit van koudgewalst staal te beheersen en te voorspellen.

Het belangrijkste doel van dit proefschrift is het ontwikkelen van een fysisch gebaseerd multi-scale model voor de voorspelling van de hoeveelheid slijtagedeeltjes die tijdens het koudwalsen gegenereerd worden. Dit model is gebaseerd op het fundamenteel inzicht dat verkregen is over de relevante sljitagemechanismes aan het grensvlak tussen band en walsrol tijdens koudwalsen. Het resultaat is een model dat slijtage tijdens het koudwalsproces in het grenssmeringsregime beschrijft. Het slijta model bestaat uit verschillende submodellen. Het slijtagemodel is ontwikkeld door middel van verschillende stappen, waaronder het modelleren van het werkwals-strip contact op macroschaal en het modelleren van het slijtage gedrag op mircoschaal van een enkele schuivende, ruwheidspiek die door een metalen band glijdt.

Een contact model is ontwikkeld dat gebaseerd is op bestaande modellen uit de literatuur, om begrip te verkrijgen hoe de ware contact ratio en aard van het werkwals-strip contact afhangen van de relevante procesparameters. Dit is van belang voor de verschijnselen aan het grensvlak tussen wals en strip en dus de slijtage mechanismes die een rol spelen tijdens koudwalsen. In het contactmodel worden de punten met waar contact tussen walsrol en strip geïdentificeerd, en de ware contact ratio wordt bepaald. De invloed van verschillende walsparameters, zoals diktereductie, strip/wals ruwheid en walssnelheid, op de ware contact ratio zijn onderzocht met het model. De nauwkeurigheid van het ontwikkelde model is experimenteel gevalideerd met experimenten op een 2-hoog proefwals.

Het slijtage gedrag van een individuele, schuivende, ruwheidspiek tegen een zachter substraat is zowel experimenteel (met krasexperimenten) als numeriek onderzocht. De zogenaamde 'Material Point Method' (MPM) is gebruikt om zo'n contact driedimensionaal te modelleren zodat inzicht verkregen is in het slijtagegedrag en de schademechanismes. De invloed van de straal van de bolvormige ruwheidspiek, de afschuifsterkte van de grenslaag en oppervlaktechemie op de generatie van slijtagedeeltjes is onderzocht. Deeltjes met een equivalente rek groter dan een bepaalde kritische waarde werden verondersteld slijtagedeeltjes te worden. De waarde voor de kritische rek is bepaald met krasexperimenten. Daarnaast is onderzocht welke invloed een harde Chroom-coating, aangebracht op de walsrollen, heeft op de vorming van slijtagedeeltjes. Het bestuderen van contact van individuele ruwheidspieken heeft geleid tot fundamenteel inzicht waarom deze Chroom-coating een positieve invloed heeft op de bandreinheid.

Het multi-scale slijtage model is een combinatie van het contactmodel op macroschaal en het slijtagemodel van één individuele ruwheidspiek op microschaal. Dit is gerealiseerd door ieder microcontact te beschouwen als een paraboloïde met elliptisch grondvlak. Het slijtagemodel is gevalideerd met experimenten op de proefwals waarin relevante procesparameters gevarieerd zijn. Het kan gesteld worden dat het ontwikkelde slijtagemodel de belangrijkste fysische fenomenen en de slijtagemechanismes goed beschrijft zodat het gebruikt kan worden in walsmodellen, zowel als voorspelling als ook voor hulpmiddel bij analyse. 


\section{Acknowledgements}

This thesis is a collective effort of many people who have contributed directly or indirectly. Therefore, I would like to thank all the people who helped me undertake this research and write this thesis.

First, I would like to express my sincere gratitude to my promoter and daily supervisor Prof.dr.ir Matthijn de Rooij for his continuous guidance, cordial mentoring and encouragement at all stages of this research work. I would also like to express my heartfelt gratitude to my co-promoter Dr. David Matthews for his candid supervision, critical observations, timely corrections and amiable approach. Our weekly meetings and conversations were vital in inspiring me to think outside the box and from multiple perspectives to form a comprehensive and objective critique. I would also like to thank my promoter Prof.dr.ir. Dirk Schipper for his valuable inputs and indispensable suggestions.

I would also like to acknowledge Tata Steel Nederlands for the support in carrying out rolling experiments. Particularly, my deepest gratitude to Leon Jacobs for his immense help in planning and facilitating the rolling experiments and the iron tape measurements. These experiments would have not been possible without your invaluable support. I am very thankful to Daphne van de Giesen, Hans Weel, Bart van Rookhuizen and Marco Appelman for their assistance during the experiments. I would also like to thank Dr. Chrostophe Pelletier for being my industry contact at the beginning of my PhD and the useful discussions regarding the research at the progress meetings. I also thank Dr. Henk Bolt for the discussions on rolls.

Many thanks to my colleagues and friends at University of Twente. I am particularly grateful to Erik de Vries, Walter Lette, Nik Nijhuis and Robert Jan Meijer for their indispensable support in the laboratory. I am also thankful to Belinda and Debbie for their kind help in administrative tasks. A special thanks to Dr. Tanmaya for his help on setting up the MPM USER-SMD package. Thank you Dmitrii, Naveed, Can, Xavier, Mohammad, Pramod, Faizan, Andreas, Pedro, Michel, Yuxin, Febin, Aydar, Shivam, Matthias, Matthijs, Luigi, Hasib, Nadia, Marek, Tsietse, Liangyong, Shakil, Ida, Hilwa for the cheerful coffee and lunch breaks, M2i conferences and futsal games.

I would also like to thank my friends Gina, Melesse, Manuel, Angela, Fasil, Tekie, Taha, Dagnachew, Mekuanent, Mersha, Nebeyu, Melaku, Jemal, Nine and Ayesha for the great memories and continuous moral support. Finally, I would like to thank my family for their unconditional love. 



\section{Contents}

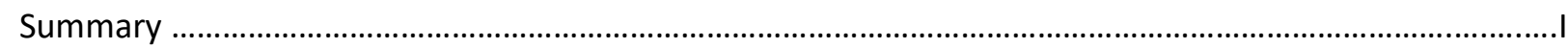

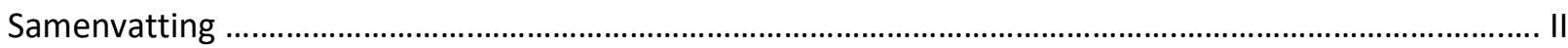

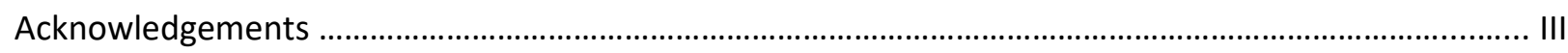

\section{Part I}

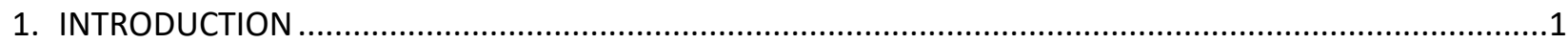

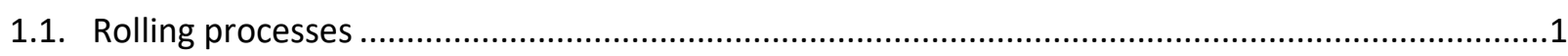

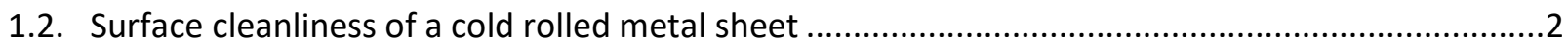

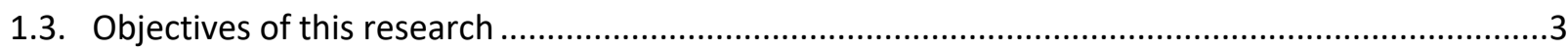

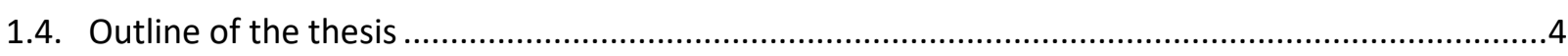

2. FUNDAMENTALS OF WEAR PARTICLES FORMATION IN COLD ROLLING PROCESSES ..............................5

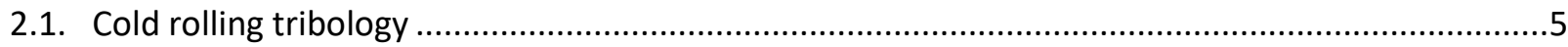

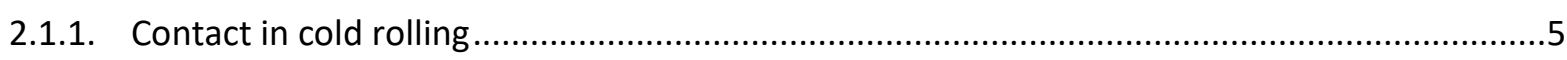

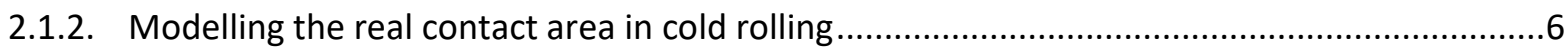

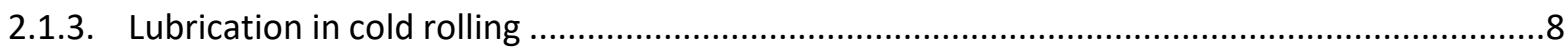

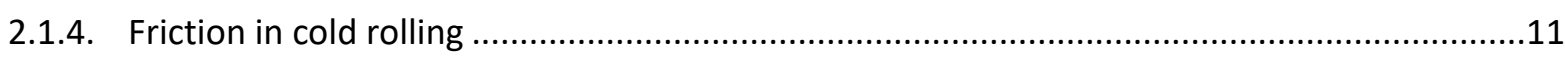

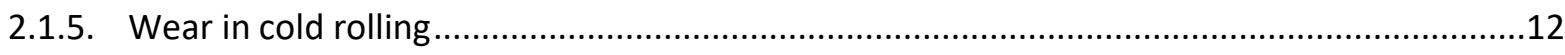

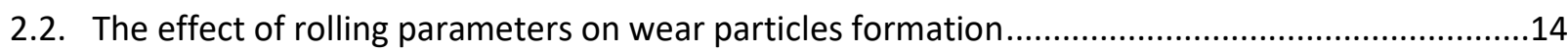

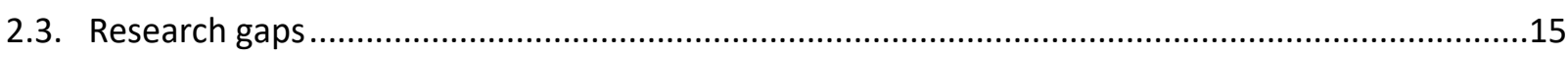

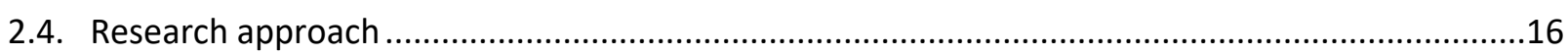

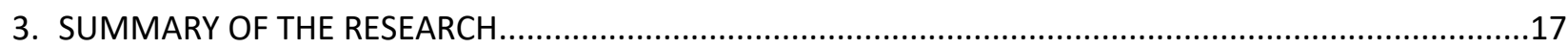

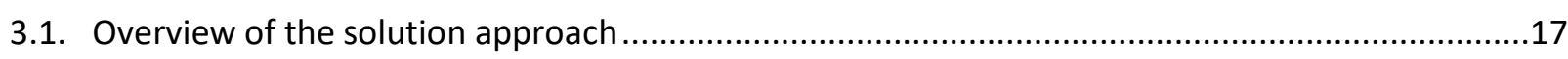

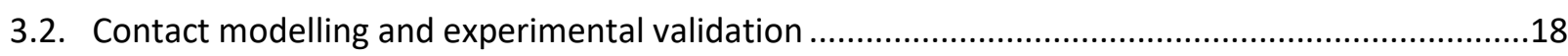

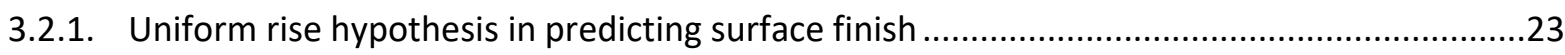

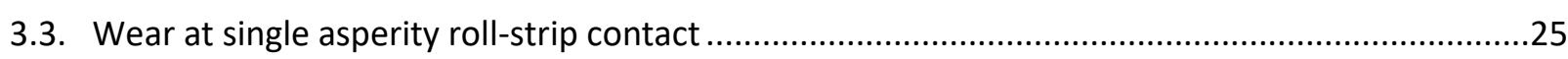

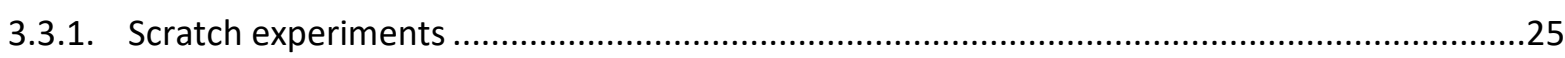

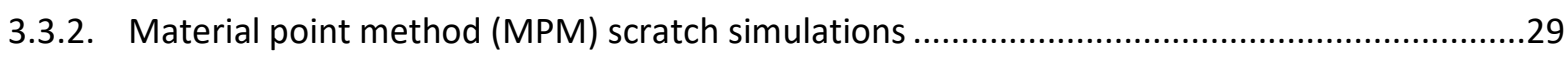

3.4. Multi-scale wear model results and experimental validation ......................................................33

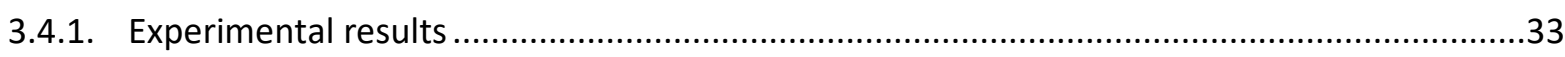

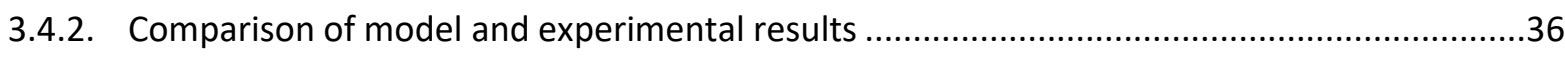

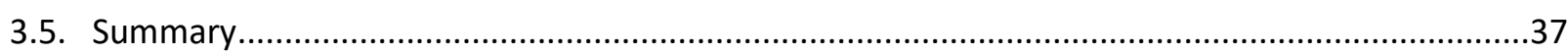

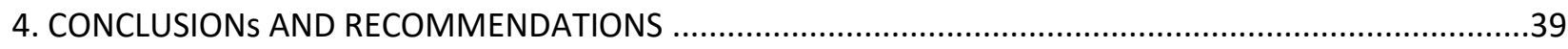

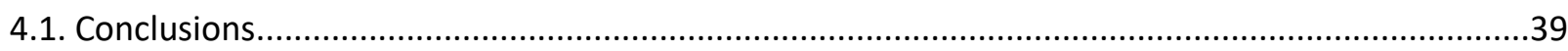

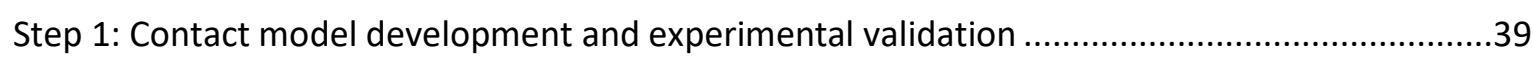

Step 2: Wear at single asperity contact - experimental and numerical study ................................39

Step 3: Multi-scale wear model development and experimental validation ....................................40

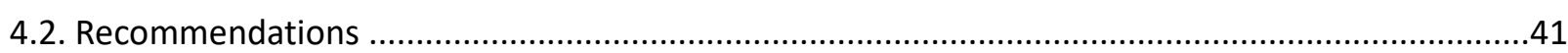

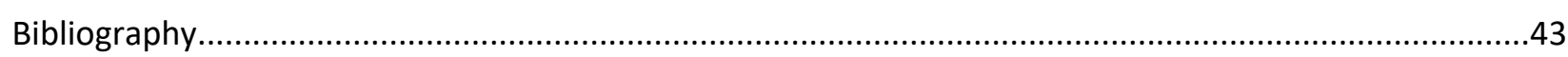

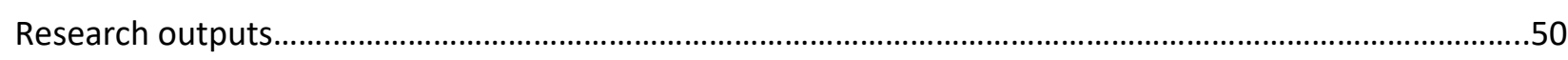

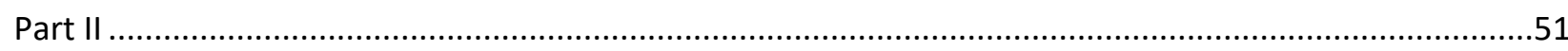




\section{Part II}

\section{Publications}

Paper A: Mekicha MA, de Rooij MB, Jacobs L, Matthews DTA, Schipper DJ. Experimental validation of contact models for cold-rolling processes. J Mater Process Technol 2020;275:116371. https://doi.org/10.1016/j.jmatprotec.2019.116371.

Paper B: Mekicha MA, Mishra T, de Rooij MB, Matthews DTA, Jacobs L, Schipper DJ. Study of wear particles formation at single asperity contact: An experimental and numerical approach. Wear 2021;470471:203664. https://doi.org/10.1016/j.wear.2021.203644.

Paper C: Mekicha MA, de Rooij MB, Matthews DTA, Pelletier C, Jacobs L, Schipper DJ. The effect of hard chrome plating on iron fines formation. Tribol Int 2020;142: 106003. https://doi.org/10.1016/j.triboint.2019.106003.

Paper D: Mekicha MA, de Rooij MB, Jacobs L, Matthews DTA, Schipper DJ. Understanding the generation of wear particles in cold rolling processes. Tribol Int 2021;155:106789. https://doi.org/10.1016/j.triboint.2020.106789. 


\section{Nomenclature}

Abbreviations

2D

3D

FEM

LAMMPS

MPHL

MPM

PSD

r.m.s.

SEM

$\mathrm{SPH}$

Ti-IF steel

TLSPH

XPS

\section{Greek Symbols}

$\varepsilon_{b u l k}$
$\varepsilon_{c}$
$\mu_{a}$
$\mu_{a p}$
$\mu_{p}$
$\sigma_{y}$
$\varnothing$
$\theta$
$\lambda$
$\alpha$
$\varepsilon$
$\mu$
$\tau$

\section{Roman Symbols}

$A_{g}$
$A_{s}$
$H_{\text {strip }}$
$\overline{\bar{P}}$
$\bar{P}$
$P_{\text {nom }}$
$S_{f w d}$

$A_{g}$

strip

nom two dimensional

three dimensional

finite element method

Large-scale atomic/molecular massively parallel simulator micro-plastohydrodynamic lubrication

material point method

power spectral density

root mean square

scanning electron microscopy

smooth particle hydrodynamics

Titanium stabilized - interstitial free steel

total Lagrangian smooth particle hydrodynamics

$\mathrm{x}$-ray photoelectron spectroscopy

bulk plastic strain

$[-]$

critical plastic strain

$[-]$

adhesion component of friction coefficient

$[-]$

apparent friction coefficient

$[-]$

ploughing component of friction coefficient

$[-]$

uniaxial yield strength

$[\mathrm{Pa}]$

bite angle

asperity slope

0

o

film parameter

$[-]$

real contact area ratio

$[-]$

plastic strain

$[-]$

Coulomb friction coefficient

$[-]$

interfacial shear stress groove area of wear track

$\left[\mathrm{m}^{2}\right]$

shoulder area of a wear track

$\left[\mathrm{m}^{2}\right]$

strip material hardness

$[\mathrm{Pa}]$

non-dimensional mean contact pressure (ratio of

nominal contact pressure to yield stress)

non-dimensional mean contact pressure (ratio of

contact pressure to shear strength)

nominal contact pressure

forward slip 


$\begin{array}{llc}S_{q} & \text { root mean square (r.m.s.) surface roughness } & {[\mathrm{m}]} \\ S_{q_{-} \text {equi }} & \text { combined r.m.s. roughness of the roll and strip } & {[\mathrm{m}]} \\ V_{\text {exit }} & \text { exit strip speed } & {[\mathrm{m} / \mathrm{s}]} \\ V_{r} & \text { rolling speed } & {[\mathrm{m} / \mathrm{s}]} \\ d_{p} & \text { degree of penetration } & {[-]} \\ d_{w} & \text { degree of wear } & {[-]} \\ D & \text { separation between the roll and the strip } & {[\mathrm{m}]} \\ U & \text { rise of non-contacting asperities or valleys } & {[\mathrm{m}]} \\ W & \text { asperity flattening rate } & {[-]} \\ f & \text { interfacial shear stress ratio or friction factor } & {[-]} \\ k & \text { shear strength } & {[\mathrm{Pa}]} \\ p & \text { normal pressure } & {[\mathrm{Pa}]}\end{array}$




\section{Part I}





\section{INTRODUCTION}

\subsection{Rolling processes}

Rolling is a widely used process of plastically deforming a metal to produce different structural shapes, bars and rods, plated sheets and strips. Metal rolling is not a new technology. Primitive hand driven rolls were used to flatten gold and silver in the fourteenth century. One of the earliest rolling mills of which any record exists was designed by Leonardo da Vinci in 1480 [1]. Rolling mills were used to roll gold and silver to obtain uniform thickness for making coins in the late sixteenth century. At the beginning of the seventeenth century, simple two-high mills were built to roll lead and tin. The mills started to become more complicated (e.g. four-high and tandem mills were introduced) and started to look like their modern counterpart in the eighteenth century. Cold rolling of steel commenced in the late eighteenth century and became more widely used in the nineteenth century. Initially, steel was rolled to profiles (rails, beams, channels, rounds), but since about 1930 flat products (sheet and strip) have become increasingly dominant [2]. The size and power of mills increased during the nineteenth and into the twentieth century. By the late nineteenth and in the twentieth centuries, an immense variety of hot and cold rolled aluminum, copper, brass, lead, tin, titanium, zirconium, and specialty alloys sheet became commercially available [3]. Today's mills are designed for processing a multitude of metals for extensive end-user applications with high standards in dimensional accuracy, surface and material properties.

Rolling processes can be identified as hot or cold rolling depending on whether the rolling temperature is above (hot) or below (cold) the recrystallization temperature of the material being processed. Hot rolling allows a large plastic deformation with less load and is generally used to convert slab (typically $225 \mathrm{~mm}$ thick) to flat sheet down to $2 \mathrm{~mm}$ thickness, which becomes the starting stock for cold rolling [2]. On the other hand, cold rolling is used to produce sheet, strip and foils with superior surface finish and dimensional tolerances compared with hot-rolled strip. The focus of this thesis is on cold rolling. Rolling mills are designed with several configurations depending on the number of rolls, arrangement of roll mills and direction of rolling. Typical rolling mill configurations are illustrated in Figure 1.1.

a)

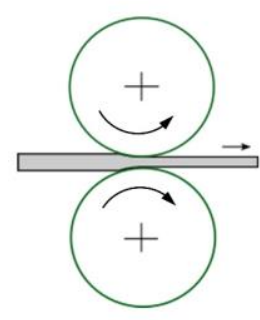

b)

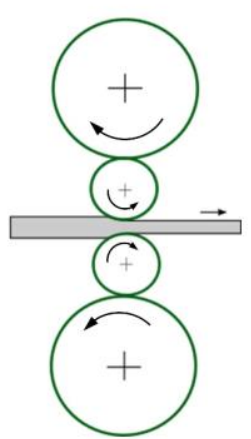

c)

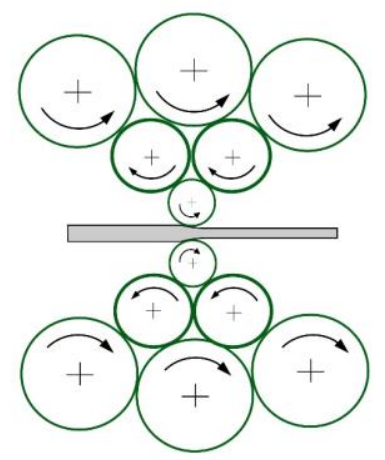

d)

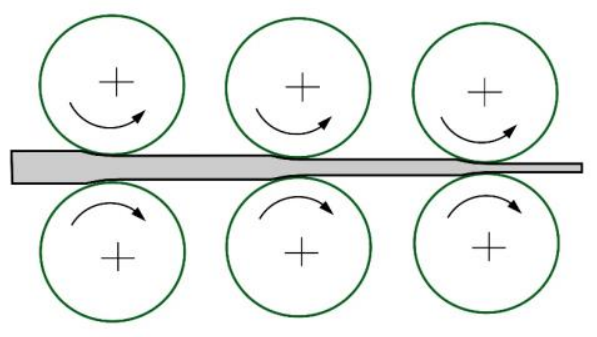

Figure 1.1: Schematic of the typical rolling mill configurations: a) two high, b) four high, c) cluster and d) tandem mill.

Cold rolled metal sheet is extensively used in many sectors such as automotive, furniture, white goods, coated products, packaging etc., see for example Figure 1.2. In metal sheet applications, high requirements are put on the surface quality, not only for aesthetic reasons, but essentially to ensure optimal product performance: be it to ensure excellent coating adhesion, to increase the stacking factor in stacked electrical transformers or to promote optimal forming process conditions during deep drawing of automotive or packaging products. The requirements in terms of surface cleanliness and topography are continuously rising to higher levels with narrower tolerances. In this regard, a detailed understanding of the microscale mechanisms at the roll-strip interface, relevant for surface quality, is crucial to have control and predictability over the surface quality of the final product. 


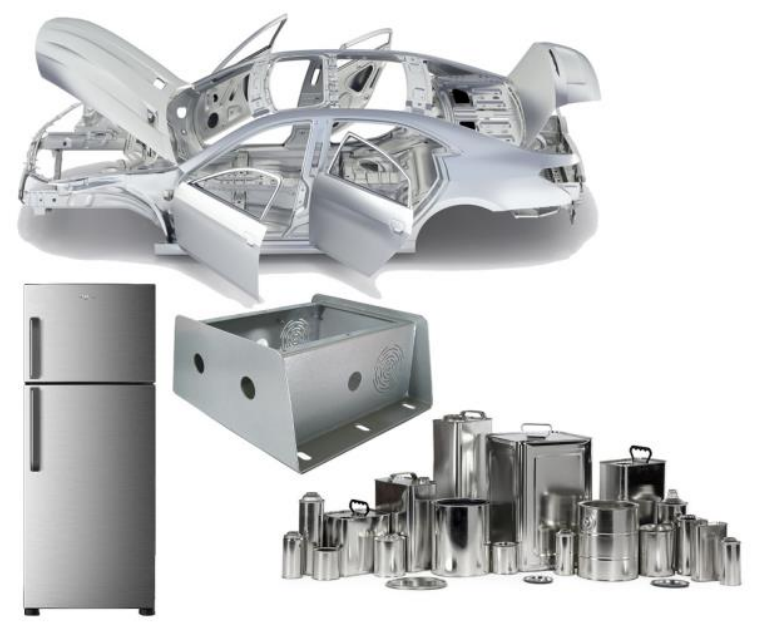

Figure 1.2: Some applications of cold rolled sheet metals.

\subsection{Surface cleanliness of a cold rolled metal sheet}

Surface cleanliness, which can be defined as the absence of contaminants on the surface, is one measure of the surface quality of a rolled strip. Wear particles, oil residue and/or exogenous particles (such as dust or sand) are some of the factors that contaminate the surface of a rolled strip [4]. Among these, wear particles are the primary cause of the degradation of strip surface cleanliness. An example of wear particles on a cold rolled steel strip surface are shown in Figure 1.3. Wear particles (commonly referred as 'iron fines') are produced during cold rolling due to the complex dynamic interaction between the roll asperities and the material being rolled in the roll bite. During cold rolling processes, the strip, pressed between a pair of rolls to reduce its thickness and/or imprint a certain roughness, is subjected to (heavy) plastic deformation (typically between $0.5 \%$ and $40 \%$ reduction per pass). This leads to the formation of wear particles, which originate mainly from the strip, as the strip is generally much softer than the roll $[4,5]$. These particles can remain on the strip surface or are removed by the emulsion/sprays used to lubricate the rolling process.
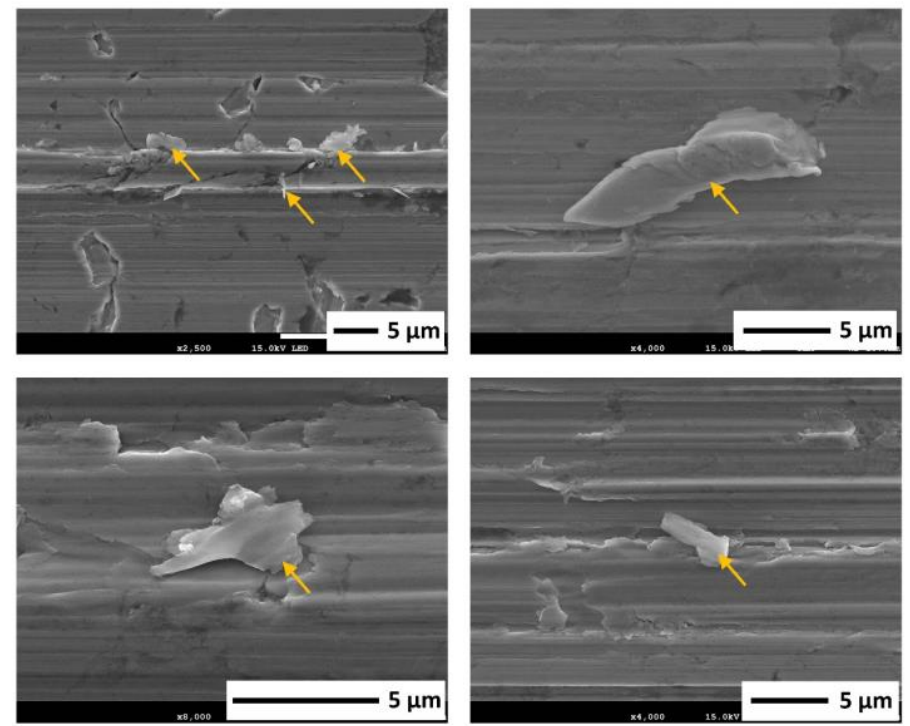

Figure 1.3: Image of wear particles (iron fines) indicated by yellow arrows on a cold rolled strip surface.

Wear particles can cause problems in fouling the cold rolling mill as well as negatively affect the performance of downstream processes such as annealing, galvanizing, filtration, forming and painting [57]. For example, the wear particles that remain on the strip surface can cause excessive dross formation, locally reduce the adherence of zinc coating during galvanizing, and consequently, decrease corrosion resistance $[8,9]$. A large amount of wear debris can block the filtration system, which is crucial to maintain 
the cleanliness of the lubricant/coolant oil. Moreover, cleaning the strips to remedy poor surface cleanliness incurs an extra cost and is environmentally undesirable. Therefore, there is a constant interest to minimize wear during rolling process and to achieve high strip cleanliness. In this regard, it is essential to understand the tribology, and the wear mechanisms in particular, during rolling processes on a fundamental level. Tribology is the study of interacting bodies in relative motion. It includes the study and application of the principles of friction, lubrication and wear.

In cold rolling operations, several microscale processes act simultaneously, together controlling the surface quality of the rolled strip. All parts of the cold rolling tribological system, which involves the dynamic interaction of the rolls, the strip and the lubricant, and their chemical and thermo-mechanical behavior govern strip surface cleanliness. Process parameters such as rolling pressure, thickness reduction and rolling speed, as well as the surface roughness of the roll and strip, material properties, surface treatment of the rolls, lubricant type and composition control the tribological behavior, and eventually, the total amount of wear particles formed (Figure 1.4) $[9,10]$. Therefore, a thorough understanding of the rolling tribological system and the main process parameters that influence wear particles generation is crucial for designing a well-controlled cold rolling process in terms of surface quality.

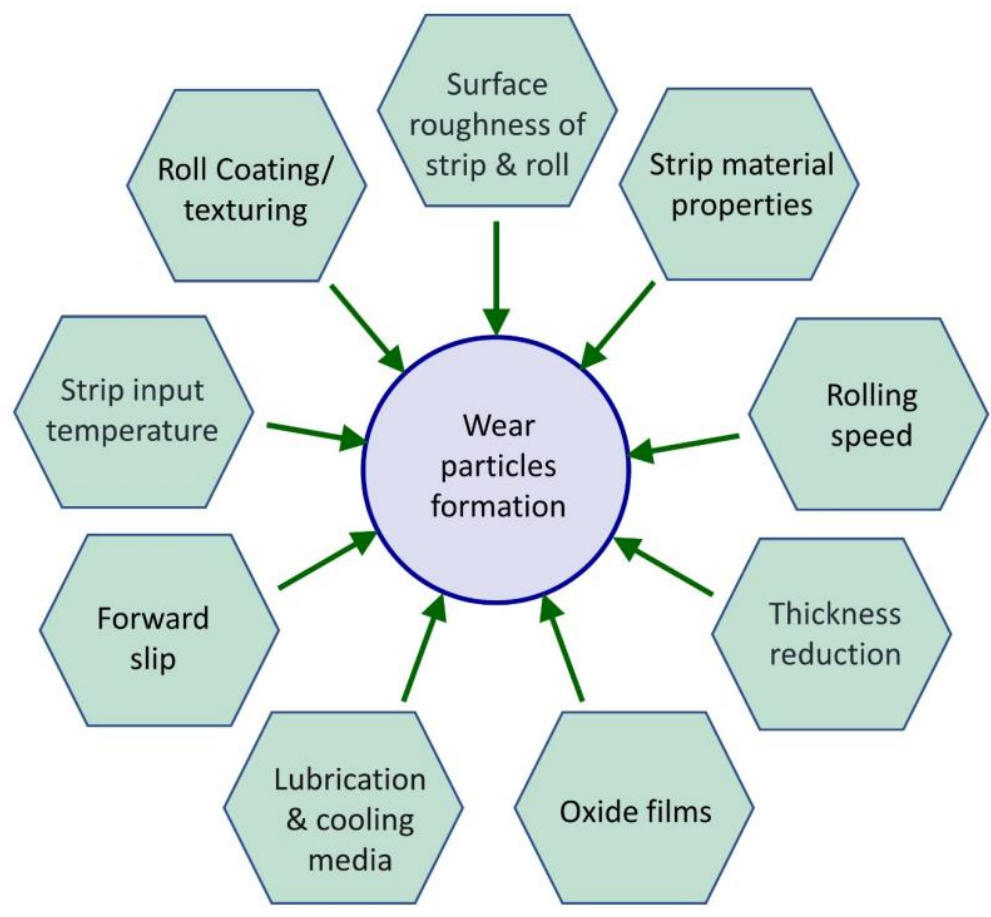

Figure 1.4: Factors affecting wear particles formation in cold rolling processes.

\subsection{Objectives of this research}

The aim of this research is to develop a multi-scale model and the related fundamental understanding on factors influencing surface quality in cold strip rolling. More specifically, to develop a model that is based on the physical (microscopic wear) processes involved but also has predictive capabilities on the macroscale. The innate complexity of the interacting interfacial processes and their consequences on the surface quality of rolled sheet material is the reason for pursuing a multi-scale modelling approach. The objective is to develop a surface quality indicator, which is formulated based on the inputs from rolling parameters, from which the severity of wear particles generation of cold rolled strips can be predicted. From this main objective, the following secondary objectives can be deduced:

- Development of a contact model, which includes bulk deformation, applicable to cold rolling processes. 
- Establish full understanding of the relevant wear and damage mechanism at microscale (asperity level) contact between a single hard asperity and a soft flat strip sample.

- Increase the understanding on the relationship between rolling parameters and the amount of wear particles on the strip after cold rolling.

- Development of a physically based strip wear model taking into account the rolling parameters and the material being rolled.

The knowledge developed in this research and the model can be used as a tool to study surface quality of cold rolling process in the simulation stage and enable production of improved strip surface quality.

\subsection{Outline of the thesis}

This thesis focuses on developing a multi-scale wear model for predicting the generation of wear particles in cold rolling operations. The thesis is structured in two main parts. Part I provides an overview of the objective of current research, literature review and the main outcomes of the research. Part II contains the publications that came from this research. Part I is categorized in four chapters. The current chapter gives a brief introduction and describes the aim and objective of the research. Chapter 2 presents a literature review on the tribological properties of cold rolling process and the effect of rolling parameters on wear particles formation. Chapter 3 summarizes the main outcomes of the current research. In the first section of Chapter 3, contact model development for cold rolling processes and its experimental validation on pilot rolling mill facility is presented. In the second section of Chapter 3 , experimental and numerical study of wear and the relevant damage mechanism in the elementary (microscale) contact between a single hard asperity and a soft flat strip sample is elaborated. Part I is concluded in Chapter 4 by listing the conclusions and recommendations for further research. The four publications that came from the findings of this research (Papers A to D) are included in Part II of the thesis. 


\section{FUNDAMENTALS OF WEAR PARTICLES FORMATION IN COLD ROLLING PROCESSES}

\subsection{Cold rolling tribology}

\subsubsection{Contact in cold rolling}

Cold rolling involves pushing a sheet or strip into the gap between two rotating rolls, which then simultaneously draw and compress it to reduce its thickness and increase its length. Figure 2.1 illustrates roll-strip contact geometry. Soon after entry, the stresses increase and the elasticity limit of the strip is reached, which is followed by plastic deformation of the strip on the plane where the yield criterion is first satisfied. The plastic deformation region extends throughout the roll bite, followed by the elastic unloading region, which starts when the converging channel of the roll gap begins to diverge. The externally applied rolling force, entry and exit tensions, roll diameter, friction and the yield stress of the strip determine the magnitude of the thickness reduction. As the strip width is very large compared to its thickness, the width remains almost constant. Therefore, cold rolling can be considered as being under plane-strain conditions.

The velocity of the strip steadily increases in the roll bite from entry to exit, as the compression of the strip proceeds. Since the rotational speed of the rolls remains constant, the relative speed between the roll and the strip surface varies throughout the roll bite. The peripheral speed of the rolls and the speed of the strip are equal only at one point, known as the neutral point. The roll moves faster than the strip before the neutral point and the strip moves faster than the roll after the neutral point. In other words, the roll moves forward and backward relative to the strip before and after the neutral point, respectively. The sliding length depends on the thickness of the strip, the reduction ratio and the location of the neutral point. The shear stress between the roll and the strip also changes direction at the neutral point. Rolling is commonly done with the neutral point kept close to the exit of the roll bite for the reasons of process stability (to avoid chattering) and optimum friction [11]. This complex relative motion has a great influence on the formation of wear particles and the surface quality of the strip after cold rolling.

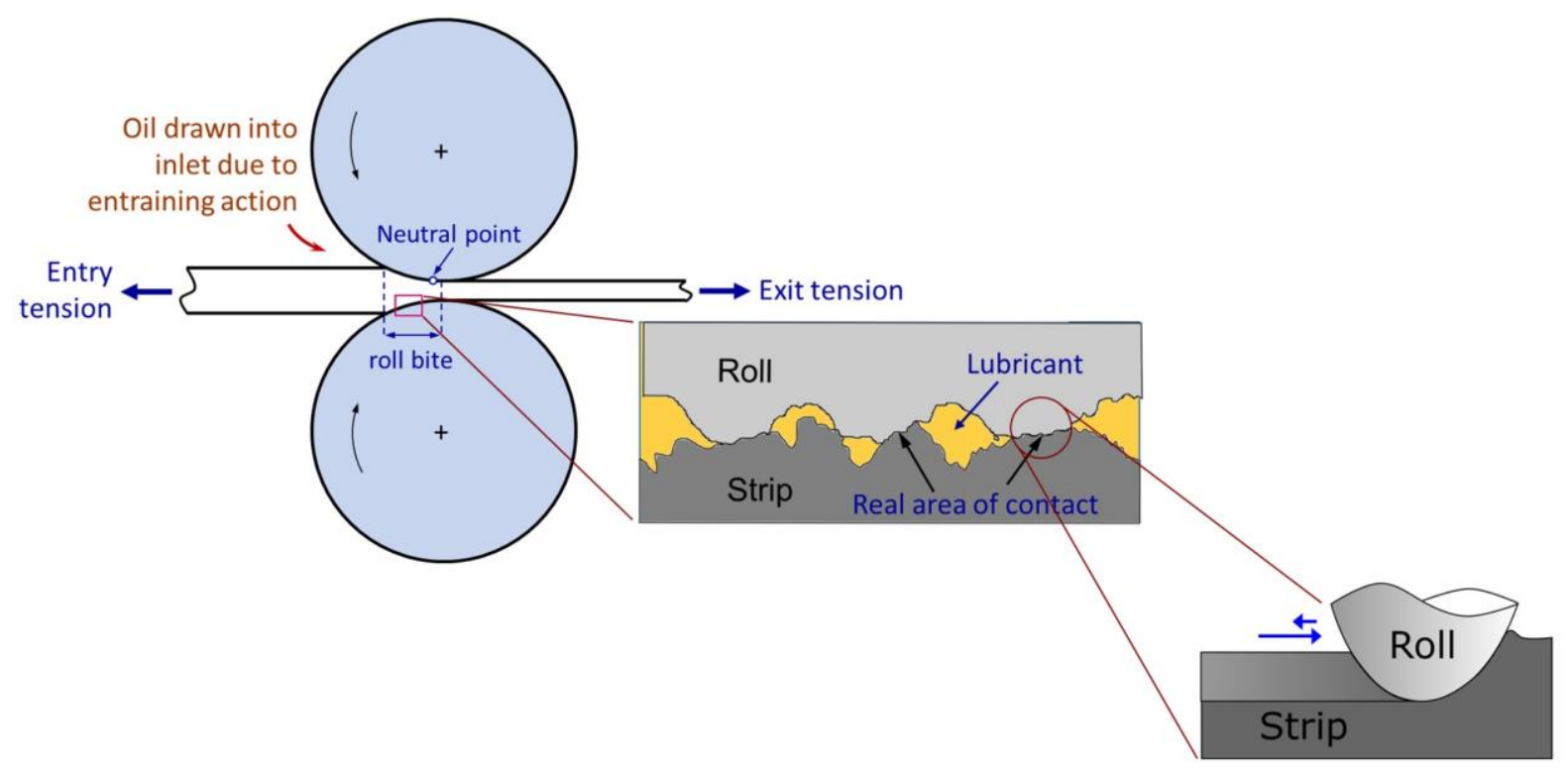

Figure 2.1: Schematic illustration of the roll-strip contact geometry and details of contact in cold rolling processes.

The contact in cold rolling is determined by the material properties and the roughness of the roll and the strip, the rolling parameters as well as the lubrication. The contact between the asperities of the roll and the strip mainly govern wear particles generation (Figure 2.1) [11,12]. The initial surface roughness, rolling parameters (e.g. thickness reduction, rolling speed and lubrication), and hardness of the roll and strip asperities are the major factors that determine the friction, real area of contact, and the surface quality of 
the rolled product [13]. The surface roughness of the input strip is determined by the prior upstream processes (i.e. hot rolling and pickling). The roughness and surface topography of strip are different depending particularly on the pickling process parameters and the strip material [5]. A roll's surface is commonly prepared by either grinding or surface texturing (such as shot blasting, laser beam texturing or electrical discharge texturing). The surface roughness of commercially used work rolls in cold mills and temper mills typically vary from 0.2 to $5 \mu \mathrm{m}[14]$.

\subsubsection{Modelling the real contact area in cold rolling}

Understanding how the apparent and the real area of contact are related and how the nature of contact changes as the process parameters change is crucial, as this will affect all the interfacial phenomena. The apparent area of contact is the overall dimension of the contact surface, while the real area of contact is the sum of the microcontacts at the asperity tips. The real area of contact plays a fundamental role in the friction, wear and material transfer behavior of tribological contacts. Hence, accurate modelling of the real contact area is vital in describing the tribological behavior of cold rolling processes such as estimating the rolled strip surface finish, friction and wear rate.

Analysis of the real contact area in cold rolling process is challenging because of its dependence on many variables and the complex dynamic nature of the contact. The asperities may deform elastically or plastically, sink into the bulk or flatten. Moreover, bulk deformation of the strip [13], presence of bidirectional sliding [15] and asperity persistence due to the asperity interaction at high pressure [16] are other aspects that complicate the analysis.

One special aspect of tribology in cold rolling processes is the plastic deformation of the underlying bulk material. It has a great influence on the real contact area ratio (i.e., the ratio of the real contact area to the apparent contact area), and consequently, on the surface finish, friction and wear (surface quality) of the rolled strip. When a soft material is subjected to stretching under normal loading, only a small stress in the underlying bulk (perpendicular to the loading direction) initiates further plastic deformation of asperities when asperities are already in plastic state due to normal loading [13,17-21]. This is known as the decrease in effective hardness due to bulk straining of the underlying material [22]. This process is caused by the multiaxial deformation, which permits the material below the true contacts to easily penetrate into the bulk [13].

Few analytical models exist in literature to estimate the real contact area ratio as a function of bulk plastic strain [13,17,23-25]. Wilson \& Sheu [17], Sutcliffe [13], and Kimura \& Childs [23] developed analytical asperity flattening models considering bulk deformation for idealized triangular shaped asperities (Figure 2.2). Wilson \& Sheu [17] used upper bound analysis to study the effect of bulk deformation on flattening of asperities parallel to the direction of bulk strain. Sutcliffe [13] presented a slip-line field analysis of flattening of asperities aligned perpendicular to the direction of bulk deformation and proposed an alternative deformation model for Wilson and Sheu's longitudinal roughness. Kimura \& Childs [23] proposed kinematically admissible velocity fields for the crushing of asperities aligned parallel to the direction of bulk deformation on a plastically flowing foundation by applying an energy minimization method. 


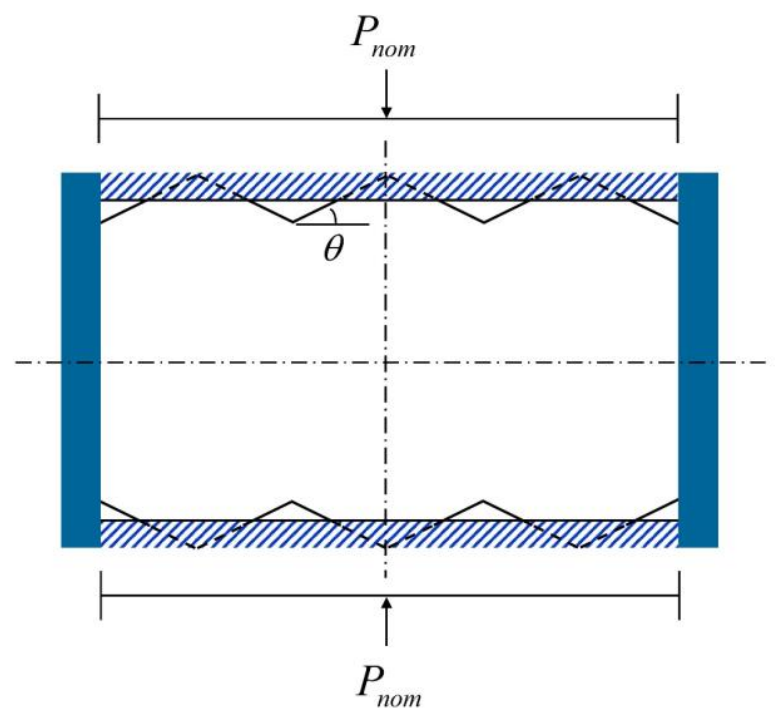

Figure 2.2: The idealized wedge-shaped geometry of asperities (after [23]).

Analytical calculation of the real contact area in the presence of bulk deformation is possible only when plane stress or plane strain deformation of asperities is assumed. For asperities running parallel to the direction of bulk deformation, which is the case for roll asperities prepared by grinding, the rate of change of real contact area ratio $(\alpha)$ with bulk strain $\left(\varepsilon_{\text {bulk }}\right)$ is given by [13]:

$$
\frac{d \alpha}{d \varepsilon_{\text {bulk }}}=\frac{W}{\tan \theta}
$$

where, $W$ is the dimensionless local asperity flattening rate and $\theta$ is the asperity slope (see also Figure 2.2). The asperity flattening rate $(W)$ was shown (empirically) to be dependent on the contact pressure and the real contact area ratio $[17,18,26,27]$.

Several authors have carried out numerical simulations of the flattening process of surface asperities in the presence of bulk strain using elastic-plastic finite element codes [18-20,28-30]. Among these, Korzekwa et al. [18] used finite elements to analyze the general case where components of strain are present in directions both longitudinal and transverse to the asperity direction.

The main limitation of all of the above analytical and numerical models is that these studies idealize the contact geometry by a series of identical (roughness) asperities with triangular cross section, and they assume the asperities are flattened by a smooth rigid counter face. It is assumed that all the roughness resides on the workpiece (strip) and the tool (roll) is smooth. In practice, both the strip and the roll surfaces are rough. When roll surfaces are prepared by grinding in the circumferential direction, the result is a roll roughness with a pronounced lay with asperities running along the rolling direction.

Sutcliffe [26] analyzed the flattening of random rough surfaces using a model of a surface consisting of short wavelength asperities superimposed on longer wavelength asperities. The power spectral density of the roughness was used to choose the amplitudes of the two wavelengths. However, engineering surfaces contain irregularities with a wide range of wavelengths in several orders of magnitude, ranging from the order of interatomic distances to shape deviations, and corresponding amplitudes. Westeneng [24] developed a strain flattening model for arbitrarily shaped asperities based on work energy balance and volume conservation taking into account the effect of bulk deformation. His model has been further updated and implemented to study the friction and wear behavior of deep drawing and hot stamping processes [31-33]. The main limitation of Westeneng's model is the calibration parameters, which need to be measured or estimated from numerical modelling.

Another aspect of cold rolling that affects the real contact area is the presence of tangential stresses at the asperity tips due to friction. The presence of these stresses increases the real contact area due to junction growth [15]. Wilson [34] extended Wilson and Sheu's [17] model by including the effect of sliding 
and showed that the presence of sliding can influence the rate of asperity flattening, and consequently the real contact area ratio. Nevertheless, for high contact pressures such as in rolling, sliding was shown to have little effect on the real contact area [34].

Despite the existence of these analytical and numerical models (with their limitations), there is a lack of a detailed experimental study on the validity of these models in cold rolling processes and their accuracy in predicting the surface finish of industrially cold rolled strips.

\subsubsection{Lubrication in cold rolling}

Lubrication in cold rolling is used to control friction, reduce roll separating force (rolling force) and torque, control the quality of the resulting surfaces and provide cooling [35]. A cold rolling lubricant typically consists of boundary, anti-wear and extreme pressure additives that adsorb or react with the strip and/or roll surface to form a protective tribochemical film limiting the number of real metal contacts and friction. Lubrication in industrial metal rolling is commonly realized by using an emulsion of oil-in-water (commonly $<3 \%$ oil) [7]. The emulsions used in rolling are composed of three primary ingredients: oil, water and an emulsifier. Spherical micelles of oil, with diameters ranging from 1 to $10 \mu \mathrm{m}$, are dispersed in the water phase [2]. The emulsifier prevents the oil micelles from coalescing.

Cold rolling processes comprise an inlet zone, contact zone (work zone) and exit zone as illustrated in Figure 2.3. The inlet zone, which extends to the first contact between the roll and the strip, has a wedge shape. As a result, the lubricant film is rapidly pressurized from ambient pressure to the pressure at the roll bite entry and the film thickness is significantly reduced. The lubricant is sheared into the roll bite due to the velocities of the roll and the strip. Owing to the slip between roll and strip, the lubricant can be sheared at relatively high shear rates. The entry zone is where the entrained film thickness is determined. The film thickness depends on process conditions such as thickness reduction, roll bite geometry, oil viscosity, roll and strip speed, temperature, and surface topography $[11,36]$. No deformation of asperities takes place in the inlet zone. At the end of the inlet zone, elasto-plastic deformation of asperities occurs without bulk deformation, as no thickness reduction has taken place yet. In the contact zone, plastic deformation of the bulk and the contacting asperities occurs. In this zone, the thickness of the dragged lubricant film is reduced and the lubricant viscosity is modified by pressure variation, increase in temperature as well as the presence of high shear rates, which in turn define the lubrication regime. In the exit zone, the film pressure drops to the ambient pressure.

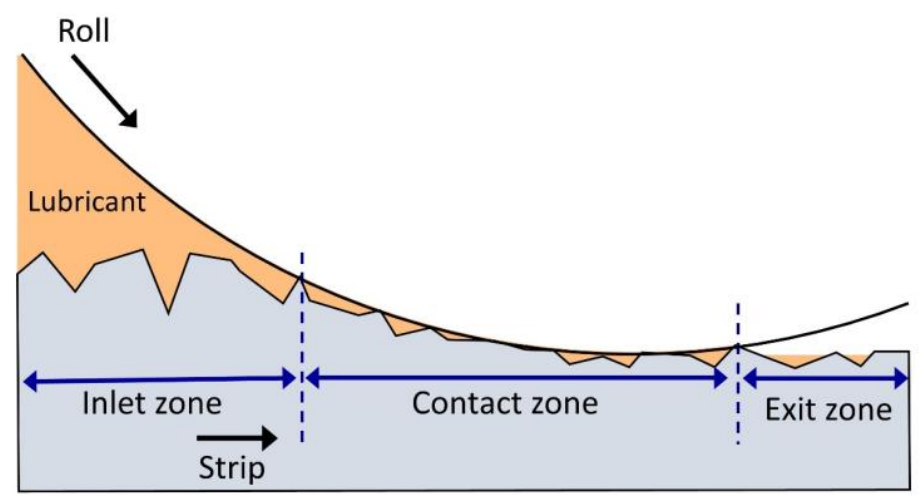

Figure 2.3: Schematic illustration of the inlet, contact and exit zones of a roll bite.

The thickness of the oil film in rolling is determined by the conditions in the inlet zone. Higher rolling speed and/or higher viscosity of the oil results in greater pressure buildup and higher film thickness. The most commonly used mathematical model to calculate the inlet film thickness in cold rolling is that of Wilson and Walowit [37], who derived a simple equation for calculating the 'smooth' entry film thickness in rolling processes based on Reynold's equation [38] .

The combined roughness of the strip and the roll is needed in addition to the film thickness to properly assess the lubrication regime. The film parameter $\lambda$, which is defined as the ratio of film thickness to the combined surface roughness, is used to determine the lubrication regime. At low $\lambda$ values $(\lambda<0.1)$ there 
is asperity-to-asperity contact and the lubrication regime is referred to as boundary lubrication [39]. In the boundary lubrication regime, the contact load is carried by the asperities of the contacting surfaces and the interacting surfaces are protected from dry friction by thin boundary layers attached to the surfaces. Friction in this regime is determined by shearing of the boundary layers built by adsorption of the lubricant additives on the surfaces of the contacting bodies. The coefficient of friction in this regime is in the order of 0.1 [22]. At high $\lambda$ values $(\lambda>3)$, a relatively thick lubricant film fully separates the two surfaces and is termed the full hydrodynamic lubrication regime. In this lubrication regime, mechanical wear is negligible and the friction coefficient is determined by the bulk lubricant properties [40]. The transition between the above two regimes is the mixed lubrication regime, which is characterized by both local film separation and asperity contact.

The cold rolling process generally operates in the mixed or boundary lubrication regime, with contact between the asperities of the strip and the roll mainly governing the contact, as shown schematically in Figure $2.1[11,12]$. If the lubrication mechanism is hydrodynamic in cold rolling, friction will usually be too low, causing skidding of the rolls or requiring very large entry and exit tensions [41]. In addition, surface roughening will occur in the case of full film lubrication leading to unacceptable surface quality $[42,43]$.

\subsubsection{Micro-plastohydrodynamic lubrication}

The variation of speed difference between the roll and strip within the roll bite leads to roughness evolution and potentially to micro-plastohydrodynamic lubrication (MPHL) [44-47]. MPHL is the trapping of lubricant in closed surface cavities and the subsequent permeation of the trapped lubricant into the neighboring real contact area due to deformation. MPHL is schematically illustrated in Figure 2.4. The lubricant may escape either opposite to the direction of rolling (i.e. backward) or forward or both [48]. Backward escape is caused by viscous forces due to the relative sliding speed between the roll and the strip surface. On the other hand, the forward escape occurs when the hydrostatic pressure in the trapped lubricant exceeds the roll/strip contact pressure on the surrounding plateau [47].

MPHL can play a role in the lubrication of cold rolling processes as it results in in-bite film formation. Although the resulting film thickness might be very small, the escaped oil will create an oil film and cover the adjacent area [46-49]. The oil drawn out of the pits forms a thin hydrodynamic film, approximately one order smaller than the asperity height, and lowers friction coefficient [50]. The tendency of microplastohydrodynamic film formation is shown to be dependent on relative speed (between he roll and strip), thickness reduction, lubricant viscosity, pit geometry and yield stress of the strip [46,51,52]. The strong directionality of roll roughness (which is commonly prepared by grinding the roll in the circumferential direction) inhibits micro-plastohydrodynamic film formation in cold rolling processes, as the squeezed lubricant can escape through the grooves created by the roll roughness [53]. Furthermore, for rolling operations involving multiple passes, the strip asperities are flattened in subsequent rolling passes as the later stands are usually smoother than the first stand. As a result, the cavities become elongated and are not deep enough to permit oil trapping. Thus, oil trapping is negligible in the second and third passes due to the surface texture generated $[7,42,54]$.

a)

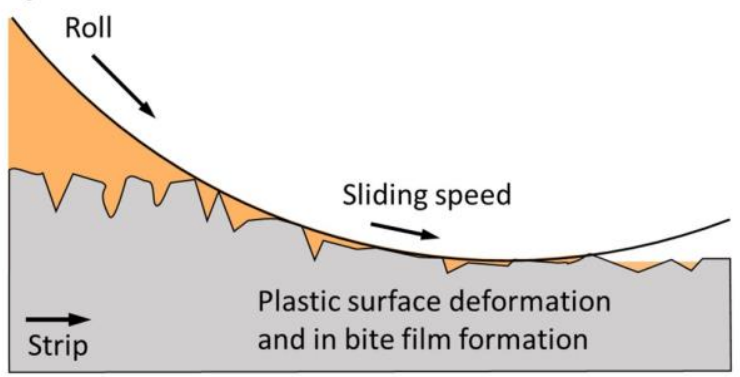

b)

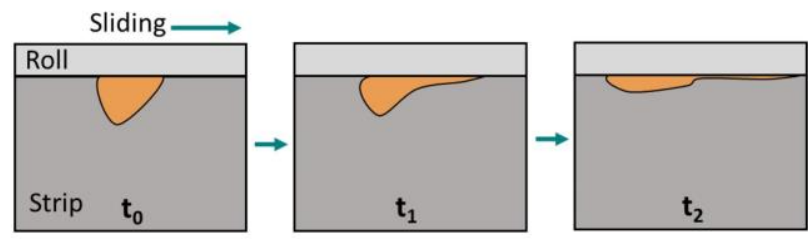

Figure 2.4: a) MPHL and micro-plastohydrodynamic film formation, and b) schematic evolution of a pit in time, from $t_{0}$ to $t_{1}$ and $t_{2}$ (after [51]). 


\subsubsection{Lubrication theories for oil-in-water emulsions}

In industrial cold rolling operations, an emulsion of oil-in-water is generally used instead of pure oil. Thus, understanding the mechanism of oil film formation by an emulsion is important to create accurate lubrication models as well as to understand the wear behavior. Three theories exist to describe the mechanisms of entrapment of oil-in-water emulsions in cold rolling processes: plate-out theory [55], mixture theory [56] and dynamic concentration theory [57,58].

The plate-out theory is based on the idea that a film of essentially pure oil is formed driven by the preferential wetting of the metal surfaces by the oil phase $[55,59]$. Plate-out theory proposes that oil droplets are trapped on the roll or on the strip because of their polar affinity towards the two metallic bodies, as schematically represented in Figure 2.5a. This theory does not explain the importance of oil concentration and droplet size [11]. The limitation of the plate out theory is that there might not be sufficient time for the film to be formed at high industrial rolling speeds, which may reach $20-30 \mathrm{~m} / \mathrm{s}$.

The mixed theory treats the emulsion as a homogeneous isotropic continuum of two phases $[56,60]$. It is based on determining the effective viscosity based on the mechanical and chemical properties of the two phases $[61,62]$. An oil-rich film is assumed to enter the roll bite while the water-rich film is rejected out because water as a lubricant requires high sliding speed to enter the roll bite [57]. Hence, there is oil pool formation at low speeds with coarse droplets, where oil-in-water to water-in-oil inversion takes place [63]. This model has been shown to be unsuitable for operations with relatively thin films, such as in cold rolling where the inlet film thickness is generally smaller than $1 \mu \mathrm{m}[61]$.

Dynamic concentration theory is based on the idea that once the oil droplets of the emulsion are trapped in the roll bite, the concentration of oil increases while excluding the water from the roll bite [59]. This theory is based on pressure buildup in the roll bite and higher viscosity of the oil. As the pressure between the strip and roll increases, the oil droplets are flattened. Tangential forces in the oil droplets are higher than on water due to high viscosity of the oil. Thus, the oil droplets are dragged into the inlet while the water phase is rejected. As a consequence, a tiny amount of water enters the roll bite. Figure $2.5 \mathrm{~b}$ shows the schematic of dynamic concentration theory. After the water phase is mostly rejected, an invert (waterin-oil) emulsion will be created, which now behaves almost as neat oils [64].

Schmid and Wilson [61] reviewed the above three theories and concluded that the dynamic concentration theory is the most applicable to the process of cold flat rolling. Dick \& Lenard [14] examined the tribological mechanisms of several oil-in-water emulsions during cold rolling of low carbon steel strips at several roll roughnesses, rolling velocities, thickness reductions, viscosities of oil in the emulsions, and reported that the dynamic concentration theory fits well to their observation. In practice, more than one film formation mechanism may occur at the same time. All the three theories suggest that water is mostly rejected and nearly pure oil enters the roll bite. Therefore, the lubricant entering the roll bite can be treated as a pure oil for lubrication, friction and wear characterization of the contact interface.

a)

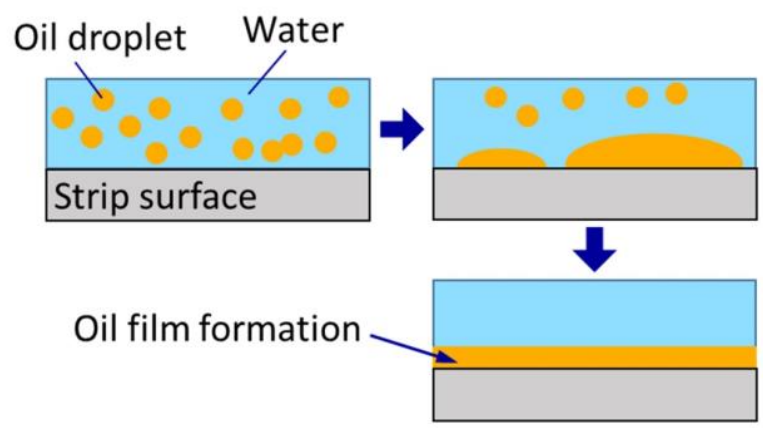

b) Rolling

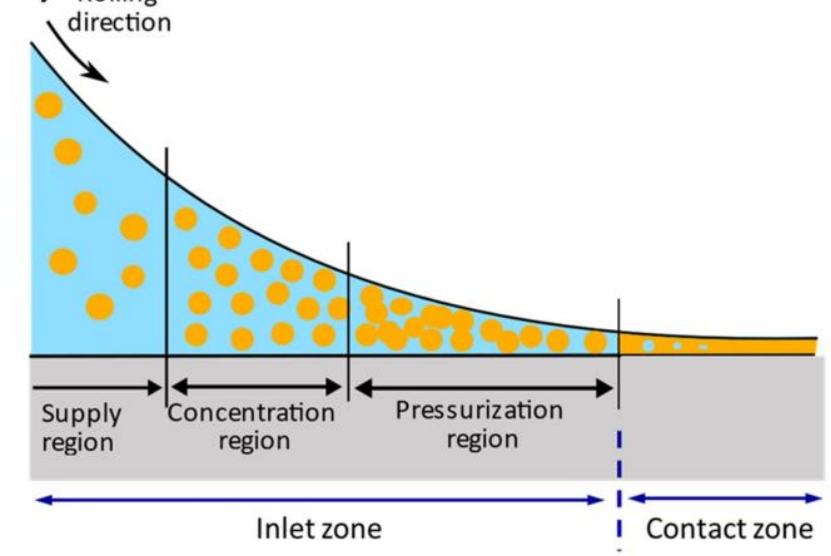

Figure 2.5: Schematic of a) plate-out formulation and b) dynamic concentration theory. 


\subsubsection{Friction in cold rolling}

Friction coefficient and friction factor are the two approaches used to express the frictional phenomena in metal forming processes $[65,66]$. The classical Amonton-Coulomb friction coefficient $\mu$, which is applied in most of the metal forming applications including cold rolling, is defined as the ratio of interfacial shear stress $\tau$ to the normal pressure $p$ :

$$
\mu=\tau / p
$$

Friction factor $f$, commonly used at very high normal pressures, is the ratio of the interfacial shear stress and the shear strength of the softer material $k$ in contact:

$$
f=\tau / k \text { where } 0 \leq f<1
$$

Friction plays an essential role in cold rolling. It has a large impact on force and power requirements of the mill as well as on the surface quality of the rolled strip [5]. The friction coefficient affects the rolling pressure distribution. An increase in friction coefficient results in higher roll pressure distribution, increases the rolling force and may lead to surface defects called friction pickup, which result from local welding of the strip to the roll surface [67]. An example of the influence of the friction coefficient on the contact pressure distribution across the roll bite (also commonly known as friction hill), obtained using the standard theory of plastic working $[68,69]$ is illustrated in Figure 2.6. Another consequence resulting from high friction is a large temperature rise at the contact interface. On the other hand, rolling with too low friction leads to the rolls skidding on the strip and new material will not flow into the bite. The minimum coefficient of friction necessary for successful unaided entry of the strip, from force balance, is given by:

$$
\mu_{\text {min }}=\tan \emptyset
$$

where, $\varnothing$ is the bite angle.

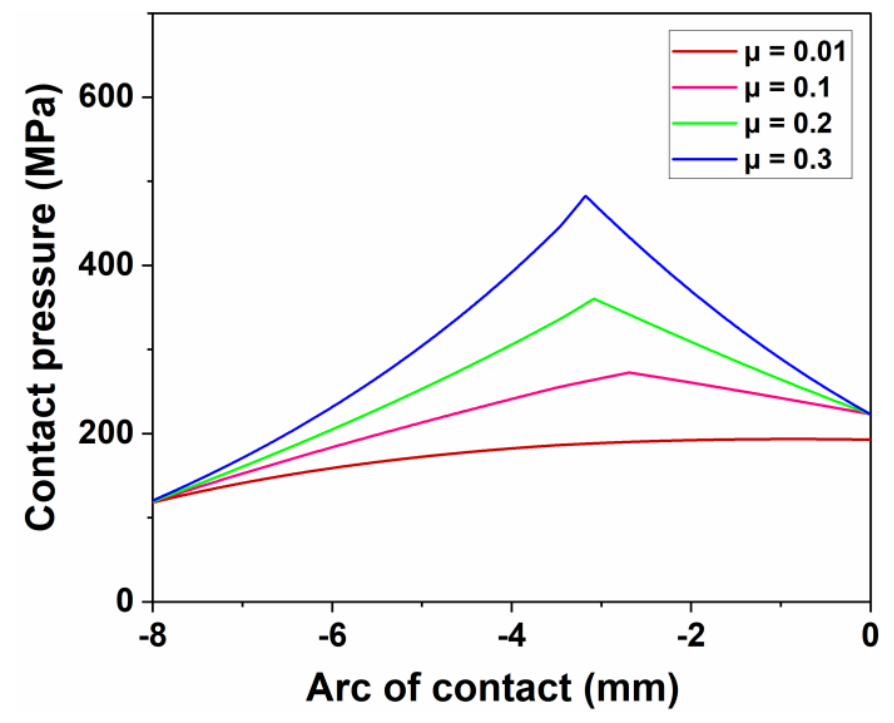

Figure 2.6: The influence of friction coefficient on the calculated distribution of contact pressure in the roll bite from entry (left) to exit (right) at $10 \%$ thickness reduction of $\mathrm{Ti}-\mathrm{IF}$ steel.

Although the friction coefficient or the friction factor cannot be measured directly, several experimental approaches are available to measure the interfacial friction forces in cold rolling and deduce their value. These include the embedded pin method [70-73] and the ring compression test $[49,74,75]$. Very often in industry, Coulomb friction is assumed and its value is estimated by the use of a mathematical model in combination with data from rolling operation. Empirical models $[76,77]$ are often used to estimate friction coefficient, by choosing a value that allows matching the calculated and measured rolling forces.

Numerous methods have been proposed in literature to correlate friction coefficient to process parameters in cold rolling. In particular, there are several expressions that relate forward slip and 
coefficient of friction [1,78-80]. Forward slip $\left(S_{f}\right)$ is the relative difference between the peripheral roll speed $\left(V_{r}\right)$ and the strip exit speed $\left(V_{\text {exit }}\right)$, which is given by:

$$
S_{f}=\left(V_{\text {exit }}-V_{r}\right) / V_{r}
$$

Forward slip can be adjusted via roll-strip speed, lubrication, thickness reduction as well as by equilibrium of front/back tension and torque. Negative forward slip is usually avoided as it may result in the rolls skidding of over the strip being processed. The coefficient of friction in the roll bite affects the position of the neutral point, and consequently, the forward slip. A low friction coefficient is commonly associated with low forward slip $[73,81]$.

Friction in cold rolling depends on a large number of process parameters $[55,82]$. These include thickness reduction, temperature, rolling speed, surface roughness, surface hardness, resistance to deformation of the strip material and lubricant viscosity. The general agreement is that friction coefficient decreases as the thickness reduction increases, for example, when rolling low carbon steel. For a well lubricated contact, an increase in rolling speed leads to a decrease in friction due to the increased amount of lubricant dragged into the contact [83]. The friction coefficient is shown to increase with an increase in roll roughness $[14,84,85]$. This is ascribed to an increase in the contribution of the ploughing component by the roll asperities ploughing through the strip material.

Friction coefficient values in cold rolling range from 0.04 to 0.08 , which is a typical range for the mixed lubrication regime [86]. The mean friction coefficient in the mixed lubrication regime can be estimated from the real contact area ratio $\alpha$, by considering both the contact between roll-strip asperities and the pressure buildup in the lubricant:

$$
\mu=\alpha \mu_{p}+(1-\alpha) \mu_{a}
$$

where, $\mu_{p}$ is the friction coefficient of asperities in contact due to ploughing and adhesion, and $\mu_{a}$ is the friction coefficient of the lubricant-filled valleys calculated from the viscous shear of the oil (see Figure 2.1).

In cold rolling processes, ploughing and adhesion are most likely the main contributors to the frictional resistance as full hydrodynamic condition is undesirable and is hardly realized in practice [87]. The sharpness (roughness) of asperities determine the relative contribution of ploughing and adhesion to the frictional resistance. Ploughing is likely the most dominant mechanism causing the frictional resistance in the case of rough rolls (i.e. sharp asperities with steep angles) [14]. Therefore, the manner in which the contacting surfaces conform to each other at the contacting spots and the friction mechanisms at these contacting areas (and the valleys in between) are the main factors that determine the frictional behavior $[66,88]$.

\subsubsection{Wear in cold rolling}

Different wear mechanisms can act in cold rolling depending on the roll/strip roughness and material properties, lubrication and process parameters. Usually several wear mechanisms act simultaneously. Abrasion and adhesion are the two main wear mechanisms that contribute to wear in cold rolling operations $[4,10,89]$. However, fatigue, corrosive and erosive wear are also potential contributors. The dominant wear mechanism may change from one to another due to changes in surface material properties and dynamic surface responses caused by tribofilm formation, frictional heating and/or wear.

Abrasive wear has been shown to be the principal wear mechanism and the main cause of wear particles formation in lubricated cold rolling $[4,9,10,12,89,90]$. Wear debris are generated during cold rolling as a result of the roughness peaks of the much harder roll ploughing through the soft strip material (see Figure 2.1). Wear particles originate mainly from the sheet being rolled, which is generally much softer than the roll $[4,5]$. Wear particles may be washed away by the emulsion. However, part of them will generally remain on the strip surface and act as a third body abrasive or adhere to the roll surface and form a transfer layer $[12,89]$. This may result in scratches in the finished strip product. If uncontrolled, it is a fundamental factor which may lead to lubrication failure with friction increasing sharply in the roll-bite and the surface 
quality being jeopardized. In certain rolling conditions, such as dry rolling or rolling of stainless steel [9193] or soft metals such as aluminum [94-96], adhesion may be the predominant wear mechanism causing adhesion induced problems such as the formation of a transfer layer (material pickup) [89] and 'heat scratches' on the surfaces being rolled [91]. A transfer layer in rolling processes is manifested by a change in the color of the roll surface [89]. Transfer layers can have major tribological consequences (e.g. increase roughness, friction, temperature, rolling force and torque). Heat scratches negatively affect the surface finish of the strip after cold rolling.

Abrasive wear can occur in three wear modes (i.e. ploughing, wedge forming and cutting) depending on the asperity geometry and the interfacial shear strength of the contact [97-99], see Figure 2.7. In ploughing, a shallow groove is formed, in which material flows to both sides of the groove without wear particles generation. Ploughing is characterized by a low degree of penetration and low interfacial shear stresses. In the cutting mode, flake-type as well as long and curled ribbon like wear particles are formed [98]. Wedge forming is the transient wear situation between ploughing and cutting wear modes, where some part of the groove volume is lost and the other part remains at the sides of the groove. It is characterized by lump formation, growth and detachment ahead of the ploughing asperity. Strong adhesion and high friction promote this wear mode. Lubrication can influence the active wear mechanism. Lubrication promotes the cutting wear mode, i.e. cutting occurs for a smaller degree of penetration in lubricated contact than unlubricated one [22].

Hokkirigawa and Kato [100] introduced an abrasive wear mode diagram showing the three abrasive wear modes as a function of the degree of penetration and the interfacial shear strength ratio based on Challen and Oxley's model, [101] which describes the sliding contact between a rigid plastic wedge using a two dimensional slip line analysis. A schematic representation of abrasive wear mode diagram is shown in Figure 2.7. Degree of penetration $d_{p}$, which is a measure of sharpness of the indenting asperity, is the quotient of indentation depth $d$ and contact radius for a spherical indenter $a$ (Figure 2.8a):

$$
d_{p}=d / a
$$

The interfacial shear strength ratio, or friction factor, $f$, is a dimensionless shear strength at the contact interface, derived as the ratio of the shear strength of the interface $\tau$ and the bulk shear strength of the soft surface $k$ (Eq. 2-3).

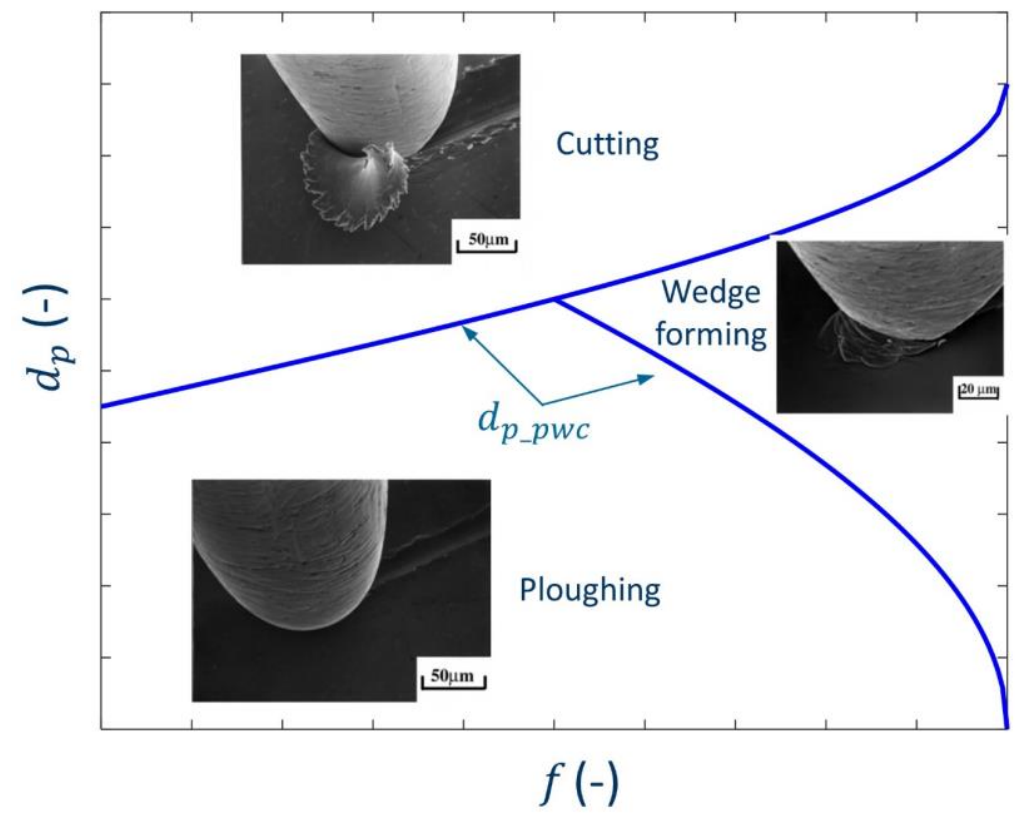

Figure 2.7: Schematic representation of abrasive wear mode diagram, after Hokkirigawa and Kato $[98,100]$. 
The amount of material removed from a wear groove is influenced by the predominant active wear mode. The degree of wear $d_{w}$, which describes the proportion of the actual amount of material removed from the groove, can be used as a measure of the efficiency of material removal process (Figure 2.8b):

$$
d_{w}=\left(A_{g}-A_{s}\right) / A_{g}
$$

where, $A_{g}$ is the amount of material removed from the surface and $A_{s}$ is the amount of material transferred to the shoulders of the wear groove.

An ideal state of material removal without the formation of ridges corresponds to $d_{w}=1$. Whereas, $d_{w}=$ 0 means ideal ploughing or no material removal. Practically, the ploughing regime has a characteristic $d_{w}$ value of $0.0-0.15$, wedge forming in the range of $0.20-0.80$ and cutting $0.80-0.95$ [102]

a)

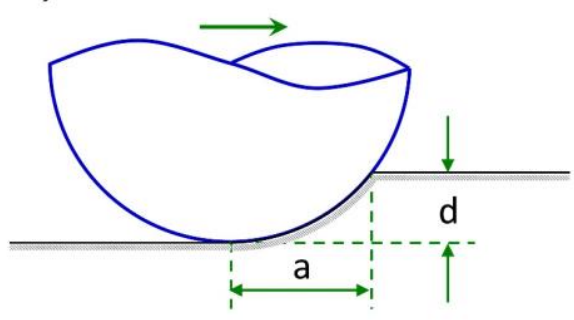

b)

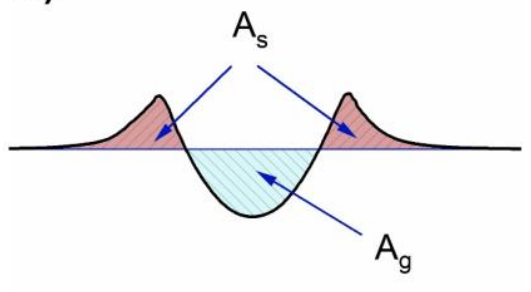

Figure 2.8: Schematic of a) degree of penetration and b) geometry of wear scar.

The total amount of wear particles generated due to abrasive wear in lubricated contacts depends on the real contact area, the geometry of the microscale contacting asperities, the sliding distance, lubricant properties, material properties and surface treatment of the interacting surfaces $[99,103,104]$. Therefore, it is necessary to understand the type(s) of the active wear mechanism(s) and the rolling parameters that have the most influence on the rate of wear debris formation in order to tailor and control the surface cleanliness of a cold rolled sheet metal.

\subsection{The effect of rolling parameters on wear particles formation}

Rolling parameters have a decisive role on wear particles formation and the surface quality of the strip after cold rolling. Several experimental studies have been conducted to investigate the influence of rolling parameters on wear particles formation. Jacobs et al. [4,9] carried out extensive rolling experiments on pilot rolling mills and studied the origin and composition of wear particles. Moreover, they studied the influence of roll roughness, $\mathrm{Cr}$ plating the rolls, thickness reduction, rolling speed, incoming strip temperature and lubricant composition on the generation of wear particles (strip cleanliness). Dubar and co-workers developed a laboratory experimental setup to simulate cold rolling contact conditions and investigated the influence of several rolling parameters such as thickness reduction [105], roughness and lubricant entrapment $[7,11]$, interface temperature [11], and forward slip $[11,105]$ on wear particles formation. Labiapari et al. [5] performed laboratory cold rolling experiments and investigated the influence of thickness reduction, lubricant temperature, previous annealing and surface finish of the sheet on wear debris formation in stainless steel cold rolling. Jacobs et al. [4,9] studied the influence of chrome plating the rolls on the efficiency of oil adherence to the roll or strip surface by performing experiments on a specially designed plate-out tester using oil in water emulsion. De Mello et al. [106] investigated the combined influence of surface texturing and hard chromium coating on the wear behavior of cold rolling mill rolls by conducting reciprocating sliding tests. Montmitonnet et al. [90] studied the effect of chrome plating on strip cleanliness by performing plane strain compression tests under lubricated conditions.

These studies showed that increasing the thickness reduction and roll roughness increases the amount of wear particles generated $[5,9,105]$. A high thickness reduction means harsher contact conditions with higher sliding length, increased contact stress, increased real contact area ratio, and higher interfacial 
temperature which lead to more wear [7,9]. Increasing the roughness of rolls results in deeper asperity ploughing, and consequently, increased strip wear [5]. Furthermore, the lubrication regime will be more towards to hydrodynamic lubrication for lower roll roughness. Similarly, rough strip roughness is related to an increase in wear of the strip.

Increasing the rolling speed decreases the wear rate because it results in thicker lubricant film in the roll bite and lowers friction [9]. Contradicting results were reported on the influences of forward slip and temperature. Huart et al. [7] and Deltombe et al. [105] indicated that increased forward slip contributes to the increase in quantity of wear particles produced, its effect being more pronounced for high thickness reductions. In contrast, Jacobs et al. [9] reported that forward slip has no significant influence on strip cleanliness. Louaisil et al. [11] reported that rolling at high temperature $\left(120^{\circ} \mathrm{C}\right)$ gives a slightly cleaner strip (less wear particles) than at room temperature. They ascribed this behavior to the adhesive wear and the transfer layer being favored at high temperatures. More wear particles may adhere to the strip or the roll at higher temperatures, which form a transfer layer and cannot be collected and measured. Jacobs et al. [9] attributed the decrease in the amount of wear particles at high temperatures to the better efficiency of the additives present in the lubricant at high temperatures. On the contrary, Labiapari et al. [55] reported a higher wear rate when the lubricant temperature was increased. They attributed this to the reduced viscosity of the oil (and hence reduced film thickness) at higher temperature, leading to more metal to metal contact, which increased the formation of wear particles.

Hard chrome coating the rolls has been shown to reduce wear rate $[9,90,106]$. However, different mechanisms are proposed for this positive influence. These include: (i) better adherence of oil to the chrome plated surface than to the steel surface [9]; (ii) the formation of $\mathrm{Cr} / \mathrm{CrO}_{\mathrm{x}}$ tribolayer with desirable tribological properties; and (iii) smoothening of the sharp and aggressive features from the grinding process with gentler features [90]. Oil concentration and composition of the lubricant are reported to have negligible direct influence on abrasive wear [9]. Nevertheless, thermal stability of the lubricant can have a significant influence on suppressing heat scratches $[6,107]$.

Although the above studies provide an insight on the influence of rolling parameters on the generation of wear particles, little or no attempt has been made to develop a wear model for cold rolling processes to estimate the amount of wear particles generated. The dynamic and complex nature of cold rolling with many interacting variables makes it very challenging to develop such a wear model. Developing a wear model for cold rolling process requires the coupling of both the macroscale rolling parameters that define the contact conditions at the microscale and the microscale wear mechanism(s) at asperity level.

\subsection{Research gaps}

The objective of this thesis is to develop a multi-scale model to predict wear particles generation and the related fundamental understanding on factors influencing surface quality in cold strip rolling.

Given the roll and strip surface roughness and the process parameters, the model must be able to estimate the severity of wear particles formation. In cold rolling, the rolling force, thickness reduction and forward slip define the real contact area and the sliding distance. The roughness of the rolls and the strip set the geometry of the microscale contacting asperities. The strip/roll material properties and hardness, pretreatment of the strip and the rolls (e.g. pickling and chrome coating, respectively), temperature, and lubricant composition establish wear at each micro-contact. Thus, the model should take into account process parameters, surface roughness and material properties, as well as lubrication conditions that have the most influence on wear debris formation.

Understanding how the apparent and the real area of contact are related and how the nature of contact changes as the process parameters change is crucial, as this will affect the interfacial phenomena and the wear rate. Bulk deformation of the strip has a big influence on the real contact area during cold rolling. Despite the existence of a number of contact models that consider the influence of bulk deformation on the real contact area, there is a lack of a detailed experimental study on the validity of these models for practical industrial cold rolling processes. 
Although the rolling process parameters define the contact conditions at the macroscale, the microscale is where the actual wear particles generation takes place. At this scale, the hard roll asperities indent and plough through the soft sheet surface. This can lead to strip wear and subsequently the generation of wear particles depending on the wear regime. Therefore, a study of the contact between a single hard roll asperity and a flat soft strip sample is essential in order to obtain a complete insight on the macroscale wear properties of the cold rolling tribological system. Even though experimental studies exist on the influence of rolling parameters on the wear rate, little study has been done to understand the wear behavior at single asperity (microscale) roll-strip contact.

\subsection{Research approach}

The approach followed in this research is depicted in Figure 2.9. First, a cold rolling mill of interest where wear particle generation occurs is identified in Tata Steel (The Netherlands). Next, the operating parameters (such as thickness reduction, lubrication regime and rolling speed) of this mill are examined. In addition, the mechanical properties and the surface roughness properties of the roll and the strip are characterized. Since it is necessary to know the real contact area of the roll-strip contact in order to predict wear particles generation, a contact model is developed and experimentally validated on a pilot rolling mill. The contact model, for a rough-hard on rough-soft surface under fully plastic contact condition, takes into account bulk deformation and work hardening. The total amount of wear particles generated during cold rolling is determined not only by the real contact area ratio at macroscale but also by the details of the wear mechanism(s) at individual roll-strip asperity contacts (microscale). Thus, the wear behavior at single asperity contact (i.e. a single roll asperity sliding against a flat soft sheet) is investigated both experimentally and numerically. Finally, a macroscale wear model, which considers the combination of relevant rolling parameters as variables, is developed and validated for the prediction of wear particles generation (strip cleanliness).

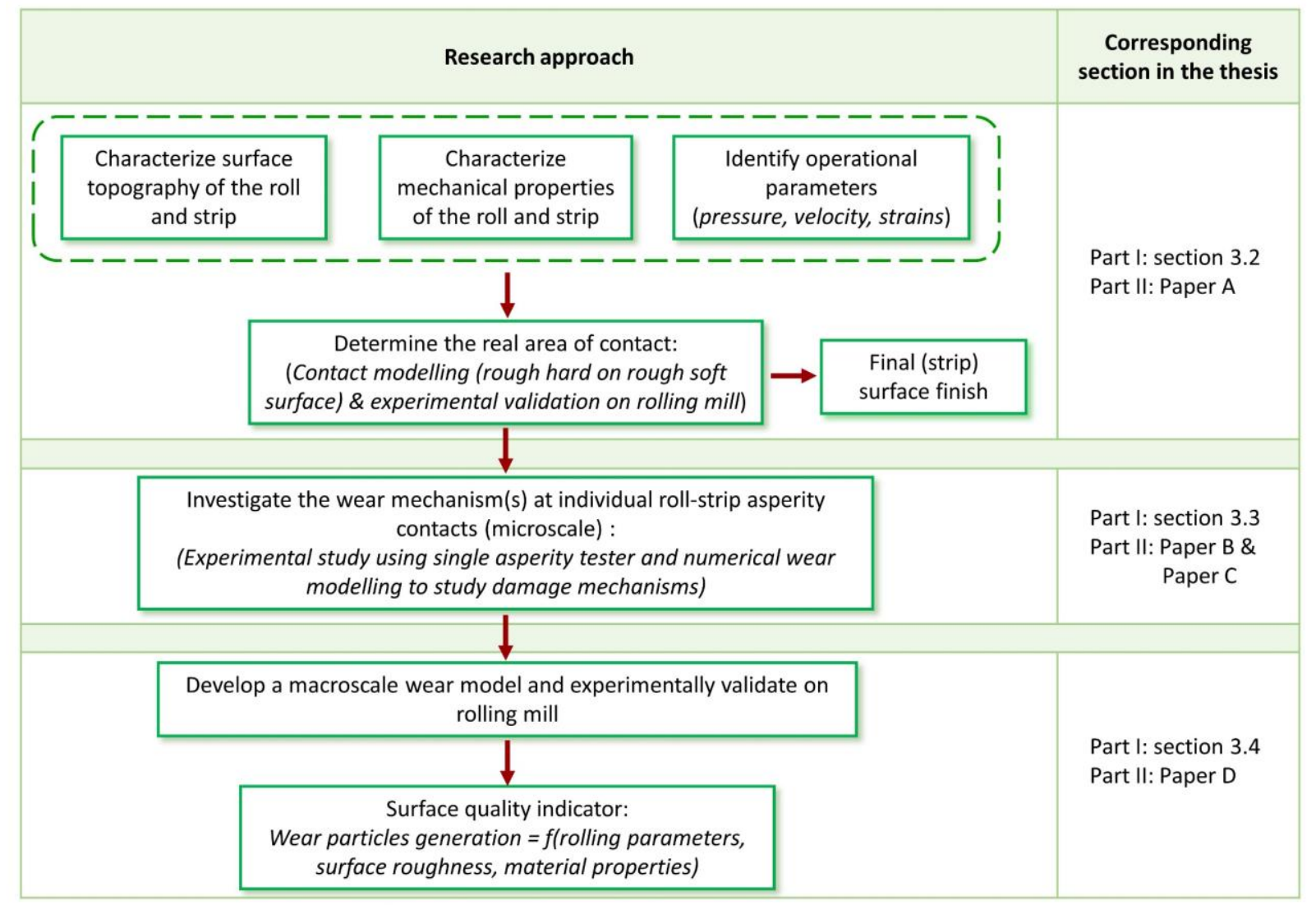

Figure 2.9: A diagram showing the solution approach followed in this thesis. 


\section{SUMMARY OF THE RESEARCH}

\subsection{Overview of the solution approach}

As explained in section 1.3, the objective of this thesis is to develop a model to predict the surface quality of a cold rolled strip. For this purpose, a multi-scale wear model to estimate the severity of wear particles formation in cold rolling processes operating in the boundary lubrication regime is developed. The model combines a semi-analytical deterministic multi-asperity contact model and wear at microscale single asperity contact. The flow diagram of the model is provided in Figure 3.1.

The inputs to the model are the three-dimensional (3D) strip and roll roughness topography, a constitutive equation of the strip material, and the rolling parameters. First, the real area of contact between the roll and the strip surface is calculated by employing a contact model, in which the influence of normal loading and bulk deformation of the strip are taken into account. The mean contact pressure, which is an input to the contact model, is determined from the friction hill calculations made using slab analysis under plane strain conditions. Outputs of the contact model are: (i) identification of the micro contacts, (ii) the real contact area ratio and (iii) the surface finish of the rolled strip. Next, each micro-contact in the contact model is idealized by an elliptical-paraboloid to map the macroscale contact model with the microscale (single asperity) wear. The size and shape of the elliptical paraboloid is determined using the least squares fit through the measured height data of each contact patch. The details of the contact model and the corresponding experimental validation are explained in Paper A of Part II.

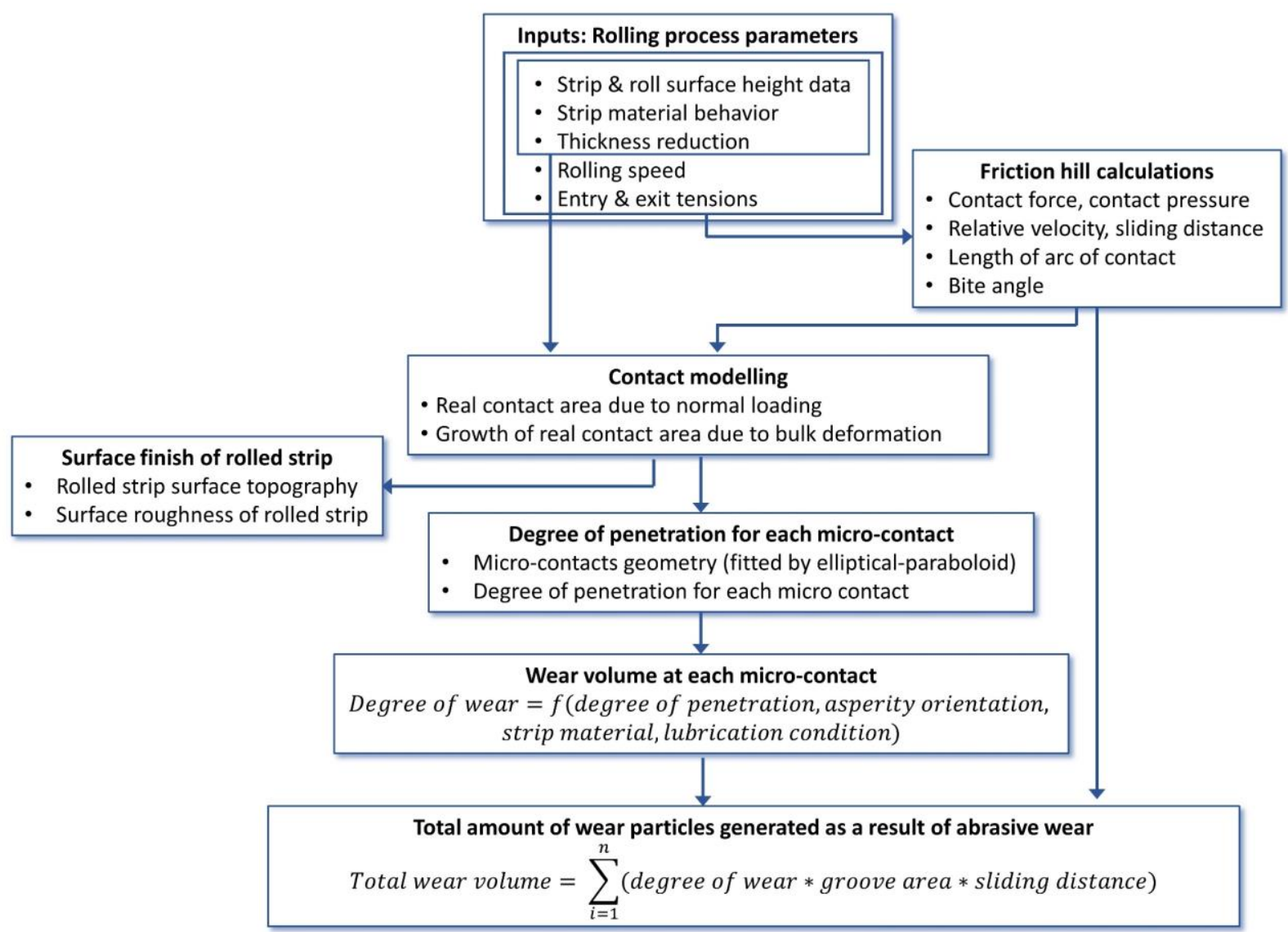

Figure 3.1: Flow diagram of the computational approach used to predict iron fines formation.

In the next step, the amount of material removed as wear debris at each micro contact is determined. It is assumed that all removed material will end up as wear particles. This is an assumption, leading to an upper bound of the particle volume. To attain this objective, scratch experiments and scratch simulations of a single (model) roll asperity sliding over a flat strip surface was carried out. Wear at single asperity (microscale) is mapped to the contact model (macroscale) by fitting each-micro contact with an equivalent 
mathematical geometry (elliptical paraboloid) and using a non-dimensional parameter - specifically, the degree of penetration, $d_{p} . d_{p}$ is a commonly used measure of the sharpness of an indenting asperity $[100,102]$. It is the ratio of indentation depth to the semi-axis of a contact spot in the sliding direction. For a spherical indenter, $d_{p}$ is defined by (also see Figure 3.2a):

$$
d_{p}=d / a
$$

The $d_{p}$ of each micro-contact is computed by assuming the tips of the contacting asperities to have an elliptical-paraboloid shape (Figure 3.2b). The details of the experimental and numerical study of wear at single asperity contact is provided in Papers B \& C of Part II.

a)

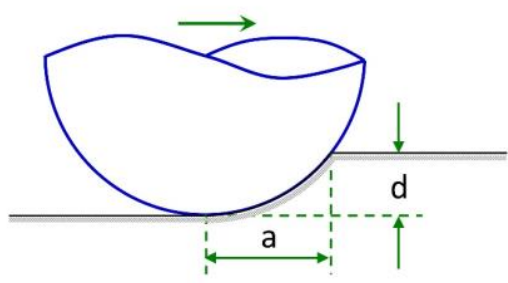

b)

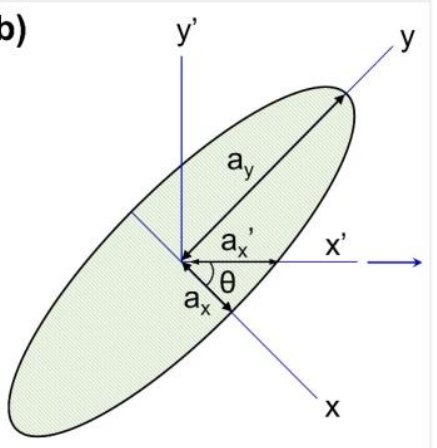

c)

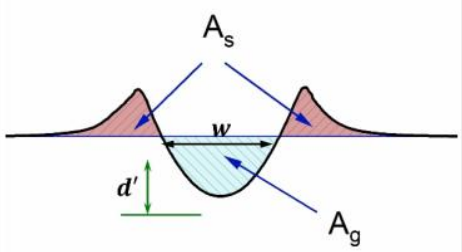

Figure 3.2: a) degree of penetration for a spherical indenter, b) an elliptic micro-contact: $x^{\prime}$ is the sliding direction, $\mathrm{a}_{\mathrm{x}}$ and $\mathrm{a}_{\mathrm{y}}$ are the semi-minor and semi-major axis, respectively, and $\mathrm{c}$ ) cross section of a scratch wear scar.

Next, the proportion of groove volume removed as wear debris at each micro contact, denoted by the degree of wear $\left(d_{w}\right)$, is evaluated. $d_{w}$ can be calculated from the average two-dimensional scratch cross section (illustrated in Figure $3.2 \mathrm{c}$ ) by:

$$
d_{w}=\left(A_{g}-A_{s}\right) / A_{g}
$$

The degree of wear depends on many variables such as material properties and surface treatment of the interacting surfaces, surface chemistry, contact temperature and lubricant composition. For this reason, $d_{w}$ values, as a function of $d_{p}$, are obtained from the scratch experiments. The volume of material removed due to wear at each micro contact is the product of the degree of wear, frontal area of the groove, and the sliding distance.

Finally, the total volumetric wear (per unit area) caused by all asperities is calculated as the sum of the volume of material removed due to wear at each micro contact. Experimental verification of the wear model was carried out by performing rolling experiments on a semi-industrial rolling mill in lubricated and dry conditions at several thickness reductions, rolling speeds and exit tensions using smooth and rough rolls. The experimental details as well as comparison of the model results and experimental measurements are presented in Paper D of Part II. The main findings of the contact model, the single asperity wear study, the wear model and the corresponding experimental validations are discussed in the following sections.

\subsection{Contact modelling and experimental validation}

Accurate modelling of the real contact area is the basis for characterizing the tribological behavior of cold rolling processes such as estimating the rolled strip surface finish, friction, and wear rate. As described in section 2.1.2, the real area of contact in cold rolling mainly depends on the rolling parameters, lubrication, roughness of the roll/strip and material properties of the strip. This section discusses the contact model development, based on existing contact models in literature, and the detailed experimental study on the validity of the model for practical industrial cold rolling processes. 
The contact of cold rolling processes operating in the boundary lubrication regime, which corresponds to the first stand of a tandem mill, is considered in this study. This was chosen because it has been observed empirically that the first stand is where the most wear particles are generated [108]. In addition to operating in the boundary lubrication regime, this stand is where the largest thickness reduction occurs (up to $35 \%$ ). High thickness reduction means harsher contact conditions, with high contact stresses and increased contact area and slip, which leads to more wear. Moreover, the typical input strip in this stand is soft (hot rolled and pickled) and has very irregular surface roughness features created by pickling. These both contribute to the high strip wear observed in this stand.

During rolling, the strip deforms plastically in the roll bite. The real contact area varies as a function of the (strip) bulk plastic strain. Thus, the real contact area changes throughout the roll bite as bulk deformation increases from the roll-bite entry to the exit. Although there are a number of contact models that examine flattening of model asperities by taking into account bulk deformation (see section 2.1.2), a detailed experimental verification was lacking on the accuracy of these models in industrial cold rolling conditions (i.e. at relatively high contact pressures and bulk strain). Hence, an experimental approach has been developed in this study to verify these contact models in predicting the real contact area ratio and the surface finish of industrially cold rolled strips. This was attained by performing cold rolling experiments on a two-high pilot mill at Tata Steel Technology B.V. (IJmuiden, The Netherlands) under boundary lubricated conditions using an industrially hot-rolled and pickled Titanium-stabilized interstitial-free (Ti-IF) steel strip, as widely used in automotive outer body part applications. The effects of thickness-reduction, roll and strip roughness, and rolling speed on the real contact area ratio have been investigated. The experimental details are presented in Paper A of Part II.

Step 1: Rolling parameters \& strip material characteristics

Strip \& roll surface height data, strip material behavior, apparent contact pressure, thickness reduction, rolling speed

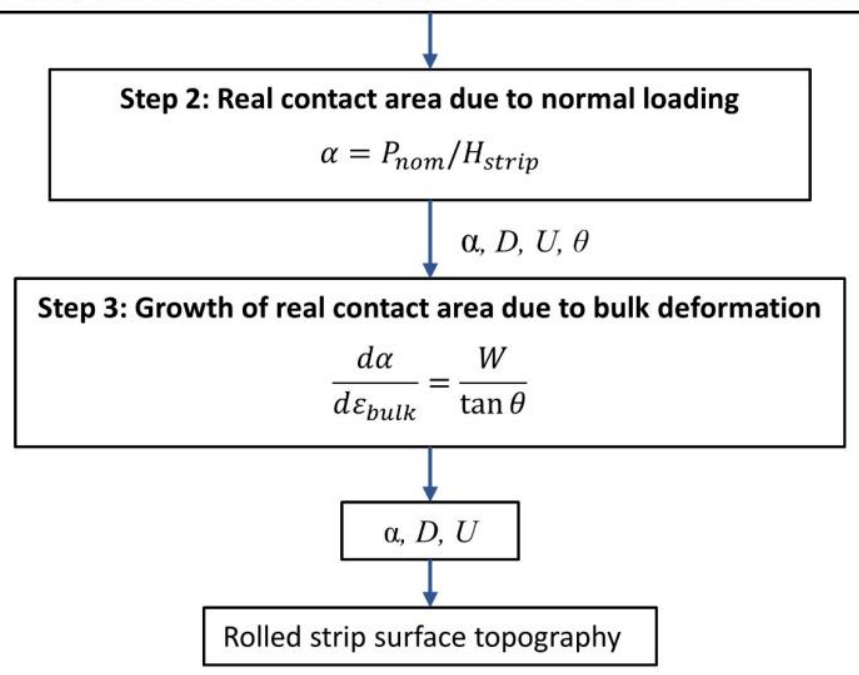

Figure 3.3: Solution procedure for the contact model.

The experimentally measured 3D surface topography of the rolled strip was compared with the model predicted surface (Wilson and Sheu [17] analytical and Korzekwa et al. [18] numerical models). An overview of the procedure for calculating the real contact area and the model predicted surface topography of the rolled strip is illustrated in Figure 3.3. The real contact area calculation procedure starts by defining the rolling parameters, strip material behavior, and strip/roll surface height data (step 1). The roughness texture of the roll and the strip surface is modelled as bars, which can represent any arbitrarilyshaped asperities (see Figure 3.4). Since the work roll surface is typically much harder (more than 3 times) than the hardness of the strip surface, the roll surface is considered as a rigid surface and the strip as a deformable surface in the modelling. In step 2, the real area of contact $(\alpha)$ due to normal loading and the separation $(D)$ between the roll and the strip are calculated. In this step, the average asperity slope is calculated by characterizing the contact patches by elliptical paraboloids [109]. Asperity slope $(\tan \theta)$ plays an important role on the rate of asperity flattening $(W)$ with an increase in bulk strain $\left(\varepsilon_{\text {bulk }}\right)$ [17][18]. In 
step 3, the increase in the real area of contact due to bulk strain is calculated. Finally, the surface topography of the rolled strip is calculated from the real contact area and the surface height distribution of the roll and the strip. The surface topography of the rolled strip is determined by assuming the roll surface topography is imprinted on the strip surface. Furthermore, similar to Pullen \& Williamson [110], the non-contacting valleys are assumed to rise uniformly $(U)$ (see Figure 3.4).

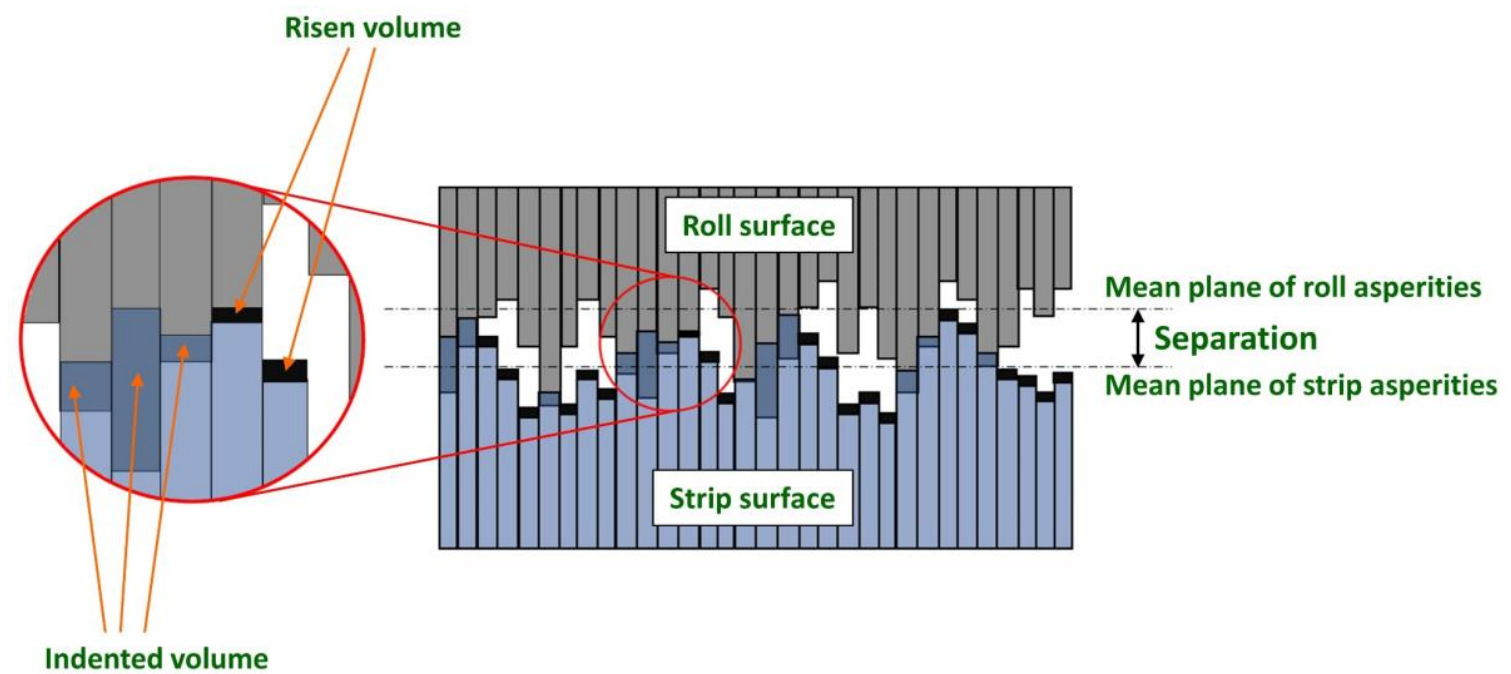

Figure 3.4: Schematic of the contact between rough strip and rough roll surfaces, surface roughness represented as bars.

One important aspect of contact in cold rolling is that the real contact area ratio $(\alpha)$ varies throughout the roll bite as it increases with bulk strain. An illustration of the variation of the real contact area variation throughout the roll bite (calculated using the contact model) is shown in Figure 3.5.

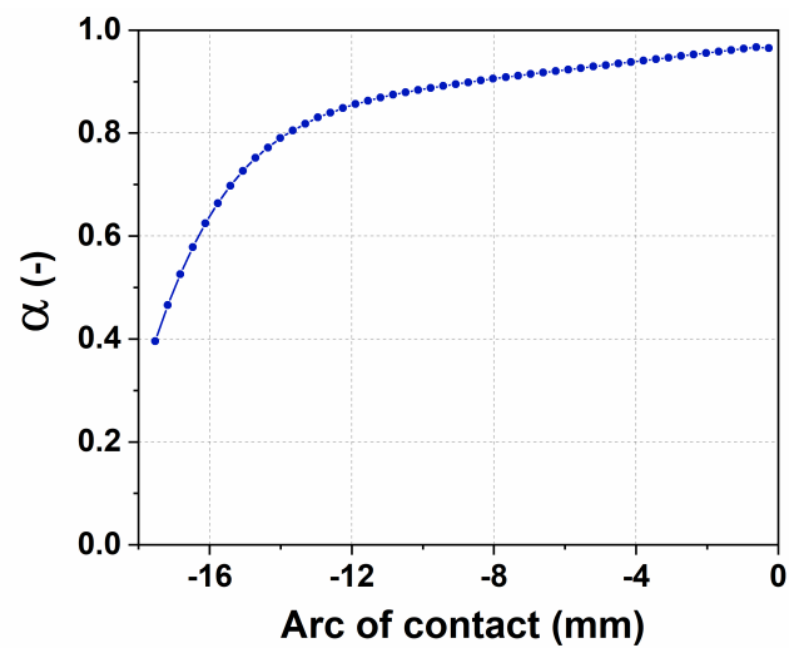

Figure 3.5: Calculated real contact area ratio throughout the roll bite from entry (left) to exit (right) for $40 \%$ thickness reduction.

Figure 3.6 displays the calculated real contact area ratio, using the contact model, for the rolling experiments. The real contact area ratio $(\alpha)$ increased from approximately 0.5 at $10 \%$ thickness reduction to about 0.8 at $35 \%$ thickness reduction. Moreover, rolling experiments done with a higher combined r.m.s. roughness $S_{q_{\_} e q u i}$ (rough roll - smooth strip, $S_{q_{\_} e q u i}=3.3 \mu \mathrm{m}$ ) showed a lower real contact area ratio than those done with a lower combined roughness (smooth roll-rough strip, $S_{q_{-} e q u i}=2.6 \mu \mathrm{m}$ ). This is due to the dependence of the real contact area ratio on asperity slope, which in turn is dependent on the strip and roll roughness. The higher the strip roughness, the higher is the average asperity slope and the lower the rate of asperity flattening. 


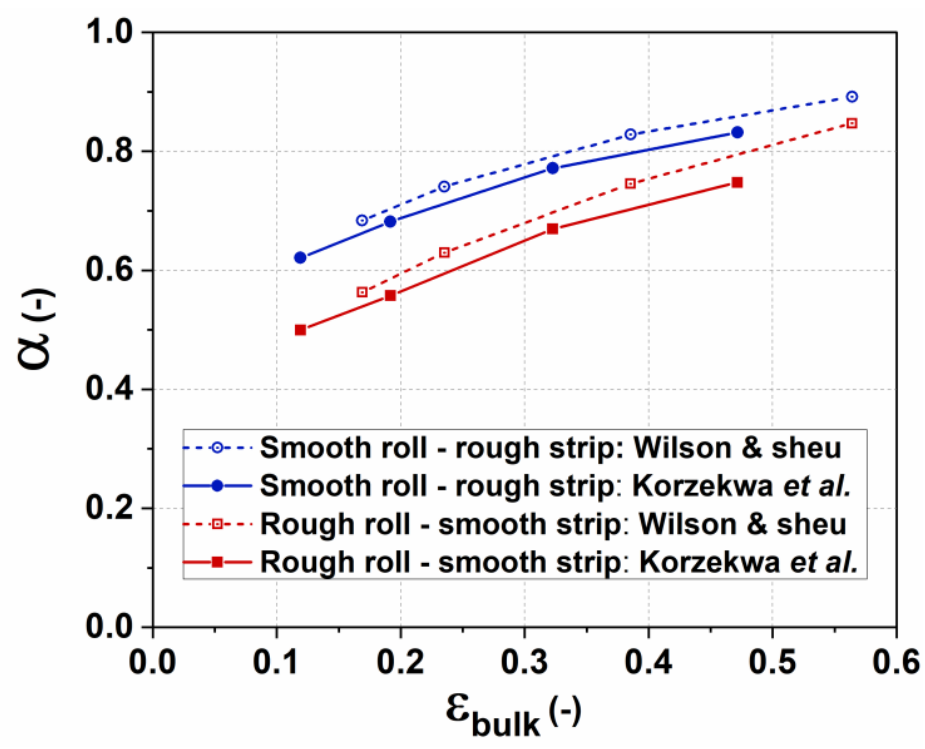

Figure 3.6: The real contact area ratio (model results) of the rolling experiments.

The influence of rolling parameters on the real contact area and flattening behavior of strip asperities during rolling is reflected in the average roughness value $\left(S_{q}\right)$, surface height distribution and bearing area curves. These parameters can be used to describe some of the functional properties of a rolled strip surface. Figure 3.7 shows roughness of the rolled strip as a function of bulk strain and rolling speed, and its comparison with the model results. The roughness changes show that thickness reduction is the prime rolling parameter that determines the real contact area ratio, and hence, the surface finish of the rolled strip. The roughness of the rolled strip approaches the roughness of the roll with an increase in thickness reduction. As mentioned earlier, bulk deformation of the underlying material greatly enhances the flattening/indentation of strip asperities. This means a higher real contact area and more conformity to the roll surface as the thickness reduction increases.

The rolling speed $\left(V_{r}\right)$ and roll/strip roughness only had a minor influence on the asperity flattening rate. This is expected as the rolling experiments were performed in the boundary lubrication regime with little hydrodynamic effect in the roll bite. The effects of rolling speed and roll/strip roughness might be more pronounced for cold rolling processes operating under mixed or hydrodynamic lubrication conditions, as in the latter cases, they can play an important role in the occurrence of oil-pits and the amount of rolling oil introduced into the roll bite.

The roughness of measured rolled strip surfaces and the surfaces predicted using Wilson and Sheu's [17] model showed good agreement for both rolling experiments done using smooth and rough rolls. Korzekwa et al. [18] model, on the other hand, gave lower roughness values for strips rolled with a rough roll (Figure $3.7(a, b)$ ) and higher roughness for strips rolled with a smooth roll (Figure $3.7(c, d)$ ). This suggests that Korzekwa's model underestimates the real contact area ratio. 

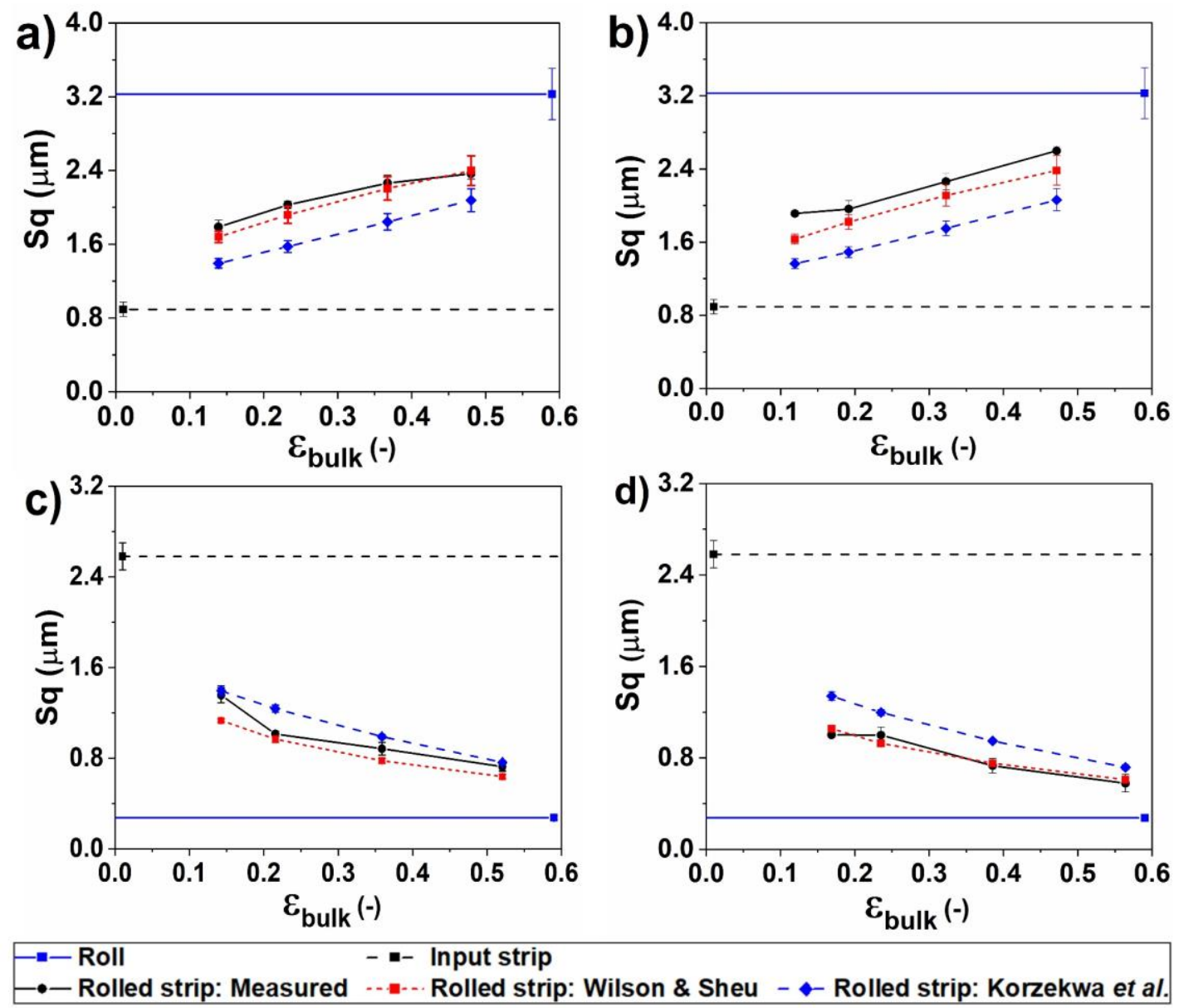

Figure 3.7: Roughness evolution of the strips - Measured vs Model; rolled with (a, b) rough rolls and (c, d) smooth rolls at a rolling speed of $(\mathrm{a}, \mathrm{c}) V_{r}=0.5 \mathrm{~m} / \mathrm{s}$ and $(\mathrm{b}, \mathrm{d}) V_{r}=2 \mathrm{~m} / \mathrm{s}$.

The surface height distribution and bearing area curve comparison of the measured surfaces and model predicted (Wilson \& Sheu) surfaces showed good agreement for strips rolled using a smooth roll (see Figure 3.8). However, for strips rolled using rough rolls, a significant difference was observed in the surface height distribution between the measured and model-predicted surfaces. Although the model corresponds in terms of $S_{q}$ with the experiments, strips rolled with a rough roll showed a different behavior in terms of surface height distribution and bearing area curve compared to the surfaces predicted using the contact model. The measured surfaces have spiky ridges while the model predicts surfaces having plateaus. This is reflected by the long tail of the surface height distribution of the measured surfaces. The main cause of this difference was found to be the non-uniform rise of non-contacting valleys, as will be discussed in detail in the next section. 

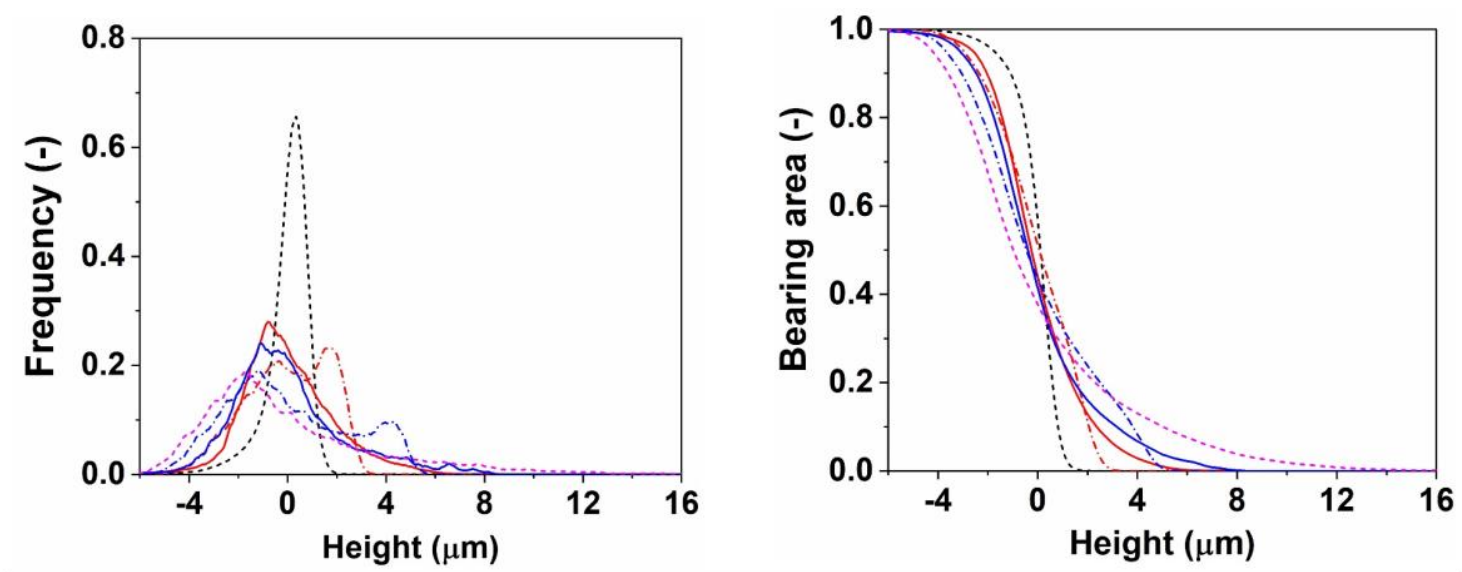

\begin{tabular}{|c|c|}
\hline -...-Input strip & $\longrightarrow$ Rolled strip: $\varepsilon_{\text {bulk }}=0.14-$ Measured - Rolled strip: $\varepsilon_{\text {bulk }}=0.14-$ Model \\
\hline Rolled strip: $\varepsilon_{\text {bulk }}=0.48-$ Measured & -... Rolled strip: $\varepsilon_{\text {bulk }}=0.48-$ Model \\
\hline
\end{tabular}
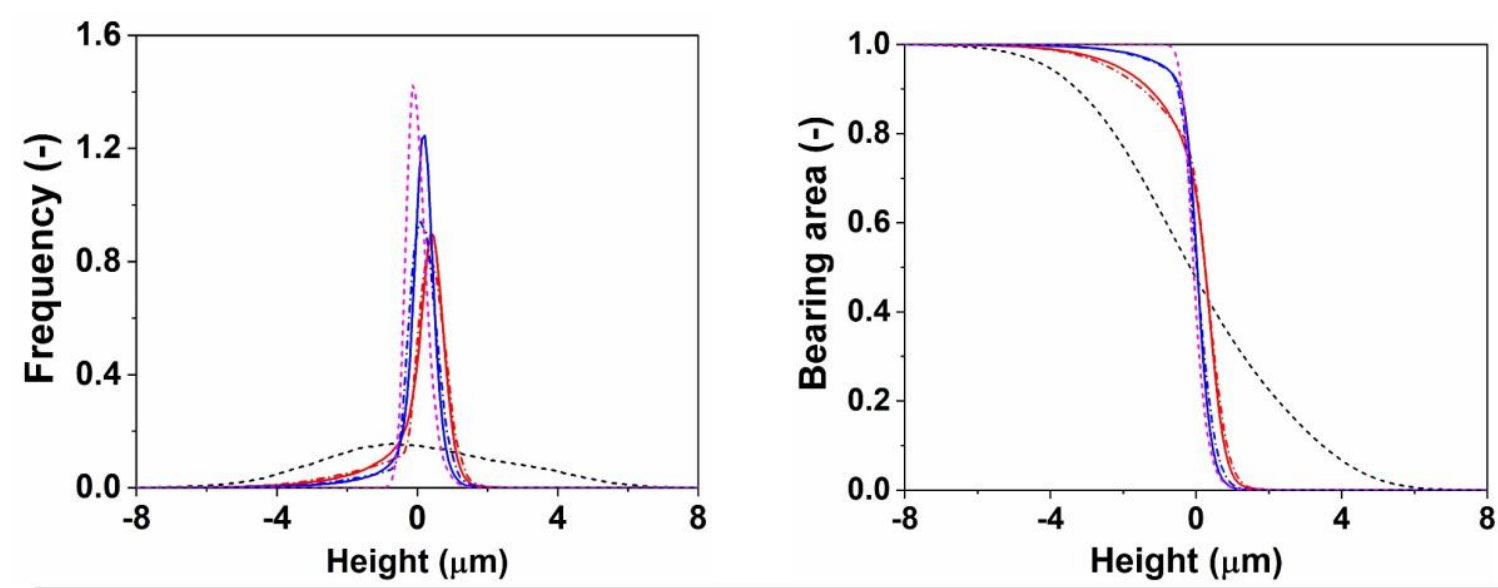

\begin{tabular}{|c|c|c|}
\hline $\begin{array}{l}\text { Rolled strip: } \varepsilon_{\text {bulk }}=0.56 \cdot \text { Measured } \\
\text { Rnput strip }\end{array}$ & $\begin{array}{l}- \text { Rolled strip: } \varepsilon_{\text {bulk }}=0.17-\text { Measured } \\
--- \text { Rolled strip: } \varepsilon_{\text {bulk }}=0.56-\text { Model }\end{array}$ & $\begin{array}{l}-\cdots-\text { Rolled strip: } \varepsilon_{\text {bulk }}=0.17-\text { Model } \\
-\cdots \text { Roll replica }\end{array}$ \\
\hline
\end{tabular}

Figure 3.8: Normalized surface height distribution (L) and bearing area curve (R) of strips rolled using rough rolls (top) and smooth rolls (bottom), Measured vs Model.

\subsubsection{Uniform rise hypothesis in predicting surface finish}

The uniform rise hypothesis of the non-contacting surface was employed to predict the surface finish of rolled strips [110]. For strips rolled with smooth rolls, this assumption provides a good estimation of the roughness (Figure 3.7) and surface height distribution (Figure 3.8). However, the surface height distribution of strips rolled with rough rolls was substantially different from the model predicted ones using the uniform rise hypothesis. The main cause of this difference is the non-uniform rise of noncontacting surface due to an inhomogeneous deformation field at the contact interface. This was confirmed by performing static pressing experiments using the same pilot mill as described in the rolling experiments.

Pressing experiments were realized by pressing two rolls at several combinations of pressing force and strip/roll roughness. Indentation marks were placed on both the roll and the strip surface near the contact zone so that the $3 \mathrm{D}$ height images can be easily matched before and after the experiment. Before the actual pressing was performed, surface replicas of the roll and the strip in the contact zone were taken. The 3D profiles of the roll (replica) and the strip surface, both before and after pressing, were measured. Image matching was done, using a Matlab code, for the non-pressed and the pressed strip using the indentation marks as reference points. The height profile and roughness of the model-predicted surface was calculated by applying the contact model (see for example Figure 3.9). Next, the rise of non-contacting valleys is calculated by subtracting the height of the non-pressed strip from the pressed strip surface. This 
was done both for the measured and model predicted surfaces. Finally, a comparison of the rise of noncontacting surface for the measured and model predicted surfaces was performed. Figure 3.10 illustrates an example of a comparison of the rise of non-contacting surface for the strip and roll surfaces shown in Figure 3.9.
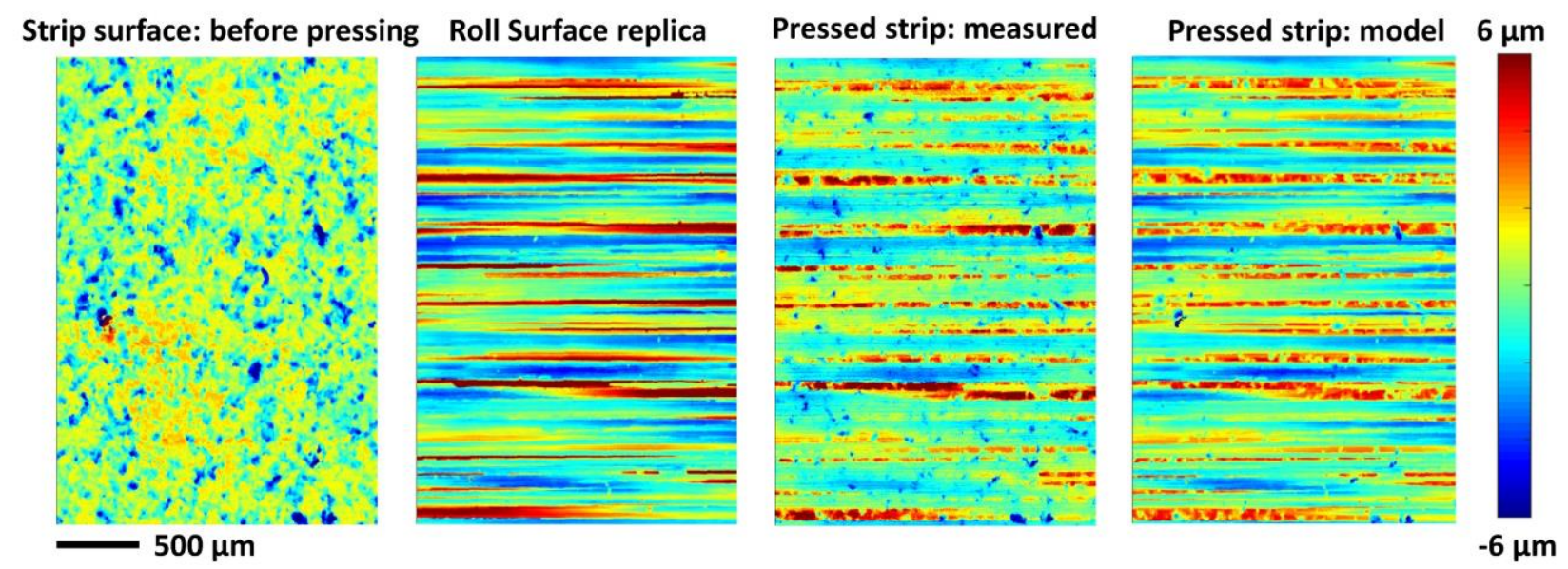

Figure 3.9: Surface topography of the pickled strip, roll replica, and the strip before and after pressing: measured vs model. Pressing force $=800 \mathrm{kN}(540 \mathrm{MPa})$.
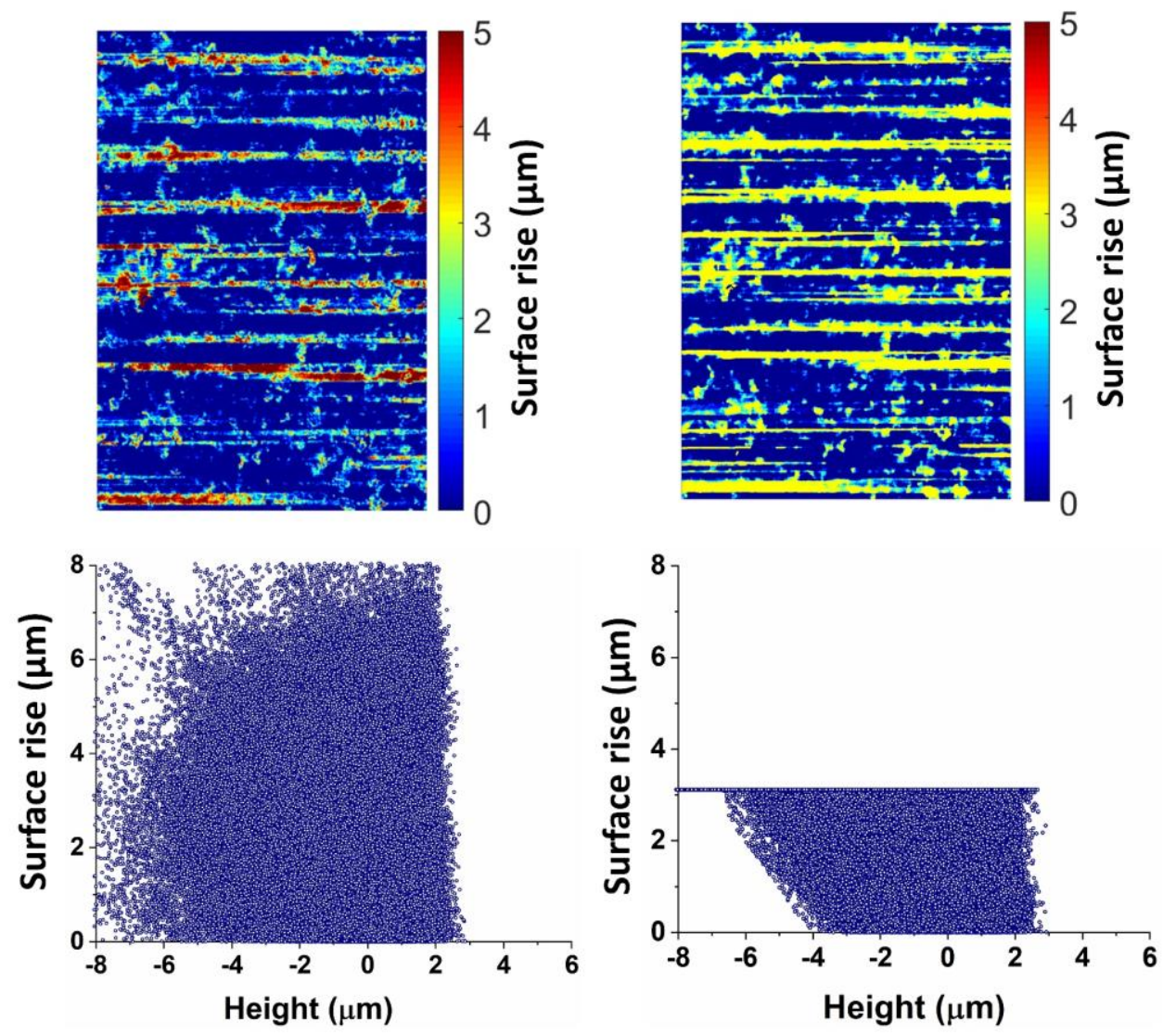

Figure 3.10: Rise of the non-contacting surface: measured (L) vs model (R) for the strip and roll surfaces in Figure 3.9.

Figure 3.10 clearly shows that the rise of non-contacting valleys is not uniform. As the strip deforms in the roll bite, the strip material flows to conform to the roll surface topography. This flow of strip material at the contact interface is a complex, dynamic, asperity interaction process. There is interaction between neighboring contacting asperities and the local deformation field depends on the exact surface topography of the roll and the strip at and near the contact spot. Elastic recovery of the pressed asperities may also 
have a role on the observed discrepancy between the Abbott-Firestone curves of the experimental and model results. Considering all these factors, a more advanced model that accounts three-dimensional stress/strain distribution is required to describe the non-uniform rise of valleys.

In summary, the simplistic uniform rise model can provide a very quick way to calculate the real contact area ratio as well as to anticipate the rolled strip surface roughness and surface finish during cold rolling processes. Moreover, it can be extended to calculate the real contact area for cold rolling processes operating in the mixed-lubrication regime, although this is outside the scope of this thesis.

\subsection{Wear at single asperity roll-strip contact}

In the previous section, the development and experimental validation of a contact model to predict the real contact area ratio taking into account the macro scale rolling parameters and roll/strip surface topography is presented. The formation of wear particles during cold rolling is determined not only by the real contact area ratio (macroscale) but also by the details of the wear mechanism(s) at individual roll-strip asperity contacts (microscale). The macroscale rolling process parameters, together with the surface properties of the roll and strip, define the contact conditions at the macroscale. Microscale is where the actual wear particles generation takes place. At this scale, the hard roll asperities indent and plough through the soft strip surface. This can lead to strip wear, and subsequently, the generation of wear particles, depending on the wear regime [98]. Therefore, understanding the wear mechanism of the contact between a single roll asperity and a strip surface is essential in order to obtain a complete insight on the wear properties of the cold rolling tribological system. In the following sections, the wear behavior of a single roll asperity sliding against a flat soft sheet is investigated experimentally and numerically.

\subsubsection{Scratch experiments}

Scratch experiments were performed to study the wear mechanism(s) and to evaluate the volume of material removed as wear debris when a roll asperity ploughs through a strip surface. The scratch experiments were further implemented to study the influence of hard chrome plating the rolls on wear particles formation. The experiments were carried out using conical indenters with a hemispherical tip which represent a roll asperity, sliding on a polished flat strip surface under lubricated as well as unlubricated (dry) conditions. The indenters are made of cold work tool steel with similar composition as work roll material and has a tip radius in the order of roll asperity (radius ranging between $175 \mu \mathrm{m}$ and $225 \mu \mathrm{m}$ ). Hot rolled and pickled Ti-IF steel was used as a strip sample and the lubricant was a fully formulated industrial rolling (mineral) oil that contains anti wear and extreme pressure additives.

\subsubsection{Wear mechanisms}

Figure 3.11 illustrates an example of the microscopic image of the indenters and the corresponding scratch profiles on the strip after the lubricated scratch experiments. The scratch experiments showed nearly ideal ploughing at a low degree of penetration $\left(d_{p}\right)$. In ploughing wear mode, the material from the groove is primarily pushed to the ridges without any actual material removal. Therefore, no wear particles are generated and little or no material transfer is observed on the indenters. This was also reflected on the relatively smooth wear track profile. Increasing the $d_{p}$, by increasing the applied normal load, led to a gradual transition of the wear mechanism from ploughing to predominantly wedge forming. Moreover, the degree of strip material transfer to the indenters increased with an increase of the degree of penetration. Owing to the higher shear strength of the contact interface, the unlubricated experiments transitioned from ploughing to wedge forming regime at a lower degree of penetration and showed a higher degree of wear compared to the lubricated ones (see Paper B of Part II for more details). 


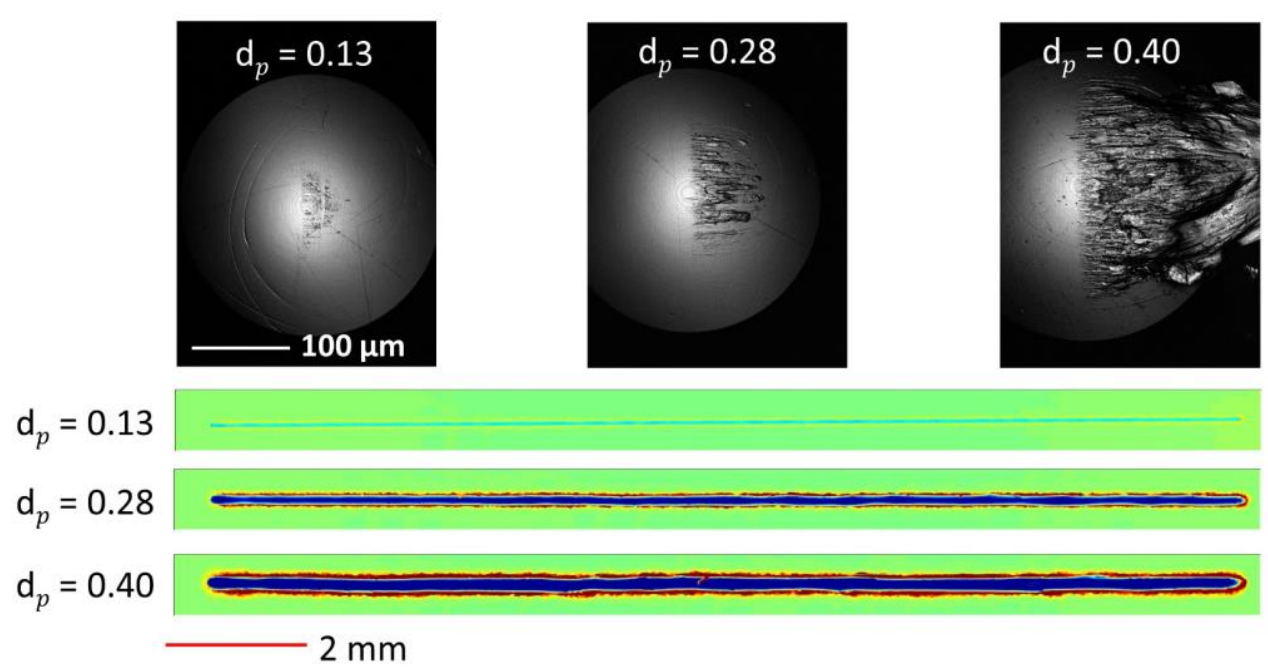

Figure 3.11: Microscopic image of the indenters after the (lubricated) scratch experiments (top) and the surface height morphology of the corresponding wear tracks (bottom). The direction of sliding is from left to right.

In the wedge forming wear mode, a lump builds up in front of the indenter as the scratch proceeds. Once the lump reaches a certain critical height, it is detached and wear debris are formed as a result. This lump growth and detachment results in rough scratches (see Figure 3.11). A transfer layer on the tip of the indenters at high $d_{p}$ (see Figure 3.11 top right) means that there is a local lubricant failure at some locations. In the scratch experiments, a plastic wave is formed as the indenter ploughs through the strip surface. At low load, the boundary layer prevents direct metal to metal contact and slip occurs at the contact interface. As the normal load is increased, the indentation depth increases and the lubricant starts to fail locally due to the high contact pressure involved. Eventually, metal to metal adhesion takes place causing the material transfer observed on the tip of the indenters. Note that the buildup of the transfer layer is very sensitive to the materials mating in the tribological system [111].

\subsubsection{Degree of wear}

During scratching, only part of the material displaced by the groove is removed as wear debris to cause material loss. The remaining material is displaced by plastic flow to form piled up ridges at the sides of the grooves. The relative amount of material removed from the wear track can be described by the degree of wear $\left(d_{w}\right.$, eq. 3-2). The variation of $d_{w}$ as a function of $d_{p}$ depends on the specific material under investigation, the lubrication condition, and the type of active abrasive wear mode [112]. The typical values of the degree of wear in literature are $d_{w}<0.15$ for ploughing, $0.2<d_{w}<0.8$ for wedge forming and $0.8<d_{w}<0.95$ for cutting $[98,113,114]$. Figure 3.12 displays the degree of wear of the lubricated scratch experiments as a function of the degree of penetration. The degree of wear for the experiments range between 0.05 and 0.34 . Ploughing is the dominant wear mechanism at low $d_{p}$; hence, a low $d_{w}$. The value of the degree of wear increases with the increase of the degree of penetration, corresponding the transition of the predominant wear mode from ploughing to wedge forming (see also Figure 3.11). 


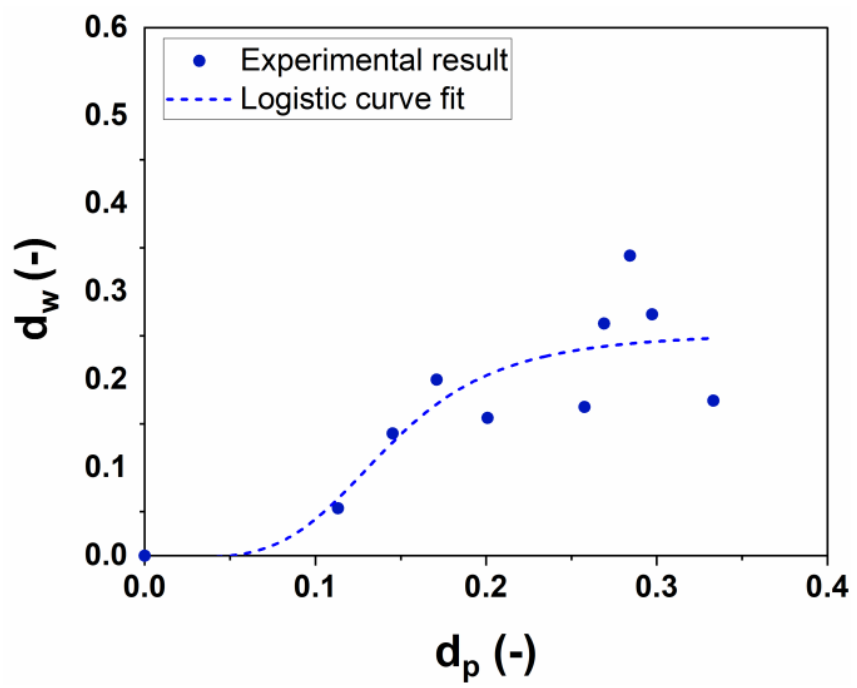

Figure 3.12: Degree of wear as a function of degree of penetration for Ti-IF steel scratched by a hemispherical (175 $\mu \mathrm{m}$ radius) cold work tool steel indenter.

The high ductility and work hardening property of the Ti-IF steel explains the resulting lower experimental value of $d_{w}$ compared to the ones in literature [114] [115]. Increasing ductility increases the critical degree of penetration of the transition from ploughing to wedge forming and cutting and it decreases the degree of wear within the cutting regime [114]. Further, significant work hardening can be expected, especially at the vicinity of the scratch where the actual deformation and tearing takes place [115]. Work hardening influences not only the wear regime transition boundaries but also spreads the plastic zone further from the indenter reducing the pile-up around the indenter and hinders chip formation $[116,117]$.

It is necessary to define the relationship between $d_{w}$ and $d_{p}$ in a mathematical equation to incorporate the scratch experiment results into the wear model being developed. The degree of wear is expected to increase from 0 to a maximum value following an S-shaped curve, in which the maximum value depends on the material being scratched [114]. Considering this and following typical expressions used in literature [102], the experimental results are fitted by a logistic sigmoid function, which has a characteristic S-shaped curve, using a least squared method curve fitting approach. The resulting equation is given by Eq. 3-3 and is plotted as a dashed line in Figure 3.12.

$$
d_{w}=\frac{-0.253}{1+\left(d_{p} / 0.143\right)^{4.348}}+0.253
$$

As the degree of penetration increases, the contribution of ploughing decreases while material removal by wedge forming becomes more pronounced. The material extrudes from the sides of the contact giving rise to flakes which subsequently break off and produce wear particles, similar to that reported in [118].

\subsubsection{The effect of Cr plating}

Another phenomenon studied in the scratch experiments is the influence of hard chrome plating of the rolls on wear particles formation. Hard chrome plating the rolls has been known to have a positive influence on strip cleanliness by reducing the rate of wear particles formation in cold steel rolling [4,9]. However, to date, there are only a few inconclusive studies on the governing mechanisms why this coating reduces wear particles formation. Besides, there is a need to find a replacement for this coating due to health and safety regulations [119]. Hence, it is important to understand the fundamental mechanism behind its positive influence on strip cleanliness to find a more environmentally friendly substitute.

Scratch experiments were conducted at several normal loads in lubricated and dry conditions using a polished hot rolled-pickled Ti-IF steel strip sample and uncoated or hard chrome plated indenters. The lubricant used in the scratch experiments is a commercial fully formulated (palm based) oil that contains friction modifiers, antioxidant, extreme pressure (EP) and anti-wear additives. The in-situ camera 
observations of the scratch experiments revealed that wear particle generation is accompanied by material transfer (Figure $3.13 \mathrm{a}-\mathrm{b}$ ). Larger quantities of wear debris are generated and loosely adhered to the uncoated indenters than the clean hard $\mathrm{Cr}$ plated ones. The $\mathrm{Cr}$ plated indenters displayed a significantly lower quantity of adhered strip material compared to the uncoated ones (Figure $3.13 \mathrm{c}-\mathrm{d}$ ). Further, the quantity of both loosely detached and adhered iron fines on the strip surface of the scratches made using the chrome plated pins is substantially smaller than the scratches made with the uncoated pins (Figure 3.13 e-f).
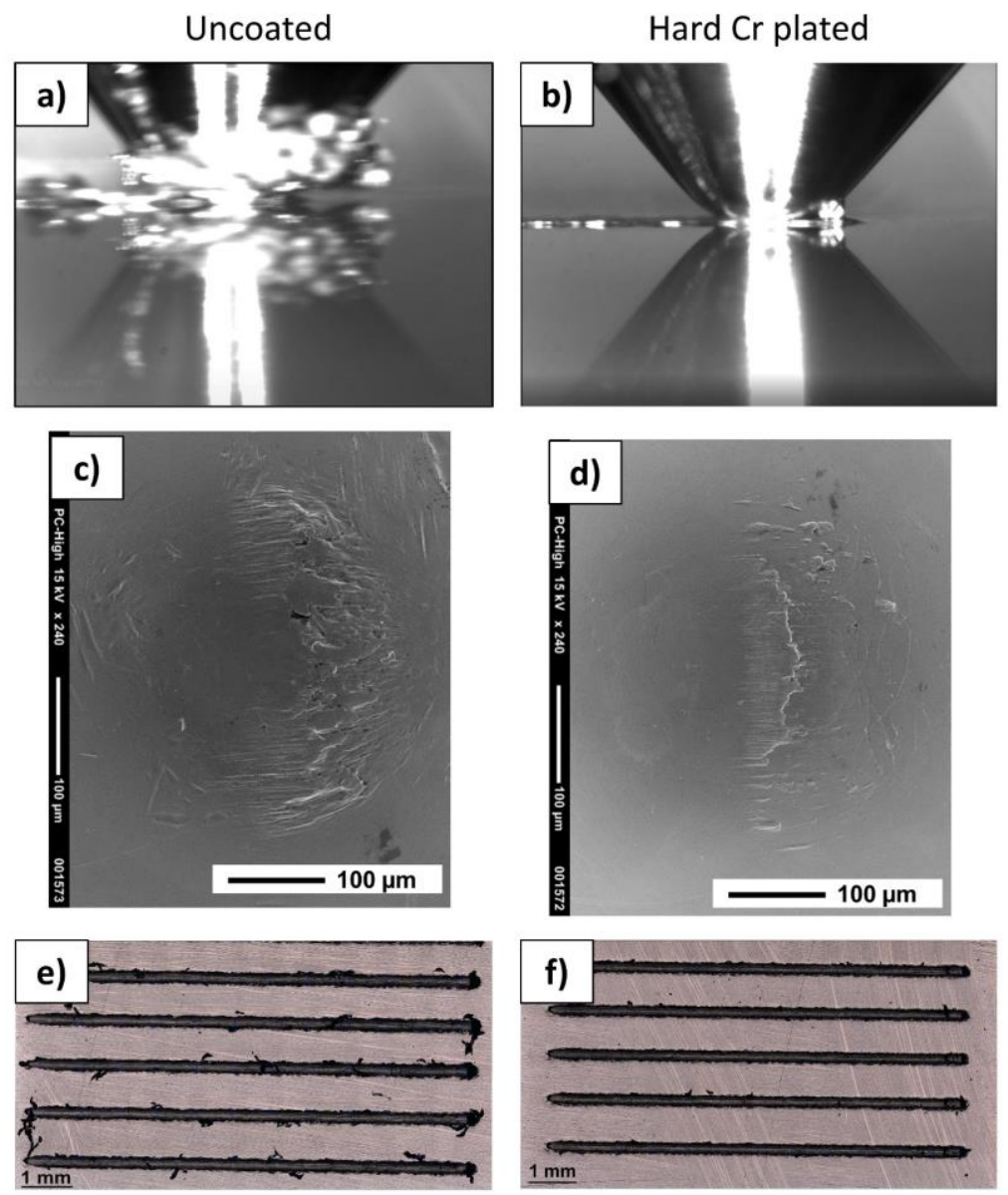

Figure 3.13: A comparison of the snapshot of the scratch experiments using uncoated and hard $\mathrm{Cr}$ plated indenters $(a, b)$; scanning electron microscopy (SEM) images of the indenters after the scratch experiments $(c, d)$; and wear grooves of the scratch experiments with various chips $(e, f)$. The direction of the scratch is from the left to the right.

Since all the experimental parameters were kept the same (including the micro roughness of both the strip sample and the indenter) except the surface condition of the indenter (uncoated or hard $\mathrm{Cr}$ plated), the difference in the tribochemistry of the contacting pairs can be considered as the sole cause of this wear behavior. X-ray photoelectron spectroscopy (XPS) analysis on the tip of the worn indenter surface suggested formation of a protective tribolayer consisting a carbonate and amine species on the chrome plated surface but not on the uncoated steel surface (see Figure 3.14). This demonstrates that the surface chemistry of the chromium layer and its interaction with the additives plays an important role in reducing adhesion and wear particles formation. See Paper C of Part II for further details. 

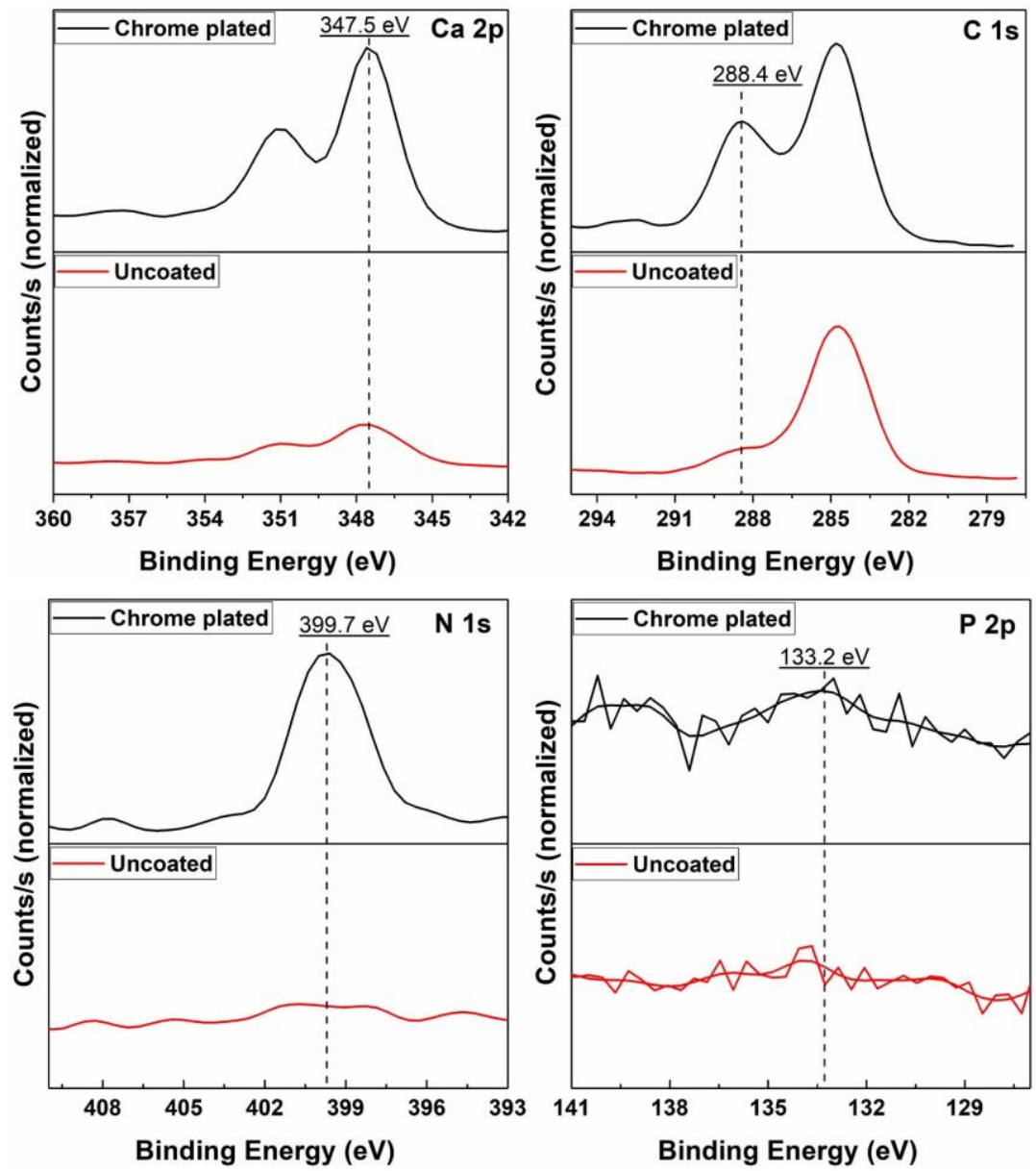

Figure 3.14: XPS spectra of the tribofilm on the worn pin surface.

Chrome plating the indenters did not have the same advantage in the dry scratch experiments as in the lubricated ones. In fact, dry scratch experiments performed using chrome coated indenters showed a higher degree of wear and lower critical $d_{p}$ of the transition from ploughing to wedge forming wear regime (see Part II, paper C for more details). This suggests that the favorable performance of $\mathrm{Cr}$-plating in the lubricated experiments and cold rolling operations originates from its reaction with the lubricant and/or additives.

\subsubsection{Material point method (MPM) scratch simulations}

Although scratch experiments provide information about the microscopic wear mechanism and the volume of material removed as wear particles at single asperity contact, the amount of information that can be obtained from such scratch experiments is limited. For example, one of the important qualities which is difficult to determine experimentally but can be easily deduced from computer simulations is the effect of asperity geometry on wear. Numerical modelling offers a fast, predictive capability to study the influence of several parameters such as asperity geometry, sliding speed and/or temperature on the wear behavior of single asperity contacts, which cannot be easily realized in the experiments.

The material point method (MPM) has been implemented to numerically model the scratch process in three dimensions. MPM, which combines both a background mesh and meshless concepts, can handle problems involving arbitrarily large deformations and material detachment such as abrasive wear and machining [120-122]. The scratches were simulated using a hemispherical rigid indenter (representing the roll asperity) sliding on a deforming substrate (representing the strip). The constitutive equation of the TiIF steel was employed for the deforming substrate. A snapshot of the MPM simulation setup is illustrated in Figure 3.15. 


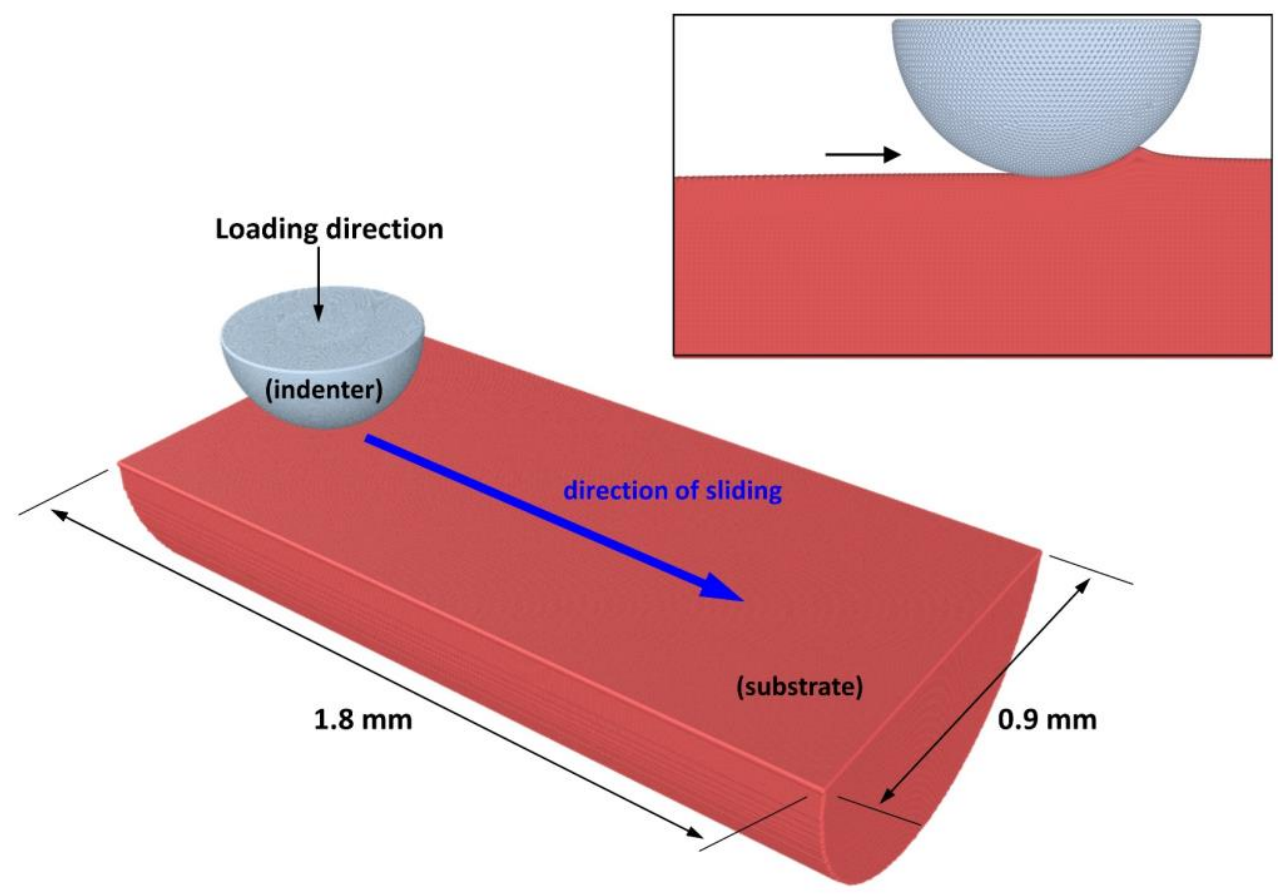

Figure 3.15: Snapshot of the scratch simulation setup.

The effect of interfacial shear strength (realized by varying the Coulomb friction) and degree of penetration (realized by varying the normal load) on the apparent friction coefficient as well as on the wear behavior has been studied in the scratch simulations. Besides, a separate set of scratch experiments (using the same indenter radius as the MPM simulations and applied loads) has been carried out to compare with the numerical model. The scratch experiments were carried out using uncoated and $\mathrm{Cr}$ coated indenters in dry and lubricated conditions. A polished hot rolled and pickled Ti-IF steel was used as a strip sample.
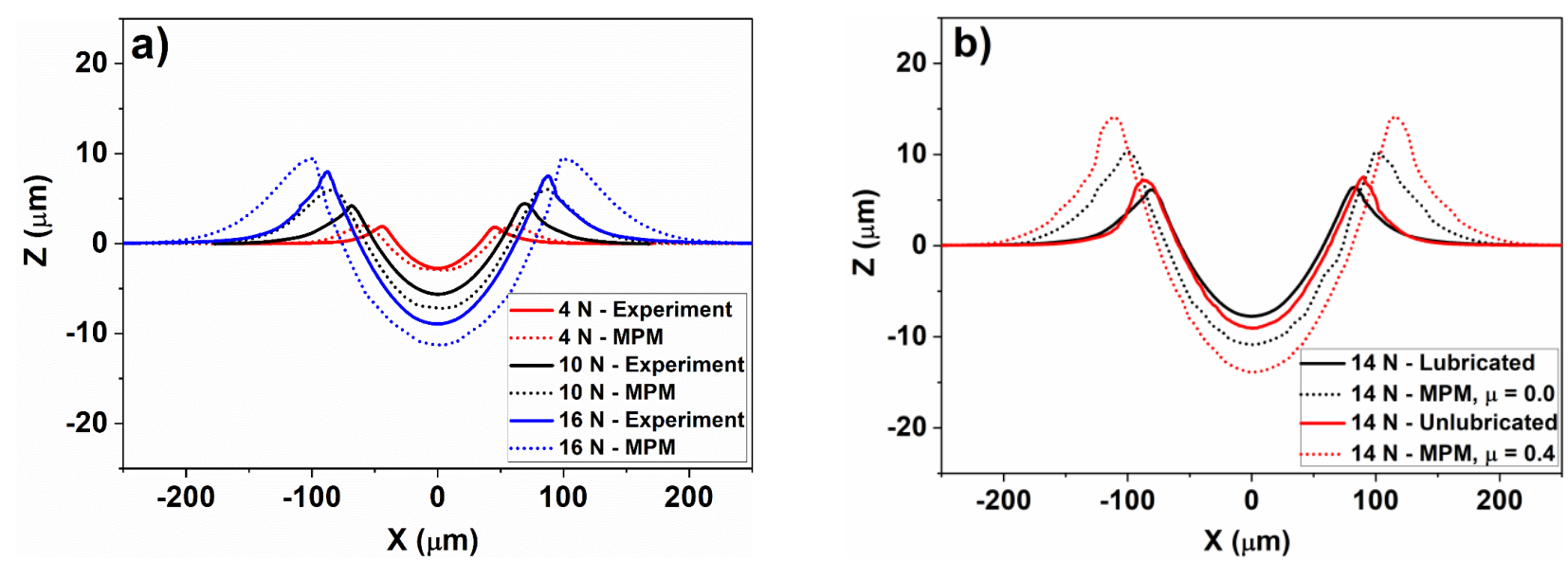

Figure 3.16: Comparison of the wear grooves of MPM simulations and experimental scratch experiments:

a) at various normal loads under lubricated conditions (experiments) and with $\mu$ corresponding to lubricated scratch experiments (MPM simulations); b) the effect of interface shear strength on scratch width and depth.

Agreement between the experiments and the simulations can be judged by comparing the wear groove profiles and the degree of wear values at the same loads. Figure 3.16 presents a comparison of the wear grooves of MPM simulations and the experimental scratch experiments. The MPM simulations slightly overestimated the scratch width, depth and the material displaced to the sides as a consequence of plastic deformation. This overestimation is likely caused by the fact that there is no physically based damage model in the MPM simulations. Furthermore, the use of the bulk material behavior, which may be different from the surface behavior on the top few micrometers, may also contribute to this difference. Another 
contributor could be that the severe strain hardening under the complex stress state in the vicinity of the scratches might not be properly accounted for in the constitutive model. Regardless, MPM simulations capture junction growth very well, see Figure $3.16 \mathrm{~b}$. The real area of contact, and as a consequence, the indentation depth in the scratch experiments increases as the interface shear strength is increased, for instance in the absence of a lubricant, for a given normal load [15].

A comparison of the degree of wear results of MPM simulations with the experimental results are presented in Figure 3.17. It can be clearly seen that the MPM simulations underestimate the degree of wear, which is also reflected in the size of the shoulders of the wear grooves (Figure 3.16). As mentioned earlier, there is no physically-based damage model in the MPM simulations. Material detachment is simply taken into account by using a connectivity criteria between neighboring particles [123]. The interaction between the MPM particles is lost as the separation between neighboring particles exceeds the defined kernel radius. This might be unsatisfactory when it comes to predicting the mechanical behavior of ductile materials experiencing damage in compression.
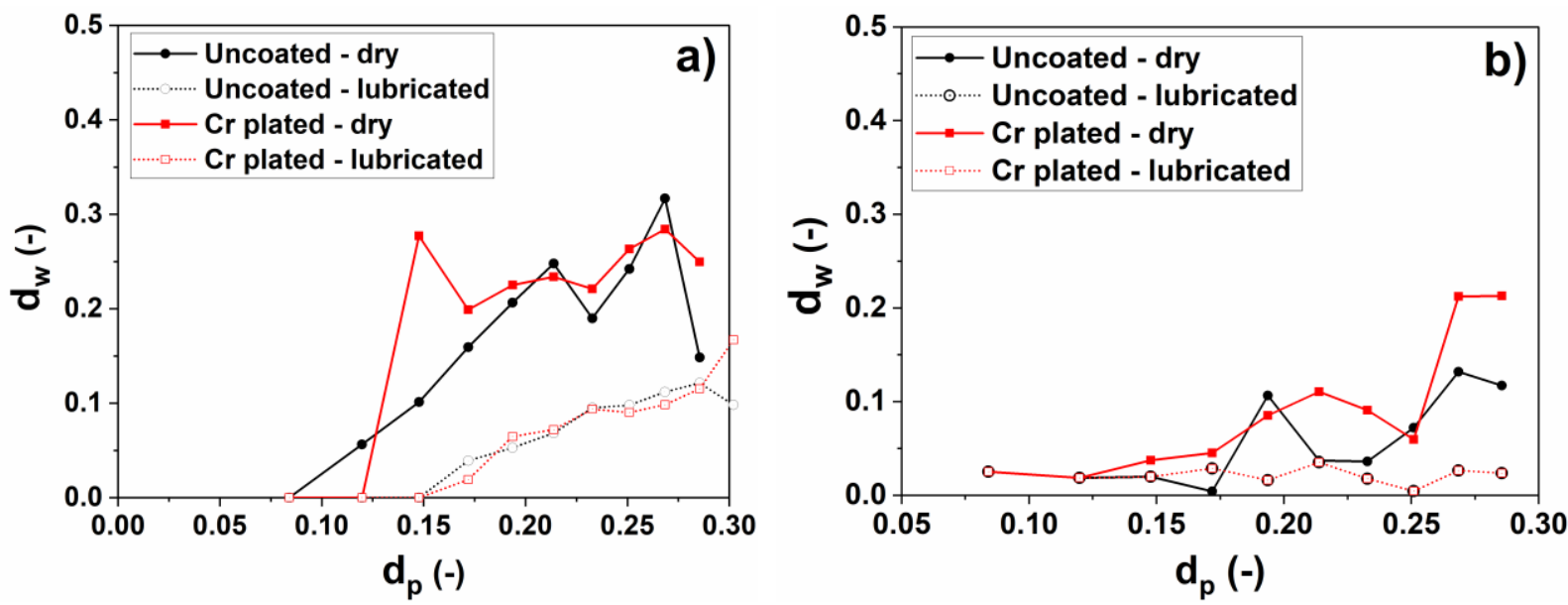

Figure 3.17: Degree of wear of a) the scratch experiments and b) MPM scratch simulations.

In order to study the variation of degree of wear in MPM simulations and compare it with the scratch experiments, a physically-based material removal criterion should be defined to allow debris separation from the deforming material. Therefore, a wear particle removal criterion based on a critical equivalent plastic strain was implemented. More specifically, a wear particle is assumed to be formed if the equivalent plastic strain $\varepsilon$ exceeds the critical value $\varepsilon_{c}$, as schematically displayed in Figure 3.18. The criterion for failure can then be defined as $\varepsilon / \varepsilon_{c} \geq 1$.

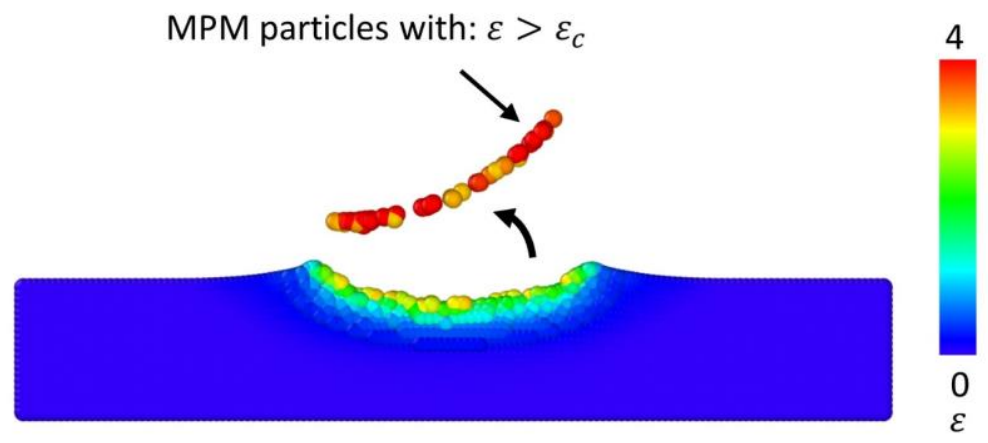

Figure 3.18: Schematic representation of wear particle removal.

The critical plastic strain needed to produce wear particles for the material under investigation (Ti-IF steel) is estimated by relating the degree of wear in the scratch experiments and the plastic strain produced by asperity interaction in MPM simulations. Figure 3.19 presents the calculated degree of wear values for several $\varepsilon_{c}$ values, based on the calculated cross section of the wear track. It can be clearly seen that when $\varepsilon_{c}=2$, the degree of wear is greatly overestimated, whereas $\varepsilon_{c}$ values greater than 5 underestimate the 
degree of wear. A critical strain in the range of 3 to 4 gives a reasonable agreement with the experiments in terms of predicting the degree of wear. Although the materials and loading conditions are different, these critical strain values are in the range reported by other researchers who have conducted scratch and abrasion tests $[124,125]$ but lower than the values reported elsewhere for multiple loading cycles or upscaled model asperity experiments [126-129]. This suggests that failure occurs at a lower critical strain in monotonic loading than cyclically loaded contacts. It must be noted that the occurrence of wear particle formation will depend on the magnitude of the plastic strain imparted to the deforming material and the magnitude of the corresponding hydrostatic stress. Such large plastic strains on the wearing surfaces are possible due to the high hydrostatic compression, which greatly enhances plastic strain to failure.
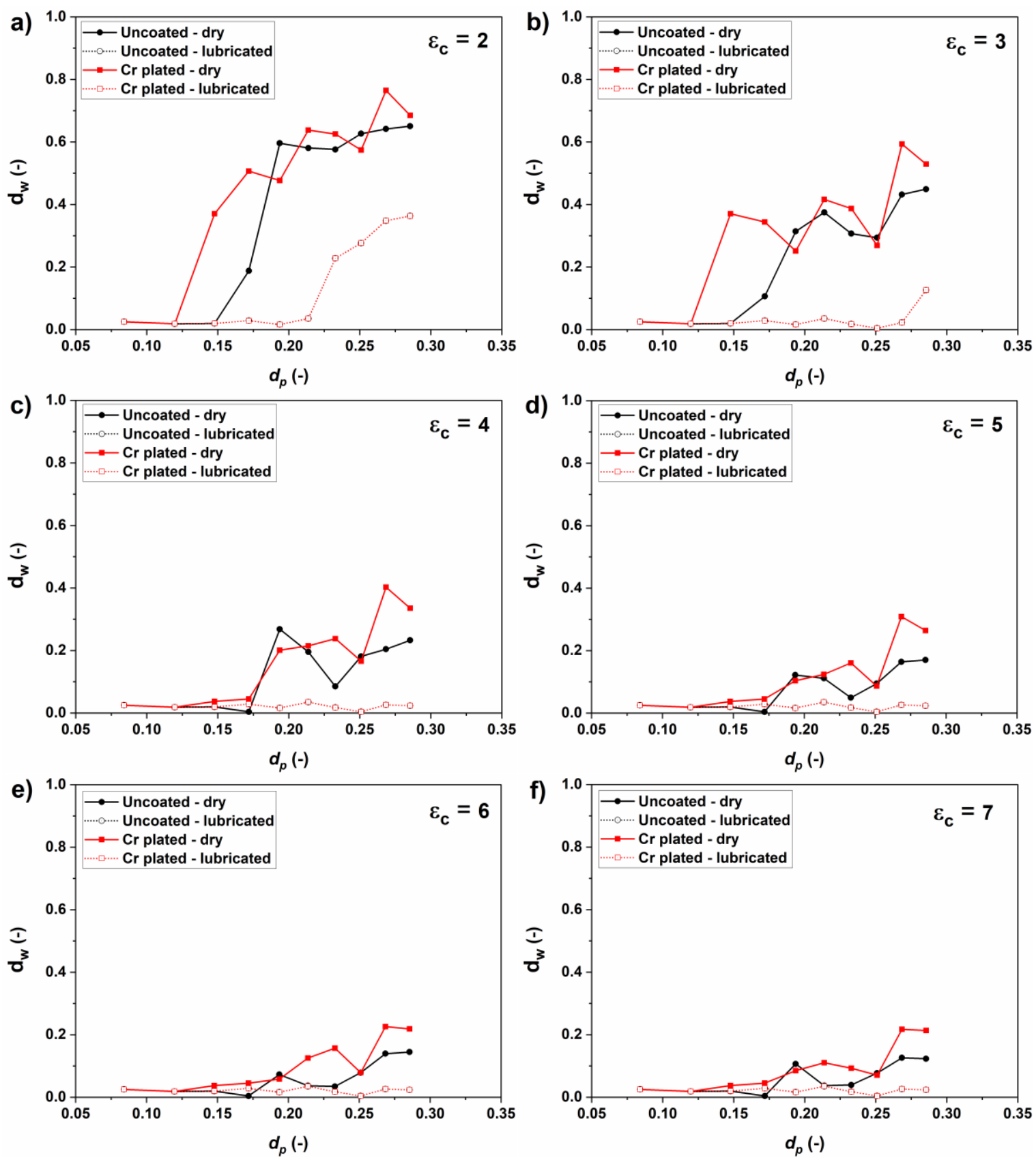

Figure 3.19: Degree of wear of MPM scratch simulations for different critical strain $\varepsilon_{c}$ values.

Although the trends are consistent between the scratch experiments and the MPM simulations, the absolute values of $d_{w}$ are not completely comparable. Note that only one scratch experiment was performed for each load and a scratch of length $<1 \mathrm{~mm}$ was used to calculate $d_{w}$ in the case of MPM simulations in contrast to $12 \mathrm{~mm}$ scratch length in the experiments. More scratch experiments are 
necessary to conduct a statistically significant comparison. The accuracy of MPM scratch simulations as regards strain distribution can be improved further by refining the particle size at the expense of higher computational cost. One limitation of the MPM model is the fact that, due to the absence of adhesion between the indenter and the substrate in the current contact implementation, the MPM particles do not stick to the indenter as in the case of the scratch experiments in the current implementation of the contact behavior.

In summary, MPM scratch modelling provides a suitable way to include the 3D details of strains induced by asperity interaction in calculating the degree of wear in single asperity abrasive contacts. Besides, the MPM model can be extended to study the effect of different aspects (such as asperity geometry, sliding speed and temperature), individually on the scratch behavior, which are too complex to be realized in experiments.

\subsection{Multi-scale wear model results and experimental validation}

As described earlier, the contact model (section 3.2) and wear at microscale (section 3.3) are combined to develop the multi-scale wear model. In this section, the wear model results and its experimental validation is discussed. Cold rolling experiments were conducted on a pilot scale rolling mill in lubricated and dry conditions with varying process parameters for the purpose of studying the influence of rolling parameters on wear particles formation and validating the wear model. The rolling experiments were carried out at several thickness reductions, rolling speeds and variable exit tensions using both smooth and rough work rolls.

\subsubsection{Experimental results}

The influence of rolling parameters on wear particles formation (strip cleanliness) in the rolling experiments is presented in Figure 3.20. Wear particles in steel cold rolling consist mostly of iron [4]. The amount of wear particles is quantified by measuring the mass of (iron) wear particles per unit area using "iron tape" method. In the iron tape method, a commonly used technique in the steel industry to measure strip cleanliness, the wear debris from the rolled strip surface is removed using an ash-less adhesive tape. The tape is burnt afterwards and the weight of the remaining wear debris is measured.

Wear particles formation increases with thickness reduction; higher thickness reduction leading to more wear and dirtier strip (Figure 3.20 a). Higher thickness reduction means higher rolling forces and higher contact stresses, higher real area of contact, increased length of the arc of contact, higher sliding lengths, higher interfacial temperature, and higher depth of indentation by roll asperities. These contact conditions promote the observed higher rate of wear particles formation. Furthermore, higher thickness reduction may result in more material pickup as it increases the sliding length, normal stress and contact time, which promote adhesion and adhesive wear [89]. The impact of thickness reduction on strip cleanliness is far greater for the rolling experiments when using rough rolls than smooth ones. This is due to the asperities of rough rolls ploughing deeper into the strip material and resulting in increased wear. Furthermore, the high sliding distance at high thickness reduction means bigger difference, in terms of total wear volume (see figure 3.1), between the two cases (i.e. when rough rolls and smooth rolls are used) at high thickness reduction than at low thickness reduction. The proportion of asperities operating in the cutting/wedgeforming abrasive wear regimes, i.e. wear regimes which lead to wear particles generation, increases with an increase in the roughness of the rolls. 

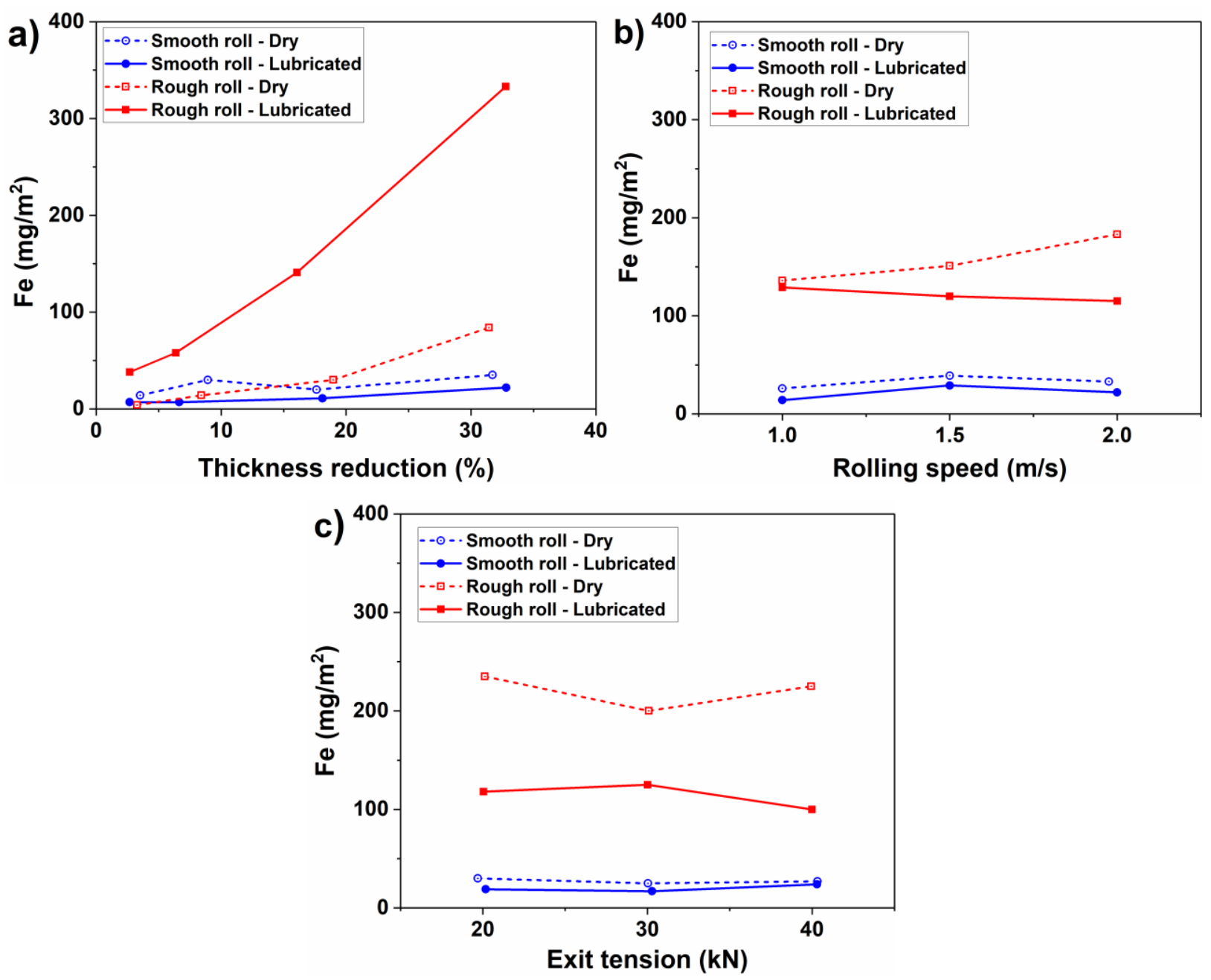

Figure 3.20: The influence of a) thickness reduction (at $0.5 \mathrm{~m} / \mathrm{s}$ rolling speed and $10 \mathrm{kN}$ exit tension), b) rolling speed (at 20\% thickness reduction and $10 \mathrm{kN}$ exit tension) and c) exit tension (at $20 \%$ thickness reduction and $0.5 \mathrm{~m} / \mathrm{s}$ rolling speed) on wear particles formation.

Another influence clearly seen in Figure 3.20a is the influence of lubrication on wear rate. For the rolling experiments conducted using rough rolls, the strips rolled under lubricated conditions showed more wear than the ones in dry condition at a given thickness reduction. On the contrary, the strips rolled using smooth rolls in lubricated experiments are cleaner (i.e. showed less wear) than the dry ones. This can be explained by the differences in active abrasive wear modes in dry and lubricated conditions, the effect of lubrication on the real contact area, and the average degree of penetration of the roughness asperities of the rough and smooth rolls.

Due to the high interfacial shear strength in the dry rolling experiments, the roll asperities are presumed to operate predominantly either in ploughing or wedge forming regime (see Figure 2.7). Lubrication reduces the shear strength at the contact interface. The reduced interfacial shear strength results in the transition of the wear mode from wedge forming to cutting for the asperities with $d_{p}$ higher than the critical degree of penetration corresponding to the transition from ploughing to wedge forming/cutting $\left(d_{p_{-} p w c}\right)$. For asperities with $d_{p}<d_{p_{-} p w c}$, lubrication has little influence on the wear mechanism and they stay in the ploughing wear mode. Thus, the roll asperities operate primarily either in ploughing or cutting regime in the lubricated rolling experiments. A higher proportion of the wear groove volume is removed as wear particles in the cutting wear mode than in wedge forming $[98,100,114]$. Owing to the higher average $d_{p}$ of the rough roll asperities than the smooth ones, more asperities transition from wedging to cutting in the former as a result of the lubrication. This explains the higher wear rate of the lubricated experiments compared to the dry ones when using rough rolls. In contrast, a small proportion 
of asperities are expected to have a $d_{p}$ greater than the critical degree of penetration corresponding to the transition from ploughing to wedge forming/cutting in the smooth rolls, hence little increase in wear rate as a result of lubrication is expected. The slight decrease of the wear rate in the lubricated experiments compared to the dry ones when rolling using smooth rolls can be explained by the reduction in the real area of contact due to lubricant entrapment (see paper $\mathrm{D}$ of Part 2 for more details).

Varying the rolling speed (Figure 3.20b) and the exit tension (Figure 3.20c) keeping the thickness reduction constant did not show any substantial influence on the wear rate. The rolling speed is expected to have little influence on the rate of wear particles formation in the current experiments, which are operated in the boundary lubrication regime, as there are basically no velocity dependent effects. The exit tension was varied, keeping the entry tension constant, to investigate the influence of the sliding length before and after the neutral point on wear particles formation. Increasing the exit tension moves the neutral point towards the inlet zone and thereby increases the degree of forward slip [69]. The strip asperities are deformed by the roll in the rolling direction before the neutral point. After the neutral point, strip asperities are deformed counter to the rolling direction as the roll asperities plough backwards relative to the strip surface. No clear influence of the forward slip on the rate of wear particles formation is witnessed in the current experiments.

\subsubsection{Wear particle size distribution}

Microscopic analysis of the wear particles and their size distribution has been done with the aim of visualizing the shape and/or size of the wear particles, and to study how the characteristics of the particles change (if any) with process parameters. An example of microscopic image of wear particles is provided in Figure 3.21. The size of the wear particles is defined by an equivalent diameter, which is the diameter of a circle with the same area as the particle.
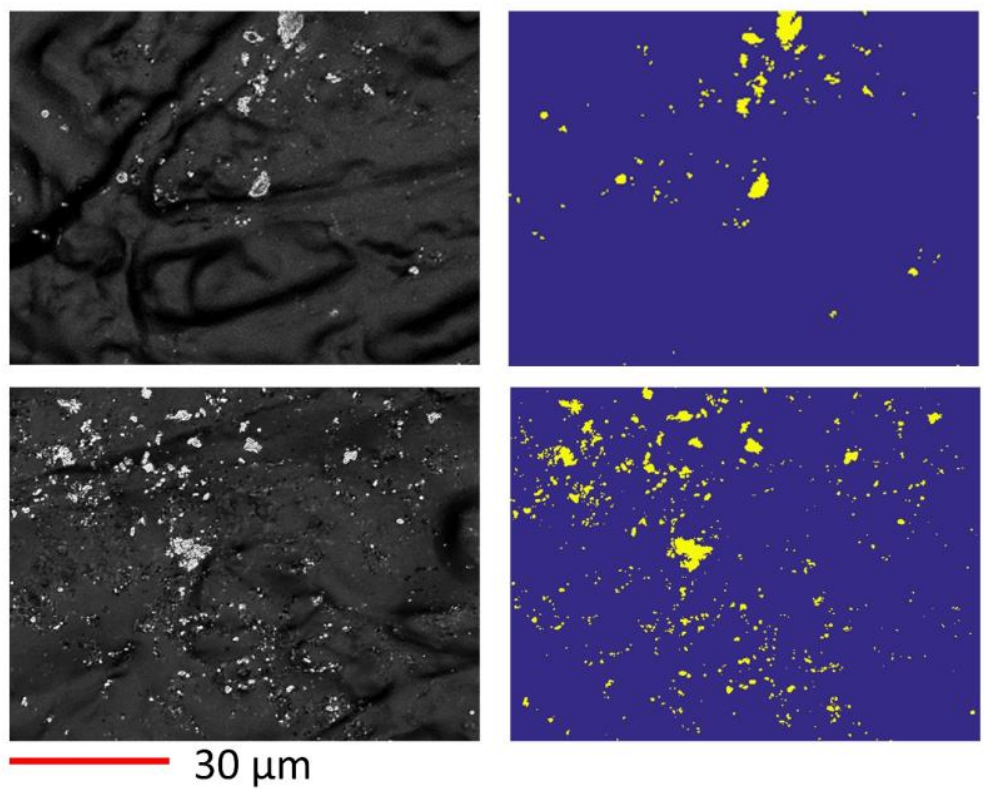

Figure 3.21: Microscopy images of the wear particles of the rolling experiments (left), and the corresponding images after wear particle extraction - represented by yellow for wear particle size distribution analysis (right).

Figure 3.22 presents the statistical results of the quantity and size distribution of the wear particles. The wear particles less than $5 \mu \mathrm{m}$ in diameter constitute nearly $99 \%$ of the total number of the wear particles and $80 \%$ to $97 \%$ of the total area covered by wear particles. In contrast, particles bigger than $10 \mu \mathrm{m}$ constitute only a very small fraction, less than $2 \%$ and $7 \%$ of the total area in the lubricated and dry experiments, respectively. Moreover, the amount of wear particles having a size $>5 \mu \mathrm{m}$ increases with thickness reduction from about $5 \%$ of the total area at $5 \%$ thickness reduction to $19 \%$ at $35 \%$ thickness reduction. The reason for this is twofold; firstly, the roll asperities plough deeper into the strip surface 
(increase in $d_{p}$ ) and secondly slide larger distances (increase in lump growth) as the thickness reduction is increased, leading to the formation of these larger wear particles observed at high thickness reductions.
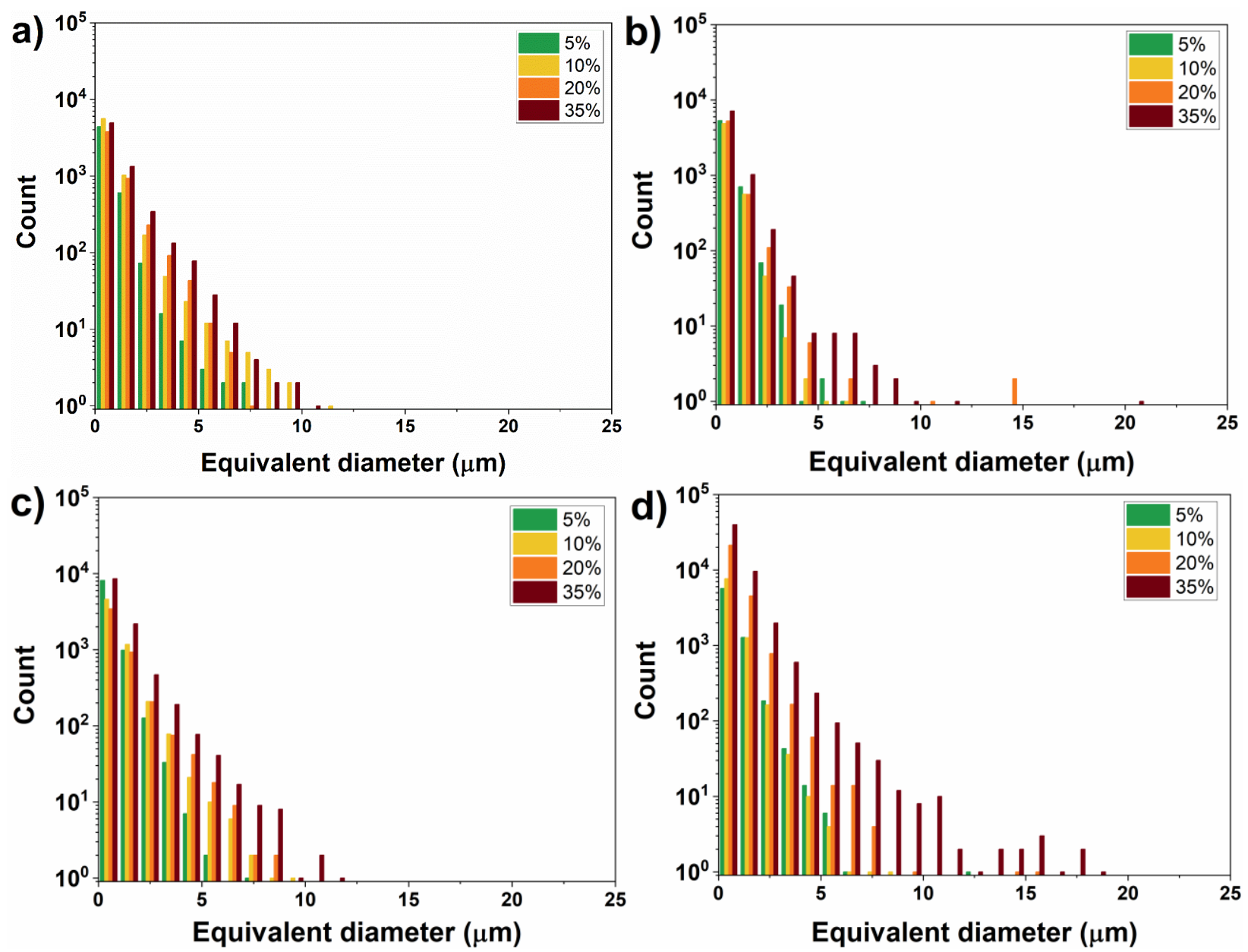

Figure 3.22: Wear particle size distribution of the rolling experiments at several thickness reductions (5\%, $10 \%, 20 \%$ \& 35\%): a) smooth roll - dry, b) smooth roll - lubricated, c) rough roll - dry, d) rough roll lubricated. The microscopy images were taken at four different locations for every rolling condition, each covering an area of $473 \times 356 \mu \mathrm{m}$.

\subsubsection{Comparison of model and experimental results}

Comparison of the model results and the measured wear rate for the lubricated cold rolling case is shown in Figure 3.23. The model results presented here are an average of 18 simulations. Dissimilar surface roughness measurements $(1.6 \mathrm{~mm} \times 1.2 \mathrm{~mm})$ of the roll and the strip were used for each simulation. The model results confirm that roll roughness and thickness reduction are the predominant rolling parameters that determine the amount of wear particles formation, rough roll and high thickness reduction giving the most amount of wear particles. The observed higher wear when using rough rolls compared to smooth ones is attributed to the larger degree of penetration of asperities in the former. Figure 3.24 illustrates an example of the degree of penetration distribution for rough and smooth rolls at $20 \%$ thickness reduction. When smooth rolls are used, most asperity contacts will be in the ploughing regime and wear will occur only for relatively small number of asperity contacts which are sufficiently sharp to operate in wedge forming or cutting wear regimes. The increased wear rate at high thickness reductions is due to the increased severity of contact, i.e. the increased real area of contact and sliding distance at high thickness reduction. The high standard deviation of the model results suggest that variation of the local roll roughness significantly influences the amount of wear. This can, however, be improved by utilizing surface roughness measurements covering a larger area. 


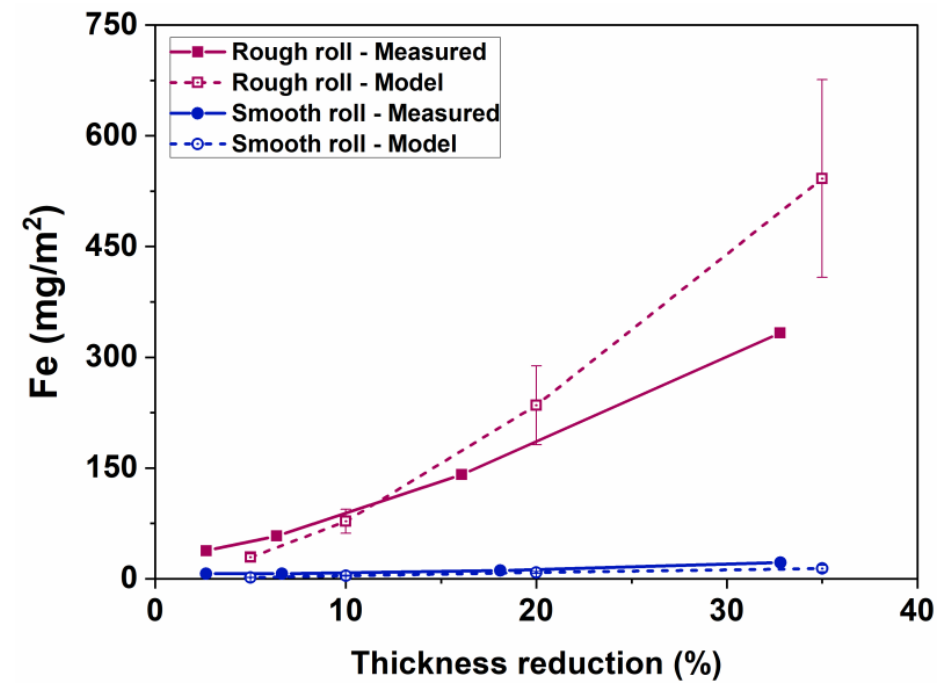

Figure 3.23: The effect of thickness reduction on wear particles formation for the lubricated rolling experiments: measured vs model.

The wear model captures the trend correctly and give values in the same order of magnitude as the experiments. Nonetheless, a noticeable difference is observed in terms of the absolute amount of wear between the measured and the model results. Particularly, the model overestimates the wear volume when using rough rolls at high thickness reductions. Only abrasive wear is considered in the current model. Although abrasive wear can be regarded as the prime wear mechanism, usually several wear mechanisms act simultaneously and the wear mechanisms interact. Adhesive, fatigue, corrosive and erosive wear are the potential other wear mechanisms that may also contribute to wear in cold rolling operations [10]. Additionally, the scratch experiments were performed using spherical indenters. However, real roughness asperities do not have a regular form and this shape may affect the wear mechanism and the degree of wear.
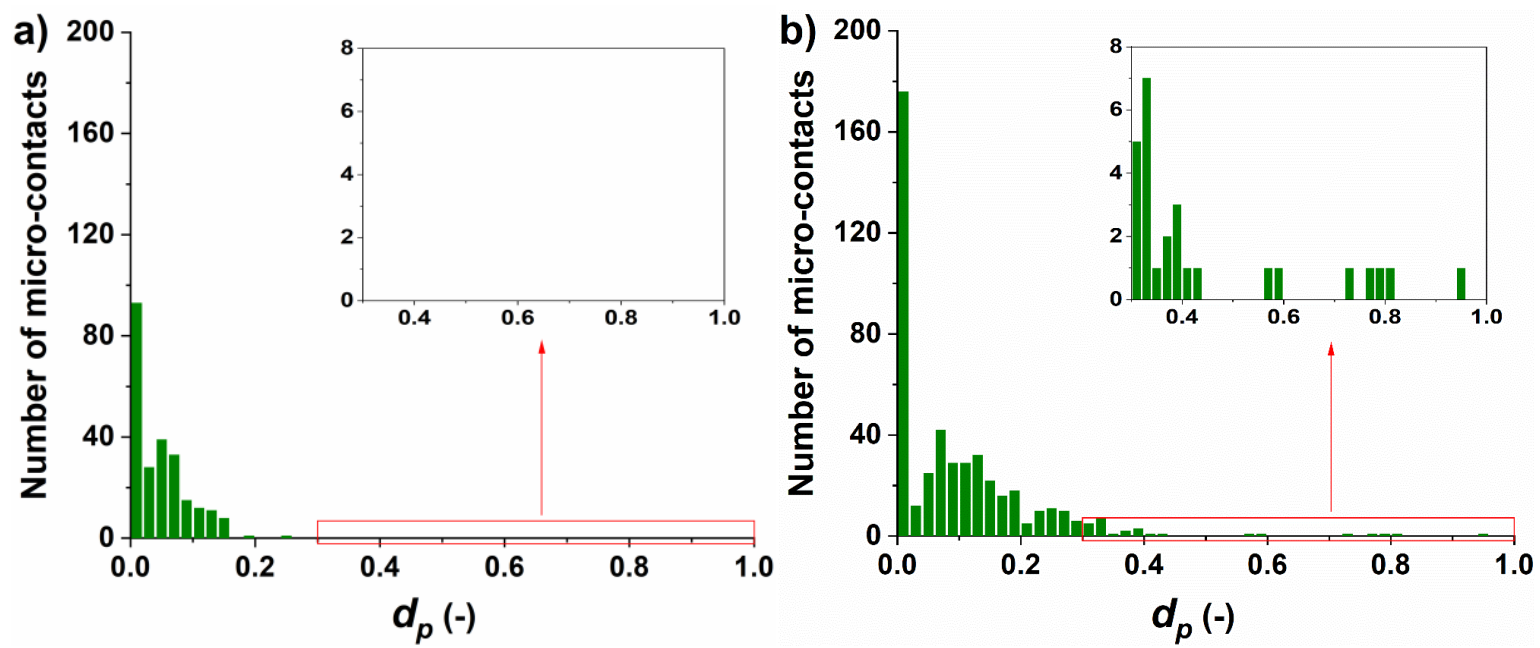

Figure 3.24: The distribution of degree of penetration $\left(d_{p}\right)$ of roll asperities in contact with the strip at $20 \%$ thickness reduction for $a$ ) smooth roll and $b$ ) rough roll.

\subsection{Summary}

In summary, the developed multi-scale wear model covers the main physical phenomena related to wear particles generation at microscale. The model results showed good agreement with the (rolling) experiments. The wear model can be developed further by including the influence of several other rolling parameters and influencing factors. For example, it can be extended for different material grades and cold rolling processes operating in the mixed lubrication regime. 



\section{CONCLUSIONS AND RECOMMENDATIONS}

\subsection{Conclusions}

Wear particles, generated during cold rolling, contaminate the surface and reduce the surface quality of a cold rolled strip. In this thesis, a multi-scale wear model to predict the formation of wear particles in cold rolling processes operating in the boundary lubrication regime has been developed. The model was verified experimentally by performing rolling experiments on a pilot mill. The wear model combines a semianalytical deterministic multi-asperity contact model with wear due to micro-scale single asperity contact based on numerical simulations and micro scale experiments. The multi-scale model was developed through several steps.

\section{Step 1: Contact model development and experimental validation}

Firstly, a contact model was developed to understand how the apparent and the real area of contact are related and how the nature of the contact changes as the process parameters change, as this affects the interfacial phenomena and thus the wear mode of the tribological system. The contact model, developed based on existing models in the literature, is for cold rolling processes operating under the boundary lubrication regime. Since the work roll surface is typically much harder than the hardness of the strip surface, only the deformation of the strip is taken into consideration in the model. The model takes into account bulk deformation (i.e. thickness reduction in cold rolling) and surface roughness of the strip (characterized by the asperity slope) as well as the roll. The surface texture of the roll and the strip surface are modelled as bars, which can represent any arbitrary shaped asperities. The asperity slope was calculated for each microcontact, by fitting each microcontact by an elliptical paraboloid, based on the surface height data at the microcontact. Furthermore, the non-contacting asperities/valleys are assumed to rise uniformly. The contact model was experimentally validated by performing rolling experiments on a two-high pilot mill. The rolling experiments were carried out under boundary lubricated conditions at several combinations of thickness reduction, rolling speed and roll/strip roughness.

The experimentally measured (rolled strip) and model predicted (deterministic asperity slope calculation combined with uniform rise hypothesis and Wilson \& Sheu's upper bound model [17]) surfaces showed good agreement in terms of the average surface roughness. Furthermore, the surface height distribution and Abbott-Firestone curve comparison of the measured and model predicted surfaces showed good agreement for strips rolled using a smooth roll. However, a notable difference was observed in the surface height distribution between the measured and model-predicted surfaces for strips rolled using rough rolls. The main cause of this difference was found to be the non-uniform rise of non-contacting valleys, which was confirmed by performing static pressing experiments using the same mill as the rolling experiments. Regarding the effect of rolling parameters, thickness reduction was shown to be the prime rolling parameter that determines the real contact area ratio, and hence, the surface finish of the rolled strip. Whereas, rolling speed and roll/strip roughness only had a minor influence on the real contact area ratio.

\section{Step 2: Wear at single asperity contact - experimental and numerical study}

Wear particles formation is determined not only by the real contact area ratio (macroscale) but also by the details of the wear mechanism(s) at individual roll-strip asperity contacts (microscale). Thus, the wear behavior of a microscale single asperity contact between an individual roll asperity sliding against a flat soft strip was investigated experimentally and numerically. Dedicated scratch experiments were carried out for this purpose, using conical indenters with a hemispherical tip, which represent a roll asperity, sliding on a polished flat strip surface. The effect of asperity sharpness (degree of penetration), interface shear strength (lubricated and dry conditions) and surface chemistry (using either uncoated steel indenter or hard chrome plated indenter) were investigated.

The scratch experiments showed nearly ideal ploughing at low degree of penetration $\left(d_{p}\right)$. The wear mode transitioned gradually to wedge forming with an increase in $d_{p}$. Owing to the higher shear strength of the contact interface, the unlubricated experiments transitioned from ploughing to wedge forming regime 
at lower degree of penetration and showed a higher degree of wear compared to the lubricated ones. The degree of wear of the scratch experiments ranged between 0.05 and 0.34 .

Chrome plating the rolls is a common practice in the steel industry both to increase roll service life and improve strip cleanliness. However, there is an urgent need to find a replacement for this coating due to health and safety regulations as the electrolyte used in the coating process is hazardous to human health and environmentally harmful. Hence, the effect of chrome plating on wear particles formation, at single asperity contact, was investigated to understand the fundamental mechanisms behind the positive effects of chrome plating on strip cleanliness and to systematically develop alternative coatings.

Using hard chrome plated indenters, under lubricated conditions, showed a substantially lower quantity of wear particles formation and reduced amount of transfer layer compared to the uncoated steel indenters. Nevertheless, similar effect was not observed in the unlubricated conditions. It was found out that the interaction of the chromium layer with the lubricant and/or additives plays an important role in reducing adhesion and wear particles formation. X-ray photoelectron spectroscopy analysis on the tip of the worn indenter surface suggested formation of a protective tribolayer consisting a carbonate and amine species on the chrome plated surface but not on the uncoated steel surface. This demonstrates that the tribochemistry of the $\mathrm{Cr} / \mathrm{CrOx}$ layer with the lubricant/additives contributes to the reported strip cleanliness improvement when hard chrome plated rolls are used in industrial cold rolling.

Further, a material point method (MPM) was implemented to numerically model the scratching process in three dimensions. The effect of interfacial shear strength and degree of penetration on the friction and wear behavior has been studied in the MPM simulations. MPM simulations revealed that almost all the frictional resistance arises from deforming the substrate in the case of an interfacial shear strength corresponding to the lubricated contact. In contrast, MPM simulations showed that, in unlubricated sliding, the frictional resistance is primarily due to shearing of the adhesion junction and tearing the deforming body. Furthermore, a wear particle removal criterion based on critical equivalent plastic strain was implemented in the MPM simulations. Using the degree of wear of the scratch experiments as a benchmark, a critical plastic strain needed to produce wear particles was found to be between 3 to 4 for the investigated interstitial-free steel.

\section{Step 3: Multi-scale wear model development and experimental validation}

Finally, the contact model and the degree of wear at single asperity contact are combined to develop the multi-scale wear model. Cold rolling experiments were conducted on a pilot scale rolling mill with varying process parameters for the purpose of studying the influence of rolling parameters on wear particles formation and validating the wear model.

The rolling experiments and model results showed that thickness reduction and roll roughness are the main process variables that control wear particles generation. Explicitly, higher thickness reduction and/or high roll roughness leads to the formation of more wear particles. Increasing the thickness reduction from $5 \%$ to $35 \%$ increased the volume of wear particles generated by 3 (for the smooth rolls) to 9 times (for the rough rolls). The amount of wear when rough rolls were used was 15 times higher than smooth rolls, in lubricated conditions at $35 \%$ thickness reduction. Varying the rolling speed and the exit tension (forward slip) while keeping the thickness reduction constant did not show any substantial influence on the amount of wear particles generated. Analysis of the wear particles size distribution, under the assessed experimental boundaries, for the investigated Titanium-stabilized interstitial-free (Ti-IF) steel, showed that most of the wear particles are less than $5 \mu \mathrm{m}$ in diameter. The wear model captures the trend correctly and give values in the same order of magnitude as the experiments.

In summary, the developed wear model, which is governed by the main physical phenomena related to wear particles generation at the microscale, showed good agreement with the (rolling) experimental results at the macroscale. Due to its modular nature, the model can be relatively simply further developed to include the influence of several other rolling parameters and influencing factors. Likewise, it be included in industrial rolling models as both a predictive and retrospective tool. 


\subsection{Recommendations}

Further research could usefully explore the following points:

- In the contact model, a simplistic uniform rise hypothesis was employed. While this approach gives a good estimation of the rolled strip roughness and provides a very quick way to (roughly) anticipate its surface finish, it was observed that due to the non-uniform rise of the non-contacting asperities and valleys the surface height distribution of strips rolled with rough rolls is different from the one predicted with the uniform rise hypothesis. The non-uniform rise of asperities can be investigated in future research by including the local inhomogeneous deformation field, elastic recovery of the asperities and microplastic hydrodynamic lubrication (e.g. by performing finite element analysis). Additionally, the contact model can be extended for rolling processes operating in mixed-lubrication by including the hydrodynamic effect of the lubricant (e.g. by using load sharing concept).

- The wear behavior study at single asperity contact in this thesis was conducted using indenters having a hemispherical tip. However, the actual roughness asperities have random shapes, and this affects wear behavior. The effect of asperity geometry, temperature, sliding speed and adhesion can be explored (experimentally and numerically) in future research. In addition, further experimental research can be carried out to investigate whether the type of lubricant and additives as well as strip material grade affect the performance of chrome plating and potential alternative coatings on wear particles formation (strip cleanliness).

- Only one steel grade (Ti-IF steel) was investigated in this thesis. However, a multitude of steel grades are rolled in the steel industry. Hence, the influence of strip material on wear particles formation can be investigated further both at microscale (i.e. single asperity contact) and at macroscale by carrying out appropriate rolling experiments.

- The multi-scale approach followed in developing the wear model can be implemented in other applications where particle formation is a problem like lithography. 



\section{Bibliography}

[1] Roberts WL. Cold rolling of steel. 1st edition. New York: Routledge; 1978. doi:10.1201/9781315139661.

[2] Lenard JG. Primer on Flat Rolling. 2nd editio. Elsevier; 2014. doi:10.1016/C2012-0-06474-5.

[3] Halmos GT. Roll forming handbook. CRC Press; 2005. doi:10.1201/9781420030693.

[4] Pesci C, Monfort G, Torre V, Van Steden H, Kurzynski J, Vervaet B, et al. Controlling wear and surface cleanliness during cold rolling (LOWWEAR). 2012. doi:10.2777/23177.

[5] Labiapari W da S, de Alcântara CM, Costa HL, De Mello JDB. Wear debris generation during cold rolling of stainless steels. J Mater Process Technol 2015;223:164-70. doi:10.1016/J.JMATPROTEC.2015.03.050.

[6] Pathak, P and Jha, SK and Singh A. Tribological approach for improvement in productivity and quality of flat rolled steel products: a review. Int J Tech Res 2012;1.

[7] Huart S, Dubar M, Deltombe R, Dubois A, Dubar L. Asperity deformation, lubricant trapping and iron fines formation mechanism in cold rolling processes. Wear 2004;257:471-80. doi:10.1016/J.WEAR.2004.01.012.

[8] Fisher TW, lezzi RA, Madritch JM. Theoretical and practical considerations of sheet steel surface cleanliness. SAE Trans 1980;89:923-35. doi:10.2307/44632465.

[9] Jacobs L, Vervaet B, Hermann H, Agostini M, Kurzynski J, Jonsson N-G, et al. Improving strip cleanliness after cold rolling. Proc Inst Mech Eng Part J J Eng Tribol 2011;225:959-69. doi:10.1177/1350650111413639.

[10] Turner $\mathrm{CH}$. Tribology - understanding the cost of quality in cold rolling. Steel Times Iternational 1995;223:s6-7.

[11] Louaisil K, Dubar M, Deltombe R, Dubois A, Dubar L. Analysis of interface temperature, forward slip and lubricant influence on friction and wear in cold rolling. Wear 2009;266:119-28. doi:10.1016/J.WEAR.2008.06.003.

[12] Hui Z, Manxing W. A study of wear mechanisms in the cold rolling of aluminium strip. J Mater Process Technol 1992;31:235-43. doi:10.1016/0924-0136(92)90024-M.

[13] Sutcliffe MPF. Surface asperity deformation in metal forming processes. Int J Mech Sci 1988;30:847-68. doi:10.1016/0020-7403(88)90010-0.

[14] Dick K, Lenard JG. The effect of roll roughness and lubricant viscosity on the loads on the mill during cold rolling of steel strips. J Mater Process Technol 2005;168:16-24. doi:10.1016/J.JMATPROTEC.2004.09.091.

[15] Tabor D. Junction growth in metallic friction: the role of combined stresses and surface contamination. Proc R Soc London Ser A Math Phys Sci 1959;251:378-93. doi:10.1098/rspa.1959.0114.

[16] Childs THC. The persistence of roughness between surfaces in static contact. Proc R Soc A Math Phys Eng Sci 1977;353:35-53. doi:10.1098/rspa.1977.0020.

[17] Wilson WRD, Sheu S. Real area of contact and boundary friction in metal forming. Int J Mech Sci 1988;30:475-89. doi:10.1016/0020-7403(88)90002-1.

[18] Korzekwa DA, Dawson PR, Wilson WRD. Surface asperity deformation during sheet forming. Int J Mech Sci 1992;34:521-39. doi:10.1016/0020-7403(92)90028-F.

[19] Makinouchi A, Ike H, Murakawa M, Koga N. A finite element analysis of flattening of surface asperities by perfectly lubricated rigid dies in metal working processes. Wear 1988;128:109-22. 
doi:10.1016/0043-1648(88)90178-0.

[20] Ike H, Makinouchi A. Effect of lateral tension and compression on plane strain flattening processes of surface asperities lying over a plastically deformable bulk. Wear 1990;140:17-38. doi:10.1016/0043-1648(90)90119-U.

[21] Azushima A, Kuba S, Tani S, Olsson DD. Direct observation of asperity deformation of specimens with random rough surfaces in upsetting and indentation processes. Wear 2006;260:258-64. doi:10.1016/j.wear.2005.04.022.

[22] Stachowiak GW, Batchelor AW. Engineering tribology. Fourth edi. 2014.

[23] Kimura Y, Childs THC. Surface asperity deformation under bulk plastic straining conditions. Int J Mech Sci 1999;41:283-307. doi:10.1016/S0020-7403(98)00051-4.

[24] Westeneng JD. Modelling of contact and friction in deep drawing processes. University of Twente, 2001.

[25] Legrand N, Counhaye C, Oliveira D. Roughness transfer model for cold and temper rolling processes. 10th Int. Roll. Conf., Graz: 2016.

[26] Sutcliffe MPF. Flattening of random rough surfaces in metal-forming processes. J Tribol 1999;121:433. doi:10.1115/1.2834086.

[27] Le HR, Sutcliffe MPF. A friction model for cold strip rolling with two-wavelength surface roughness in the "mixed" lubrication regime. J Tribol 2003;125:670-7. doi:10.1115/1.1538191.

[28] Wang ZG, Yoshikawa Y, Suzuki T, Osakada K. Determination of friction law in dry metal forming with DLC coated tool. CIRP Ann 2014;63:277-80. doi:10.1016/J.CIRP.2014.03.050.

[29] Nielsen C V, Martins PAF, Bay N. Modelling of real area of contact between tool and workpiece in metal forming processes including the influence of subsurface deformation. CIRP Ann 2016;65:2614. doi:10.1016/J.CIRP.2016.04.126.

[30] Ma B, Tieu AK, Lu C, Jiang ZY. Comparison of asperity flattening under different wavelength models for sheet metal forming. J. Mater. Process. Technol., vol. 140, Elsevier; 2003, p. 635-40. doi:10.1016/S0924-0136(03)00804-5.

[31] Hol J. Multi-scale friction modeling for sheet metal forming. University of Twente, 2013.

[32] Karupannasamy DK. Friction modelling on multiple scales for deep drawing processes. University of Twente, 2013.

[33] Venema J. Tribological interactions and modelling of friction in hot stamping. University of Twente, 2019. doi:10.3990/1.9789036548175.

[34] Wilson WRD. Friction models for metal forming in the boundary lubrication regime. J Eng Mater Technol 1991;113:60. doi:10.1115/1.2903383.

[35] Broekhof NLM, Mueller CE. Impact of novel cold rolling oil technologies and novel materials on strip cleanliness. AISE Annu. Conv. Expo., 2001.

[36] Button ST. Numerical and experimental analysis of lubrication in strip cold rolling. J Brazilian Soc Mech Sci Eng 2011;33:189-96. doi:10.1590/S1678-58782011000200010.

[37] Wilson WRD, Walowit JA. An isothermal hydrodynamic lubrication theory for strip rolling with front and back tension. J Lubr Technol 1971;92:69-74.

[38] Reynolds O. IV. On the theory of lubrication and its application to Mr. Beauchamp tower's experiments, including an experimental determination of the viscosity of olive oil. Philos Trans $R$ Soc London 1886;177:157-234. doi:10.1098/rspl.1886.0021.

[39] Spikes HA, Olver A V. Basics of mixed lubrication. Lubr Sci 2003;16:1-28. 
doi:10.1002/ls.3010160102.

[40] Johnson KL, Greenwood JA, Poon SY. A simple theory of asperity contact in elastohydro-dynamic lubrication. Wear 1972;19:91-108. doi:10.1016/0043-1648(72)90445-0.

[41] Reid J V., Schey JA. Full fluid film lubrication in aluminum strip rolling. ASLE Trans 1978;21:191-200. doi:10.1080/05698197808982874.

[42] Atala HF, Rowe GW. Surface roughness changes during rolling. Wear 1975;32:249-68. doi:10.1016/0043-1648(75)90272-0.

[43] Wilson WRD. Workpiece surface roughening in a hydrodynamically lubricated metal forming process. J Tribol 1977;99:10-4. doi:10.1115/1.3452956.

[44] Azushima A, Yoneyama S, Yamaguchi T, Kudo H. Direct observation of microcontact behavior at the interface between tool and workpiece in lubricated upsetting. CIRP Ann - Manuf Technol 1996;45:205-10. doi:10.1016/S0007-8506(07)63048-0.

[45] Azushima A, Uda M, Kudo H. An interpretation of the speed dependence of the coefficient of friction under the micro-PHL condition in sheet drawing. CIRP Ann - Manuf Technol 1991;40:22730. doi:10.1016/S0007-8506(07)61974-X.

[46] Bay N, Bech Jl, Andreasen JL, Shimizu I. Studies on micro plasto hydrodymic lubrication in metal forming. Met. Form. Sci. Pract. A state-of-the-Art Vol. Honor. Prof. J.A. Schey, vol. Chapter 7., Elsevier; 2002, p. 115-34.

[47] Bech J, Bay N, Eriksen M. Entrapment and escape of liquid lubricant in metal forming. Wear 1999;232:134-9. doi:10.1016/S0043-1648(99)00136-2.

[48] Lenard JG. Metal Forming Science and Practice. Elsevier; 2002. doi:10.1016/b978-0-08-0440248.x5000-0.

[49] Mizuno T, Kamiya S, Okamoto M. Lubricant behaviors in the compression-friction test of strip metals. Trans Japan Soc Mech Eng 1978;44:3240-3240. doi:10.1299/kikai1938.44.3240.

[50] Sutcliffe MP. Surface finish and friction in cold metal rolling. Met. Form. Sci. Pract. , 2002, p. 9-59.

[51] Smeulders JB a F. Lubrication in the cold rolling process described by a 3D Stribeck curve. AISTech - Iron Steel Technol Conf Proc 2013:1681-9.

[52] Lo SW, Wilson WRD. A theoretical model of micro-pool lubrication in metal forming. J Tribol 1999;121:731-8. doi:10.1115/1.2834129.

[53] Patir N, Cheng HS. An average flow model for determining effects of threedimensional roughness on partial hydrodynamic lubrication. J Tribol 1978;100:12-7. doi:10.1115/1.3453103.

[54] Lu SS, Chuang YH. Effects of Surface Roughness on Lubrication in Cold Rolling of Metals. J Tribol 1985;107:522-6. doi:10.1115/1.3261123.

[55] Schey J. Tribology in Metalworking: Friction, Lubrication, and Wear. J Appl Metalwork 1984;3:173173. doi:10.1007/BF02833697.

[56] Al-Sharif A, Chamniprasart K, Rajagopal KR, Szeri AZ. Lubrication with binary mixtures: Liquid-liquid emulsion. J Tribol 1993;115:46-55. doi:10.1115/1.2920985.

[57] Wilson WRD, Sakaguchi Y, Schmid SR. A mixed flow model for lubrication with emulsions. Tribol Trans 1994;37:543-51. doi:10.1080/10402009408983327.

[58] Wilson WRD, Sakaguchi Y, Schmid SR. A dynamic concentration model for lubrication with oil-inwater emulsions. Wear 1993;161:207-12. doi:10.1016/0043-1648(93)90471-W.

[59] Fujita N, Kimura Y. Plate-out efficiency related to oil-in-water emulsions supply conditions on cold rolling strip. Proc Inst Mech Eng Part J J Eng Tribol 2013;227:413-22. 
doi:10.1177/1350650112467873.

[60] Szeri AZ. On the flow of emulsions in tribological contacts. Wear 1996;200:353-64. doi:10.1016/S0043-1648(96)07251-1.

[61] Schmid SR, Wilson WRD. Lubrication of aluminum rolling by oil-in-water emulsions. Tribol Trans 1995;38:452-8. doi:10.1080/10402009508983428.

[62] Schmid SR. Hydrodynamic segregation, entrainment and rejection of oil in emulsion lubrication problems. J Tribol 1997;119:342-8. doi:10.1115/1.2833225.

[63] Wang SH, Szeri AZ, Rajagopal KR. Lubrication with emulsion in cold rolling. J Tribol 1993;115:52331. doi:10.1115/1.2921669.

[64] Benner JJ, Sadeghi F, Hoeprich MR, Frank MC. Lubricating properties of water in oil emulsions. J Tribol 2006;128:296-311. doi:10.1115/1.2164464.

[65] Wanheim T. Friction at high normal pressures. Wear 1973;25:225-44. doi:10.1016/00431648(73)90074-4.

[66] Nielsen CV, Bay N. Overview of friction modelling in metal forming processes. Procedia Eng., vol. 207, Elsevier Ltd; 2017, p. 2257-62. doi:10.1016/j.proeng.2017.10.991.

[67] Lugt PM. Lubrication in cold rolling. Numerical simulation using multigrid techniques. University of Twente, 1992.

[68] Orowan E. The calculation of roll pressure in hot and cold flat rolling. Proc Inst Mech Eng 1943;150:140-67. doi:10.1243/pime_proc_1943_150_025_02.

[69] Dieter GE, Bacon DJ. Mechanical metallurgy. London: McGraw-Hill; 1988.

[70] Lenard JG, Malinowski Z. Measurements of friction during the warm rolling of aluminum. J Mater Process Tech 1993;39:357-71. doi:10.1016/0924-0136(93)90169-7.

[71] Hum B, Colquhoun HW, Lenard JG. Measurements of friction during hot rolling of aluminum strips. J Mater Process Technol 1996;60:331-8. doi:10.1016/0924-0136(96)02350-3.

[72] Lu C, Tieu AK. Measurement of the forward slip in cold strip rolling using a high speed digital camera. J. Mech. Sci. Technol., vol. 21, Korean Society of Mechanical Engineers; 2007, p. 1528-33. doi:10.1007/BF03177370.

[73] Lenard JG. Friction and Forward Slip in Cold Strip Rolling. Tribol Trans 1992;35:423-8. doi:10.1080/10402009208982138.

[74] Mizuno T, Hasegawa K. Effects of die surface roughness on lubricating conditions in the sheet metal compression-friction test. J Tribol 1982;104:23-8. doi:10.1115/1.3253160.

[75] Depierre V, Gurney FJ. A method for determination of constant and varying friction factors during ring compression tests. J Lubr TEech Trans ASME SerF 1974;96:482-8. doi:10.1115/1.3452015.

[76] Hoffman O, Sachs G. Introduction to the theory of plasticity for engineers. Pp. Xiv. 276. McGrawHill Book Co.: New York; 1953.

[77] Rowe GW. Principles of industrial metalworking processes. Edward Arnold; 1977.

[78] Ekelund S. Analysis of factors influencing rolling pressure and power consumption in the hot rolling of steel. Place of Publication Not Identified: publisher not identified; 1933.

[79] Inhaber H. The coefficient of friction in cold rolling. J Manuf Sci Eng Trans ASME 1966;88:421-9. doi:10.1115/1.3672676.

[80] Sargent LB. Friction and slip in the cold rolling of metals. ASLE Trans 1978;21:20-4. doi:10.1080/05698197808982857. 
[81] Schipper DJ. Transitions in the lubrication of concentrated contacts. University of Twente, 1988.

[82] Rabinowicz E. Friction and wear of materials (2nd Edition). 1995.

[83] Saha PK, Wilson WRD. Influence of plastic strain on friction in sheet metal forming. Wear 1994;172:167-73. doi:10.1016/0043-1648(94)90284-4.

[84] Lenard JG. The effect of roll roughness on the rolling parameters during cold rolling of an aluminum alloy. J Mater Process Technol 2004;152:144-53. doi:10.1016/j.jmatprotec.2004.03.026.

[85] Szakaly ED, Lenard JG. The effect of process and material parameters on the coefficient of friction in the flat-die test. J Mater Process Technol 2010;210:868-76. doi:10.1016/j.jmatprotec.2010.01.019.

[86] Corporation QC. Surface microstructure of normal and defected cold rolled sheet, investigated by SEM / EDS and 2015:2915-25.

[87] Sutcliffe MPF, Le HR. Measurements of surface roughness in cold metal rolling in the mixed lubrication regime. TribolTrans 2000;43:39-44. doi:10.1080/10402000008982310.

[88] Ahmed R, Sutcliffe MPF. Identification of surface features on cold-rolled stainless steel strip. Wear 2000;244:60-70. doi:10.1016/S0043-1648(00)00442-7.

[89] Montmitonnet P, Delamare F, Rizoulieres B. Transfer layer and friction in cold metal strip rolling processes. Wear 2000;245:125-35. doi:10.1016/S0043-1648(00)00473-7.

[90] Montmitonnet P, Bouadjadja N, Luong LP, Bertrandie JJ, Dietsch H. On the mechanism by which chromium improves strip surface cleanliness in steel strip cold rolling. Key Eng Mater 2018;767:240-7. doi:10.4028/www.scientific.net/KEM.767.240.

[91] Shen J, Wu C, Zhang L. Effects of sliding speed and lubrication on the tribological behaviour of stainless steel. Int J Adv Manuf Technol 2018;94:341-50. doi:10.1007/s00170-017-0907-8.

[92] Ma B, Tieu AK, Lu C, Jiang Z. An experimental investigation of steel surface characteristic transfer by cold rolling. J. Mater. Process. Technol., vol. 125-126, Elsevier; 2002, p. 657-63. doi:10.1016/S0924-0136(02)00377-1.

[93] Ahmed R, Sutcliffe MPF. An experimental investigation of surface pit evolution during cold-rolling or drawing of stainless steel strip. J Tribol 2001;123:1. doi:10.1115/1.1327580.

[94] Sutcliffe MPF, Combarieu R, Repoux M, Montmitonnet P. Tribology of plane strain compression tests on aluminum strip using ToF-SIMS analysis transfer films. Wear 2003;254:65-79. doi:10.1016/S0043-1648(02)00295-8.

[95] Shi Z, Sun Y, Bloyce A, Bell T. Unlubricated rolling-sliding wear mechanisms of complex aluminium bronze against steel. Wear 1996;193:235-41. doi:10.1016/0043-1648(95)06773-6.

[96] Groche P, Resch F. Dry forming of aluminum alloys - Wear mechanisms and influencing factors. Materwiss Werksttech 2015;46:813-28. doi:10.1002/mawe.201500429.

[97] Kayaba T, Kato K, Hokkirigawa K. Theoretical analysis of the plastic yielding of a hard asperity sliding on a soft flat surface. Wear 1983;87:151-61. doi:10.1016/0043-1648(83)90030-3.

[98] Kayaba T, Hokkirigawa K, Kato K. Analysis of the abrasive wear mechanism by successive observations of wear processes in a scanning electron microscope. Wear 1986;110:419-30. doi:10.1016/0043-1648(86)90115-8.

[99] Kato K. Classification of wear mechanisms/models. Proc Inst Mech Eng Part J J Eng Tribol 2002;216:349-55. doi:10.1243/135065002762355280.

[100] Hokkirigawa K, Kato K. An experimental and theoretical investigation of ploughing, cutting and wedge formation during abrasive wear. Tribol Int 1988;21:51-7. doi:10.1016/0301-679X(88)901284. 
[101] Challen JM, Oxley PLB. An explanation of the different regimes of friction and wear using asperity deformation models. Wear 1979;53:229-43. doi:10.1016/0043-1648(79)90080-2.

[102] Masen MA, de Rooij MB, Schipper DJ. Micro-contact based modelling of abrasive wear. Wear 2005;258:339-48. doi:10.1016/J.WEAR.2004.09.009.

[103] Bhushan B. Modern tribology handbook. vol. 1. 1st edition. CRC Press; 2000.

[104] Xuan JL, Cheng HS. Microscopic wear debris generation and surface topography. Tribol Ser 1992;21:247-56. doi:10.1016/S0167-8922(08)70530-3.

[105] Deltombe R, Dubar M, Dubois A, Dubar L. A new methodology to analyse iron fines during steel cold rolling processes. Wear 2003;254:211-21. doi:10.1016/S0043-1648(03)00005-X.

[106] De Mello JDB, Gonçalves JL, Costa HL. Influence of surface texturing and hard chromium coating on the wear of steels used in cold rolling mill rolls. Wear 2013;302:1295-309. doi:10.1016/J.WEAR.2013.02.006.

[107] Dauchot G, De Castro E, Repoux M, Combarieu R, Montmitonnet P, Delamare F. Application of ToFSIMS surface analysis to tribochemistry in metal forming processes. Wear 2006;260:296-304. doi:10.1016/j.wear.2005.03.034.

[108] Pelletier C. Lubrication in cold rolling. IJmuiden: 2016.

[109] Ma X, de Rooij M, Schipper D. A load dependent friction model for fully plastic contact conditions. Wear 2010;269:790-6. doi:10.1016/J.WEAR.2010.08.005.

[110] Pullen J, Williamson JBP. On the plastic contact of rough surfaces. Proc R Soc A Math Phys Eng Sci 1972;327:159-73. doi:10.1098/rspa.1972.0038.

[111] Schedin E. Galling mechanisms in sheet forming operations. Wear 1994;179:123-8. doi:10.1016/0043-1648(94)90229-1.

[112] Zum Gahr KH. Modelling of two-body abrasive wear. Wear 1988;124:87-103. doi:10.1016/00431648(88)90236-0.

[113] Kayaba T, Hokkirigawa K, Kato K. Experimental analysis of the yield criterion for a hard asperity sliding on a soft flat surface. Wear 1984;96:255-65. doi:10.1016/0043-1648(84)90040-1.

[114] Hokkirigawa K, Kato K, Li ZZ. The effect of hardness on the transition of the abrasive wear mechanism of steels. Wear 1988;123:241-51. doi:10.1016/0043-1648(88)90102-0.

[115] Challen JM, Oxley PLB, Doyle ED. The effect of strain hardening on the critical angle for abrasive (chip formation) wear. Wear 1983;88:1-12. doi:10.1016/0043-1648(83)90307-1.

[116] Garrison WM. Abrasive wear resistance: the effects of ploughing and the removal of ploughed material. Wear 1987;114:239-47. doi:10.1016/0043-1648(87)90090-1.

[117] Childs THC, Rowe GW. Physics in metal cutting. Reports Prog Phys 1973;36:223. doi:10.1088/0034$4885 / 36 / 3 / 001$.

[118] Stroud MF, Wilman $\mathrm{H}$. The proportion of the groove volume removed as wear in abrasion of metals. Br J Appl Phys 1962;13:173. doi:10.1088/0508-3443/13/4/312.

[119] European Parliament and Council. Regulation Concerning the Registration, Evaluation, Authorisation and Restriction of Chemicals (REACH). Eur Chem Agency 2006:1-849.

[120] Varga M, Leroch S, Eder SJ, Rojacz H, Ripoll MR. Influence of velocity on high-temperature fundamental abrasive contact: A numerical and experimental approach. Wear 2019;426-427:3707. doi:10.1016/J.WEAR.2018.12.013.

[121] Mishra T, Ganzenmüller GC, de Rooij M, Shisode M, Hazrati J, Schipper DJ. Modelling of ploughing in a single-asperity sliding contact using material point method. Wear 2019;418-419:180-90. 
doi:10.1016/J.WEAR.2018.11.020.

[122] Mishra T, de Rooij M, Shisode M, Hazrati J, Schipper DJ. A material point method based ploughing model to study the effect of asperity geometry on the ploughing behaviour of an elliptical asperity. Tribol Int 2020;142:106017. doi:10.1016/j.triboint.2019.106017.

[123] Ganzenmüler G. Smooth-Mach-Dynamics package for LAMMPS. Fraunhofer Ernst-Mach Inst HighSpeed Dyn 2014:66.

[124] Moore MA, Douthwaite RM. Plastic deformation below worn surfaces. Metall Trans A 1976;7:18339. doi:10.1007/BF02659813.

[125] Zum Gahr KH. Formation of wear debris by the abrasion of ductile metals. Wear 1981;74:353-73. doi:10.1016/0043-1648(81)90173-3.

[126] Challen JM, Oxley PLB, Hockenhull BS. Prediction of Archard's wear coefficient for metallic sliding friction assuming a low cycle fatigue wear mechanism. Wear 1986;111:275-88. doi:10.1016/00431648(86)90188-2.

[127] Challen JM, McLean LJ, Oxley PLB. Plastic deformation of a metal surface in sliding contact with a hard wedge: its relation to friction and wear. Proc R Soc London, Ser A Math Phys Sci 1984;394:16181. doi:10.1098/rspa.1984.0074.

[128] Yang $Y$, Torrance AA, Oxley PLB. Modelling mechanical wear processes in metallic sliding friction. J Phys D Appl Phys 1996;23:600-8. doi:DOI: 10.1088/0022-3727/29/3/018.

[129] Tyfour WR, Hayajneh MT, Momani A, AL-Hajji MB. Sliding wear mechanism of ductile materials Effect of sliding direction reversal. Proc Inst Mech Eng Part J J Eng Tribol 2018;232:315-25. doi:10.1177/1350650117713878. 


\section{Research outputs}

\section{Journal articles}

1. Mekicha MA, de Rooij MB, Jacobs L, Matthews DTA, Schipper DJ. Experimental validation of contact models for cold-rolling processes. J Mater Process Technol 2020;275:116371. https://doi.org/10.1016/j.jmatprotec.2019.116371.

2. Mekicha MA, Mishra T, de Rooij MB, Matthews DTA, Jacobs L, Schipper DJ. Study of wear particles formation at single asperity contact: An experimental and numerical approach. Wear 2021;470471:203664. https://doi.org/10.1016/j.wear.2021.203644.

3. Mekicha MA, de Rooij MB, Matthews DTA, Pelletier C, Jacobs L, Schipper DJ. The effect of hard chrome plating on iron fines formation. Tribol Int 2020;142: 106003 https://doi.org/10.1016/j.triboint.2019.106003.

4. Mekicha MA, de Rooij MB, Jacobs L, Matthews DTA, Schipper DJ. Understanding the generation of wear particles in cold rolling processes. Tribol Int 2021;155:106789. https://doi.org/10.1016/i.triboint.2020.106789.

\section{Conference presentations}

1. $11^{\text {th }}$ International Rolling Conference (IRC 2019). In-situ investigation of the effect of hard chrome plating on iron fines formation. Sao Paulo, Brazil, 2019.

2. STLE Tribology Frontiers Conference. Modeling of iron fines formation in cold rolling processes using material point method. Chicago, USA, 2019.

3. M2i annual conference, Meeting Materials. The effect of hard chrome plating on iron fines formation in cold rolling. Noordwijk, The Netherlands, 2019.

\section{Master thesis supervision}

1. Investigation of the effect of hard chrome plating \& Ni-P plating on Iron fines formation. Maarten Kaandorp. University of Twente. 2019-2020. 
Part II 



\section{Paper A}

Mekicha MA, de Rooij MB, Jacobs L, Matthews DTA, Schipper DJ. Experimental validation of contact models for cold-rolling processes. J Mater Process Technol 2020;275:116371.

https://doi.org/10.1016/j.jmatprotec.2019.116371. 



\title{
Experimental validation of contact models for cold-rolling processes
}

\author{
M.A. Mekicha ${ }^{a}$, M. B. de Rooij ${ }^{a}$, L. Jacobs ${ }^{a, b}$, D.T.A. Matthews ${ }^{a, b}$, D. J. Schipper ${ }^{a}$ \\ a Department of Mechanics of Solids, Surfaces \& Systems (MS', Faculty of Engineering Technology, University of Twente, \\ Enschede, The Netherlands. \\ ${ }^{\mathrm{b}}$ Tata Steel, Research \& Development, IJmuiden, The Netherlands.
}

\section{Key words}

Cold rolling; Contact mechanics; Bulk strain; Strip surface topography; Real contact area

\begin{abstract}
Many functional properties of a cold rolled strip such as wear resistance, friction in a forming process, and optical properties depend on its surface finish. Accurate modelling of the real contact area is critical in predicting the surface finish of strips after cold rolling processes. The aim of this work is to experimentally verify existing contact models to predict the surface finish of industrially cold rolled strips. For this purpose, rolling trials were done on a two high mill under boundary lubricated conditions at several combinations of thickness reduction, rolling speed, and roll and strip roughness. The surface finish of the rolled strip for a given rolling condition is predicted using selected contact models. Further, a new deterministic approach to calculate the average asperity slope is proposed. Statistical properties of the three dimensional surface topography of rolled strips are compared with surfaces predicted employing selected contact models. The surface finish of measured and model-predicted surfaces showed very good agreement for strips rolled with a smooth roll. However, for strips rolled with rough rolls, a significant difference was observed in the surface height distribution between the measured and model-predicted surfaces. It was shown in these experiments that a non-uniform rise of valleys plays an important role on the surface finish of strips rolled with a rough roll.
\end{abstract}

\section{Introduction}

The surface quality of sheet metals produced by cold strip rolling is a crucial aspect not only for aesthetic reasons but also essential for optimal product performance in many markets, such as the automotive and packaging industries. Surface finish and cleanliness are two aspects of the surface quality of a rolled sheet metal. Predicting the surface finish changes during the cold rolling process is important in order to fulfil the specific surface finish requirements of certain rolled sheet products as well as to estimate friction and wear accurately. One of the main factors that reduce strip surface cleanliness are iron fines, comprised of mainly the strip material, which are produced due to the relative sliding of the roll asperities through the strip surface in the roll bite. To optimally tailor the surface quality of a cold rolled steel strip to a given specification, a detailed and comprehensive understanding of the tribological behavior of the roll-strip interface is necessary.

The real area of contact, which is typically a small fraction of the nominal contact area, plays a vital role in characterizing friction, wear and material transfer of tribological contacts. Accurate modelling of the real contact area is the basis for characterizing the tribological behavior of cold rolling processes such as estimating the rolled strip surface finish, friction, and wear rate. The nature of contacts in cold rolling processes depends on rolling parameters, lubrication condition and lubricant properties, surface chemistry, roughness and material property of the roll and the strip. Cold rolling processes generally operate in the mixed or boundary lubrication regimes with the asperities of the strip and the roll mainly governing the contact. The focus of this paper is on rolling processes operating in the boundary lubrication regime, where all the rolling load is carried by direct metal-to-metal contact between the strip and the work roll. 
During rolling, the strip deforms plastically in the roll bite. It is well known that the asperities flatten considerably more, under a given contact pressure, in the presence of sub-surface bulk deformation than in the absence of bulk deformation. This phenomenon is caused by the lowered effective hardness of the asperities as a result of bulk straining the underlying material. Thus, the real contact area changes throughout the roll bite as bulk deformation grows. Full analysis of asperity flattening with associated bulk deformation has been difficult. The mechanics of contacting asperities in rolling processes is further complicated by two factors: firstly, there is interaction between the neighboring contacting asperities due to the high contact pressure involved, secondly there is slip between the roll and the strip surfaces. Therefore, understanding how the real contact area changes as a function of bulk deformation in the presence of sliding with friction is very important in cold rolling processes.

Several authors developed analytical asperity flattening models taking into account bulk deformation. Wilson and Sheu [1] used an upper bound analysis to study the effect of bulk deformation on flattening of asperities parallel to the direction of bulk strain. Sutcliffe [2] presented a slip-line field analysis of flattening of asperities aligned perpendicular to the direction of bulk deformation and proposed an alternative deformation model for Wilson and Sheu's longitudinal asperities. Kimura and Childs [3] proposed kinematically admissible velocity fields for the crushing of asperities aligned parallel to the direction of bulk deformation on a plastically flowing bulk by applying an energy minimization method. The above analytical models can be used to estimate the real contact area ratio as a function of bulk plastic strain. The main assumptions of these models are: (i) triangular shaped asperities with equal height and spacing; (ii) the asperities deform in a rigid perfectly plastic way; (iii) the slope of the triangular asperities does not change during subsequent deformation, i.e. non-contacting valleys rise uniformly or the deformed volume disappears in the deforming bulk; (iv) the asperities are flattened by a smooth rigid counter-face and (v) asperities have the same mechanical properties as the bulk. Furthermore, analytical calculation of the real contact area in the presence of bulk deformation is possible only when a plane stress or a plane strain deformation of asperities is assumed. The main limitations of those analytical models are: (i) roughness peaks are simulated by ideal asperities which is a very rough approximation of the true roughness profile; (ii) frictionless contacts are assumed or implied; (iii) a perfectly plastic asperity deformation behavior assumption oversimplifies the deformation. In reality, the strip has a certain strain hardening that influence asperity crushing. In particular, this strain hardening plays an amplification role because the top of asperities are subjected to a higher strain than the bulk material; (iv) the assumption of asperities having the same mechanical behavior as the bulk is not accurate because a ground or shaped surface usually has a hardened surface layer; and $(v)$ the mode of deformation is chosen such that the velocity field satisfies the boundary conditions; however, many alternate modes of deformation can be formulated.

These limitations of analytical models led to the use of numerical analysis to simulate the flattening process of surface asperities in the presence of bulk strain. In numerical models, the effect of strain hardening can be taken into account and non-idealized asperity shapes can be modelled. However, they cannot give direct analytical expressions. Makinouchi and lke [4] carried out a two dimensional finite element analysis of a model specimen using three triangular asperities with free side edges for perfectly lubricated conditions under plane strain conditions. The deformation of these few asperities, which may be strongly influenced by the presence of free side edges, is not representative of the asperities in actual surfaces. In actual surfaces, most of the asperities are far away from any side edge. Ike and Makinouchi [5] later extended the model by increasing the number of asperities to five as well as introduced a single asperity model with periodic boundary conditions and studied the effect of lateral compression and tension on flattening of asperities. In another study, Korzekwa et al. [6] used finite elements to analyze the general case where components of strain are present in directions both longitudinal and transverse to the asperity direction. Recently, Nielsen et al. [7] performed a two dimensional finite element numerical study of the real contact area ratio as a function of tensile and compressive subsurface bulk strain at different normal pressures. They simulated an up scaled millimeter sized triangular asperities and treated both plane stress and plane strain conditions. 
Note that in all of these analytical and numerical studies, the contact geometry is represented by an array of identical triangular asperities. It is assumed that all the roughness resides on the strip and the roll is smooth. In reality, both the strip and the roll surfaces are rough. Work roll surfaces are commonly prepared by grinding in the circumferential direction. This leads to a longitudinal roll roughness with asperities running parallel to the rolling direction. Wilson [8] extended Wilson and Sheu [1] model by including the roughness of both contacting surfaces. He showed that the presence of sliding can reduce the flattening rate of strip asperities. Nevertheless, for high contact pressures and low sliding speeds, roll roughness and sliding have little effect on the real contact area. Sutcliffe [9] analyzed the flattening of random rough surfaces using a model of a surface consisting of short wavelength asperities superimposed on longer wavelength asperities. He used the power spectral density of the roughness to choose the amplitudes of the two wavelengths. Engineering surfaces contain irregularities with a wide range of wavelengths in several orders of magnitude, ranging from the order of interatomic distances to shape deviations, and corresponding amplitudes. Since there is no established criteria to choose the two wavelengths to characterize the roughness, the two wavelengths were selected arbitrarily. Recently, Legrand et al. [10] have developed a semi-analytical model to predict roughness transfer in cold and temper rolling processes by combining the Abbot curves of the incoming strip and the work roll, and coupling the roughness transfer equations with the roll gap model. Comparison of their model results with temper rolling experiments showed reasonable agreement in terms of average roughness (Ra) value. However, their model was not validated for other roughness parameters and cold rolling processes.

While it is scientifically important to examine flattening of model asperities and changes in individual asperity areas, industrial requirements are related to average surface parameters. So far, to the authors' knowledge, a detailed experimental study has not been done on the accuracy of these models in predicting surface finish of industrially cold rolled steel strips.

The aim of the present work is to study experimentally the real contact area surface finish for boundary lubricated cold rolling of low carbon steel. For this purpose, rolling trials were carried out on a two high mill using a low carbon steel strip. Rolling trials were performed using several combinations of thickness reduction, strip and roll roughness and rolling speed. The effect of rolling parameters that have a significant influence on the real contact area ratio, i.e. thickness reduction and roll and strip roughness, have been investigated. In addition, the influence of rolling speed on the rolled strip surface finish was studied. The three-dimensional surface topography of the in-going strip, the work roll and the rolled strip were measured using confocal microscopy. After that a detailed topographic and statistical surface roughness analysis of the rolled strips was done. The surface finish and roughness of rolled strips are compared with the surfaces predicted using the Wilson and Sheu [1] analytical and Korzekwa et al. [6] numerical models.

\section{Contact model}

An overview of the procedure for calculating the real contact area and the surface topography of the rolled strip is provided in figure 1. The solution procedure starts by defining the rolling parameters (rolling speed, thickness reduction and contact pressure), strip material behavior, strip and roll surface height data (step 1). Once the input parameters are known, the real area of contact due to normal loading and the separation are calculated (step 2), section 2.1. In step 3 (section 2.2), the increase in real area of contact due to bulk strain is calculated. The average asperity slope is calculated by characterizing the contact patches by elliptical paraboloids (section 2.3). The surface topography of the rolled strip can be calculated if the real contact area and the surface height distribution of the roll and the strip are known. It should be noted that the surface topography of the rolled strip is predicted by assuming the roll surface topography is imprinted on the strip surface. The effect of ploughing due to sliding is not taken in to account. For rolling processes with a small forward slip (i.e. the neutral point close to the roll bite exit), there will be a short sliding distance after the neutral point. Furthermore, the effect of ploughing due to sliding is expected to be negligible in the current experiments because of the longitudinal roughness of the rolls from the grinding. Therefore, the imprint of the roll grinding marks will be the dominant features as demonstrated 
by Smits and Smeulders [11]. In reality, the asperity flattening due to normal loading and due to bulk deformation will occur simultaneously during rolling.

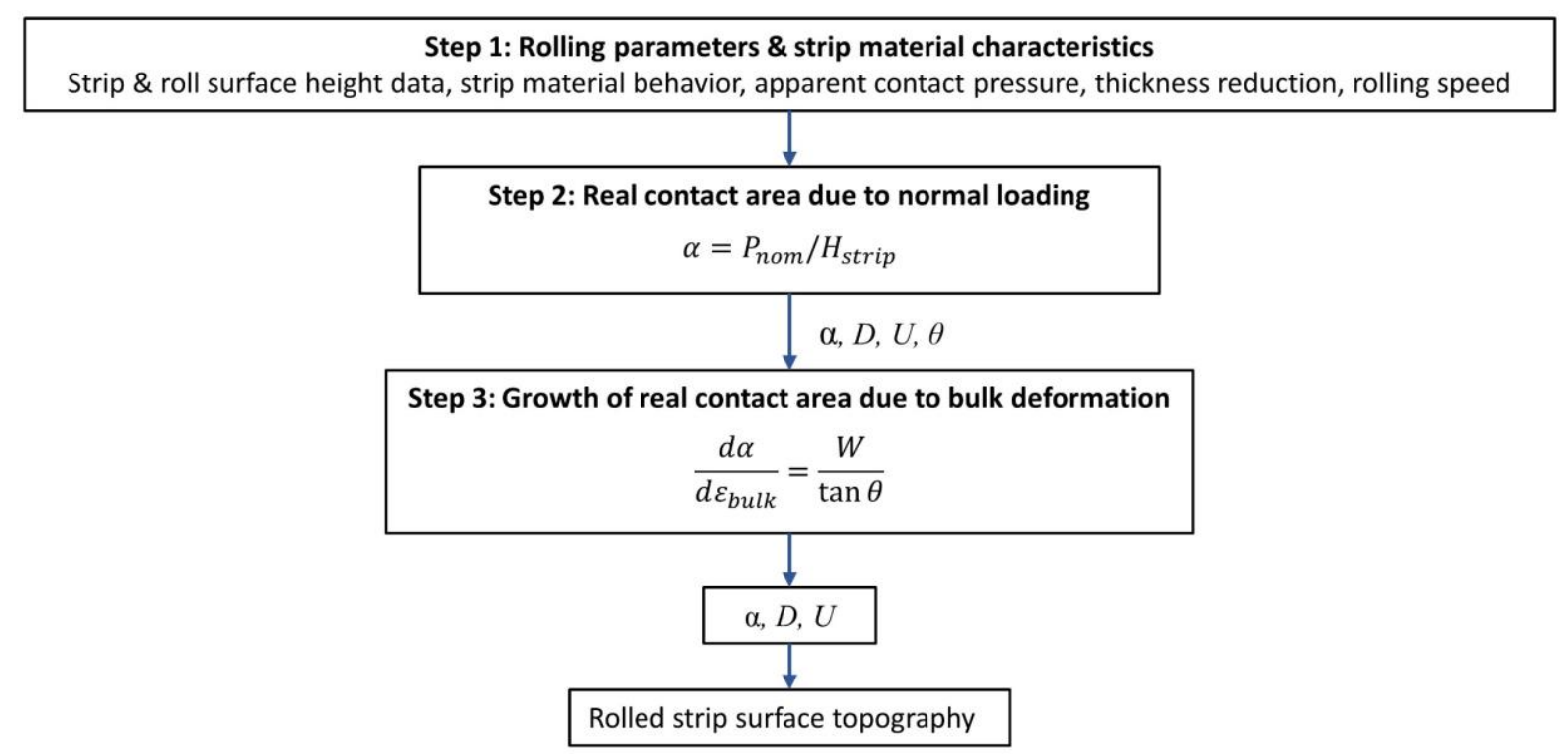

Figure 1: Solution procedure for the contact model.

\subsection{Contact area due to normal loading}

When rolling a relatively thick strip, the friction hill may be neglected and the apparent contact pressure $\left(P_{n o m}\right)$ is approximately equal to the yield stress of the strip in plane strain condition. The deformation at micro-contacts is assumed to be fully plastic and the effect of elastic asperity deformation is neglected. The roll is assumed as rigid and the strip as a rigid-plastic, incompressible surface. Similar to Pullen and Williamson [12], it is assumed that the flattened asperities cause uniform rise of the non-contacting asperities. In this work, the roughness texture of the roll and the strip surfaces are modelled as bars which can represent any arbitrary shaped asperities. A schematic of a surface texture modelled as bars and uniform rise of non-contacting asperities is depicted in figure 2 . The real contact area due to normal loading is calculated by using a simple linear plastic model. The maximum normal pressure a deforming strip asperity can carry is assumed to be equal to its hardness $H_{\text {strip }}$, which is approximately equal to 3 times its uniaxial yield stress $\left(\sigma_{y}\right)$ for steel [13]. Hence, the real contact area ratio for pure normal loading $(\alpha)$ without bulk deformation and sliding is given by:

$$
\alpha=P_{\text {nom }} / H_{\text {strip }}
$$

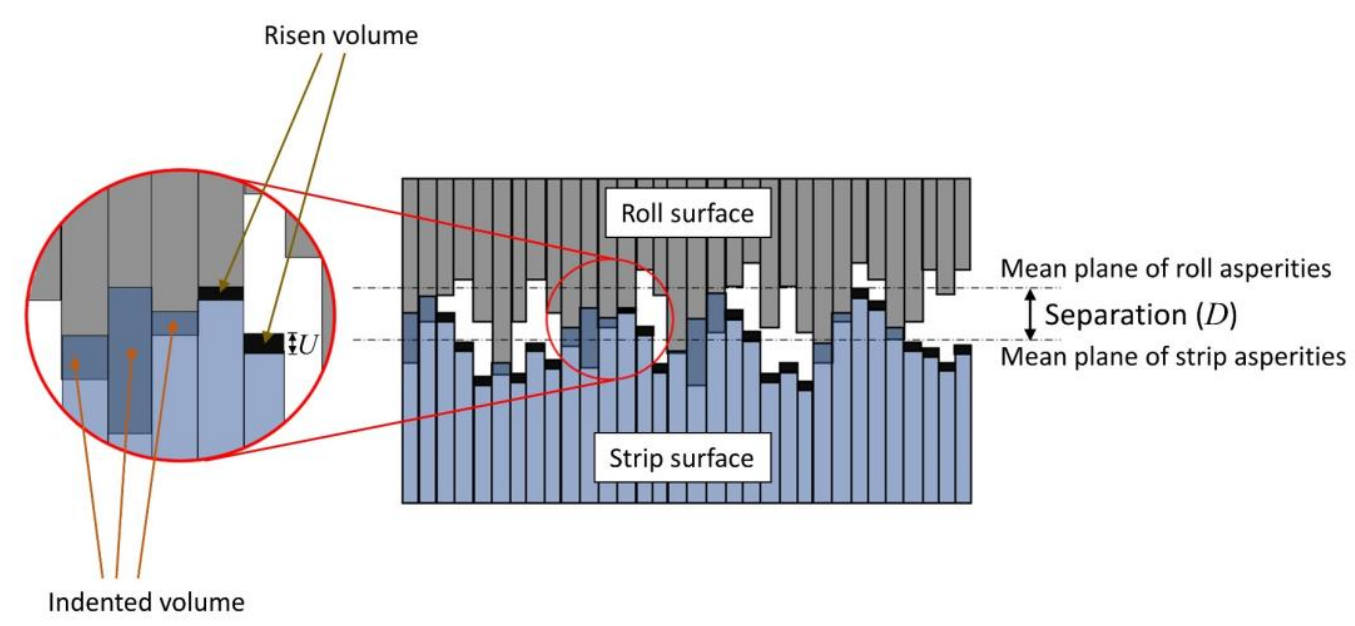

Figure 2: Schematic of the contact between rough strip and rough roll surfaces, surface roughness represented as bars. 
Neglecting the friction hill and assuming the apparent contact pressure to be the same as the yield strength of the strip material, the ratio of real contact area and nominal contact area due to normal loading is approximately 0.33 . Because there are two unknown variables, the separation $D$ and the constant rise of non-contacting asperities $U$ (see figure 2), another equation is required to compute $D$ and $U$. Volume conservation is used as the second equation, i.e. the indented volume reappears as a uniform rise in the non-contacting surface.

To translate micro contact modeling into macro contact modelling, the contact is described by stochastic parameters. The normalized surface height distribution of the roll and the strip surfaces was used for this purpose. For a given contact pressure, the separation, the amount of indentation of roll asperities into strip asperities, and the uniform rise of valleys can be calculated by solving the load balance and volume conservation equations simultaneously. A MATLAB code has been written and the Newton-Raphson procedure was used to solve these equations.

\subsection{Increase of contact area due to bulk strain}

Since the work roll surface was prepared by grinding (see section 3.1), the analytical model of Wilson and Sheu [1] and the numerical model of Korzekwa et al. [6] for the case of asperities parallel to the bulk strain direction, have been chosen for comparison with experimental results. Using these asperity flattening models, the real contact area is calculated as a function of the rolling conditions, strip material properties and the surface topography of the roll and the strip. The surface topography of the rolled strip can be predicted by applying the hypothesis of a uniform rise of non-contacting valleys.

In the Wilson and Sheu [1] model plane strain similar to that in rolling with no side spread is assumed, as illustrated in figure 3 . In their paper, asperity flattening has been analysed as an indentation problem. For small asperity slopes, the pressure required for indentation of the strip surface is equal to that required for flattening strip asperities. This is representative of the strip surface in the case of rolling.

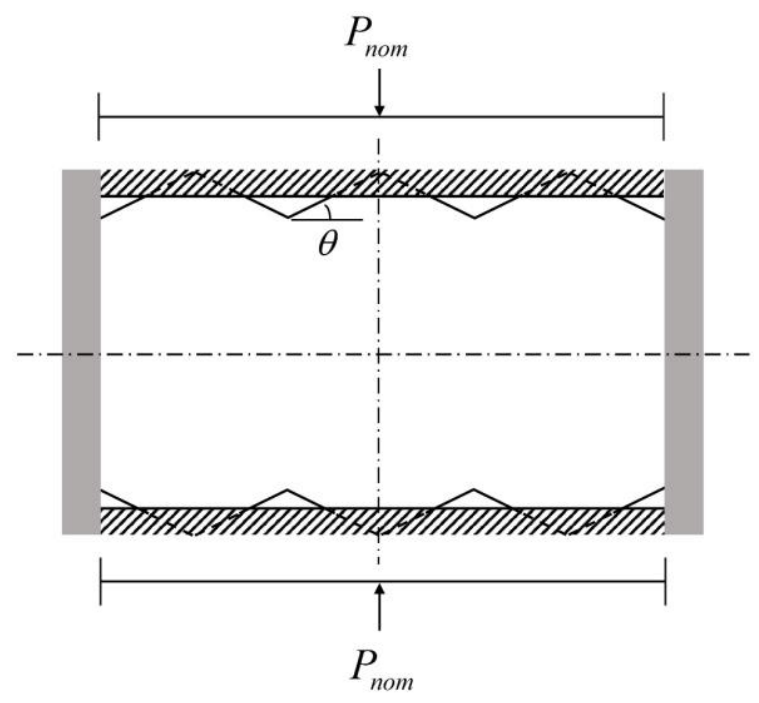

Figure 3: The idealized triangular shaped geometry of asperities, after Kimura and Childs [3].

For triangular asperities running parallel to the rolling direction, the rate of change of real contact area with bulk strain $\left(d \alpha / d \varepsilon_{\text {bulk }}\right)$ is given by [2]:

$$
d \alpha / d \varepsilon_{\text {bulk }}=W / \tan \theta
$$

where $W$ is the non-dimensional local asperity flattening rate and $\theta$ is the asperity slope (see figure 3 ).

Wilson and Sheu [1] derived the following semi empirical relation for the flattening rate as a function of the non-dimensional contact pressure and the real contact area ratio:

$$
W=\bar{P} f_{1} /\left(2 \alpha-\bar{P} f_{2}\right)
$$




$$
\begin{aligned}
& f_{1}=0.515+0.345 \alpha-0.86 \alpha^{2} \\
& f_{2}=1 /(2.571-\alpha-\alpha \ln (1-\alpha))
\end{aligned}
$$

where $\bar{P}=P_{n o m} / k$ is the non-dimensional mean contact pressure and $k$ is the shear strength of the strip

Korzekwa et al. [6] developed an asperity flattening model using a visco-plastic finite element analysis of two and three dimensional asperities. The asperity flattening was modelled as a function of the contact pressure and the straining direction. Asperity flattening was modeled as the indentation of a flat surface by a rigid punch. The model assumes an infinite array of wedge shaped asperities of uniform height and wavelength that lie along a principal strain axis, similar to figure 3. For wedge shaped asperities parallel to the rolling direction, which is the case for work roll asperities prepared by grinding, Sutcliffe [9] extracted the asperity flattening rate function from the results of Korzekwa et al. (1992) and fitted their results by:

$$
W(\overline{\bar{P}}, \alpha)=\alpha(1-\alpha)\left(C_{1} \overline{\bar{P}}+C_{2} \overline{\bar{P}} \alpha+C_{3} \overline{\bar{P}} \alpha^{2}\right)
$$

where

$$
C_{1}=5.1206 \overline{\bar{P}}-4.5258 \overline{\bar{P}}^{2}+3.5599 \overline{\bar{P}}^{3}
$$

$$
\begin{aligned}
& C_{2}=-9.5761 \overline{\bar{P}}+11.3854 \bar{P}^{2}-8.6069 \overline{\bar{P}}^{3} \\
& C_{3}=8.3193 \overline{\bar{P}}-11.7954 \bar{P}^{2}+7.6475 \bar{P}^{3}
\end{aligned}
$$

and

$$
\overline{\bar{P}}=P_{\text {nom }} / \sigma_{y}=P_{\text {nom }} / 2 k=0.5 \bar{P}
$$

Equation (2) is again used to relate the asperity flattening rate to the change of real contact area ratio as a function of the nominal strain. Korzekwa et al. [6] compared their results with Wilson and Sheu [1] for the condition where the direction of strain is parallel to the longitudinal asperities. Their results show good agreement with the upper bound results. A comparison of the two equations (equations 3 and 6 ) for a perfectly plastic material with a non-dimensional contact pressure $\bar{P}$ of 2 and asperity slope of $10^{\circ}$ is presented in figure $4(\mathrm{a})$. In both cases, the real contact area ratio increases monotonically with the bulk strain, eventually approaching unity asymptotically. For small strains $\left(\varepsilon_{\text {bulk }}<0.3\right)$, Wilson and Sheu's empirical relation (equation 3 ) gives higher flattening rate, and hence higher real contact area ratio for a given contact pressure and asperity slope. However, the two equations give approximately similar results at high strain values and low asperity slopes.

The value of asperity slope $\theta$ has a significant influence on the real contact area ratio. Korzekwa et al. [6] used a slope of $1,2,5$ and $10^{\circ}$ for calculations. Wilson and Sheu [1] used a slope of $10^{\circ}$ as this value was shown to match the results of their experiments. Figure 4(b) shows the effect of asperity slope on the real contact area ratio for a bulk strain of 0.1 and 0.4 and a non-dimensional pressure of 1 using equation (3) and equation (6). The asperity flattening rate is inversely proportional to the asperity slope. Equation 6 gives lower contact area, particularly at high asperity slopes and low bulk strain values, as compared to Wilson and Sheu's (equation 3). 


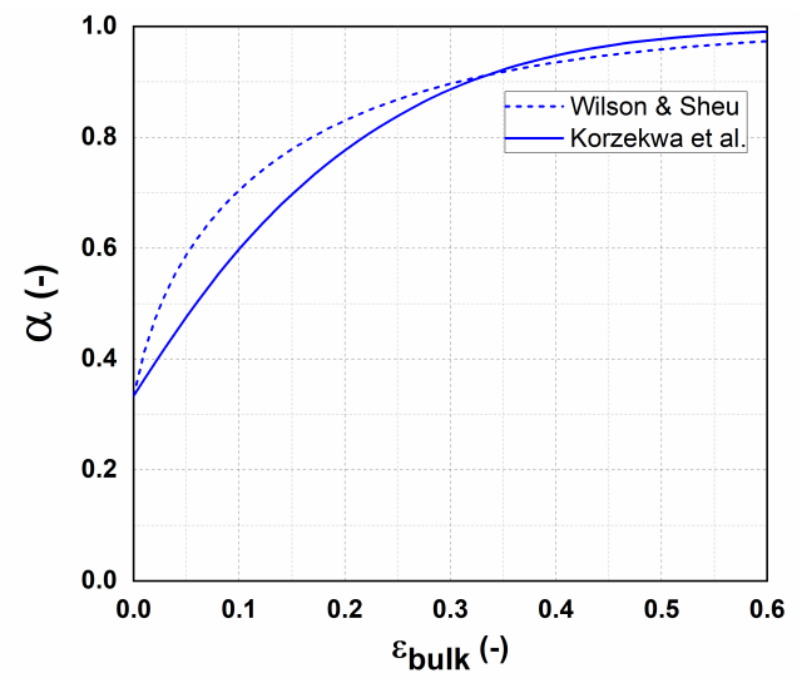

a) $\bar{P}=1, \theta=10^{\circ}$

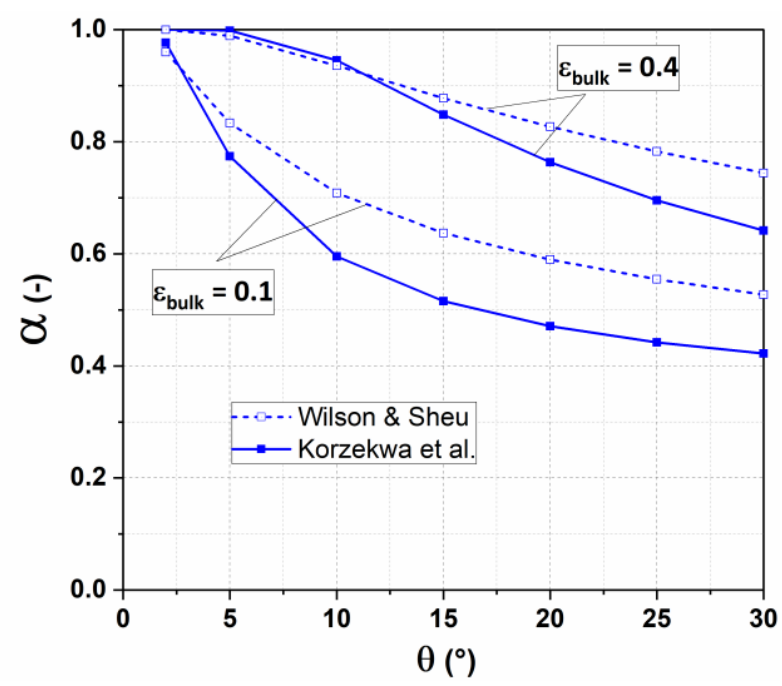

b) $\bar{P}=1$

Figure 4: Comparison of equations (3) and (6); (a) the effect of bulk strain on real contact area and (b) the effect of asperity slope on real contact area.

\subsection{Asperity slope calculation}

Determining the slope of the asperities is not a simple task for real surfaces. In the current work, we implement a scale independent, deterministic approach to calculate the average asperity slope. This is achieved by fitting each contact patch with an equivalent elliptical paraboloid as described by de Rooij et al. [14] and calculating the slope of each paraboloid in the rolling direction. The average of these slopes is taken as the asperity slope of the contact and it is assumed that this slope doesn't change during deformation.

The roll and strip surfaces are represented in a height matrix of pixels and the non-contacting valleys are assumed to rise uniformly. The contact patches are identified by calculating the separation and amount of indentation of roll asperities into strip asperities for pure normal loading at the onset of bulk deformation. The separation is calculated from the load balance by equating the sum of the load carried by each microcontact to the applied nominal contact load. The onset of strip deformation occurs when the normal contact pressure is the same as the strip yield stress (section 2.1). Each contact patch is a cluster of points that are in contact at that given separation and connected together at least with one edge. Merging of the several adjacent asperities into a single micro-contact with increasing real contact area is automatically taken into account. After the contact patches are identified, they are modelled as elliptical paraboloids. This choice was made because it allows a more precise description of surface topography than other asperity geometries such as spherical or conic shaped asperities. An example of contact patch identification and characterization is provided in figure 5 . The roll and the strip surfaces are real measured surfaces which covers an area of $4 \mathrm{~mm}$ by $2.4 \mathrm{~mm}$. The contact condition is pure normal loading with a contact pressure equal to the yield stress of the strip. The ratio of the real contact area to the nominal contact area is 0.33 .

The geometrical parameters of the contact patch such as the minor and major radius of the ellipse, the orientation angle and the total volume of this contact patch can be obtained using a deterministic approach. The base ellipse is characterized by mapping its centroid to that of the cluster of contacting points. The major and minor radius lengths and the orientation angle of this ellipse are calculated such that this ellipse has the same second central moments as the original region. The height of the paraboloid is determined from the total volume of the contact patch, which is derived by summing up the pixel height within this contact patch. The details of identification and characterization of the contact patches and the equations to calculate the geometrical parameters can be found elsewhere [15]. Some of the statistical values of the geometric parameters calculated for the example in figure 5 are tabulated in table 1 . 
a)
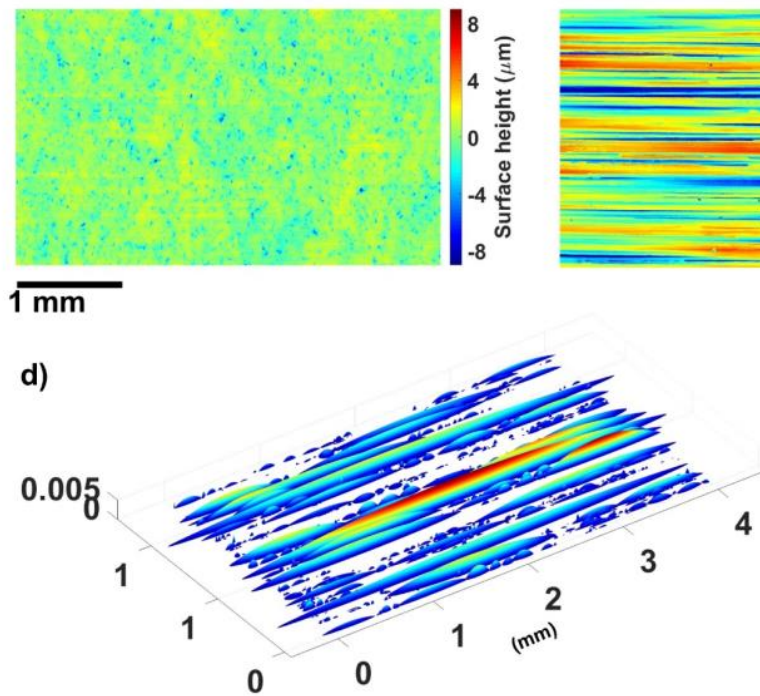

b)

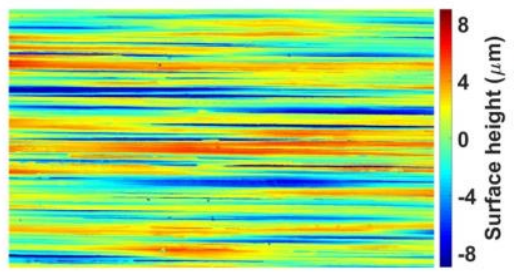

c)

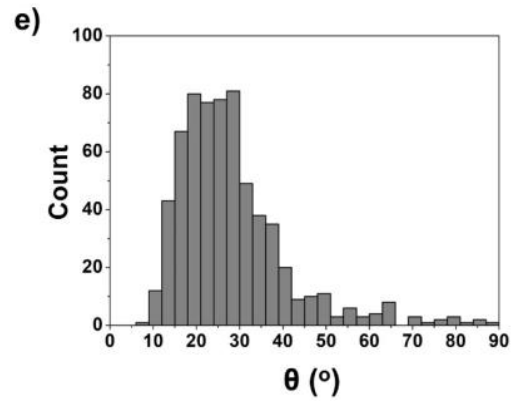

Figure 5: Identification and characterization of contact patches by elliptic paraboloids; (a) in-going strip surface, (b) roll surface replica, (c) contact patches identification (white = contact), (d) contact patches characterized by elliptical paraboloid, (e) histogram of the asperity slope $(\theta)$ for the contact patches in the rolling direction.

Table 1: Statistical values of the geometric parameters of the contact patches.

\begin{tabular}{|r|c|c|c|c|}
\hline & $\begin{array}{c}\text { Number of contact } \\
\text { patches }\end{array}$ & Mean & Minimum & Maximum \\
\hline Area $\left(\mu \mathrm{m}^{2}\right)$ & 648 & 5469 & 67 & 474908 \\
\hline Major axis length $(\mu \mathrm{m})$ & 648 & 150 & 11 & 4669 \\
\hline Minor axis length $(\mu \mathrm{m})$ & 648 & 17 & 3 & 158 \\
\hline Aspect ratio & 648 & 7 & 1 & 63 \\
\hline Paraboloid height $(\mu \mathrm{m})$ & 648 & 2 & 0.2 & 12 \\
\hline Asperity slope in the rolling direction $\left(^{\circ}\right)$ & 648 & 28 & 8 & 89 \\
\hline
\end{tabular}

\section{Experimental procedure}

\subsection{The Rolling mill and materials}

The rolling trials were carried out using a two high pilot mill setup in Tata Steel, Research \& Development, ljmuiden the Netherlands. The work roll diameters were $400 \mathrm{~mm}$ and were non-chrome plated. Two sets of rolls with a surface r.m.s. roughness of $0.3 \mu \mathrm{m}$ and $3.2 \mu \mathrm{m}$ were prepared by grinding in the circumferential direction. Hereafter, these rolls will be referred to as smooth roll and rough roll, respectively. The roughness of a freshly ground roll decreases rapidly in the start of the roll-life, after that it remains constant. To avoid this undesired change of roughness and ensure the roll has a constant roughness, a pickled low carbon steel coil ( $3.3 \mathrm{~mm}$ thick) was rolled with a $9 \%$ thickness reduction using the freshly grinded work rolls followed by another pass of $9 \%$ reduction. The roughness of the rolls stated above were measured after these two passes.

The strip material was a Titanium-stabilized interstitial-free (Ti-IF) steel. This steel grade was chosen because it is a typical steel grade extensively used in automotive applications owing to its high formability. Two coils, already rolled from $3.3 \mathrm{~mm}$ to $2.7 \mathrm{~mm}$ in two passes, were used as the in-going strip for the rolling experiments. One coil had a surface r.m.s. roughness of $0.9 \mu \mathrm{m}$ and the other one $2.6 \mu \mathrm{m}$. Hereafter, these coils will be referred to as smooth strip and rough strip, respectively. The coils were $100 \mathrm{~mm}$ wide and the in-going strip was at room temperature. The stress - strain curve of the strip material, obtained from standard tensile tests, is defined and extrapolated by a modified Bergstrom - van Liempt hardening 
relation [16]. Using this hardening relation, the yield stress can be calculated as a function of strain, strain rate and temperature. The simple rolling conditions in the current experiments (i.e. thick strip and soft steel grade) justify why the friction hill is neglected and a sophisticated roll gap model is not necessary to compute the roll gap pressure profile.

\subsection{Rolling parameters}

To examine the effect of rolling parameters on the real contact area ratio, and hence surface topography and surface roughness, rolling trials were performed using several combinations of thickness reduction, rolling speed, and strip/roll roughness. No lubricant was applied during the rolling experiments. However, no degreasing was done on the rolls or the strips before the rolling experiments. Therefore, the oil residues on the strips from previous processes provide boundary lubrication. Rolling experiments were carried out at four different thickness reductions; approximately 10\%, 20\%, 30\% and $40 \%$. For each thickness reduction, two rolling experiments were conducted at a rolling speed of $0.5 \mathrm{~m} / \mathrm{s}$ and $2.0 \mathrm{~m} / \mathrm{s}$. All of the above rolling trials were performed under the same conditions of reduction and rolling speed using two different combinations of roll and strip roughness: (i) rough roll and smooth strip and (ii) smooth roll and rough strip. A summary of the details of the rolling trials are provided in table 2 . The rolling force and the slip are acquired from the data acquisition system of the rolling mill. The specific roll pressure is calculated by dividing the vertical component of rolling force by the nominal projected area. The length of arc of contact is calculated considering Hitchcock's elastic roll flattening analysis [17].

Table 2: Parameters for rolling experiments.

\begin{tabular}{|c|c|c|c|c|c|c|c|c|}
\hline & $\begin{array}{l}\text { In-going } \\
\text { strip, } \\
\text { Sq ( } \mu \mathrm{m})\end{array}$ & $\begin{array}{c}\text { Roll, } \\
\text { Sq }(\mu \mathrm{m})\end{array}$ & $\begin{array}{l}\text { Rolling speed, } \\
\qquad \operatorname{Vr}(\mathrm{m} / \mathrm{s})\end{array}$ & $\begin{array}{c}\text { Trial } \\
\text { number }\end{array}$ & $\begin{array}{c}\text { Thickness } \\
\text { reduction, } r \\
(\%)\end{array}$ & $\begin{array}{l}\text { Total strip } \\
\text { strain, } \varepsilon[-]\end{array}$ & $\begin{array}{c}\text { Specific roll } \\
\text { pressure, } P \\
\text { (MPa) }\end{array}$ & Slip (\%) \\
\hline \multirow{8}{*}{$\begin{array}{c}\text { Rough roll } \\
\text { and } \\
\text { Smooth strip }\end{array}$} & \multirow{8}{*}{0.9} & \multirow{8}{*}{3.2} & \multirow{4}{*}{0.5} & 1 & 13 & 0.14 & 562 & 1.6 \\
\hline & & & & 2 & 21 & 0.23 & 599 & 2.5 \\
\hline & & & & 3 & 31 & 0.37 & 636 & 3.3 \\
\hline & & & & 4 & 38 & 0.48 & 663 & 3.9 \\
\hline & & & \multirow{4}{*}{2.0} & 5 & 11 & 0.12 & 600 & 0.4 \\
\hline & & & & 6 & 17 & 0.19 & 612 & 2.5 \\
\hline & & & & 7 & 28 & 0.32 & 626 & 3.0 \\
\hline & & & & 8 & 38 & 0.47 & 637 & 3.4 \\
\hline \multirow{8}{*}{$\begin{array}{c}\text { Smooth roll } \\
\text { and } \\
\text { Rough strip }\end{array}$} & \multirow{8}{*}{2.6} & \multirow{8}{*}{0.3} & \multirow{4}{*}{0.5} & 9 & 13 & 0.14 & 560 & 1.9 \\
\hline & & & & 10 & 19 & 0.22 & 612 & 2.4 \\
\hline & & & & 11 & 30 & 0.36 & 643 & 2.5 \\
\hline & & & & 12 & 41 & 0.52 & 644 & 2.6 \\
\hline & & & \multirow{4}{*}{2.0} & 13 & 16 & 0.17 & 549 & -0.1 \\
\hline & & & & 14 & 21 & 0.24 & 572 & 1.2 \\
\hline & & & & 15 & 32 & 0.39 & 589 & 1.1 \\
\hline & & & & 16 & 43 & 0.56 & 601 & 1.5 \\
\hline
\end{tabular}

\subsection{Surface roughness measurement}

For each rolling trial, the three dimensional surface topography of the in-going strip, roll surface and rolled strip was measured. A non-contact threedimensional height profiler (Sensofar S-neox confocal microscopy) was used to measure the surface topography. The surface roughness of the work rolls was measured by taking the replica of the roll surface using a surface replicating compound. The surface replicating was done as follows: (i) the roll surface was cleaned with ethanol, (ii) a fast curing, two component silicon-rubber (RepliSet-F5 from Struers) was applied using a dispensing gun, (iii) once the replication compound is dry, it was carefully peeled off from the roll surface. The same image size $4 \mathrm{~mm}$ by $2.4 \mathrm{~mm}$ ) and pixel resolution ( $2.58 \mu \mathrm{m}$ lateral resolution and $1 \mathrm{~nm}$ height resolution) was used for all 
roughness measurements. The surface topography measurements were done at three random locations for each sample. Form removal was done on the roughness measurements to remove roll form error and long wavelength components associated with lack of flatness.

\section{Results}

\subsection{Surface topography}

A visual comparison of the representative surface topography (height images) of the in-going strip, roll surface replica and rolled strips are presented in figure 6 . Note that the images are taken at random locations and are representative of the typical surface texture for the given rolling condition. The images clearly show the way the roughness of the roll is transferred to the strip surface as the strip conforms to the roll surface in the roll bite. Roll grinding marks are the dominant features on the surface finish of the rolled strips with most in-going strip topographic characteristics becoming obliterated. The long grooves are the inverse imprints of the ground roll on the strip surface. This is a typical strip surface morphology for cold rolling done under boundary lubrication conditions.

Roll marks on the strips are straight peaks or valleys running a significant distance in the rolling direction. The size of these valleys and peaks increases as the thickness reduction increases. While rough rolls indent and plough through the strip (figure $6(a, b)$ ), smooth rolls flatten the strip asperities (figure $6(c, d)$ ). As expected, a trend of increasing the rate of asperity crushing with increasing thickness reduction is observed. The effect of rolling speed is not discernable from the height images.
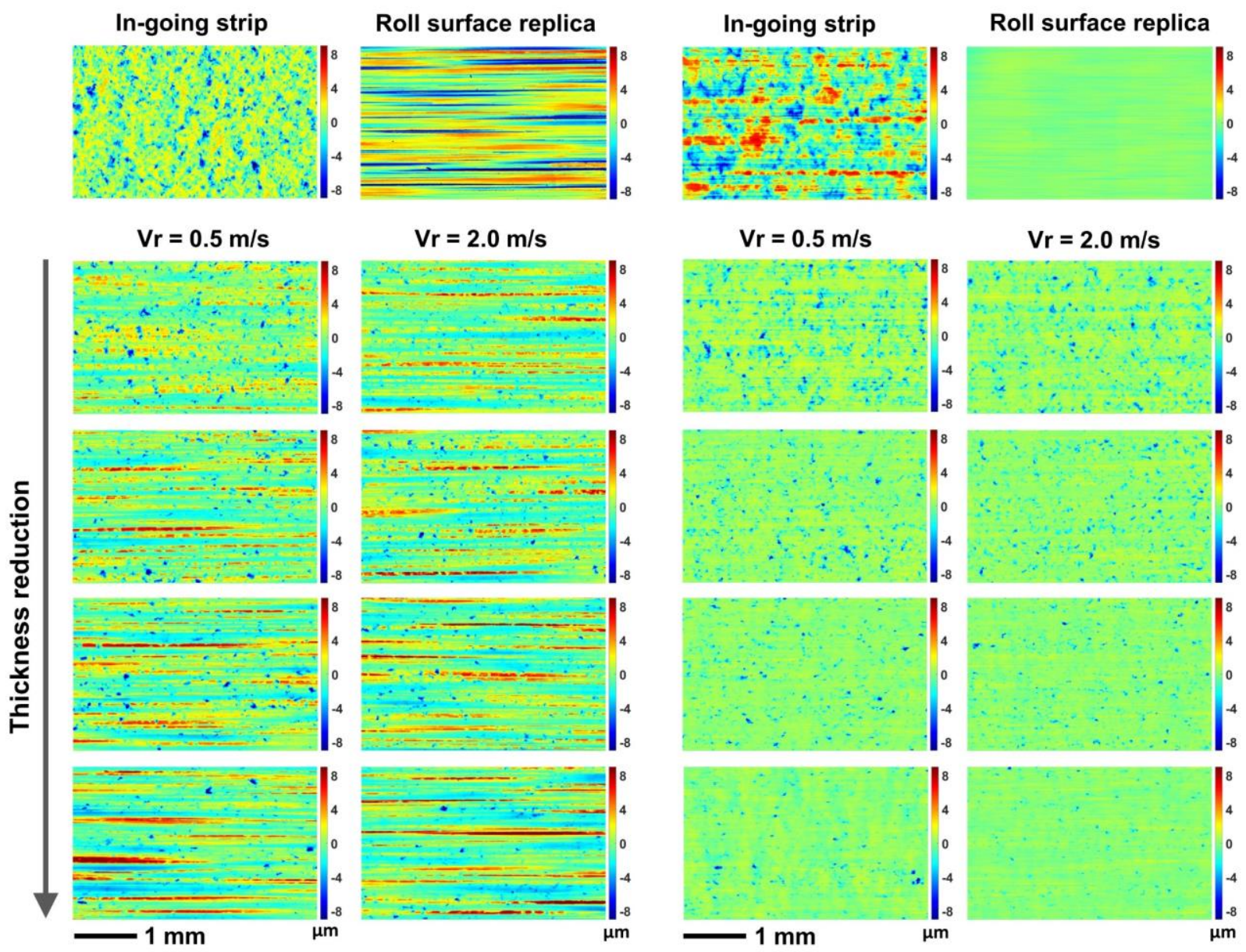

a)

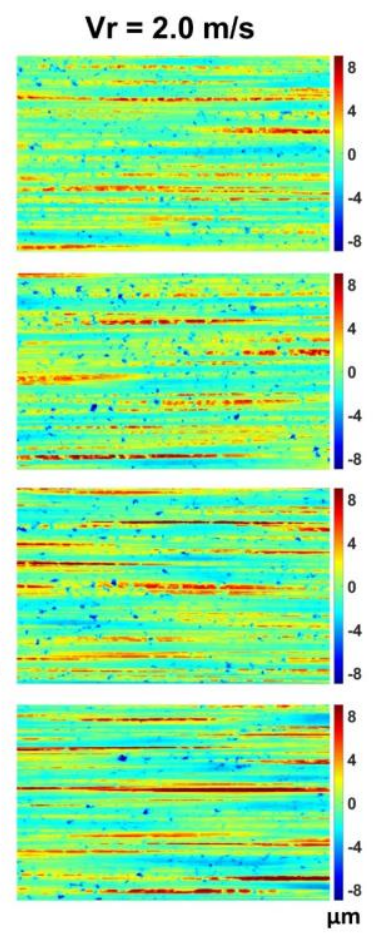

b)

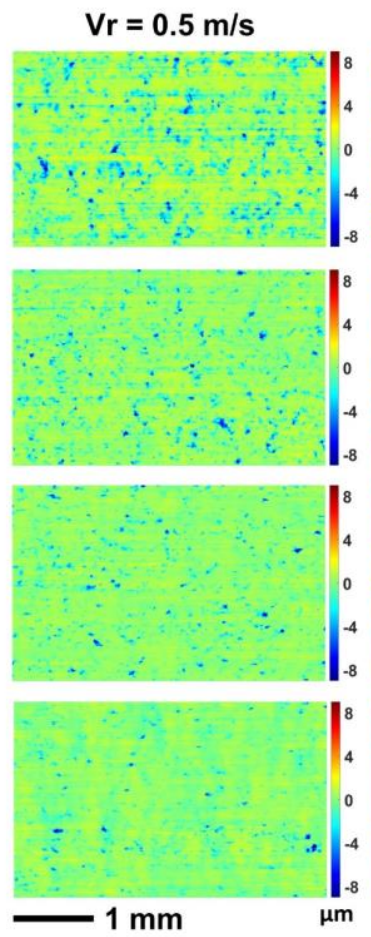

c)

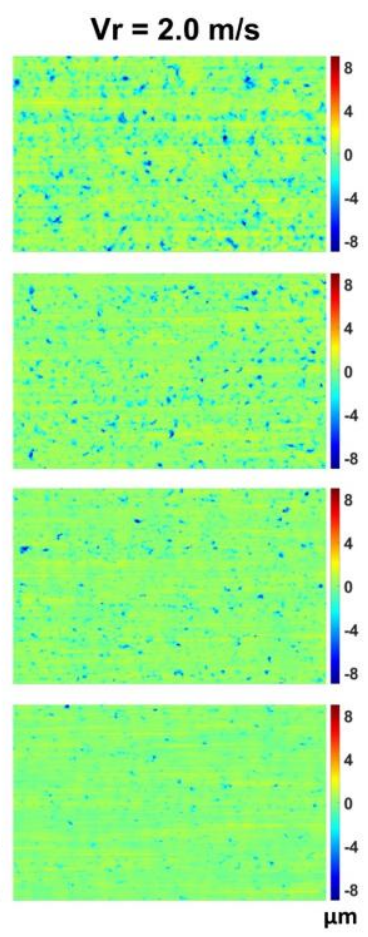

d)

Figure 6: Typical surface topography of the strips, rolled with rough rolls $(a, b)$ and smooth rolls $(c, d)$. 
Another main surface feature observed on the strips are micro pits. These micro-pits mainly originate from the surface roughness of the in-going strip. Some pits could also be formed during rolling due to strip surface fracture induced by reduced ductility as new surface is being created during rolling. In addition to affecting the visual appearance of the strip, these pits may act as lubricant trapping pockets in subsequent sheet forming processes. Irrespective of the rolling speed and roll/strip roughness, pits persist even at the highest (40\%) thickness reduction. Atala and Rowe [18] also reported that deep and narrow valleys persist much longer while the hills are very easily flattened. However, the size and frequency of pits decreases as the thickness reduction increases. This behavior is noticed for strips rolled with both rough and smooth rolls. A similar observation was reported by Ahmed and Sutcliffe [19] for cold rolled stainless steel strips, at multiple passes. Rolling speed, on the other hand, did not show any pronounced influence on the micropits.

\subsection{Statistical analysis of roughness of rolled strips}

Description of some of the functional properties of a surface can be derived from the amplitude characteristics of the surface topography. Some amplitude parameters are analyzed in this section in order to quantitatively describe the difference in surface topography between strips rolled using different rolling parameters. The parameters chosen for the analysis are the r.m.s. roughness $\left(S_{q}\right)$, the normalized surface height distribution function and bearing area curves. $\mathrm{S}_{\mathrm{q}}$ describes statistical characteristics of surface height while surface height distribution and bearing area curves describe the shape of the surface height distribution. The r.m.s. roughness evolution with respect to bulk strain (thickness reduction) and specific roll pressure are presented in figure 7 .

Figure $7(a, b)$ shows the roughness evolution of strips rolled with rough rolls. As expected, the roughness of the strip increases with thickness reduction, confirming the visual observation from the three dimensional images (figure $6(\mathrm{a}, \mathrm{b})$ ). Although the micro pits contribute to the roughness, it is dominated by the imprint of the roll grinding marks. As mentioned earlier, bulk deformation of the underlying material greatly enhances the flattening and indentation of strip asperities. This means more real contact area, and hence, more conformity to the roll surface as the thickness reduction increases. Similarly, for strips rolled with smooth rolls, the roughness of the rolled strips decreases as the thickness reduction increases, see figure $7(c, d)$. Rolling speed didn't show a substantial effect, this attests that the rolling trials were indeed performed in the boundary lubrication and there was no hydrodynamic effect in the roll bite.

Figures $7(b, d)$ show that increasing speeds caused a reduction of the rolling force needed to achieve a given thickness reduction, particularly for strips rolled with a smooth roll. The smaller rolling force needed for the same thickness reduction at $2.0 \mathrm{~m} / \mathrm{s}$ can be explained by the lower forward slip of rolling trials done at high speed (table 2). Low forward slip is commonly related to low friction coefficient in the roll gap. It is well known that the roll pressure decreases with decrease in coefficient of friction. On average, an increased roll roughness leads to an increase in the rolling force on the rolling mill. This again can be explained by the higher friction coefficient of rolling experiments done with rough rolls. This is reflected by the higher forward slip, see table 2 . When rough rolls are used, the asperities will be sharper and the ploughing component of friction force is expected to increase. 

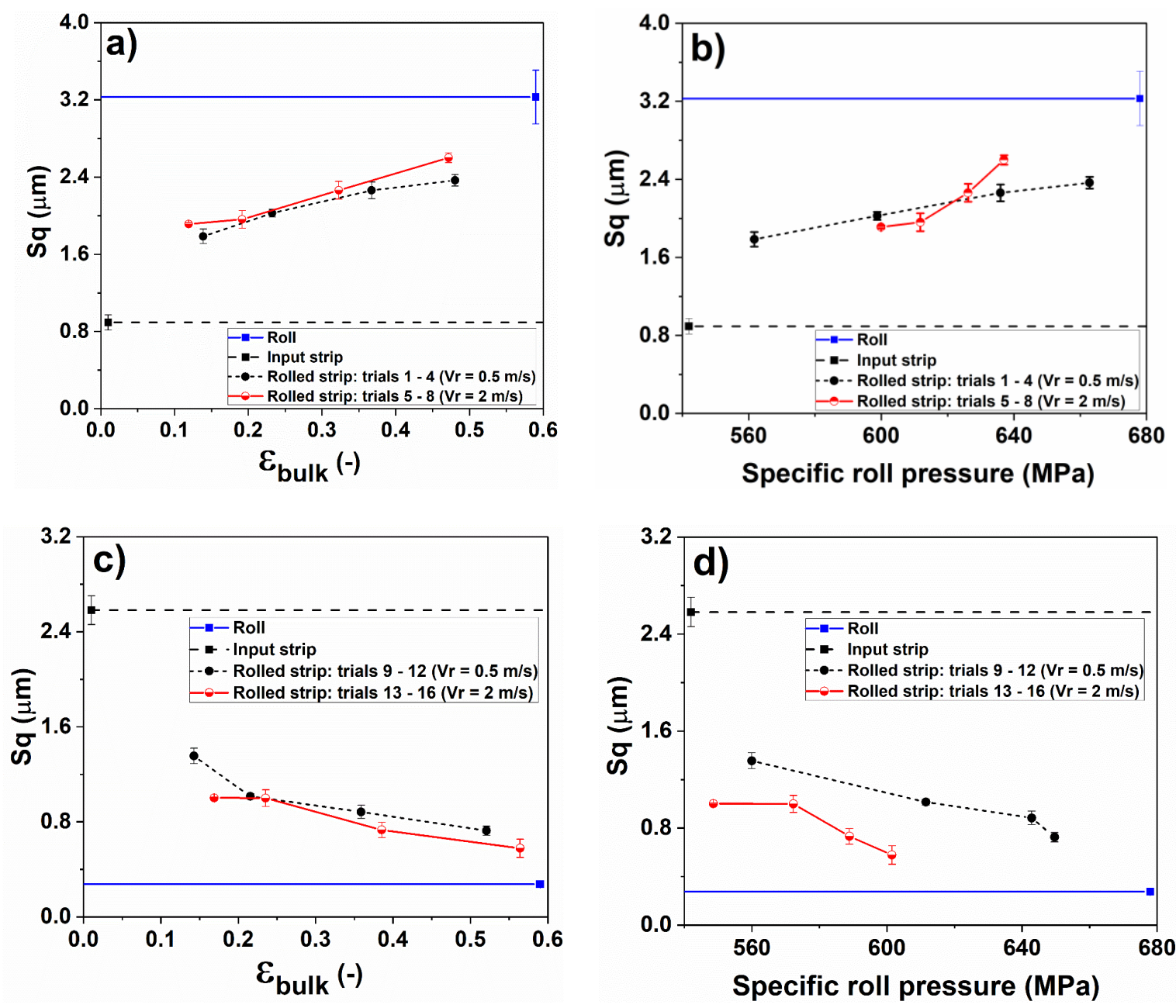

Figure 7: Surface roughness evolution of the strips rolled with rough rolls $(a, b)$ and smooth rolls $(c, d)$ as a function of bulk strain $\left(\varepsilon_{\text {bulk }}\right)$ and specific roll pressure.

The normalized surface height distribution and bearing area curves of the in-going strip, roll surface replica, and rolled strip are shown in figure 8. As expected, the surface height distribution and bearing area curve of rolled strips approach the negative of the roll surface with the increase in thickness reduction. The surface height distribution of strips rolled with rough rolls have a longer tail at the upper side of the mean plane indicating the presence of a few spikes on the surface. This is also reflected on the bearing area curves by the relatively large concave curvature of the surface in the right side of the mean plane. These spikes, which could flatten or wear quickly in contact with another surface, are formed by the strip material filling the deep valleys of the roll surface during rolling. The negatively skewed curves of the roll surface (i.e. positively skewed curve for the roll surface replica) is representative of ground surfaces with deep troughs dominating the parameter variation. On the other hand, the surface height distribution curves of strips rolled with smooth rolls are negatively skewed. This negative skewness is due to the few deep pits. The surface becomes smoother and the height distribution curve sharper as the thickness reduction increases. 

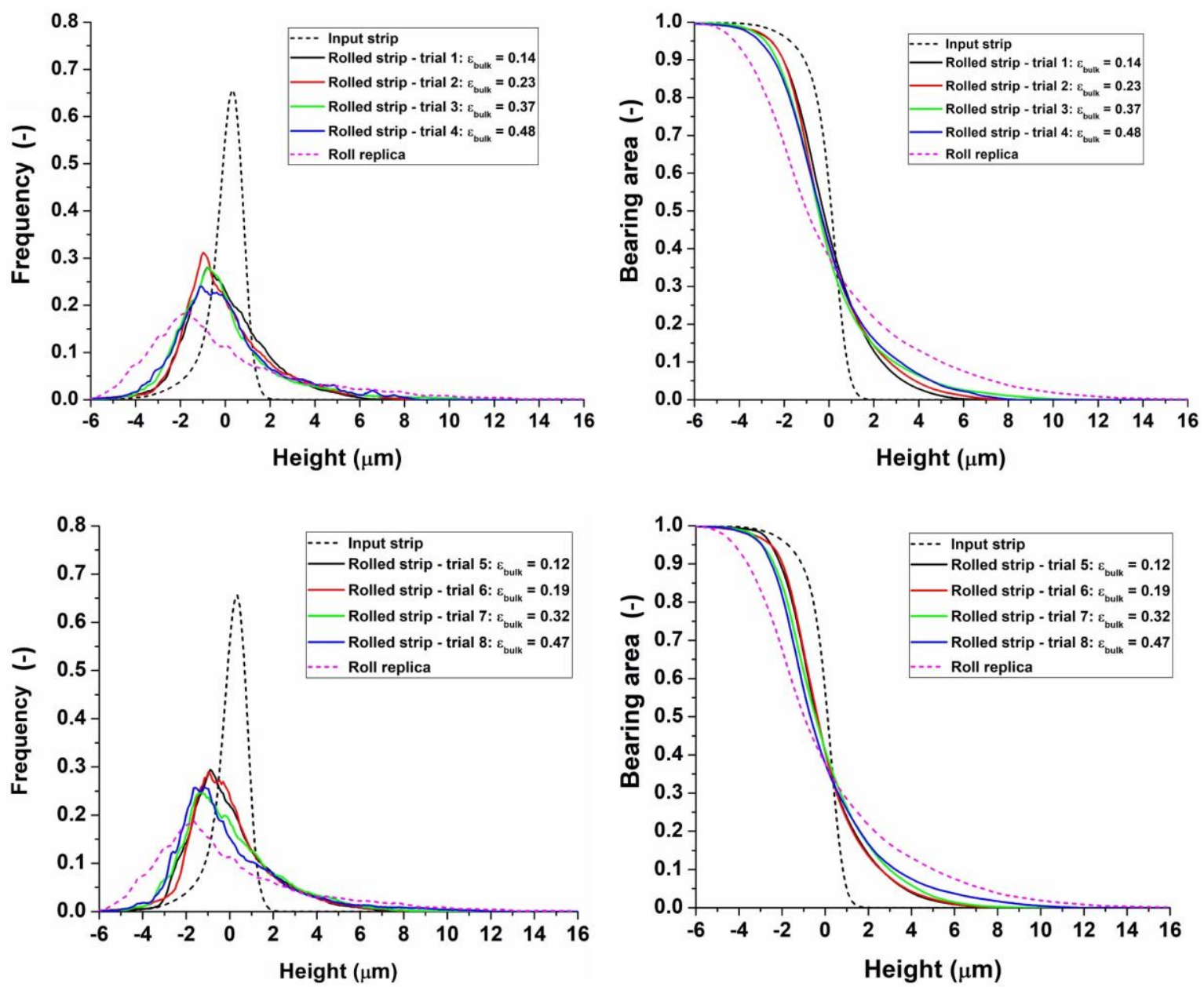

Figure 8: Normalized surface height distribution (L) and bearing area curve (R) of strips rolled with rough rolls (top) and smooth rolls (bottom), $\mathrm{Vr}=0.5 \mathrm{~m} / \mathrm{s}$.

\section{Discussion}

\subsection{Rolling parameters and asperity flattening}

Surface topography features greatly influence the functional properties of the strip, as well as the optical and coating properties of cold rolled products. Moreover, the different features of the surface topography of the strip can be used to obtain a qualitative impression about the lubrication regimes and friction coefficient in cold rolling process. The main features of the rolled strip under the current rolling conditions are the inverse imprints of the roll (grooves) and the micro-pits originated from the in-going strip. The relative proportions of the grooves and the pits affect the surface brightness of cold rolled strips. When the pits are dominant the surface may be qualified as "dull", while when the grooves are dominant it may be qualified as "bright". From the results of the present experiment (figure 6), the amount of pits decreases as the thickness reduction increases. This is due to more pits being flattened as a result of the increased roll pressure at high reductions. A similar decrease of micro-pits as the thickness reduction increases is reported by Kenmochi et al. [20] and Ahmed and Sutcliffe [21]. Additionally, Kenmochi et al. [20] showed that rough roll surface decreases the area ratio of the micro-pits. The influence of roll roughness on the area ratio of the micro-pits is not clearly evident from visual inspections in the current experiments. The effect of roll roughness in the first case was attributed to the squeezing out of the rolling oil from the roll bite through the grooves formed by the rough roll. This phenomenon is not applicable under the current rolling conditions, which were done in the boundary lubrication regime. 
The effect of rolling speed on micro-pits was not significant. This is however not surprising considering the rolling experiments were done in boundary lubricated conditions and it proves that there was no film build up in the roll bite. The rate at which micro-pits are eliminated in the roll bite depends mainly on the mechanics of asperity crushing. The role of the lubricant in retention of the micro-pits on the strip surface is small under the present rolling conditions.

The influence of rolling parameters on the flattening behavior of the strip asperities during rolling is reflected in the roughness, surface height distribution and bearing area curves. The roughness changes (figure $7(a, c)$ show that thickness reduction is the prime rolling parameter that determines the real contact area ratio. Under current rolling conditions, the rolling speed and roll and strip roughness only had a minor influence on the asperity flattening rate. Figure $7(b, d)$ show that the local contact pressure (i.e. the rolling force) changes substantially with rolling speed, which is related to the reduced friction. Nevertheless, the roughness evolution seems to be mainly dependent on the thickness reduction regardless of the rolling force. Therefore, considering the asperity flattening as a function of only the local contact pressure, ignoring the effect of bulk strain is not appropriate, as already indicated by many authors. The effect of rolling speed and strip and roll roughness is more pronounced for cold rolling processes operating under mixed or hydrodynamic lubrication. In these cases, they play a crucial role in the amount of rolling oil introduced into the roll bite and in the occurrence of oil-pits in the roll bite.

\subsection{Comparison of experimental results with the model}

The real contact area ratio for the rolling trials calculated using Wilson and Sheu [1] (equation 3) and Korzekwa et al. [6] (equation 6) contact models is provided in figure 9. The real contact area ratio increases with bulk strain, from approximately 0.5 at a thickness reduction of $10 \%$ to almost full contact $(\alpha \approx 0.9)$ at $40 \%$ thickness reduction. At any given bulk strain, as described in section 2.2, equation 6 gives lower real contact area ratio as compared to equation 3. Rolling trials done with a smooth roll (trials $1-4$ and 5 - 8) show higher real contact area ratio than rolling trials done using a rough roll (trials $9-12$ and $13-16$ ). This is due to the dependence of the real contact area ratio on asperity slope (section 2.2), which in turn is dependent on the combined roll-strip roughness. The combined r.m.s. roughness of the rough strip and smooth roll is $2.6 \mu \mathrm{m}$, while the combined roughness of the smooth strip and rough roll is $3.3 \mu \mathrm{m}$. For the rough strip and smooth roll combination the average asperity slope was $25^{\circ}$, while for smooth strip and rough roll combination it was $28^{\circ}$. Rolling speed does not have a significant influence on the real contact area ratio.
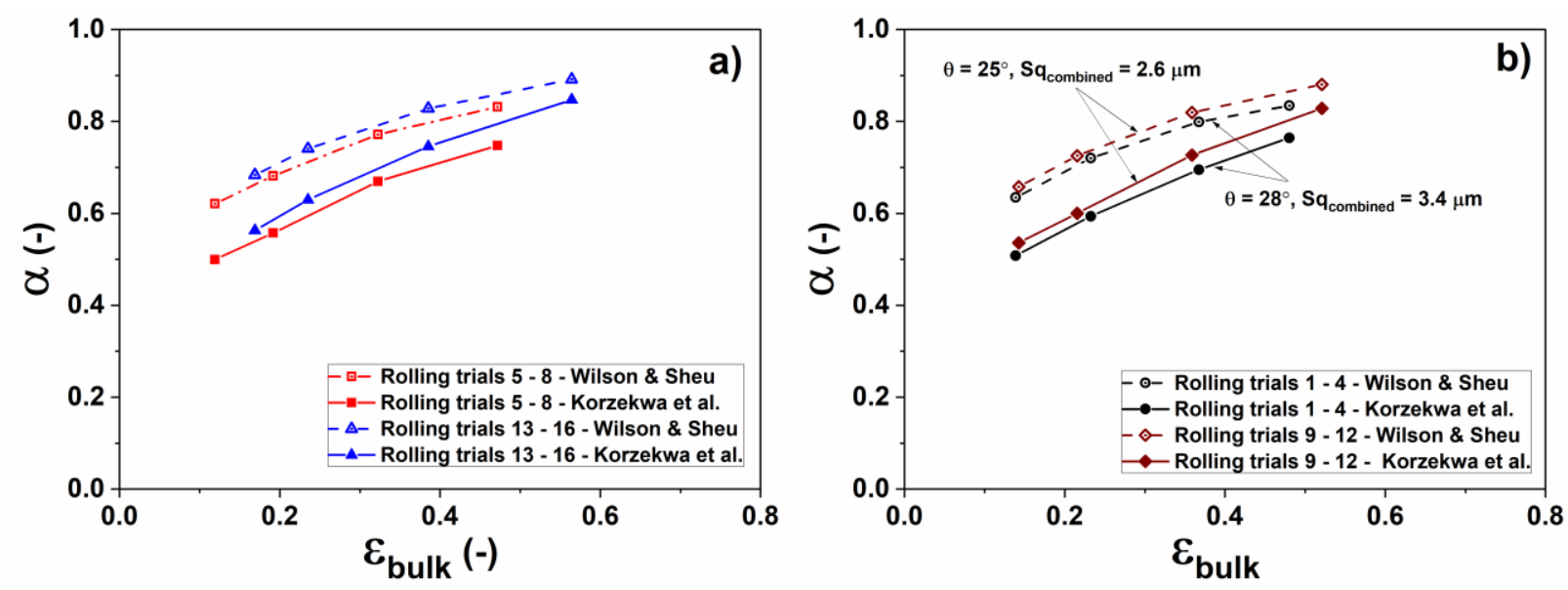

Figure 9. Real contact area ratio of rolling trials; (a) $\mathrm{Vr}=0.5 \mathrm{~m} / \mathrm{s}$ and (b) $\mathrm{Vr}=2 \mathrm{~m} / \mathrm{s}$.

A comparison of the measured and model predicted surface roughness is given in figure 10 . The measured surfaces and the surfaces predicted using Wilson and Sheu [1] semi-empirical relationship (equation 3) show good agreement for both rolling trials done with smooth and rough rolls. Equation 6 , on the other hand, gives a lower roughness values for strips rolled with a rough roll (figure $10(a, b)$ ) and higher 
roughness for strips rolled with a smooth roll (figure 10(c, d)). This indicates that equation 6 underestimates the real contact area ratio.
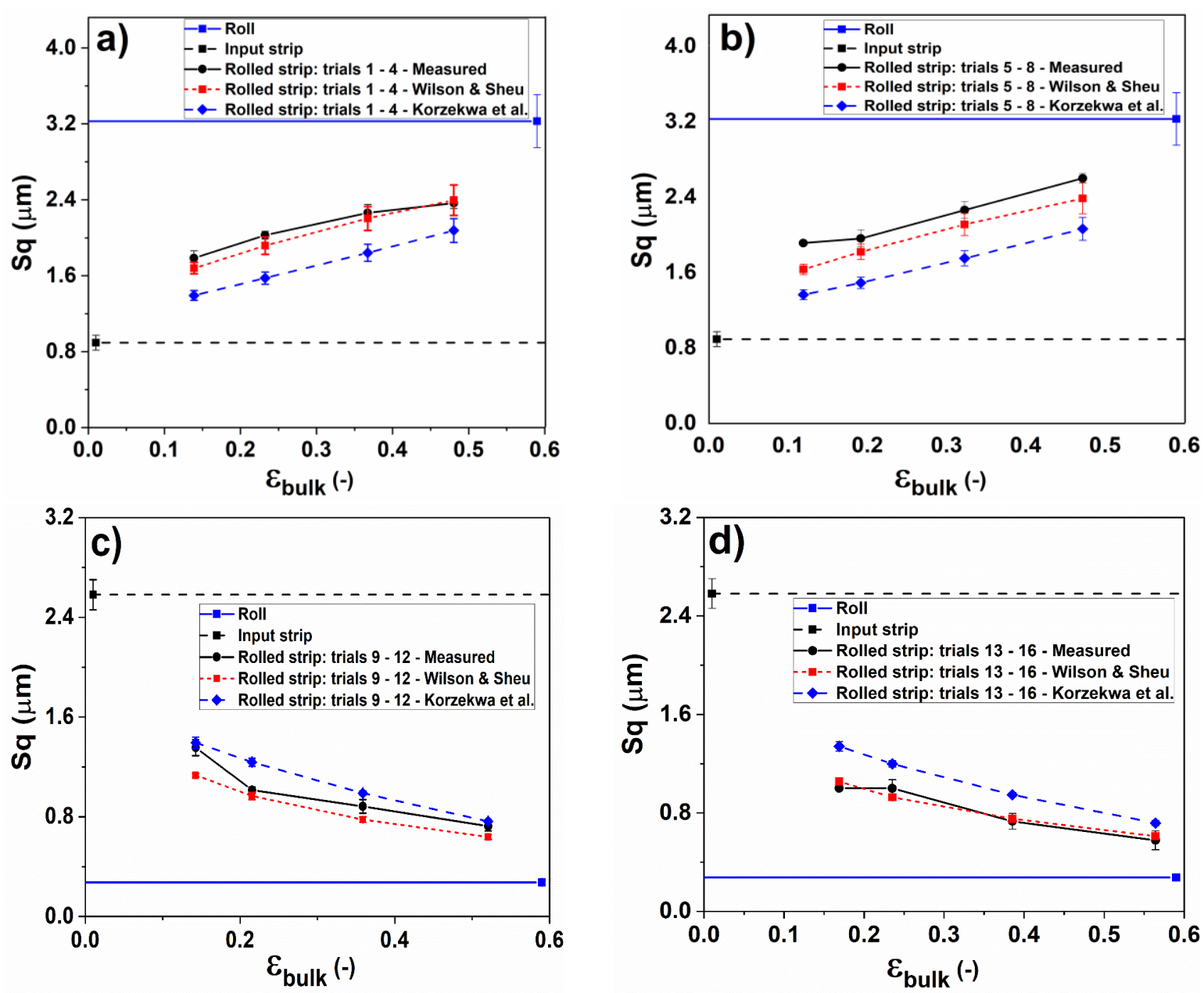

Figure 10: Roughness evolution of the strips rolled with $(a, b)$ rough rolls and $(c, d)$ smooth rolls, Measured vs Model; $(a, c) V r=0.5 \mathrm{~m} / \mathrm{s}$ and $(b, d) V r=2 \mathrm{~m} / \mathrm{s}$.

As shown in figure 10, the measured surfaces and the surfaces predicted using equation 3 show good agreement in terms of roughness. The surface height distribution and bearing area curve comparison of measured surfaces and those predicted using this equation are given in figure 11. For strips rolled with a smooth roll, the surface height distribution and the bearing area curve of the model results and measurements are in good agreement. Although the model corresponds in terms of Sq with the experiments, strips rolled with a rough roll show a different behavior in terms of surface height distribution and bearing area curve as compared to the surfaces predicted using the contact model. The measured surfaces have spiky ridges while the model predicts surfaces that have plateaus. This is reflected by the long tail of the surface height distribution of the measured surfaces. The main cause of this difference is the non-uniform rise of non-contacting valleys. A comparison of the surface texture of the measured and model predicted rolled strips is provided in figure 12 which corroborates the statistical analysis. 

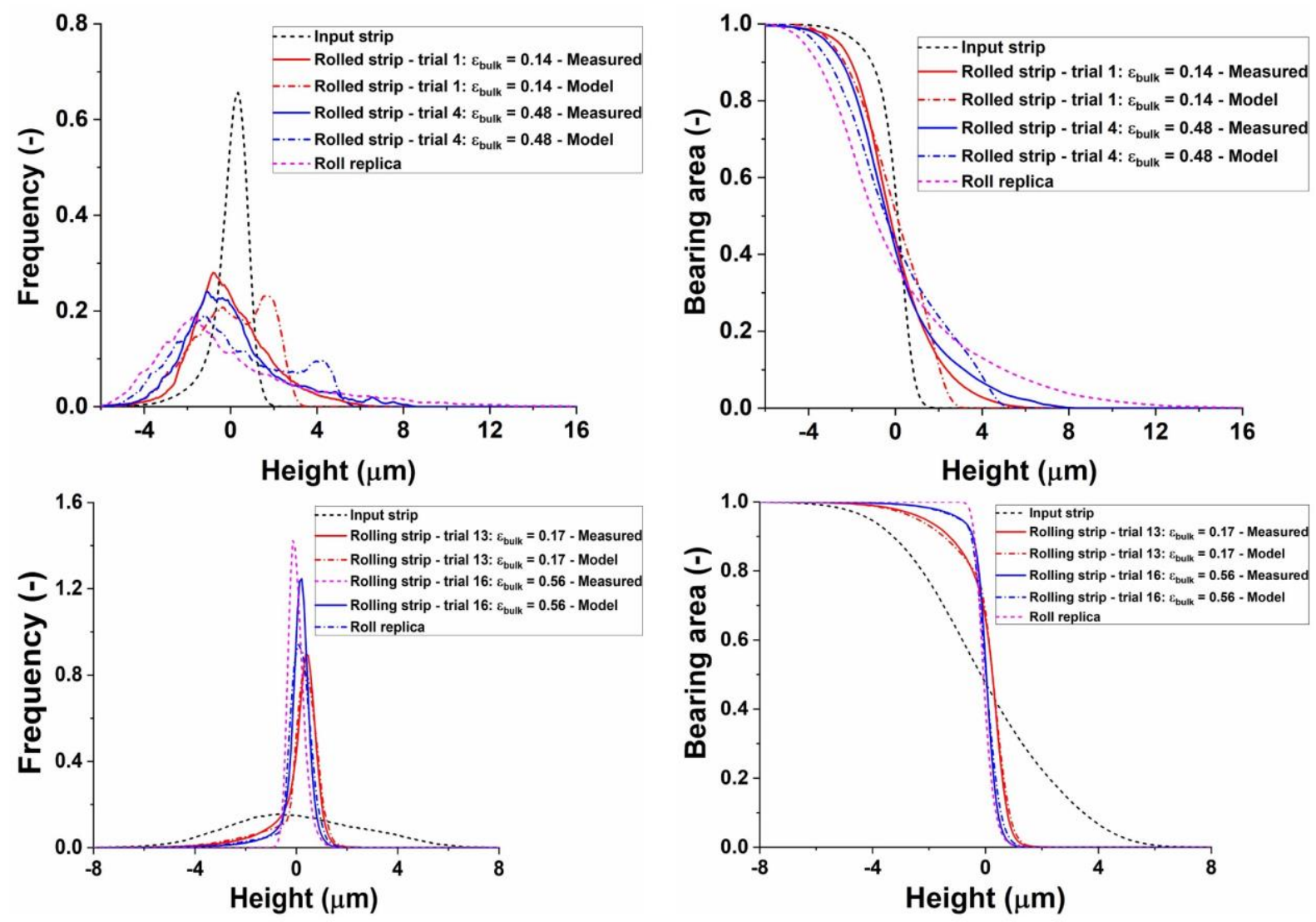

Figure 11: Normalized surface height distribution (L) and bearing area curve (R) of strips rolled using rough rolls (top) and smooth rolls (bottom), Measured vs Model.

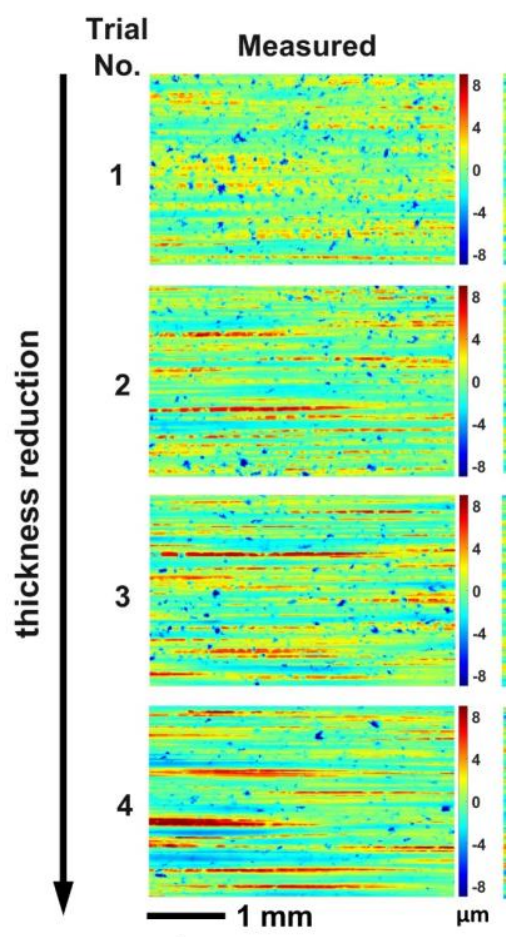

a)

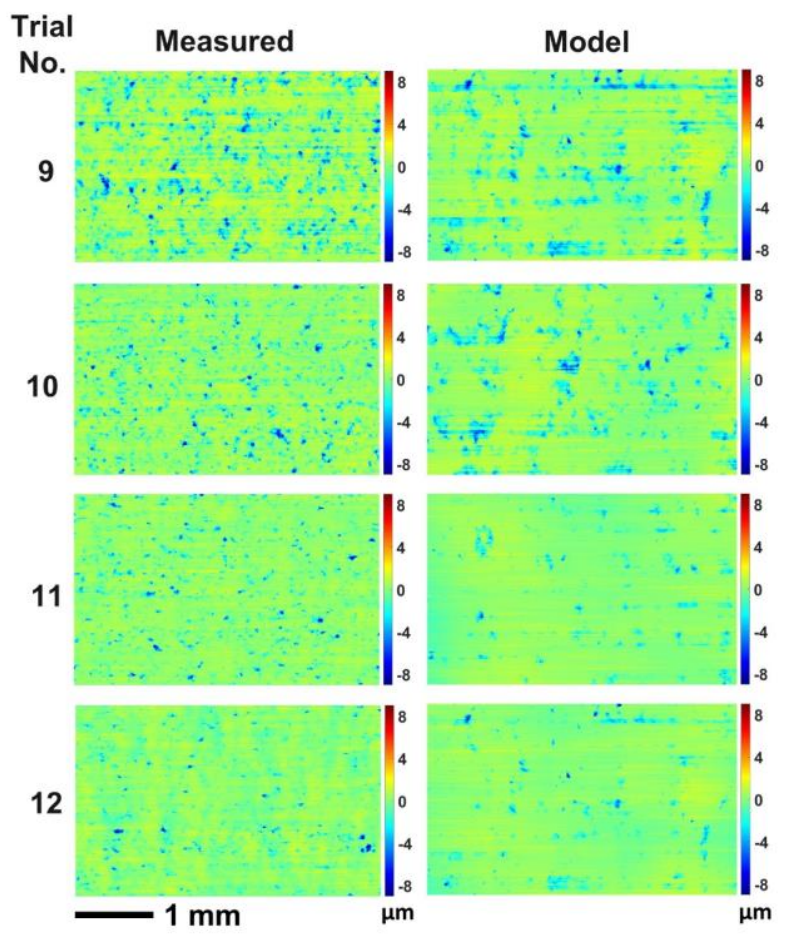

b)

Figure 12: Comparison of measured and model predicted surface topography of rolled strips at rolling speed of $0.5 \mathrm{~m} / \mathrm{s}$; (a) rolled with rough rolls and (b) rolled with smooth rolls. 


\subsection{Uniform rise hypothesis in predicting surface finish}

The uniform rise hypothesis was employed to predict the surface finish of rolled strips. For strips rolled with smooth roll, this assumption gives good estimation of roughness and surface height distribution (figures 10 and 11). However, the surface height distribution of strips rolled with rough rolls is notably different from the height distribution predicted with the uniform rise hypothesis. The measured surfaces had spiky ridges while the model predicted surfaces with plateaus (figure 11). The main cause of this difference is the non-uniform rise of non-contacting valleys due to inhomogeneous deformation field at the contact interface. Elastic recovery of the pressed asperities may also have a role. As the strip deforms in the roll bite, the strip material flows to conform to the roll surface topography. This flow of strip material at the contact interface is a complex, dynamic, asperity interaction process. There is interaction between neighboring contacting asperities and the local deformation field depends on the exact surface topography of the roll and the strip at the contact spot. Considering all these factors, it is very difficult to describe the non-uniform rise of valleys in a simple model.

In summary, a simplistic uniform rise model can provide a very quick way to anticipate the rolled strip surface finish during cold rolling processes. Also, it can be extended for rolling processes operating in mixed-lubrication and the effect of sliding (friction) can be included. The limitations of the model are: it cannot predict (a) the pits that can possibly form during rolling from surface fracture, (b) asperity persistence phenomena described by Childs [22], and (c) the micro scratches due to ploughing. Since cold rolling is typically done in lubricated condition and low forward slip, the ploughing effect on the texture of the strip is expected to be small.

\section{Conclusion}

An experimental investigation on the accuracy of the commonly used contact models for cold rolling processes to predict the surface finish of cold rolled strips has been conducted. The rolling trials were done under boundary lubricated condition.

- Thickness reduction was observed to be the prime rolling parameter that determines the real contact area ratio and surface finish of cold rolled strips.

- Rolling speed had little influence on the surface finish of the rolled strip under the current rolling conditions.

- The strip/roll roughness influences the real contact area by changing the asperity slope.

- The proposed deterministic asperity slope calculation combined with Wilson and Sheu [1] upper bound model and uniform rise hypothesis gave a good estimation of the surface finish of the cold rolled strips.

- The uniform rise hypothesis was observed to over-simplify the asperity interaction, especially for strips rolled with a rough roll.

- This simple approach can provide a very quick way to predict the surface finish of cold rolled strip, knowing roll and strip topographies, thickness reduction, lubrication condition, and strip material property.

- It can be used as a design module to predict the surface finish of the rolled product in parallel to other rolling models.

\section{Acknowledgements}

This research was carried out under project number F41.1.14551 in the framework of the Partnership Program of the Materials innovation institute M2i (www.m2i.nl) and the Foundation of Fundamental Research on Matter (FOM) (www.fom.nl), which is part of the Netherlands Organization for Scientific Research (www.nwo.nl). 


\section{References}

[1] Wilson WRD, Sheu S. Real area of contact and boundary friction in metal forming. Int J Mech Sci 1988;30:475-89. doi:10.1016/0020-7403(88)90002-1.

[2] Sutcliffe MPF. Surface asperity deformation in metal forming processes. Int J Mech Sci 1988;30:84768. doi:10.1016/0020-7403(88)90010-0.

[3] Kimura Y, Childs THC. Surface asperity deformation under bulk plastic straining conditions. Int J Mech Sci 1999;41:283-307. doi:10.1016/S0020-7403(98)00051-4.

[4] Makinouchi A, Ike H, Murakawa M, Koga N. A finite element analysis of flattening of surface asperities by perfectly lubricated rigid dies in metal working processes. Wear 1988;128:109-22. doi:10.1016/0043-1648(88)90178-0.

[5] Ike H, Makinouchi A. Effect of lateral tension and compression on plane strain flattening processes of surface asperities lying over a plastically deformable bulk. Wear 1990;140:17-38. doi:10.1016/0043-1648(90)90119-U.

[6] Korzekwa DA, Dawson PR, Wilson WRD. Surface asperity deformation during sheet forming. Int J Mech Sci 1992;34:521-39. doi:10.1016/0020-7403(92)90028-F.

[7] Nielsen CV, Martins PAF, Bay N. Modelling of real area of contact between tool and workpiece in metal forming processes including the influence of subsurface deformation. CIRP Ann 2016;65:2614. doi:10.1016/J.CIRP.2016.04.126.

[8] Wilson WRD. Friction models for metal forming in the boundary lubrication regime. J Eng Mater Technol 1991;113:60. doi:10.1115/1.2903383.

[9] Sutcliffe MPF. Flattening of random rough surfaces in metal-forming processes. J Tribol 1999;121:433. doi:10.1115/1.2834086.

[10] Legrand N, Counhaye C, Oliveira D. Roughness transfer model for cold and temper rolling processes. 10th Int. Roll. Conf., Graz: 2016.

[11] Smits RPJM, Smeulders B. Surface microstructure of normal and defected cold rolled sheet, investigated by SEM/EDS and surface profilometry. vol. 13. 2016.

[12] Pullen J, Williamson JBP. On the plastic contact of rough surfaces. Proc R Soc A Math Phys Eng Sci 1972;327:159-73. doi:10.1098/rspa.1972.0038.

[13] Tabor D. The hardness of metals. Clarendon Press; 1951.

[14] de Rooij MB, van der Linde G, Schipper DJ. Modelling material transfer on a single asperity scale. Wear 2013;307:198-208. doi:10.1016/j.wear.2013.09.006.

[15] Ma X, de Rooij MB, Schipper DJ. A load dependent friction model for fully plastic contact conditions. Wear 2010;269:790-6. doi:10.1016/J.WEAR.2010.08.005.

[16] van Liempt P. Workhardening and substructural geometry of metals. J Mater Process Technol 1994;45:459-64. doi:10.1016/0924-0136(94)90382-4.

[17] Hitchcock JH. Elastic deformation of rolls during cold rolling. ASME Rep Spec Res Comm Roll Neck Bear 1935;33.

[18] Atala HF, Rowe GW. Surface roughness changes during rolling. Wear 1975;32:249-68. doi:10.1016/0043-1648(75)90272-0.

[19] Ahmed R, Sutcliffe MPF. Identification of surface features on cold-rolled stainless steel strip. Wear 2000;244:60-70. doi:10.1016/S0043-1648(00)00442-7.

[20] Kenmochi K, Yarita I, Abe H, Fukuhara A, Komatu T, Kaito H. Effect of micro-defects on the surface 
brightness of cold-rolled stainless-steel strip. J Mater Process Technol 1997;69:106-11. doi:10.1016/S0924-0136(97)00003-4.

[21] Ahmed R, Sutcliffe MPF. An experimental investigation of surface pit evolution during cold-rolling or drawing of stainless steel strip. J Tribol 2001;123:1. doi:10.1115/1.1327580.

[22] Childs THC. The persistence of roughness between surfaces in static contact. Proc R Soc A Math Phys Eng Sci 1977;353:35-53. doi:10.1098/rspa.1977.0020. 



\section{Paper B}

Mekicha MA, Mishra T, de Rooij MB, Matthews DTA, Jacobs L, Schipper DJ. Study of wear particles formation at single asperity contact: An experimental and numerical approach. Wear 2021;470-

471:203664. https://doi.org/10.1016/j.wear.2021.203644. 



\title{
Study of wear particles formation at single asperity contact: An experimental and numerical approach
}

\author{
M.A. Mekicha ${ }^{a}$, M. B. de Rooij ${ }^{a}$, T.Mishra ${ }^{a}$, D.T.A. Matthews ${ }^{a}$, L. Jacobs ${ }^{a, b}$, D. J. Schipper ${ }^{a}$ \\ a Department of Mechanics of Solids, Surfaces \& Systems (MS ${ }^{3}$ ), Faculty of Engineering Technology, University of Twente, \\ Enschede, The Netherlands. \\ ${ }^{\mathrm{b}}$ Tata Steel, Research \& Development, IJmuiden, the Netherlands.
}

\begin{abstract}
Wear particles generated due to the relative sliding of the roll and the sheet metal in the roll bite are one of the main factors that contaminate the surface of a cold rolled steel sheet. The details of the wear mechanisms in the contact of individual roll-sheet asperities define the total amount of wear particles generated. In this paper, a micro-mechanical experimental approach is coupled with material point method (MPM) scratch simulations to study the friction and wear behavior of a single roll asperity sliding through a sheet metal. Micro-tribology experiments in the form of single asperity scratch testing showed that ploughing is the dominant wear mechanism in lubricated conditions, while wedge forming was the main wear mechanism in the absence of lubricant. The beneficial influence of chrome plating the rolls on wear particles formation is found to stem from its interaction with the lubricant as the same influence was not observed in non-lubricated test conditions. MPM single asperity simulations revealed that almost all the frictional resistance arises from deforming the substrate in the case of an interfacial shear strength corresponding to the lubricated contact. In contrast, MPM showed that, in unlubricated sliding, the frictional resistance is primarily due to shearing of the adhesion junction and tearing the deforming body. Furthermore, using the degree of wear of the scratch experiments as a benchmark, a critical plastic strain needed to produce wear particles was found to be between 3 to 4 for the investigated interstitial-free steel.
\end{abstract}

\section{Keywords:}

Wear particles; Material point method; Scratch experiments; Degree of wear; Critical plastic strain

\section{Introduction}

Surface cleanliness is an important measure of the quality of a cold rolled sheet metal, particularly in applications such as outer body parts of the automotive industry, where high requirements are put on the surface quality. The generation of wear particles (also known as iron fines) is one of the major factors that contaminate the sheet surface and cause degradation of its surface quality. Wear particles are generated during cold rolling due to the relative sliding between the roll and the sheet in the roll bite. Wear particles are mainly generated from the sheet in the rolling process [1,2]. In most rolling processes, the sheet is much softer than the roll. Some of the wear particles are removed by the coolant/emulsion used in the rolling process. However, those that remain on the sheet surface can cause problems in downstream processes such as annealing, galvanizing and forming. In addition, they can adversely affect filtration processes. It is therefore of paramount importance to reduce wear particles generation during cold rolling operations. To achieve this and in order to optimally tailor the surface quality of cold rolled sheet metals, a detailed understanding of the underlying micro-scale physical damage mechanisms at the roll-sheet metal interface is necessary.

The macro-scale rolling process parameters together with the surface properties of the roll and the sheet define the contact conditions at micro-scale. Micro-scale is where the actual wear particles generation takes place. At micro-scale, the hard roll asperities indent and plough through the soft sheet surface. This may lead to strip wear and subsequently the generation of wear particles, depending on the wear regime [3]. A study of the contact between a single hard roll asperity and a flat soft sheet is, therefore, essential in order to obtain a complete insight on the macroscale wear properties of the cold rolling tribological 
system. This can be combined with rolling process parameters, material properties and roughness properties of both the roll and the strip to tailor the rolling process with respect to surface quality. The aim of the current work is, hence, to study, experimentally and numerically, the wear behavior of a single roll asperity sliding against a flat soft sheet.

Scratch experiments are commonly used to investigate the friction and wear phenomena at single asperity interactions. In scratch experiments, a sharp tip moves across the surface under a controlled load and speed. However, the amount of information that can be obtained from such scratch experiments is limited. One of the important qualities which is difficult to determine experimentally but can be easily deduced from computer simulations is the effect of asperity geometry on wear. Numerical modelling offers a fast, predictive capability to study the influence of several parameters such as asperity geometry, sliding speed and/or temperature on the wear behavior of single asperity contacts. This cannot be easily realized in the experiments. Nevertheless, modelling single-asperity contacts that involve the formation of wear particles poses many challenges.

Analytical models are attractive due to their simplicity. However, they have several limitations. No complete analytical model of the scratching of a flat surface by an indenter has yet been developed due to the geometric complexities inherent in three-dimensional plasticity solutions. Analytical models simplify the geometry and material behavior to make it easy for analysis. Many of the analytical models involve a simplified two dimensional analysis [4]. Also, wear of brittle materials, which might involve brittle fracture, is typically not modelled in these plasticity-based models. Furthermore, modelling the generation of the wear track includes displacement and removal of material in three dimensions (3D), so modelling this process will require modelling to be done in three dimensions. Although some work has been done in this area, analytical models are complex and ultimately inadequate to capture the complex three-dimensional nature of abrasive wear [5].

In recent years, there have been attempts to develop a numerical model to study single-asperity wear, such as scratching simulations and formation of chips in grinding, machining and micro-milling. Several authors used a mesh-based finite element method (FEM) [6-11] and mesh-less continuum methods such as smooth particle hydrodynamics (SPH) $[12,13]$ and material point method (MPM) $[14,15]$ to simulate scratch experiments in three dimensions. Using mesh based techniques such as FEM has proved to be an unsuitable method for modelling wear as it involves large deformations and chip (wear particles) formation [11]. FE methods have extreme mesh distortion problems arising from large deformations in simulating abrasive wear that involves cutting. Although remeshing is possible, it leads to large computational overhead and convergence is not guaranteed. Particle based methods such as SPH have an advantage over mesh-based methods, in particular that arbitrary large deformation can be handled easily with no need for remeshing. However, classical SPH suffers from tensile instability [16]. Hence, if traditional SPH is used to simulate solids, a high and physically incorrect artificial viscosity is required to damp strong oscillatory modes and stabilize the system. A total Lagrangian SPH (TLSPH) addresses the rank deficiency and tensile instability problems by the use of artificial particle velocity damping and a hourglass control scheme similar to FEM, as described by Ganzenmüller [17]. Nevertheless, TLSPH introduces another constraint, because it utilizes a constant reference undeformed configuration to calculate the gradients and perform integration of stresses. This in turn limits the magnitude of deformation which can be simulated, as the difference between the reference configuration and the current configuration must not become too large. Although updates of the reference configuration can be performed, this approach is computationally expensive.

Recently, the material point method has been used to numerically study micro-machining processes [18] and single-asperity ploughing $[14,15,19]$. MPM can handle problems involving arbitrarily large deformations and material detachment such as abrasive wear and machining. Mishra et al. $[14,19]$ studied friction during the ploughing of a soft metallic sheet by a rigid indenter of spherical and elliptical geometries using MPM. They compared the numerical results in terms of depth of groove and friction coefficient with experiments and reported a good match between both the model and measured friction coefficients and wear depth. Leroch et al. [18] implemented MPM to model three-dimensional micro- 
milling considering both mechanical deformation and heat conduction. They studied the dependency of tool forces with uncut chips thickness and compared the MPM results with FEM simulations as well as the experimental data and found good agreements. In another recent study, Varga et al. [15] performed MPM simulations of scratch experiments at high temperatures to assess the wear mechanisms and the extent of wear of a hot rolled steel sliding against a rigid wall during transporting and compared their results with experiments. They reported a good agreement between the experiments and the simulations.

MPM combines both a background mesh and meshless concepts and can accurately model solid plastic flow and fluid behavior. It uses particles, which contain all history dependent information such as stress, strain and momentum. Furthermore, in contrast with the traditional particle methods such as SPH, it uses an auxiliary background grid to compute stresses and strain rates. Information between the particles and the grids is exchanged by using relatively simple basis functions. MPM can be considered as a true particle method, because the background grid is used as a computational scratch pad and is deleted at the end of each time step. The state of the system is then advanced by moving the particles only. A detailed computation procedure of the MPM can be found elsewhere [18].

In this study, the mechanics determining the tribological behavior (wear) of a single-asperity sliding against a flat sheet has been investigated and compared experimentally and numerically. Single-asperity scratch experiments have been carried out for this purpose and the material point method has been implemented to numerically model the scratching process in three dimensions. The effect of lubrication and degree of penetration on the degree of wear has been studied. Moreover, the correlation between tribological parameters, friction coefficient and wear mechanisms has been investigated.

\section{Materials and methods}

\subsection{Experimental procedure}

Scratch experiments have been carried out to simulate a single roll asperity sliding on a flat sheet. The experiments were performed using conical indenters with a hemispherical tip, which represent a roll asperity, sliding on a polished flat sheet surface. The indenters are made of a medium-alloyed cold work tool steel (Uddeholm Rigor $^{\circledR}$ ) that has similar composition as the commonly used work roll material. The radius of the hemispherical tip of the indenters is $225 \mu \mathrm{m}$. A hot rolled and pickled Titanium-stabilized interstitial-free (Ti-IF) steel strip ( $50 \mathrm{~mm} \times 50 \mathrm{~mm} \times 3 \mathrm{~mm}$ ) was used as a substrate. This steel grade is extensively used in exterior automotive body part applications and has been observed to be critical with respect to wear particles formation. The strip samples and the tip of the indenters were polished to a mirror like surface finish $(\mathrm{Sq}<20 \mathrm{~nm})$. The tips of the indenters were examined under microscopy at high magnifications to ensure there are no irregularities on the surface. The experiments were conducted under lubricated and dry conditions. A palm-based fully formulated industrial cold rolling oil was used for the lubricated scratch experiments.

The experiments were conducted using a multi-purpose tribometer from Bruker (UMT Tribolab). The experiments were performed using a constant normal load, ranging between 2 and $20 \mathrm{~N}$. The strip samples and the indenters were degreased and cleaned in isopropanol prior to the experiments. For the lubricated experiments, a film of $1 \mathrm{~g} / \mathrm{m}^{2}$ oil was applied on the strip surface. The amount of oil was determined by measuring the weight of the strip sample before and after applying the lubricant. The load was applied by moving the indenter downwards until the desired scratch load is reached. Once the desired load is achieved, the indenter is moved horizontally in the scratching direction at a constant speed $(1 \mathrm{~mm} / \mathrm{s})$ under load-controlled conditions. The length of the scratches is $15 \mathrm{~mm}$.

In order to investigate the influence of interfacial shear strength at the contact interface on the transition of wear modes and the rate of material removal, the scratch experiments were carried out in four different distinct contact conditions: (i) using uncoated indenter in dry condition, (ii) using uncoated indenter in lubricated condition, (iii) using hard chrome plated indenter in dry condition, and (iv) using hard chrome plated indenter in lubricated condition. A total of 10 scratches (i.e. at $2 \mathrm{~N}, 4 \mathrm{~N} \ldots, 20 \mathrm{~N}$ ) were made for each contact condition. The experiments were performed at room temperature. The normal and tangential 
forces were recorded during the experiments. Afterwards, the tips of the indenters were examined by microscopy to check for material transfer and damage. The wear grooves of the scratches were analyzed using a non-contact three-dimensional optical profiler (S neox 3D Optical Profiler from Sensofar) and an optical microscopy (Keyence VHX-5000). The three-dimensional (3D) height profile of the scratches was measured using confocal microscopy. The wear tracks were aligned so that the scratch direction becomes parallel to the Cartesian coordinate using a Canny edge detection method and a Hough transform in Matlab. Next, tilt correction and shifting the reference plane to $z=0$ was carried out by employing the flat section (away from the wear track) which is unaffected by the scratch experiments as a reference. The average two-dimensional (2D) wear groove profile for each scratch was determined by calculating the average profile of the middle $12 \mathrm{~mm}$ section of the wear track. The uneven portion at the beginning and the end of the scratches was not used to calculate the average 2D wear profile. The volume of material removed as wear particles was evaluated by calculating the degree of abrasive wear $\beta$. The degree of abrasive wear, which is a measure of the amount of material removed as a result of the abrasive wear, is defined as the ratio of groove area $\left(A_{g}\right)$ to shoulder area $\left(A_{s}\right)$. This is schematically illustrated in figure 1 . $d_{w}$ is calculated as follows:

$$
d_{w}=\left(A_{g}-A_{s}\right) / A_{g}
$$

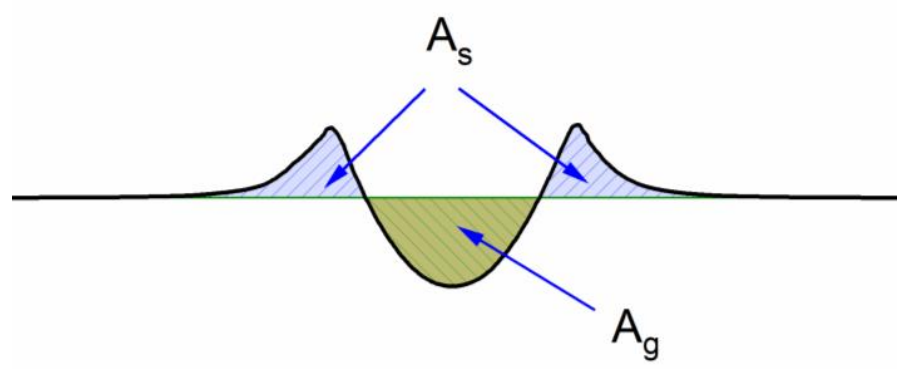

Figure 1: Illustration of degree of wear calculation.

\subsection{Computational method}

The MPM simulations were implemented using an open source particle simulation code LAMMPS and the smooth mach dynamics package by Ganzenmüller [20], which was later extended by Mishra et al. [14] to incorporate the interfacial shear strength at the indenter-substrate interface and a dislocation based material model for the substrate material deformation. The MPM results were analyzed using OVITO, a visualizing software [21]. The scratches were simulated using a hemispherical rigid indenter, with the same radius as the experiments $(225 \mu \mathrm{m})$, sliding on a deforming substrate. Figure 2 displays a snapshot of the simulation setup. The deforming substrate is created by placing particles in a half cylindrical block with a diameter of $0.9 \mathrm{~mm}$ and a length of $1.8 \mathrm{~mm}$. The outer most particles of the curved side of the cylinder are fixed in all directions. A periodic boundary condition is applied in the sliding direction. The indenter is modelled and imported as an STL file, which consists of a triangular mesh. The diameter of particles (deforming substrate) and the mesh size of the indenter was set to $5 \mu \mathrm{m}$. The interaction between the indenter surface and the deforming substrate is assumed to be purely repulsive and is given by the Hertz contact theory. A Coulomb friction is assumed at the contact interface. The length of the scratches was set to $1.4 \mathrm{~mm}$ to reduce the computation time, in contrast to $15 \mathrm{~mm}$ in the experiments. The simulations were executed under load-controlled conditions using similar constant normal loads as the scratch experiments. The indenter is moved down to the substrate until the desired load is reached and then moved in the sliding direction at a constant speed of $0.5 \mathrm{~m} / \mathrm{s}$. Since the experiments were performed at room temperature, the temperature was set to $20^{\circ} \mathrm{C}$ in the simulations. 


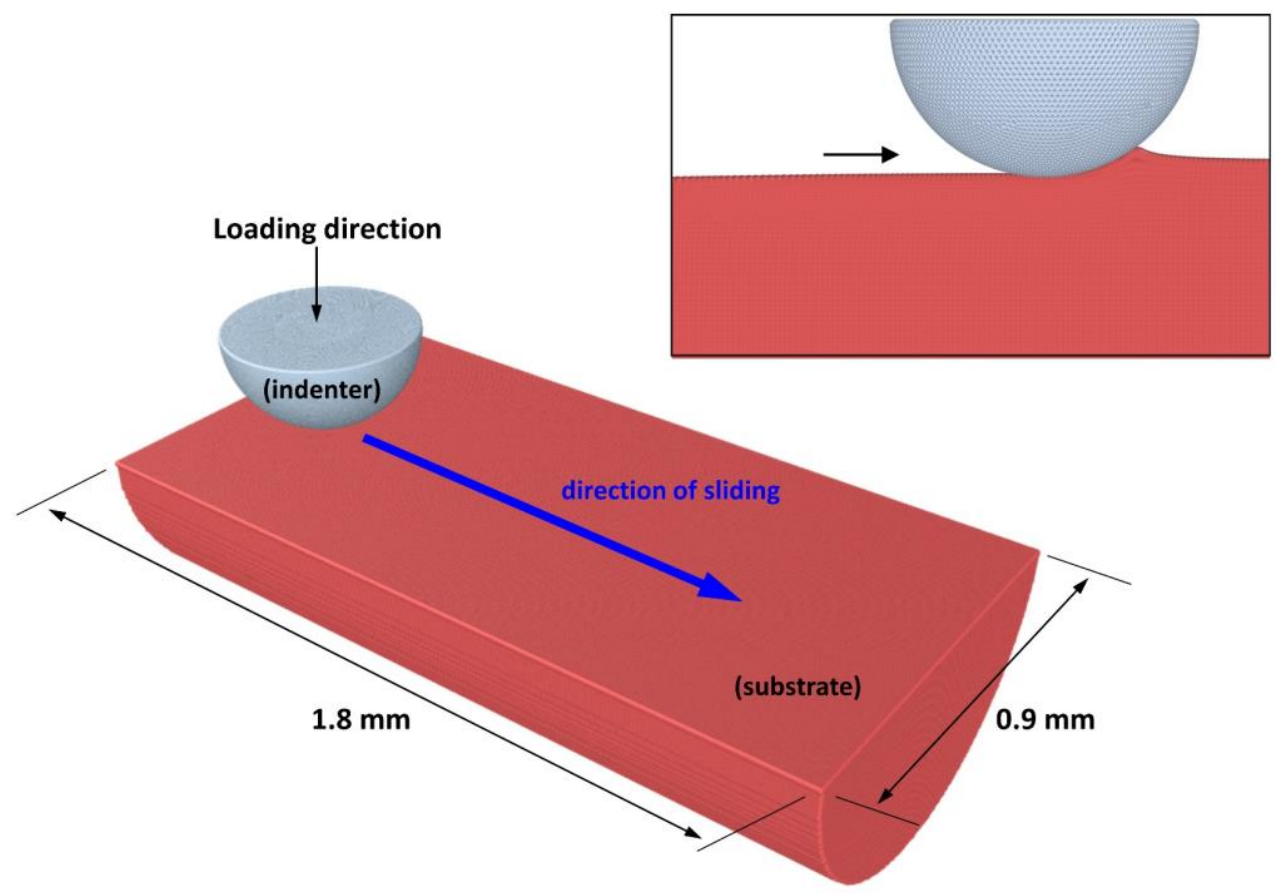

Figure 2: Snapshot of the MPM scratch simulation setup.

The indenter, which represents a roll asperity, is assumed to be rigid as the hardness of the rolls is generally much harder than the sheet material. The deforming substrate represents the sheet metal. A modified Bergstrom-van Liempt equation $[22,23]$ is used as a constitutive equation for the deforming substrate. It describes the von Mises flow stress $\sigma_{y}$ as a function of $\operatorname{strain} \epsilon$, strain rate $\dot{\epsilon}$ and temperature $T$ as follows:

$$
\sigma_{y}=\sigma_{1}+\alpha G b\left\{\frac{U}{\Omega}\left(1-e^{-\Omega \epsilon}\right)+\rho_{0} e^{-\Omega \epsilon}\right\}^{1 / 2}+\sigma_{0}^{*}\left\{1+\frac{k T}{\Delta G_{0}} \ln \left(\frac{\dot{\epsilon}}{\dot{\epsilon}_{0}}\right)\right\}^{p}
$$

where $\sigma_{1}$ is the initial static stress, $\alpha$ is a crystallographic constant, $\mathrm{G}$ is the elastic shear modulus, $b$ is the burgersvector, $U$ is the combined rate of annihilation and immobilization of mobile dislocations (measure of immobility), $\Omega$ is the remobilization probability, $\rho_{0}$ is the density of immobile dislocations, $\sigma_{0}^{*}$ is the maximum dynamic stress, $k$ is the Boltzmann's constant, $\Delta G_{0}$ is the activation energy, $\dot{\epsilon}_{0}$ is the initial strain rate and $p$ is the dynamic stress power. The material parameters of the Ti-IF steel used in the current study are provided in table 1.

Table 1: Bergstrom-van Liempt material parameters for the investigated Ti-IF steel.

\begin{tabular}{|c|l|c|l|}
\hline Parameter & Value & Parameter & Value \\
\hline$\sigma_{1}$ & $58.52 \mathrm{MPa}$ & $\sigma_{0}^{*}$ & $1229 \mathrm{MPa}$ \\
\hline$\alpha$ & 0.82 & $\rho_{0}$ & $1.0 \times 10^{12} / \mathrm{mm}^{2}$ \\
\hline$G$ & $7.9 \times 10^{4} \mathrm{MPa}$ & $k$ & $8.62 \times 10^{-5} \mathrm{eV}$ \\
\hline$b$ & $2.48 \times 10^{-10}$ & $\Delta G_{0}$ & 0.97 \\
\hline$U$ & $2.04 \times 10^{7}$ & $\dot{\epsilon}_{0}$ & $4.63 \times 10^{10} \mathrm{~s}^{-1}$ \\
\hline$\Omega$ & 7.5 & $p$ & 3.38 \\
\hline
\end{tabular}

One parameter which is varied in the simulations, although the actual value is not precisely known in the experiments, is the shear strength of the contact interface. What is measured in the scratch experiments is the overall frictional force, which is composed of the shearing resistance of the interface and the resistance to the plastic deformation. Ideally, the shear strength of the contact interface should be measured in a separate experiment and used as an input for the scratch simulations. However, measuring the shear strength of the contacting interface is very challenging. The plastic deformation component of friction should be eliminated to experimentally characterize the interfacial shear strength. This requires preparing molecularly smooth surfaces. For lubricated contacts, the boundary shear strength is typically measured by sliding a smooth sphere on flat, cylinder on flat, or orthogonal contacting cylinders using 
flamed glass or mica sheet substrates [24-26]. In the current work, a different approach was chosen. The interfacial shear strength was estimated by running a series of simulations with several Coulomb friction $(\mu)$ values $(0,0.2,0.4,0.6$ and 0.8$)$ for the different loads. The shear strength of the interface at that load is then mapped by taking the $\mu$ value which gives the same overall frictional force as the corresponding experiment. Besides, varying the interfacial shear strength in the simulations (by varying $\mu$ ) provides a detailed insight of its influence on wear mechanisms. A summary of the scratch experiment and simulation parameters is provided in table 2 .

Table 2: Scratch experiment and MPM simulation parameters.

\begin{tabular}{|l|l|}
\hline Parameter & Value \\
\hline Indenter radius & $225 \mu \mathrm{m}$ \\
\hline Sliding speed & $1 \mathrm{~mm} / \mathrm{s}$ (experiments), $0.5 \mathrm{~m} / \mathrm{s}$ (MPM simulations) \\
\hline Normal load & $2,4,6,8,10,12,14,16,18,20 \mathrm{~N}$ \\
\hline $\begin{array}{l}\text { Coulomb friction used in } \\
\text { MPM simulations }\end{array}$ & $0.0,0.2,0.4,0.6,0.8$ \\
\hline Scratch length & $15 \mathrm{~mm}$ (experiments), $1.4 \mathrm{~mm}$ (MPM simulations) \\
\hline MPM particle size & $5 \mu \mathrm{m}$ \\
\hline
\end{tabular}

The average 2D scratch profile and the degree of wear of MPM simulations were calculated the same way as the experiments. Further, the average steady state friction forces were calculated by excluding the running in period. The friction coefficient, wear groove depth and degree of wear of MPM simulations were compared with the experimental results.

\section{Results and discussion}

\subsection{Scratch experiments}

\subsubsection{Friction coefficient}

The average steady state apparent friction coefficient of the scratch experiments is plotted figure 3 . The friction curves of the individual scratches can be found in figure $S 1$ of the supplementary document. The apparent coefficient of friction $\left(\mu_{a p}\right)$ is defined as the ratio of the measured tangential force to the applied normal force. The $\mu_{a p}$ value shows dependence on the normal load. $\mu_{a p}$ increases slightly with the increase of the normal load for the lubricated scratch experiments. In contrast, in the dry scratch experiments, the friction resistance increases dramatically at low loads ( $8 \mathrm{~N}$ for the uncoated indenter and $6 \mathrm{~N}$ for the $\mathrm{Cr}$ plated indenter). This dramatic increase of friction coefficient can be related to the transition of the wear mechanism of the scratch experiments from ploughing to wedge forming [27]. The microscopic examination of the indenters after the scratch experiments (figure 4) and the morphology of the wear tracks (see figure 5 and figure S2) confirm the transition of the wear mechanism of the scratch experiments from ploughing to wedge forming. 


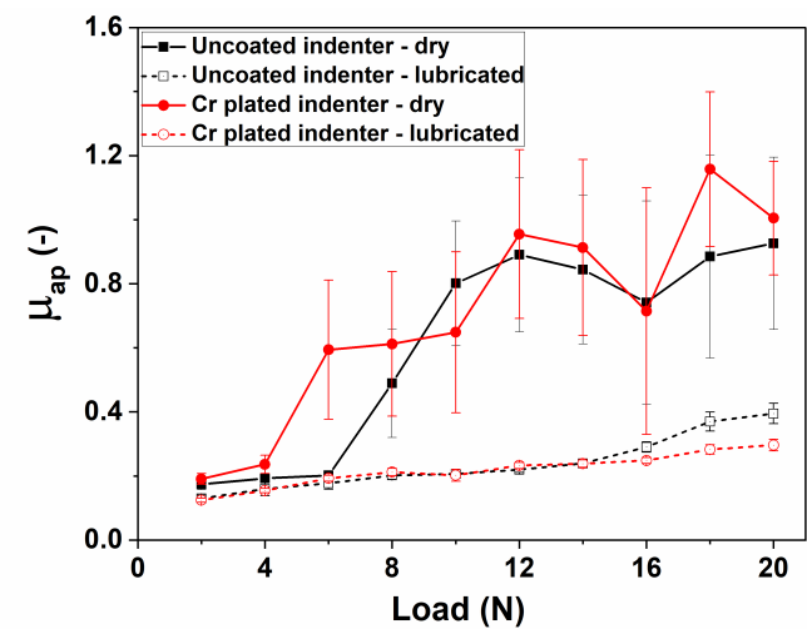

Figure 3: Average steady state apparent friction coefficient of the scratch experiments.

Different degrees of fluctuation in the friction curves were observed depending on the lubrication condition and the normal load (see also figure S1). The apparent friction coefficient is most stable in the lubricated scratch experiments and at very low loads of the dry experiments $(<6 \mathrm{~N})$. The friction curves exhibited a large fluctuation for the dry experiments at high loads. Although slight fluctuations are observed for the lubricated experiments at higher loads, the magnitude of fluctuation is much smaller than the dry ones. The scratch experiments performed using chrome coated indenters in the lubricated condition showed lower $\mu_{a p}$ values, particularly at higher loads (>16 N), than the equivalent scratches done using uncoated indenters. The opposite effect was observed for the dry scratch experiments, i.e. the experiments done using chrome coated indenters showed a higher average $\mu_{a p}$ and a transition to unstable friction at lower load $(6 \mathrm{~N})$ than the uncoated ones $(8 \mathrm{~N})$, see figure 3.

The total frictional resistance in the scratch experiments is made up of two components: (i) the adhesion component, which is the force needed to shear the boundary layer in lubricated contacts and/or the welded junctions formed by adhesion in dry contacts, and (ii) the ploughing component, which is the force needed to push waves of plastically deformed material ahead of the indenter $[4,27]$. The contribution of each component to the overall friction force depends on the lubrication condition, the geometry of the indenter, the degree of penetration and the bulk properties of the materials in contact. In frictionless contacts, the entire frictional resistance emanates from the deformation component. In the absence of deformation, the frictional force arises solely from the mechanical shear strength of the sliding interface. The presence or absence of a lubricant is theoretically expected to have little or no effect on the deformation component of the frictional resistance $[28,29]$. Another factor that affects the friction and wear behavior of the scratch experiments is the relative shear strength of the contact interface and the bulk shear strength of the deforming material. Two cases can happen depending on these values: (i) slip occurs at the interface when the interface shear strength is smaller than the shear strength of the softer counterpart, and (ii) shearing happens in the bulk of the softer counterpart when the interface shear strength is larger than the shear strength of the softer counterpart. Wear particles can form in case of the latter.

In the lubricated scratch experiments, a boundary layer prevents direct metal to metal contact and slip occurs at the contact interface. Hence, the friction resistance is predominantly due to the deformation component. As the normal load is increased, the indentation depth, and consequently, the deformation component of friction increase. As the load is increased further, the lubricant starts to fail locally and some surface irregularities may penetrate and tear through the boundary film. Eventually, metal to metal adhesion may take place, which may lead to material transfer. Material transfer was observed on the tip of the indenters after the experiments (figure 4). Nonetheless, the friction curves show only small fluctuations. The friction coefficient fluctuation in lubricated contacts corresponds to the formation of chips [3]. This happens because the reduced amount of adhesion between the strip and the indenter prevents the build-up of a lump and facilitates formation of a loose chip (see for example figure S3). 


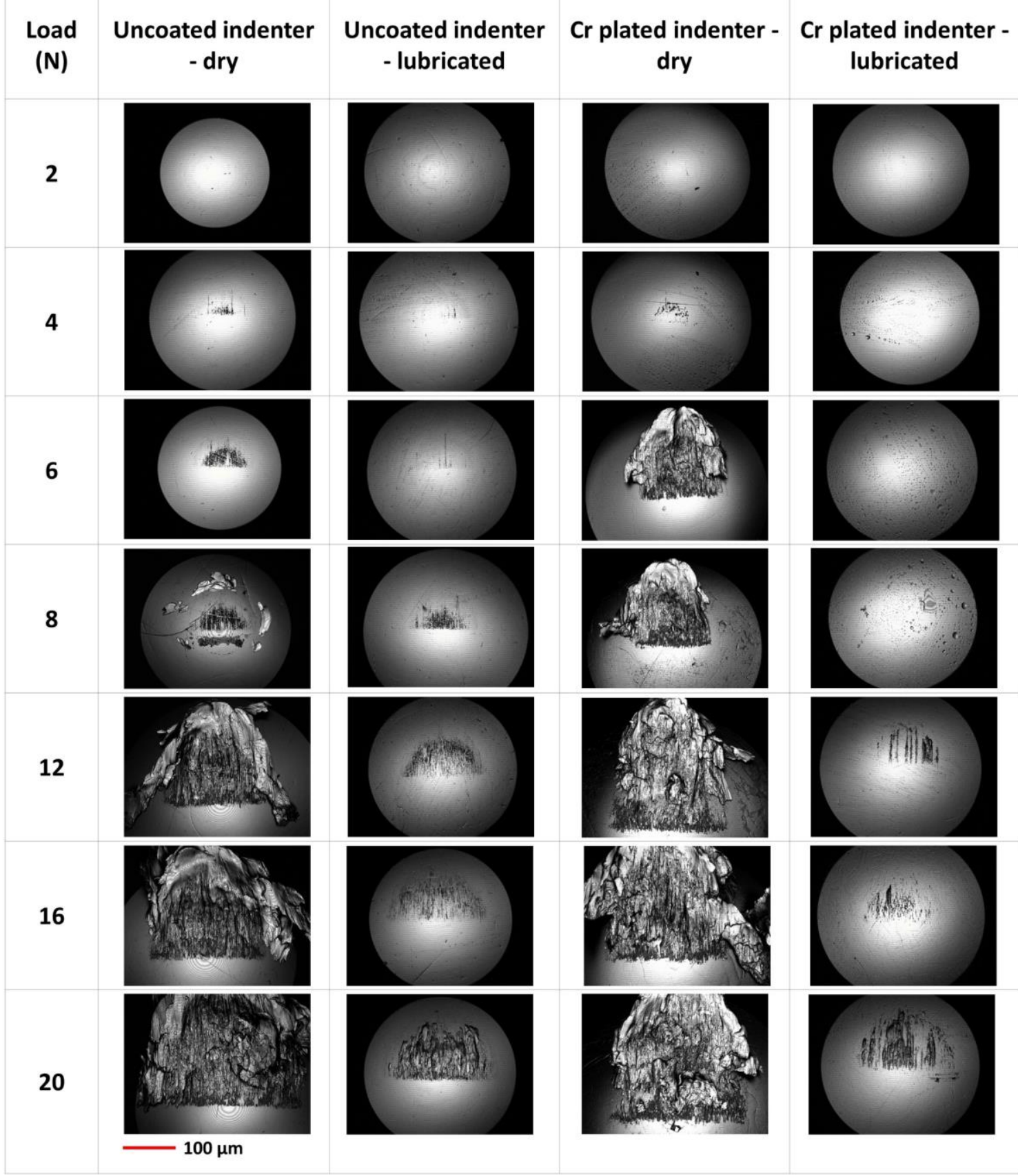

Figure 4: Microscopic image of the indenters after the scratch experiments. The direction of sliding is from top to bottom.

No clear difference was observed in terms of $\mu_{a p}$ values for the lubricated scratch experiments performed using the uncoated \& $\mathrm{Cr}$ plated indenters at low loads $(<16 \mathrm{~N})$. However, the scratch experiments carried out using $\mathrm{Cr}$ plated indenters exhibited lower friction at high normal loads, see figure 3 and figure S1. Furthermore, reduced material pickup was observed on the tip of the $\mathrm{Cr}$ plated indenters after the experiments compared to the uncoated ones (figure 4). It is known that the durability of a boundary lubricant is influenced by the bonding strength of the lubricant to the lubricated surfaces and by the rate of material transfer between rubbing surfaces [25]. Weakly adhered lubricants are easily removed by asperity contacts from the contacting interface, and hence, the lubricant fails. On the other hand, a boundary lubricant that adsorbs strongly on a solid surface will hold under extreme conditions and provide lubrication to high contact pressures. The lower friction coefficient of the lubricated experiments using $\mathrm{Cr}$ plated indenter at higher loads suggests that the chromium/chromium oxide layer promotes the formation 
of a strong tribolayer by reacting with the lubricant additives which prevented direct metal-metal contact to higher contact pressures and/or reduces adhesion between the contacting interfaces [30].

The friction coefficient of the dry scratch experiments at very low loads $(<6 \mathrm{~N})$ stays stable for the whole wear track, see figure S1. The main wear mechanism at these loads is ploughing. This higher $\mu_{a p}$ compared to the lubricated scratch experiments at these loads (figure 3) can be explained by the higher shear strength of the dry contact interface. As indicated in the work of Challen \& Oxley [4], a rapid increase in the $\mu_{a p}$ is observed when there is a transition from ploughing to wedge forming, which can happen when the interfacial shear strength is sufficiently large. In addition, unstable friction behavior with large fluctuations is observed at higher loads. The main cause of this fluctuation is lump growth and detachment. As the scratch proceeds, some material is pushed sideways by ploughing and a lump builds up in front of the indenter. The frictional resistance increases steadily as the lump accumulation progresses. Once the lump reaches a certain a critical height, it is detached and gross sliding occurs at the bottom of the lump, which is indicated by a sharp drop in the $\mu_{a p}$ value. At this point, a stable transferred layer is formed on the indenter and remains there; no new wear debris is formed in the following sliding process. This was confirmed by performing multiple scratches with an indenter at the same load (see figure S4). A similar observation is reported in [3]. The critical length of the scratch for the lump to build up and detach may vary depending on the normal load and the local property of the substrate [28]. The critical length of the scratch for a lump to build up decreases as the normal load increases. This is clearly visible in the sliding distances of the friction curves to reach a maximum value in figure S1 (b, d) and on the wear track morphologies in figure $\mathrm{S} 2$ (c, d). Chrome plating the indenter did not have the same advantage in the dry scratch experiments as in the lubricated ones. In fact, dry scratch experiments performed using chrome coated indenters decreased the critical load of the transition from ploughing to wedge forming wear mode, see figures 3 and 5 . This suggests that the unlubricated $\mathrm{Cr}$ plated surface-steel interface has a higher shear strength than the steel-steel contact and its favored performance in the lubricated experiments originates from its reaction with the lubricant and/or additives.

\subsubsection{Wear mechanisms}

The wear track morphology of the scratches can provide important information about the wear behavior. The height profiles of some of the scratches are given in figure 5. The wear track morphology of all the scratches is provided in figure S2 of the supplementary document. The scratch morphologies of the lubricated experiments are relatively smooth at all loads, whereas two distinct regions can be distinguished on the scratch morphology of the dry ones. While smooth scratches are observed at very low loads $(<6$ $\mathrm{N})$, a non-uniform wear with rough scratches indicating lump growth and detachment are seen at high loads. The non-uniform wear with rough scratches at high loads may arise from the dominant wear mechanism (i.e. wedge forming), which is not necessarily uniform, the stiffness of the system or the inhomogeneity of the material. 


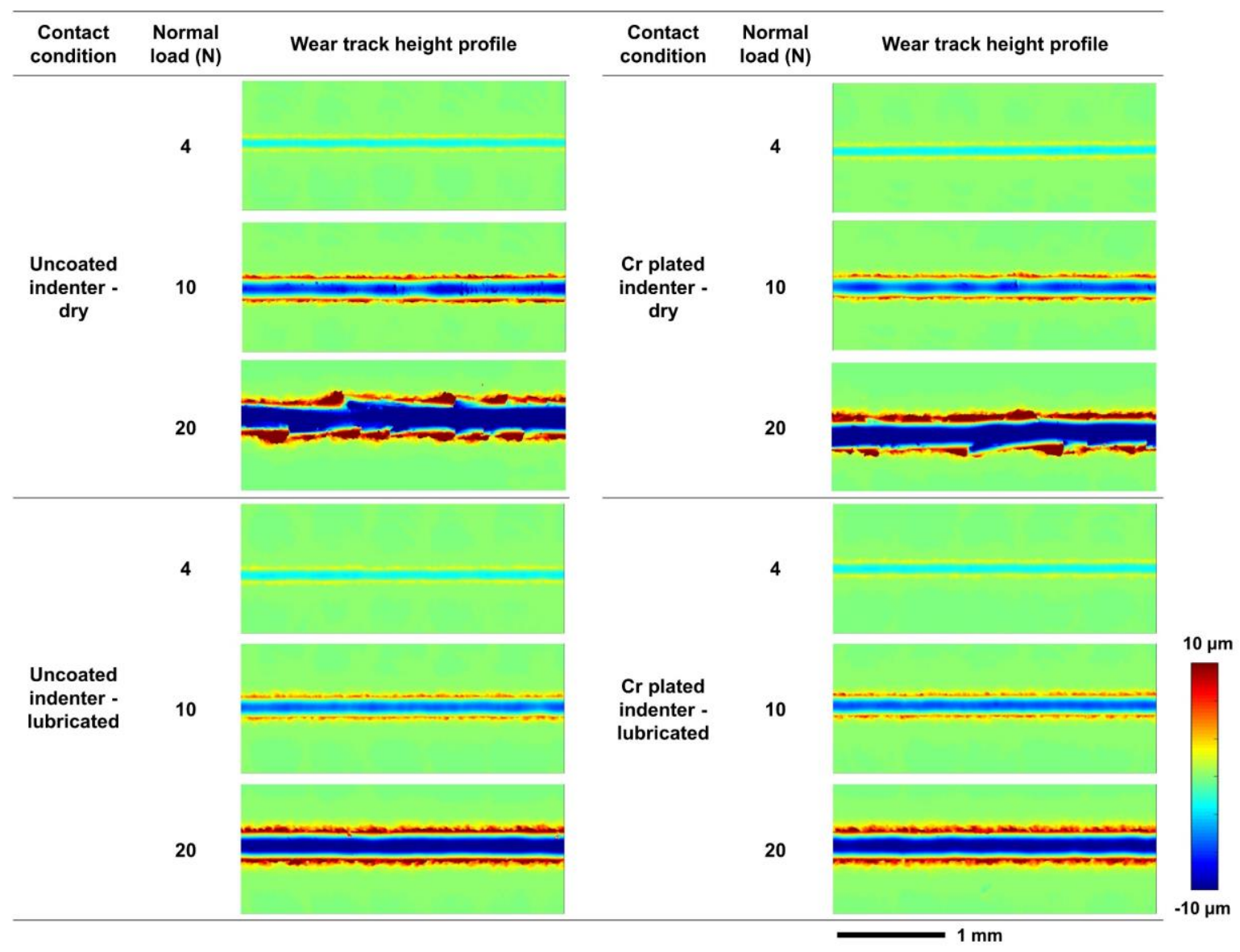

Figure 5: Confocal microscopy images of the representative wear tracks) of the scratch experiments. The length of the scratches is $15 \mathrm{~mm}$ and the direction of sliding is from left to right.

The abrasive wear behavior is controlled by the hardness, load and shape of the abrasive as well as the shear strength at the contact interface. Based on Challen \& Oxley [4] slip-line theory and experimental results, Hokkirigawa \& Kato [27] presented an abrasive wear mode diagram with three possible wear modes as a function of the non-dimensional parameters, degree of penetration $\left(d_{p}\right)$ and interfacial shear factor $(f)$. The degree of penetration is a measure of the 'sharpness' of asperities. It is defined as the ratio of the depth of the indentation to the half width of indentation in the sliding direction. Interfacial shear factor is defined as the ratio of the shear strength of the interface to the bulk shear flow stress of the deforming material. Its value ranges between $0 \leq f \leq 1$. The three possible abrasive wear modes are ploughing, wedge forming and cutting. In ploughing, the material from the groove is primarily pushed to the ridges without any actual material removal. In pure cutting all the material is removed as a wear debris without any side ridges. In wedge forming, a lump is formed in front of the indenter and wear particles are formed from the growth and detachment of lumps.

Both the lubricated and dry scratch experiments showed nearly ideal ploughing at low loads. In the lubricated scratch experiments, increasing the load led to a gradual transition of the wear mechanism from ploughing to predominantly wedge forming. This means that there is a local lubricant failure at some locations which is reflected by the material pickup seen on the indenters, see figure 4 . The effect of a lubricant is to reduce $f$ so that ploughing wear is maintained at higher degrees of penetration. Furthermore, in the lubricated experiments, the $\mathrm{Cr}$ coating played an important role in terms of increasing the critical degree of penetration of the transition from ploughing to wedge forming by delaying local lubricant failure to higher contact pressures and/or reducing adhesion between the indenter and the strip. These wear behaviors are reflected on the wear tracks of the scratch experiments (figure 5 and figure S2) and the microscopic images of the indenters after the experiments (figure 4). In the dry scratch experiments, increasing the load was accompanied by a rapid transition of the wear mechanism from 
ploughing to wedge forming, which is clearly visible on the wear track morphology (figure S2) and in the friction curves (figure S1). This transition occurred at $8 \mathrm{~N}$ and $6 \mathrm{~N}$ load for the uncoated and $\mathrm{Cr}$ plated indenters respectively, which correspond to degrees of penetration of 0.17 and 0.15 . The degree of penetration of the scratches was calculated instead of using measured height profiles. This was done to avoid measurement errors and after checking the measured scratch width values match with the calculated ones with a margin of error of $\pm 12 \% . d_{p}$ is calculated as a function of the applied normal load by assuming the front half of the indenter is in contact (see figure 2 ) and the mean contact pressure is equal to the indentation hardness of the deforming material (Ti-IF steel). An indentation hardness value of $91.5 \pm 1.5 \mathrm{HV} 0.5$ was measured from 10 Vickers hardness tests.

\subsubsection{Degree of wear}

In the scratch experiments, only part of the material displaced by the groove is removed as wear debris to cause material loss. The remaining material is displaced by plastic flow to form piled up ridges at the sides of the grooves. It is important to know the proportion of (groove) material removed to predict the quantity of wear particles generated. The relative amount of the material removed from the wear track can be described by the degree of wear $\left(d_{w}\right) \cdot d_{w}$ is defined as the ratio of the volume of material on the shoulders to the volume of material on the grooves. The details of degree of wear calculation from an average 2D scratch profile are provided in section 2.1.

Figure 6 displays the degree of wear of the scratch experiments as a function of the degree of penetration. The value of $d_{w}$ is higher for the dry scratch experiments and its value increases with the increase of the degree of penetration. The $d_{w}$ of the dry experiments that are in wedge forming wear mode range between 0.15 to 0.31 . Whereas, $d_{w}$ was less than 0.15 at all the applied normal loads in the lubricated scratch experiments. The $d_{w}$ of the scratch experiments when using $\mathrm{Cr}$ plated indenters was higher in the dry experiments and slightly lower in the lubricated ones compared to those using the uncoated indenters. This is consistent with the friction behavior (see figure 3 ).

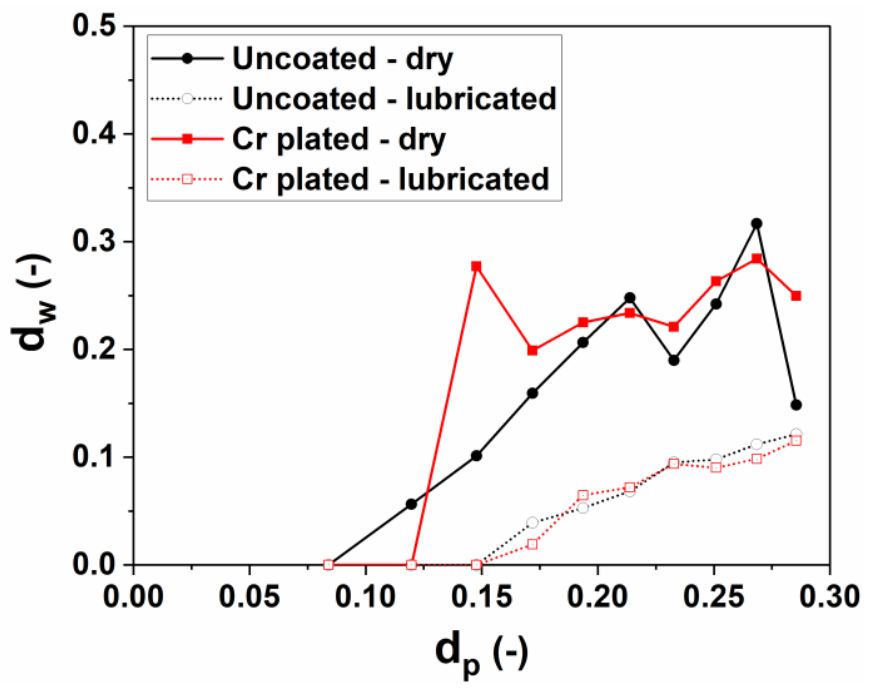

Figure 6: Degree of wear $\left(d_{w}\right)$ of the scratch experiments as a function of degree of penetration $\left(d_{p}\right)$.

The variation of degree of wear as a function of the degree of penetration depends on the specific material under investigation, the lubrication condition, and the type of active abrasive wear mode [31]. The degree of wear in pure ploughing is 0 as all the material from the groove is pushed to the ridges without any actual material removal. In pure cutting, all the material is removed as a wear debris without any side ridges $\left(d_{w}=1\right)$. Although theoretically no wear is assumed to occur in ploughing regime as all the material from the groove is pushed to the ridges without any actual material removal, wear on a much-reduced scale can occur at the interface. Similarly, not all the material is removed as wear debris in cutting wear mode. Kato and co-workers $[3,32,33]$ have experimentally studied the transitions in wear modes and the degree of wear in single asperity scratch experiments. They reported typical values of $d_{w}<0.15$ for ploughing, 
$0.2<d_{w}<0.8$ for wedge forming, and $0.8<d_{w}<0.95$ for cutting. The strength of adhesion between the contacting bodies plays an important role in wedge forming wear mode. Lubrication decreases the degree of wear by lowering the interfacial shear strength, and consequently, the strain and damage on the contacting surfaces. Hence, when wedge forming occurs in dry and lubricated contacts, the degree of wear is expected to be smaller for lubricated cases.

Ploughing is the dominant wear mechanism in the lubricated experiments. As the degree of penetration increases, the contribution of ploughing decreases while material removal by wedge forming becomes more pronounced. The material extrudes from the sides of the contact giving rise to flakes which subsequently break off and produce wear particles (see figure S3), similar to that reported in [34]. On the other hand, wedge forming is the main wear mechanism in the dry scratch experiments and the material from the groove is removed by shearing of the wedge. However, due to the ductility of the material (i.e. Ti-IF steel), the chips do not break off but remain next to the track, resulting in lower experimental value of $d_{w}$ compared to the ones in the literature. Similar observations are reported in [35].

According to literature $[3,32,33]$, the degree of wear is expected to increase from 0 to a maximum value following an S-curve depending on the scratch hardness of the material. The S-curve was not observed in the current experiments. This is ascribed to the high ductility and work hardening property of the Ti-IF steel. Hokkirigawa et al. [33] showed that increasing ductility increases the critical degree of penetration of the transition from ploughing to wedge forming/cutting and it decreases the degree of wear within cutting regime. Significant work hardening can be expected at the vicinity of the scratch where the actual deforming and tearing takes place. Challen et al. [36] studied the effect of strain hardening on the critical degree of penetration of chip formation (abrasive) wear. They demonstrated that the critical degree of penetration of the transition of wear modes increases with an increase in the rate of hardening. Moreover, past research $[37,38]$ have shown that work hardening influences not only the wear regime transition boundaries but also spreads the plastic zone further from the indenter reducing the pile-up around the indenter and making chip formation more difficult.

\subsection{MPM simulations}

\subsubsection{Friction coefficient}

The abrasive wear behavior (i.e. the wear mode and the degree of wear) at single asperity contact is highly influenced by the shear strength at the contact interface and the sharpness of the indenter [27]. MPM scratch simulations were executed at several loads and at several interfacial shear strength values for a given normal load. This allows to study the influence of degree of penetration (asperity sharpness) and interfacial shear strength on the apparent friction coefficient as well as on the wear behavior of scratch simulations. The interfacial shear strength $\tau$ in the MPM simulations was varied by changing the Coulomb friction $\mu$. The relationship between the Coulomb friction and the interfacial shear strength is given by:

$$
\tau=\mu P
$$

where, $P$ is the nominal contact pressure.

Typical friction curves of the scratch simulations at several interfacial shear strength values and the corresponding scratch morphologies are displayed in figure 7 . While the friction curves are smooth at low $\mu$ values, they exhibited fluctuation for larger values of $\mu$ and/or when particle detachment occurs. The deformation takes place mostly by ploughing at low loads, as evidenced by the ridges to the side of the scratch as material is displaced (figure 7c). A wedge is formed ahead of the indenter at higher loads, which is manifested by the lump at the end of the scratches, and chips being formed in some cases. The volume of the lump ahead of the indenter increases with the increase of interfacial shear strength. 

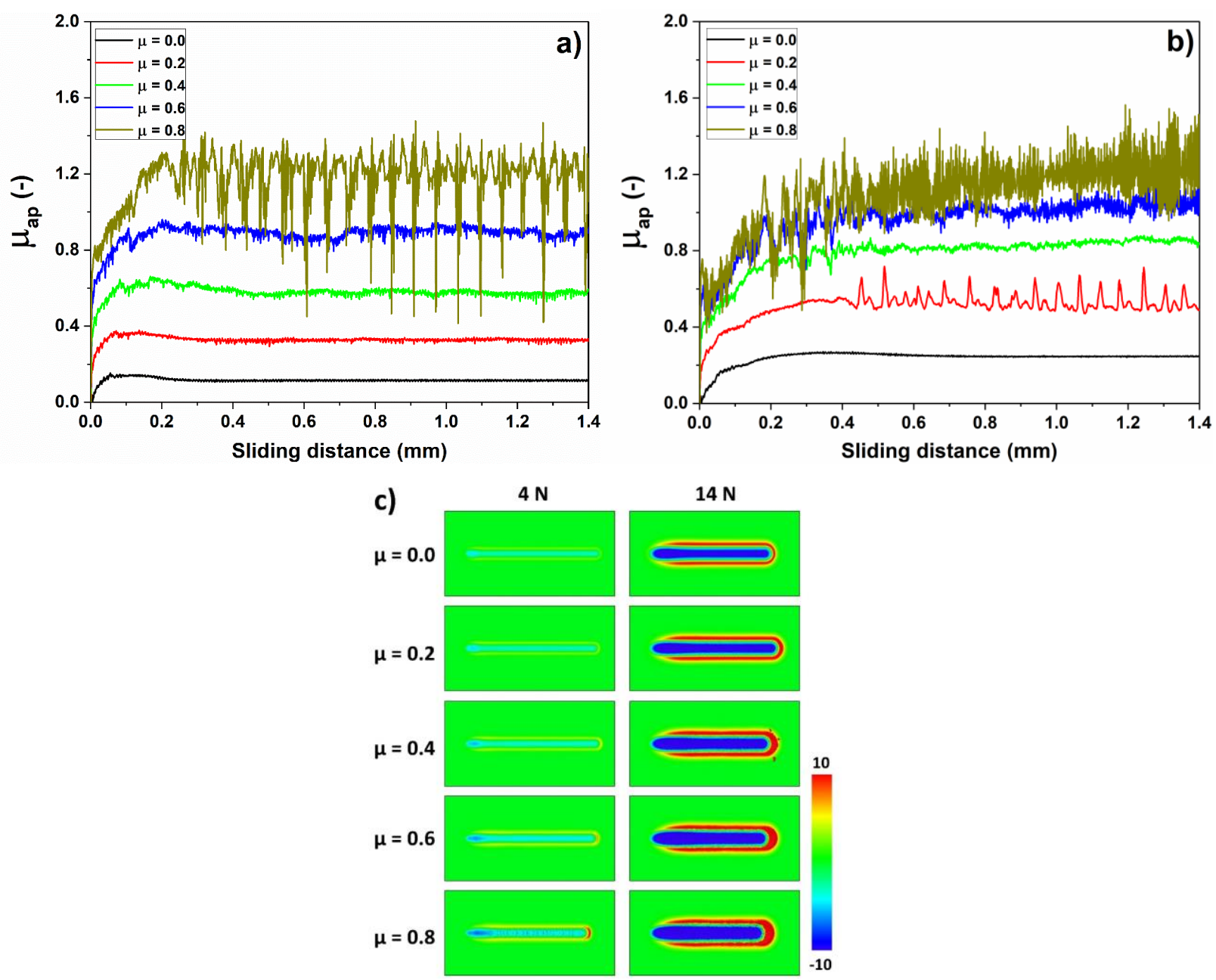

Figure 7: Friction curves of the MPM scratch simulations for a) $4 \mathrm{~N}$ and b) $14 \mathrm{~N}$ normal load, and c) the corresponding scratch morphologies. The sliding direction is from left to right and scale of the color bar is in $\mu \mathrm{m}$.

The relationship between the interfacial shear strength and the steady state apparent friction coefficient of the scratch simulations is shown in figure 8. The apparent friction coefficient increases as the normal load and the interfacial shear strength increase. The increase of the apparent friction coefficient with the normal load can be attributed to the increase of degree of penetration, which in turn increases the deformation component of friction due to the increased strain and strain hardening experienced by the substrate [14]. The apparent friction coefficient increases almost linearly at low interfacial shear strength and low loads. However, a slight deviation from the linear behavior is observed once particle detachment starts to occur at higher loads. Earlier studies on the contribution of interfacial shear strength to the overall friction force pointed out that the deformation and the adhesion component of friction seem to be simply additive only when one term is relatively small compared with the other one [26]. The simulation results clearly showed that the interfacial shear strength plays a vital role in the apparent friction value of the scratch experiments. 


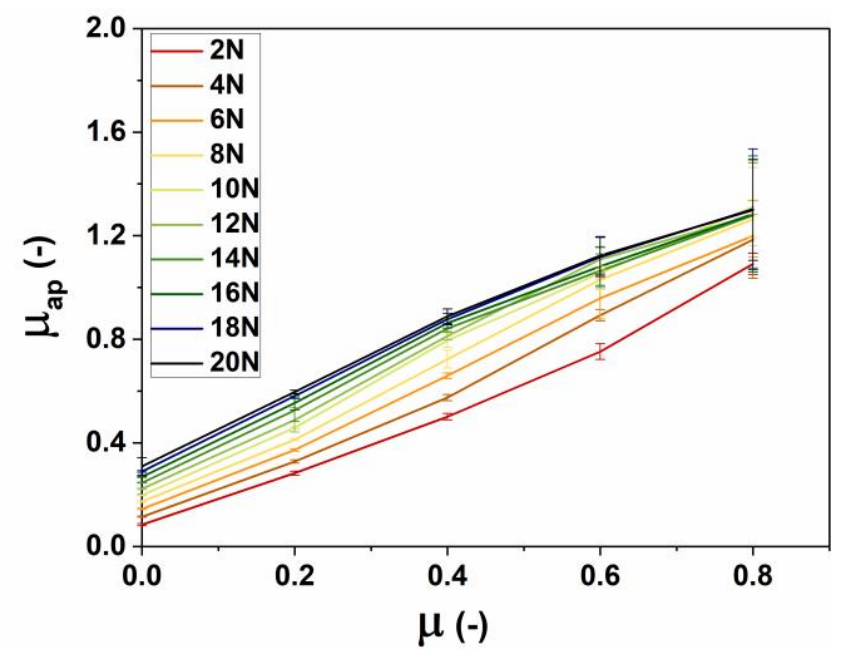

Figure 8: Variation of apparent friction coefficient $\left(\mu_{a p}\right)$ of MPM scratch simulations as a function of normal load and Coulomb friction coefficient $(\mu)$.

It has been shown that the shear strength of a boundary layer varies with the contact pressure $[24,26]$. To directly compare the friction and wear behavior of the scratch experiments and the numerical scratch simulations, the interfacial shear strength value at the given contact pressure must be known. However, measuring the interfacial shear strength of a lubricant and dry contact interfaces is very difficult. Besides, when calculating the commonly used non-dimensional parameter interfacial shear factor $f$, the effective shear strength of the deforming material should be considered. Since the material in the present study strain hardens, the shear strength of the material does not remain constant and its value depends on the accumulated strain. This requires the average flow stress to be obtained from stress-strain curve of the deforming material. Considering the above factors, classical Coulomb friction $(\mu)$ is used in this work to describe the shear strength of the contact interface. Since the shear strength of the contact interface was not experimentally measured, the $\mu$ of the scratch experiments was estimated by equating the measured apparent friction coefficient of the experiments to that of the simulations at the given normal load. More specifically, the Coulomb friction of MPM simulations for direct comparison with the experiments was estimated so that it yields the same $\mu_{a p}$ value as the experimental scratch experiments for the given load and lubrication condition. This was achieved by linear interpolation of the MPM simulation results in figure 8 to that of the measured $\mu_{a p}$ (figure 3).

The Coulomb friction of the scratch experiments estimated from MPM simulations are presented in Figure 9. The $\mu$ of the lubricated scratch experiments remained very low $(\mu<0.05)$ at all loads. Despite the material transfer seen to the indenter at higher loads, the lubricant plays a very important role in reducing adhesion and keeping the interface shear stress low. The positive influence of $\mathrm{Cr}$ plating in reducing friction for the lubricated experiments is evident at higher loads.

In dry contacts, the shear strength of the contact interface is expected to be very close to the shear strength of the softer counterpart [33]. This relationship is manifested in the measured friction values of the dry scratch experiments. The $\mu$ of the dry scratch experiments reached the theoretical maximum value of $1 / \sqrt{3}$ (according to von Mises yield criterion of the workpiece material) in some cases. In those cases, the interface shear strength exceeds the shear strength of the strip material. As a result, the strip material welds firmly on the indenter surface and tearing takes place on the strip. The MPM simulation results revealed that nearly all the frictional energy is dissipated in the plastic work of the deforming surface in the lubricated scratch experiments. By contrast, the frictional resistance in the dry scratch experiments is primarily due to shearing of the adhesion junction and from tearing the deforming substrate. 


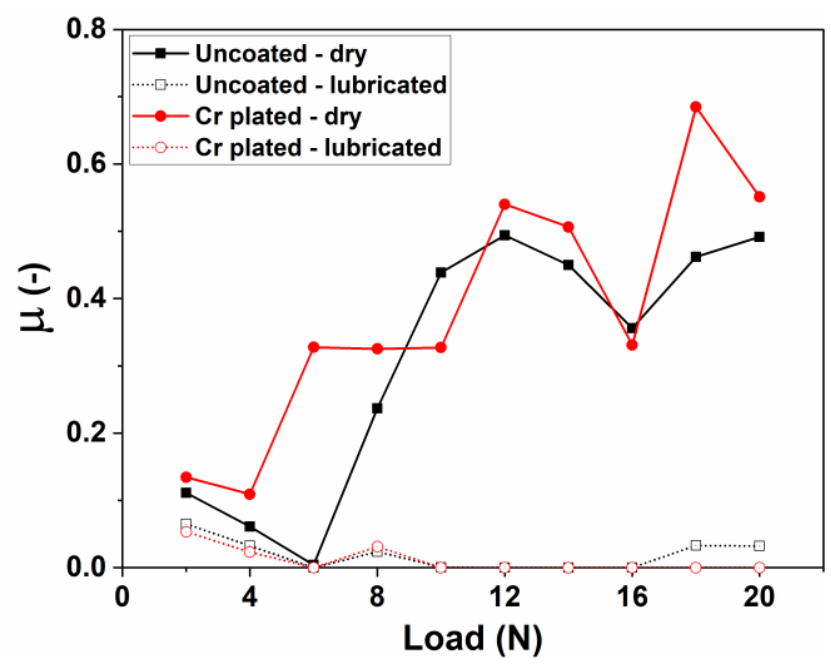

Figure 9: The Coulomb friction $\mu$ of the scratch experiments estimated from MPM simulations.

\subsubsection{Wear profile \& degree of wear}

Agreement between the experiments and the simulations can be judged by comparing the wear groove profiles and the degree of wear values at the same load. Figure 10 presents a comparison of the wear grooves of the scratch experiments and MPM scratch simulations. The MPM simulations overestimated the scratch width and depth as well as the material displaced to the sides as a consequence of plastic deformation. This overestimation implies that the investigated Ti-IF steel is in reality less ductile than considered in the MPM simulations. The reason for the overestimation is likely caused by the use of the bulk material behavior (constitutive equation) in the MPM scratch simulations, which may be different from the surface behavior on the top few micrometers. Another reason could be that the severe strain hardening under the complex stress state in the vicinity of the scratches might not be properly taken into account in the constitutive model. Regardless, MPM simulations capture junction growth very well, see for example figure $9 \mathrm{~b}$. The real area of contact, and as a result, the indentation depth in the scratch experiments increases as the interface shear strength is increased for a given normal load, for instance in the absence of a lubricant [39].
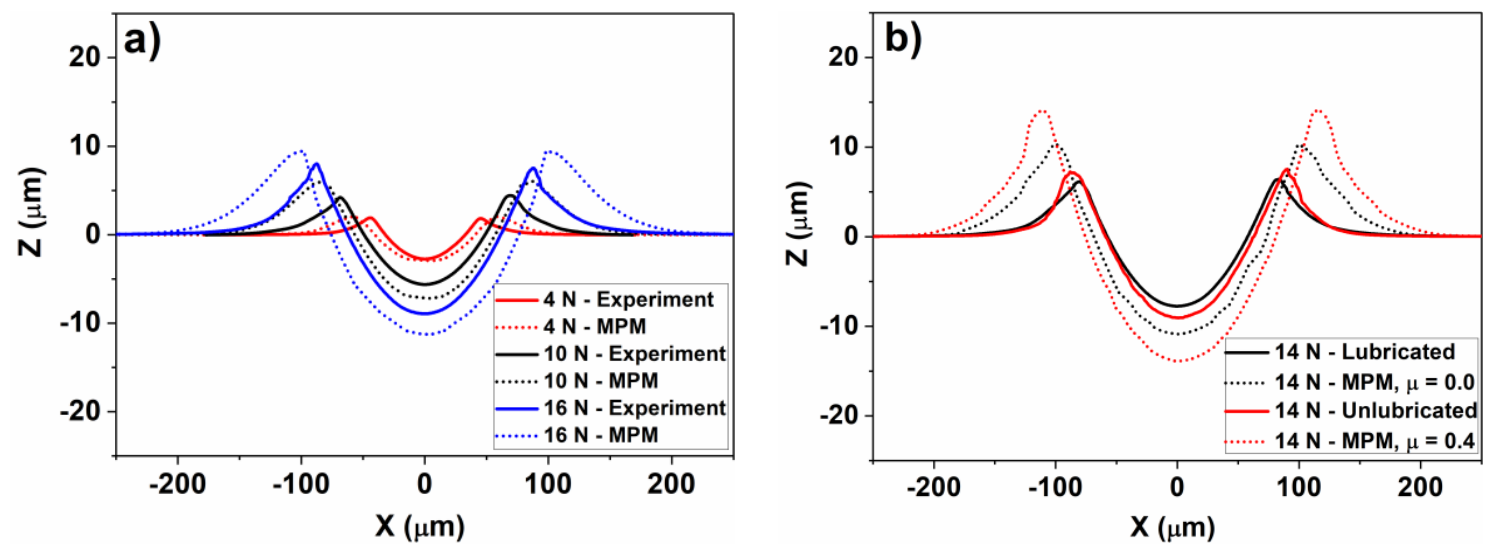

Figure 10: Comparison of the wear grooves of scratch experiments and MPM simulations: a) at various normal loads under lubricated conditions (experiments) and with $\mu$ corresponding to lubricated scratch experiments (MPM simulations); b) the effect of interface shear strength on scratch width and depth.

The degree of wear results of MPM simulations are presented in figure 11. Compared with the experimental results (figure 6), it can be clearly seen that the MPM simulations underestimate the degree of wear. This underestimation is also reflected in the shoulders of the wear grooves (figure 10). There is no physically-based damage model in the MPM simulations. Material detachment is simply taken into account by using a connectivity criteria between neighboring particles [20]. The interaction between the MPM particles is lost as the separation between neighboring particles exceeds the defined kernel radius. 
This connectivity criteria might be unsatisfactory when it comes to predicting the mechanical behavior of ductile materials experiencing damage in compression. In order to study the variation of degree of wear in MPM simulations and compare with the experiments, a physically-based material removal criterion should be defined to allow debris separation from the deforming substrate. The following section discusses wear particle formation criteria proposed in literature and the approach followed in this study.

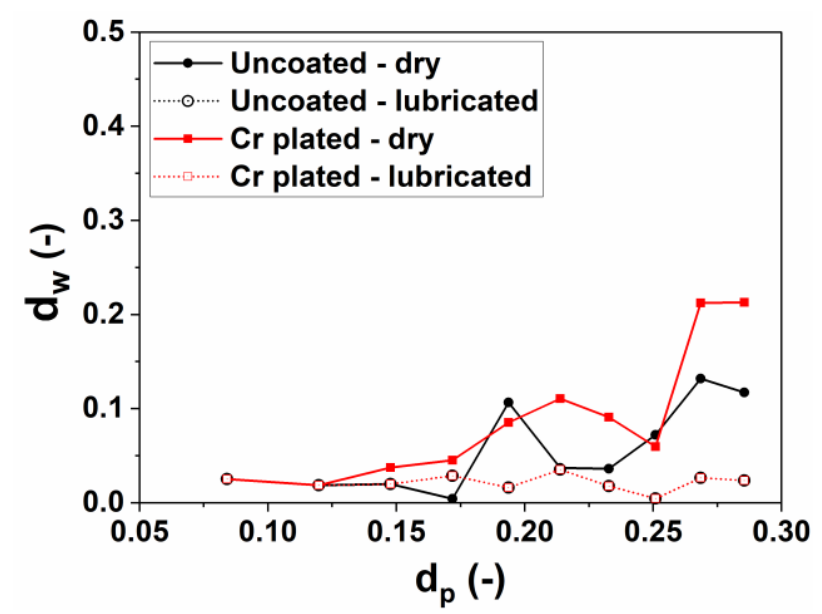

Figure 11: Degree of wear $\left(d_{w}\right)$ of MPM scratch simulations as a function of degree of penetration $\left(d_{p}\right)$.

\subsubsection{Wear particle formation criterion}

A wear particle separation criterion should consider damage mechanics and damage evolution until ultimate debris formation. Some of the physical quantities used as a damage criterion include effective plastic strain, strain energy density, fracture energy, shear failure criterion, displacement, stress, and adiabatic shearing [11]. Several authors have proposed, for ductile materials, whether a wear debris particle is produced and how much material is removed depends on the accumulated plastic shear strain (also known as ratchetting failure) [40-43]. Other researchers examined the relationship between the amount of material removed and the degree of penetration in abrasive wear based on the concept of low cycle fatigue [44-49]. In the former case, it is proposed that material is detached and wear particles are produced only when the accumulated surface plastic strain produced by the asperity interaction exceeds a critical value comparable to the strain to failure in a monotonic test. The assumption in the latter case is that the behavior of the material that experiences deformation in abrasive wear resembles failure of material during low cycle process: if the plastic strain amplitude is less than the limit plastic strain, then the material does not fail and no material removal occurs. Only when some critical amount of accumulated strain is reached can the material be removed. Some authors $[40,42]$ argue that these two failure modes are competitive, so that the actual failure corresponds to the one which would occur first. Note that both theories are for abrasive wear processes involving multiple loading cycles. In the current study, however, a single loading cycle is considered.

Although there seems to be no consensus on the underlying principle of failure mechanism for abrasive wear processes involving multiple loading cycles, and while it is not the focus of the current study, both approaches consider abrasive wear as a plastic strain controlled process. Hence, critical equivalent plastic strain $\varepsilon_{c}$ can be used as a criterion to define wear particle formation. More specifically, a wear particle will be formed if the equivalent plastic strain $\varepsilon$ exceeds the critical value $\varepsilon_{c}$. The criterion for failure can then be defined as $\varepsilon / \varepsilon_{c} \geq 1$. In this work, it was attempted to estimate the critical plastic strain $\left(\varepsilon_{c}\right)$ needed for the material under investigation (Ti-IF steel) by relating the degree of wear in the scratch experiments and the plastic strain produced by asperity interaction in MPM simulations. The analysis consists of the following steps. First, MPM particles whose value exceeds the defined $\varepsilon_{c}$ are considered to be removed as wear particles and deleted in post processing. This is schematically illustrated in figure 12 . Next, the average cross-section of the scratch wear track is determined. Finally, the degree of wear is calculated using equation 1. 


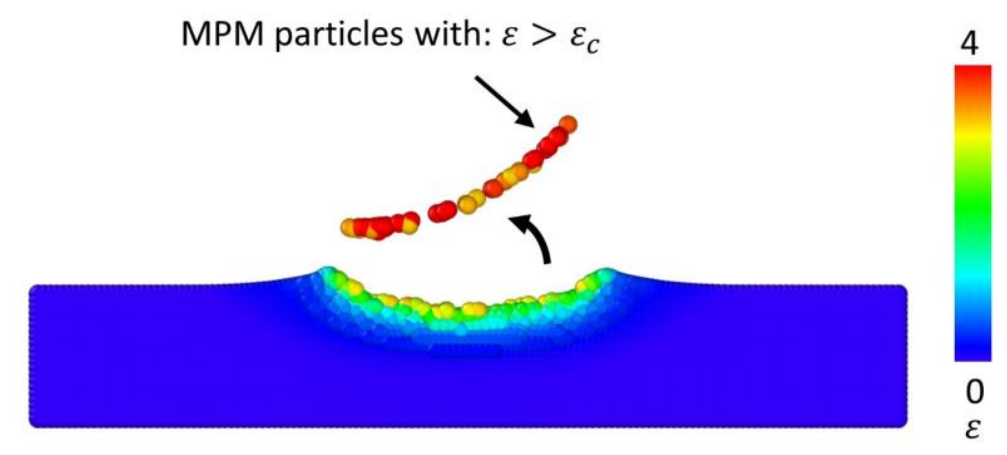

Figure 12: Schematic representation of wear particle removal.

Various studies $[43,45,46,50-52]$ demonstrated that large strains are involved in wear particle formation and the critical strain needed for failure to occur depends on the specific material under consideration and the compressive stress conditions. Zum Gahr [52] performed scratch tests using pyramidal indenter on polished surfaces of different materials. He measured a true strain of at least 3 on the wear debris and worn surfaces of brass. Challen et al. [45,50] have shown that, for Al- Mg alloy, fracture occurs only when the effective shear strain put into the surface is higher than 10 from scaled up model asperity experiments, in which a hard wedge is indented into the surface of a softer specimen and slid along it. Moore and Douthwaite [51] reported very large strains in the range of 2.5 - 8 on worn surfaces of a copper-silver composite in abrasion tests. Yanyi et al. [46] performed wear tests in which a hard tool steel wedge was pressed against the periphery of a rotating bar of soft metal and found that a monotonic effective shear strain of 9.96 for aluminum and 5.19 for brass fit their experimental values. In a recent article, Tyfour et al. [41] reported an accumulated shear strain of 30 below the contact surface in sliding experiments in which a flat ended cylindrical indenter made of hot drawn low carbon steel was run against a rotating hardened steel disc. The reported high level of ductility and large strains are attributed to the high hydrostatic stress system under and ahead of the abrading particles. The studies mentioned above involve multiple loading cycles. According to low cycle fatigue studies of metals [53,54], the linear relationship between plastic strain range and number of cycles to failure on log-log scale extrapolates back to the static fracture ductility. Since only a single cycle process is considered in the present study, the plastic strain needed to cause fracture in one stress cycle can be used as wear particle formation criterion.

In the current work, the degree of wear values obtained in the scratch experiments are used as a benchmark to estimate the critical plastic strain needed to produce wear particles for the material under consideration (Ti-IF steel). To show the variation of the equivalent plastic strain as a function of the normal load and friction coefficient (interfacial shear strength), a snapshot of MPM simulations for several loads are provided in figure 13. As expected, higher load and higher interfacial shear strength lead to higher strains in the sheet. Increasing the Coulomb friction from 0 to 0.8 increased the maximum plastic strain experienced underneath (and in the surrounding of) the scratch by three to six-fold, from 0.4 to 2.8 at $2 \mathrm{~N}$ and from 3.8 to 12.7 at $20 \mathrm{~N}$ normal load. 


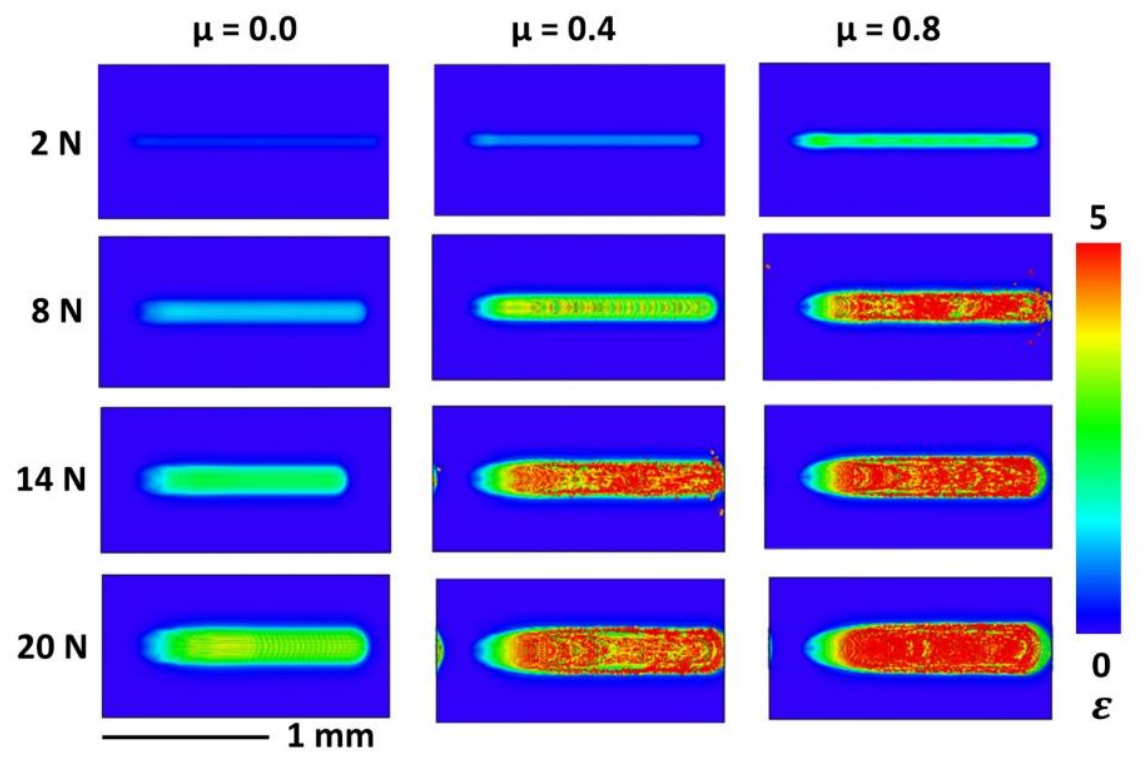

Figure 13: The variation of equivalent plastic strain $(\varepsilon)$ as a function of normal load and friction.

Analysis of the degree of wear was performed for several $\varepsilon_{c}$ values ranging from $2-8$. The calculated degree of wear values for several $\varepsilon_{c}$ values are presented in figure S5 of the supplementary material. It can be clearly seen that $\varepsilon_{c}$ of 2 greatly overestimates the degree of wear (figure S5a), whereas $\varepsilon_{c}$ values greater than 5 underestimate the degree of wear (figure $\mathrm{S} 5 \mathrm{~d}-\mathrm{f}$ ). A critical plastic strain in the range of 3 to 4 gives a reasonable agreement with the experiments in terms of predicting the degree of wear (figure S5 $b, c)$. Although the materials and loading conditions are different, these critical strain vales are in the range reported by other researchers who have conducted scratch and abrasion tests [51,52] but lower than the values reported elsewhere for multiple loading cycles or scaled up model asperity experiments $[41,45,46,50]$. This suggests that failure occurs at lower critical strain in monotonic loading than repeated contacts. It must be noted that the occurrence of wear particle formation will depend on the magnitude of the plastic strain imparted to the deforming material and the magnitude of the corresponding hydrostatic stress. Such large plastic strains on the wearing surfaces are possible due to the high hydrostatic compression which greatly enhances ductility.

Although the trends are consistent between the scratch experiments and the MPM simulations, the absolute values of $d_{w}$ are not completely comparable. Only one scratch experiment was performed for each load and a scratch of length $<1 \mathrm{~mm}$ was used to calculate $d_{w}$ in the case of MPM simulations in contrast to $12 \mathrm{~mm}$ in the experiments. More scratch experiments are necessary to conduct a statistically significant comparison. Moreover, the accuracy of MPM scratch simulations with regard to strain distribution can be improved further by refining the particle size at the expense of higher computational cost. One limitation of the MPM model is that the MPM particles do not stick to the indenter due to the absence of adhesion between the indenter and the substrate in the current contact implementation. In addition, one consequence of the failure introduced as post processing in the simulations is that the failed particles did not influence the deformation or friction coefficient. In reality, the failed particles are detached from the strip at the moment of failure, which are either removed from the contact interface as loose wear debris, stick to one of the contacting bodies, or stay in the contact and act as a third body abrasive. All these phenomena can influence the strain distribution under the sphere and the friction coefficient.

In summary, the current study provides a way to include the three-dimensional details of strain induced by asperity interaction in calculating the degree of wear in single asperity abrasive contacts. Early studies that attempted to follow similar approach did not take into account the three-dimensional nature of the deformation zone $[47,48]$. They utilized either simplistic analytical equations [48] or two dimensional FEM simulations [47] to determine the average strain induced in the deformation zone. The MPM model can be extended to study the scratch behavior in a range of different geometries, sliding speed and temperature, representative of the typical rolling processes in the industry, which are too difficult to be 
realized in the experiments. The single asperity contact can be further extended to macro scale contact with multiple asperities using a statistical approach. This, in turn, can be combined with rolling parameters to predict strip surface cleanliness (i.e. strip wear rate) in cold rolling processes.

\section{Conclusion}

Scratch experiments and numerical modelling were combined to study the formation of wear particles at a single asperity contact. The lubricated scratch experiments were ploughing dominated, whilst wedge forming was the main wear mechanism in the dry scratch experiments for both uncoated and hard $\mathrm{Cr}$ plated indenters. The lubricated scratch experiments showed both lower friction and degree of wear compared to the unlubricated condition. The lubricated scratch experiments using $\mathrm{Cr}$ plated indenters exhibited reduced friction and material transfer at high loads. On the other hand, the scratch experiments performed using $\mathrm{Cr}$ plated indenters under dry conditions showed a transition to unstable sliding at lower normal load than the ones using uncoated indenters. The scratch experiments suggested that the beneficial influence of chrome plating on wear particles formation stems from its interaction with the lubricant as the same influence was not observed in the dry experiments.

MPM scratch simulations revealed that almost all the frictional resistance arises from deforming the substrate in the case of an interfacial shear strength corresponding to the lubricated contact. In contrast, the frictional resistance in the case of dry scratch experiments is primarily due to shearing of the adhesion junction and tearing the deforming body. Additionally, MPM simulations demonstrated that increasing the interfacial shear strength from 0 to $80 \%$ of the contact pressure increases the maximum plastic strain experienced underneath and in the surrounding of the scratch by a factor of three to six. Using the degree of wear of the scratch experiments as a benchmark, the critical plastic strain needed to produce wear particles was found out to be between 3 to 4 for the investigated Ti-IF steel.

\section{Acknowledgements}

This research was carried out under project number F41.1.14551 in the framework of the Partnership Program of the Materials innovation institute M2i (www.m2i.nl) and the Foundation of Fundamental Research on Matter (FOM) (www.fom.nl), which is part of the Netherlands Organization for Scientific Research (www.nwo.nl).

\section{References}

[1] C. Pesci, G. Monfort, V. Torre, H. Van Steden, J. Kurzynski, B. Vervaet, J. Perez, K. Reuver, L. Jacobs, Controlling wear and surface cleanliness during cold rolling (LOWWEAR), 2012. https://doi.org/10.2777/23177.

[2] L. Jacobs, B. Vervaet, H. Hermann, M. Agostini, J. Kurzynski, N.-G. Jonsson, J. Perez, K. Reuver, H. Van Steden, Improving strip cleanliness after cold rolling, Proc. Inst. Mech. Eng. Part J J. Eng. Tribol. 225 (2011) 959-969. https://doi.org/10.1177/1350650111413639.

[3] T. Kayaba, K. Hokkirigawa, K. Kato, Analysis of the abrasive wear mechanism by successive observations of wear processes in a scanning electron microscope, Wear. 110 (1986) 419-430. https://doi.org/10.1016/0043-1648(86)90115-8.

[4] J.M. Challen, P.L.B. Oxley, An explanation of the different regimes of friction and wear using asperity deformation models, Wear. 53 (1979) 229-243. https://doi.org/10.1016/0043-1648(79)90080-2.

[5] A.A. Torrance, Modelling abrasive wear, Wear. 258 (2005) 281-293. https://doi.org/10.1016/J.WEAR.2004.09.065.

[6] F. Elwasli, F. Zemzemi, A. Mkaddem, S. Mzali, S. Mezlini, A 3D multi-scratch test model for characterizing material removal regimes in 5083-Al alloy, Mater. Des. 87 (2015) 352-362. https://doi.org/10.1016/J.MATDES.2015.07.121. 
[7] M. Woldman, E. Van Der Heide, T. Tinga, M.A. Masen, A Finite Element Approach to Modeling Abrasive Wear Modes, Tribol. Trans. 60 (2017) 711-718. https://doi.org/10.1080/10402004.2016.1206647.

[8] J.L. Bucaille, E. Felder, G. Hochstetter, Mechanical analysis of the scratch test on elastic perfectly plastic materials with the three-dimensional finite element modeling, Wear. 249 (2001) 422-432. https://doi.org/10.1016/S0043-1648(01)00538-5.

[9] J. Li, W. Beres, Three-dimensional finite element modelling of the scratch test for a TiN coated titanium alloy substrate, Wear. $260 \quad$ (2006) 1232-1242. https://doi.org/10.1016/j.wear.2005.08.008.

[10] M. Ben Tkaya, M. Zidi, S. Mezlini, H. Zahouani, P. Kapsa, Influence of the attack angle on the scratch testing of an aluminium alloy by cones: Experimental and numerical studies, Mater. Des. 29 (2008) 98-104. https://doi.org/10.1016/j.matdes.2006.11.021.

[11] T.T. Opoz, Investigation of Material Removal Mechanism in Grinding: A Single Grit Approach, University of Huddersfield. , 2012. http://eprints.hud.ac.uk/id/eprint/17818/ (accessed November 15, 2019).

[12] S. Leroch, M. Varga, S.J. Eder, A. Vernes, M. Rodriguez Ripoll, G. Ganzenmüller, Smooth particle hydrodynamics simulation of damage induced by a spherical indenter scratching a viscoplastic material, Int. J. Solids Struct. 81 (2016) 188-202. https://doi.org/10.1016/J.IJSOLSTR.2015.11.025.

[13] M. Varga, S. Leroch, S.J. Eder, M.R. Ripoll, Meshless microscale simulation of wear mechanisms in scratch testing, Wear. 376-377 (2017) 1122-1129. https://doi.org/10.1016/J.WEAR.2016.11.023.

[14] T. Mishra, G.C. Ganzenmüller, M. de Rooij, M. Shisode, J. Hazrati, D.J. Schipper, Modelling of ploughing in a single-asperity sliding contact using material point method, Wear. 418-419 (2019) 180-190. https://doi.org/10.1016/J.WEAR.2018.11.020.

[15] M. Varga, S. Leroch, S.J. Eder, H. Rojacz, M.R. Ripoll, Influence of velocity on high-temperature fundamental abrasive contact: A numerical and experimental approach, Wear. 426-427 (2019) 370-377. https://doi.org/10.1016/J.WEAR.2018.12.013.

[16] J.W. Swegle, S.W. Attaway, M.W. Heinstein, F.J. Mello, D.L. Hicks, An analysis of smoothed particle hydrodynamics, STIN. 95 (1994) 17439.

[17] G.C. Ganzenmüller, An hourglass control algorithm for Lagrangian Smooth Particle Hydrodynamics, Comput. Methods Appl. Mech. Eng. 286 (2015) 87-106. https://doi.org/10.1016/j.cma.2014.12.005.

[18] S. Leroch, S.J. Eder, G. Ganzenmüller, L.J.S. Murillo, M. Rodríguez Ripoll, Development and validation of a meshless 3D material point method for simulating the micro-milling process, J. $\begin{array}{lllll}\text { Mater. } & \text { Process. } & \text { Technol. } & 262 & \text { (2018) 449-458. }\end{array}$ https://doi.org/10.1016/J.JMATPROTEC.2018.07.013.

[19] T. Mishra, M. de Rooij, M. Shisode, J. Hazrati, D.J. Schipper, A material point method based ploughing model to study the effect of asperity geometry on the ploughing behaviour of an elliptical asperity, Tribol. Int. 142 (2020) 106017. https://doi.org/10.1016/j.triboint.2019.106017.

[20] G. Ganzenmüler, Smooth-Mach-Dynamics package for LAMMPS, Fraunhofer Ernst-Mach Inst. HighSpeed Dyn. (2014) 66.

[21] A. Stukowski, Visualization and analysis of atomistic simulation data with OVITO-the Open Visualization Tool, Model. Simul. Mater. Sci. Eng. 18 (2010). https://doi.org/10.1088/09650393/18/1/015012.

[22] Y. Bergström, A dislocation model for the stress-strain behaviour of polycrystalline $\alpha$-Fe with special emphasis on the variation of the densities of mobile and immobile dislocations, Mater. Sci. Eng. 5 (1970) 193-200. https://doi.org/10.1016/0025-5416(70)90081-9. 
[23] P. van Liempt, Workhardening and substructural geometry of metals, J. Mater. Process. Technol. 45 (1994) 459-464. https://doi.org/10.1016/0924-0136(94)90382-4.

[24] B.J. Briscoe, B. Scruton, F.R. Willis, The shear strength of thin lubricant films, PROC. R. Soc. LONDON, Ser. A. 333 (1973) 99-114. https://doi.org/10.1098/rspa.1973.0050.

[25] R.S. Timsit, C. V. Pelow, Shear strength and tribological properties of stearic acid films- part I: On glass and aluminum-coated glass, J. Tribol. 114 (1992) 150-158. https://doi.org/10.1115/1.2920854.

[26] T. Mishra, M. de Rooij, M. Shisode, J. Hazrati, D.J. Schipper, Characterization of interfacial shear strength and its effect on ploughing behaviour in single-asperity sliding, Wear. 436-437 (2019). https://doi.org/10.1016/j.wear.2019.203042.

[27] K. Hokkirigawa, K. Kato, An experimental and theoretical investigation of ploughing, cutting and wedge formation during abrasive wear, Tribol. Int. 21 (1988) 51-57. https://doi.org/10.1016/0301679X(88)90128-4.

[28] M.B. de Rooij, G. van der Linde, D.J. Schipper, Modelling material transfer on a single asperity scale, Wear. 307 (2013) 198-208. https://doi.org/10.1016/j.wear.2013.09.006.

[29] F.P. Bowden, D. Tabor, Friction, lubrication and wear: a survey of work during the last decade, Br. J. Appl. Phys. 17 (1966) 1521. https://doi.org/10.1088/0508-3443/17/12/301.

[30] M.A. Mekicha, M.B. de Rooij, D.T.A. Matthews, C. Pelletier, L. Jacobs, D.J. Schipper, The effect of hard chrome plating on iron fines formation, Tribol. Int. 142 (2020). https://doi.org/10.1016/j.triboint.2019.106003.

[31] K.H. Zum Gahr, Modelling of two-body abrasive wear, Wear. 124 (1988) 87-103. https://doi.org/10.1016/0043-1648(88)90236-0.

[32] T. Kayaba, K. Hokkirigawa, K. Kato, Experimental analysis of the yield criterion for a hard asperity sliding on a soft flat surface, Wear. 96 (1984) 255-265. https://doi.org/10.1016/00431648(84)90040-1.

[33] K. Hokkirigawa, K. Kato, Z.Z. Li, The effect of hardness on the transition of the abrasive wear mechanism of steels, Wear. 123 (1988) 241-251. https://doi.org/10.1016/0043-1648(88)90102-0.

[34] M.F. Stroud, H. Wilman, The proportion of the groove volume removed as wear in abrasion of metals, Br. J. Appl. Phys. 13 (1962) 173. https://doi.org/10.1088/0508-3443/13/4/312.

[35] M.A. Masen, M.B. de Rooij, D.J. Schipper, Micro-contact based modelling of abrasive wear, Wear. 258 (2005) 339-348. https://doi.org/10.1016/J.WEAR.2004.09.009.

[36] J.M. Challen, P.L.B. Oxley, E.D. Doyle, The effect of strain hardening on the critical angle for abrasive (chip formation) wear, Wear. 88 (1983) 1-12. https://doi.org/10.1016/0043-1648(83)90307-1.

[37] W.M. Garrison, Abrasive wear resistance: the effects of ploughing and the removal of ploughed material, Wear. 114 (1987) 239-247. https://doi.org/10.1016/0043-1648(87)90090-1.

[38] T.H.C. Childs, G.W. Rowe, Physics in metal cutting, Reports Prog. Phys. 36 (1973) 223. https://doi.org/10.1088/0034-4885/36/3/001.

[39] D. Tabor, Junction growth in metallic friction: the role of combined stresses and surface contamination, Proc. R. Soc. London. Ser. A. Math. Phys. Sci. 251 (1959) 378-393. https://doi.org/10.1098/rspa.1959.0114.

[40] A. Kapoor, F.J. Franklin, Tribological layers and the wear of ductile materials, in: Wear, Elsevier Sequoia SA, 2000: pp. 204-215. https://doi.org/10.1016/S0043-1648(00)00480-4.

[41] W.R. Tyfour, M.T. Hayajneh, A. Momani, M.B. AL-Hajji, Sliding wear mechanism of ductile materials - Effect of sliding direction reversal, Proc. Inst. Mech. Eng. Part J J. Eng. Tribol. 232 (2018) 315-325. 
https://doi.org/10.1177/1350650117713878.

[42] A. Kapoor, K.L. Johnson, Plastic ratchetting as a mechanism of metallic wear, Proc. R. Soc. A Math. Phys. Eng. Sci. 445 (1994) 367-381. https://doi.org/10.1098/rspa.1994.0066.

[43] W.R. Tyfour, J.H. Beynon, The effect of rolling direction reversal on the wear rate and wear mechanism of pearlitic rail steel, Tribol. Int. 27 (1994) 401-412. https://doi.org/10.1016/0301679X(94)90017-5.

[44] P. Lacey, A.A. Torrance, The calculation of wear coefficients for plastic contacts, Wear. 145 (1991) 367-383. https://doi.org/10.1016/0043-1648(91)90142-H.

[45] J.M. Challen, P.L.B. Oxley, B.S. Hockenhull, Prediction of Archard's wear coefficient for metallic sliding friction assuming a low cycle fatigue wear mechanism, Wear. 111 (1986) 275-288. https://doi.org/10.1016/0043-1648(86)90188-2.

[46] Y. Yang, A.A. Torrance, P.L.B. Oxley, Modelling mechanical wear processes in metallic sliding friction, J. Phys. D Appl. Phys. 23 (1996) 600-608. https://doi.org/DOI: 10.1088/00223727/29/3/018.

[47] A.A. Torrance, A method for calculating boundary friction and wear, Wear. 258 (2005) 924-934. https://doi.org/10.1016/j.wear.2004.09.074.

[48] J. Jiang, R.D. Arnell, The dependence of the fraction of material removed on the degree of penetration in single particle abrasion of ductile materials - NASA/ADS, J. Phys. D. Appl. Phys. 31 (1998) 1163-1167. https://doi.org/10.1088/0022-3727/31/10/006.

[49] M. Busquet, A. Torrance, A numerical slipline field for the sliding cylinder problem, Wear. 241 (2000) 86-98. https://doi.org/10.1016/S0043-1648(00)00360-4.

[50] J.M. Challen, L.J. McLean, P.L.B. Oxley, Plastic deformation of a metal surface in sliding contact with a hard wedge: its relation to friction and wear., Proc. R. Soc. London, Ser. A Math. Phys. Sci. 394 (1984) 161-181. https://doi.org/10.1098/rspa.1984.0074.

[51] M.A. Moore, R.M. Douthwaite, Plastic deformation below worn surfaces, Metall. Trans. A. 7 (1976) 1833-1839. https://doi.org/10.1007/BF02659813.

[52] K.H. Zum Gahr, Formation of wear debris by the abrasion of ductile metals, Wear. 74 (1981) $353-$ 373. https://doi.org/10.1016/0043-1648(81)90173-3.

[53] N.E. Frost, K.J. Marsh, L.P. Pook, Metal fatigue, Clarendon Press, 1974.

[54] L.P. Pook, Metal fatigue: what it is, why it matters, Springer, 2007. 


\title{
Supplementary document
}

\section{Study of wear particles formation at single asperity contact: An experimental and numerical approach}

\author{
M.A. Mekicha ${ }^{a}$, M. B. de Rooij ${ }^{a}$, T.Mishra ${ }^{a}$, D.T.A. Matthews ${ }^{a}$, L. Jacobs ${ }^{a, b}$, D. J. Schipper ${ }^{a}$ \\ a Department of Mechanics of Solids, Surfaces \& Systems (MS $\left.{ }^{3}\right)$, Faculty of Engineering Technology, University of Twente, \\ Enschede, The Netherlands. \\ ${ }^{\mathrm{b}}$ Tata Steel, Research \& Development, IJmuiden, the Netherlands.
}
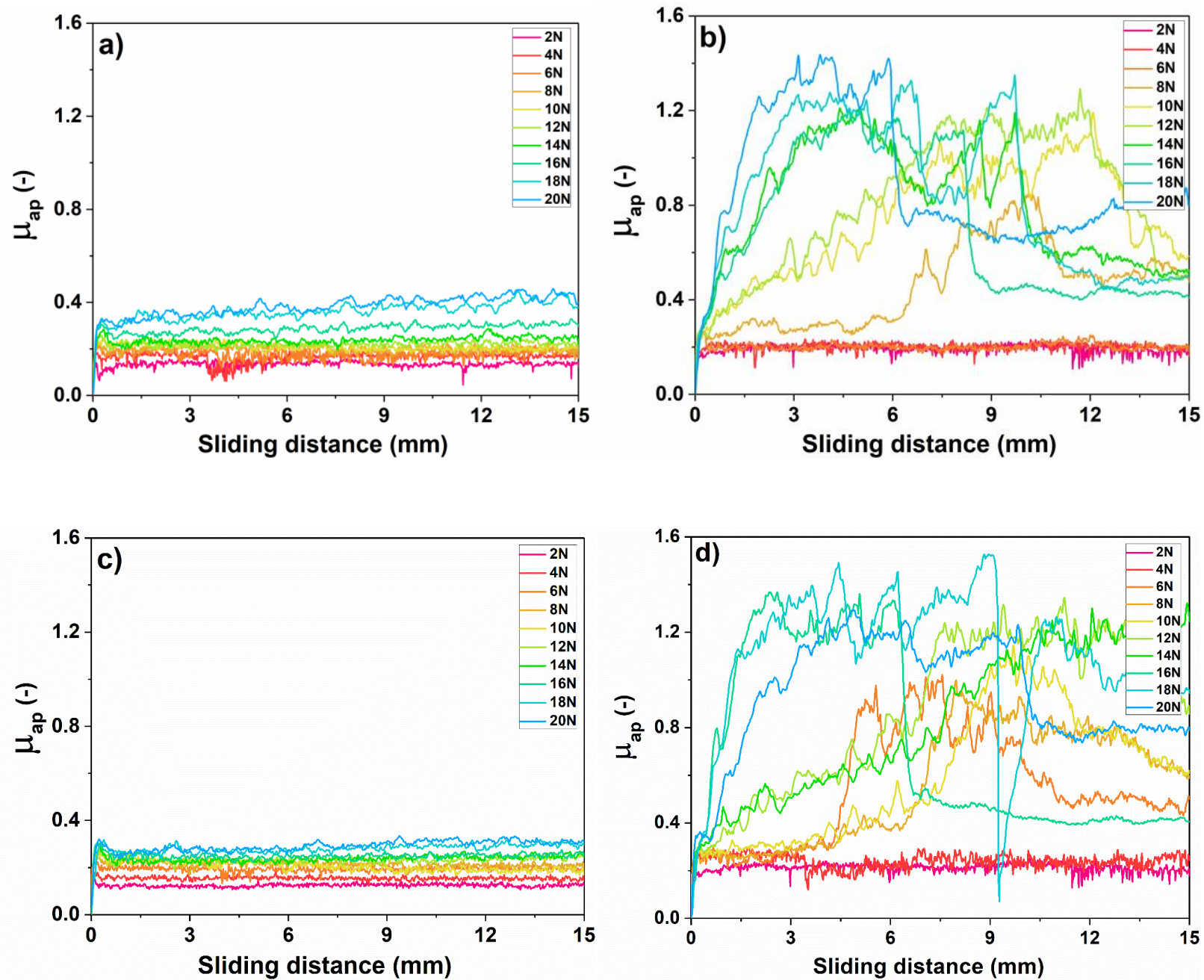

Figure S1: Friction curves of the scratch experiments: (a) uncoated indenter - lubricated, (b) uncoated indenter - dry, (c) $\mathrm{Cr}$ plated indenter - lubricated, and (d) $\mathrm{Cr}$ plated indenter - dry. The apparent friction coefficient is most stable in the lubricated scratch experiments and at very low loads of the dry experiments $(<6 \mathrm{~N})$. The friction curves exhibited a large fluctuation for the dry experiments at high loads. 

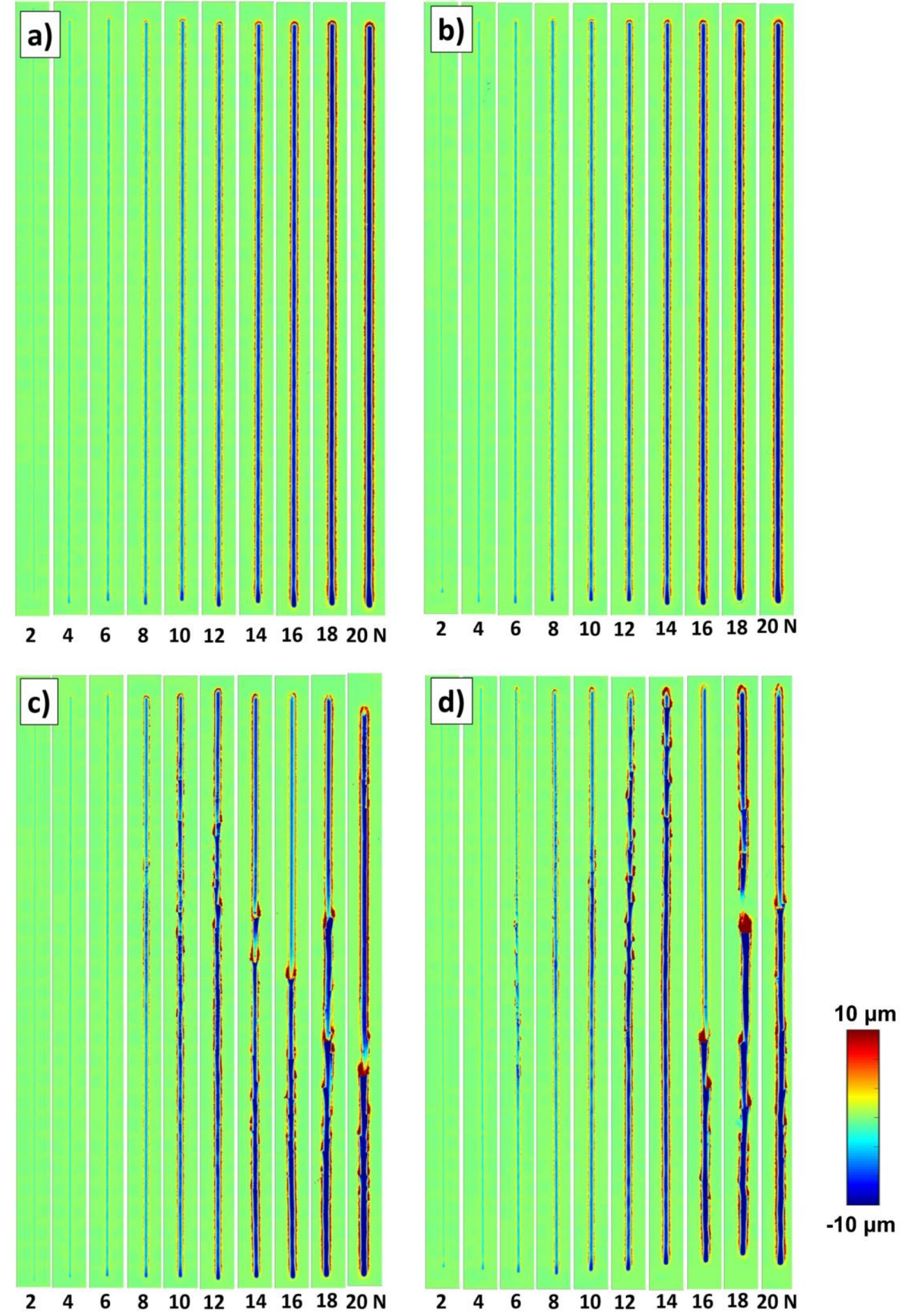

Figure S2: Confocal microscopy images of the wear tracks of the scratch experiments. The length of the scratches is $15 \mathrm{~mm}$ and the direction of sliding is from bottom to top: (a) Uncoated indenter - lubricated, (b) Cr plated indenter - lubricated, (c) Uncoated indenter - dry, (d) Cr plated indenter - dry. While smooth wear groove profiles are seen for the lubricated experiments, rough scratch profiles are observed for the dry ones (particularly at high loads). 


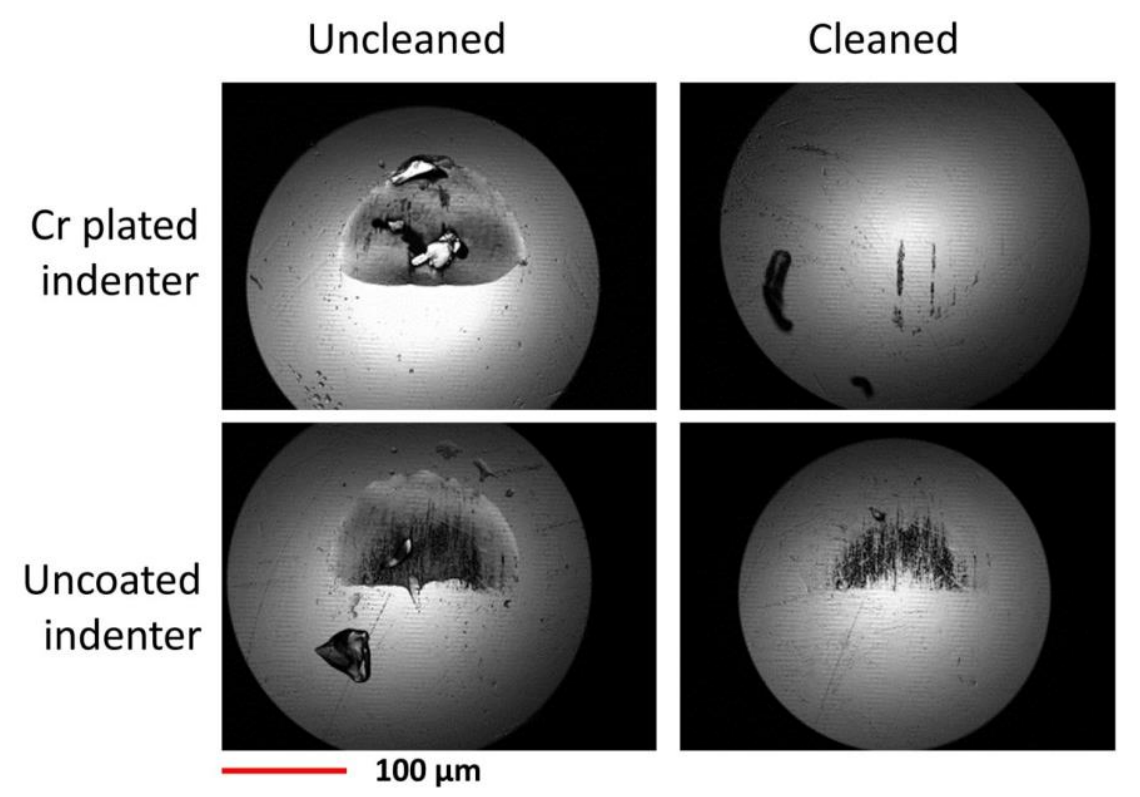

Figure S3: Indenters after $10 \mathrm{~N}$ scratch experiments in lubricated condition, uncleaned (L) and cleaned (R). Reduced adhesion between the strip and the indenter prevents the build-up of a lump and facilitates formation of a loose chip in the case of lubricated scratch experiments.

a)

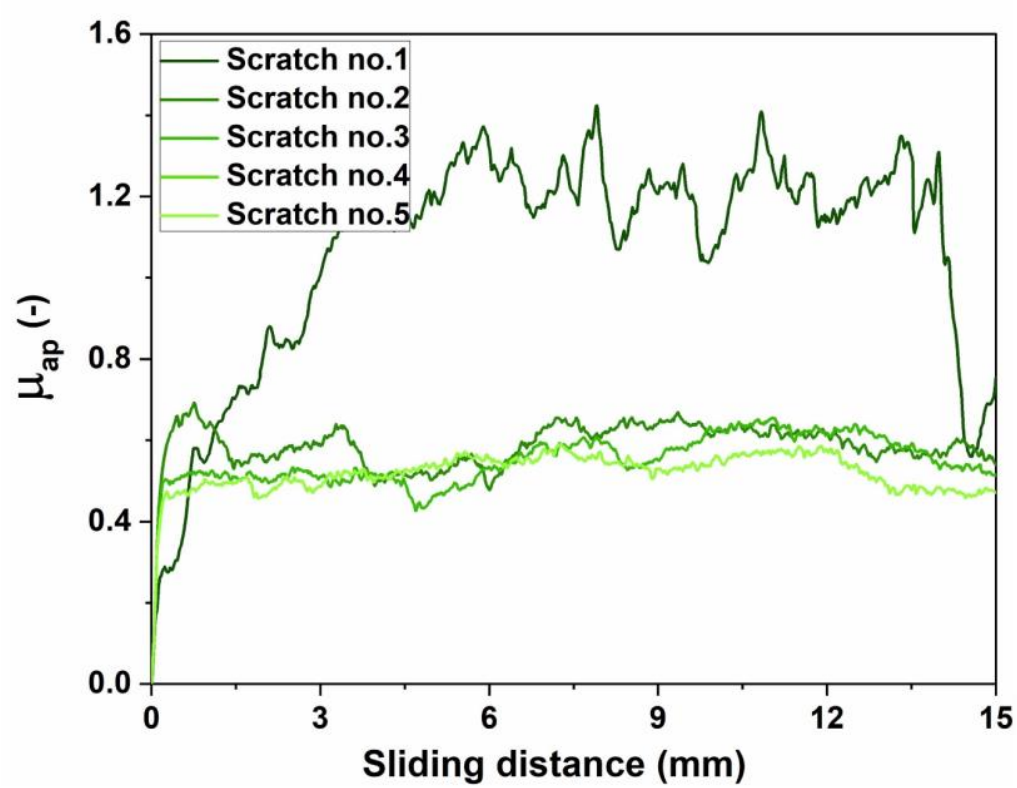

b)

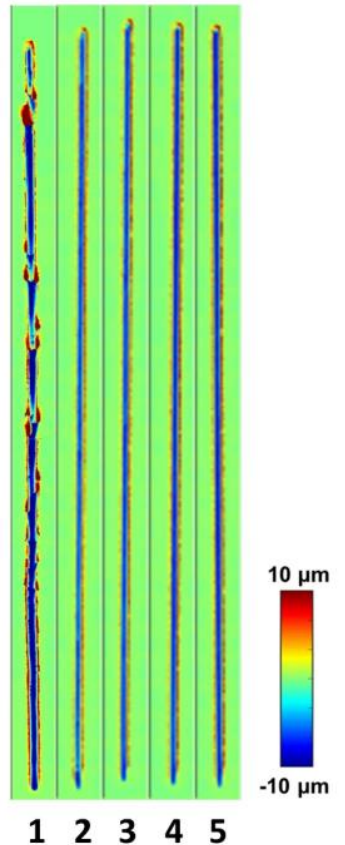

Figure S4: Friction curve (a) and wear track profile (b) of the repeated scratch experiments in dry condition using uncoated indenter at $16 \mathrm{~N}$ normal load. The direction of sliding is from bottom to top. Once the lump reaches a certain a critical height, it is detached and gross sliding occurs at the bottom of the lump - which is reflected by the friction drop at the end of scratch no.1. At this point, a stable transferred layer is formed on the indenter and remains there and no new wear debris is formed in the following sliding process. 

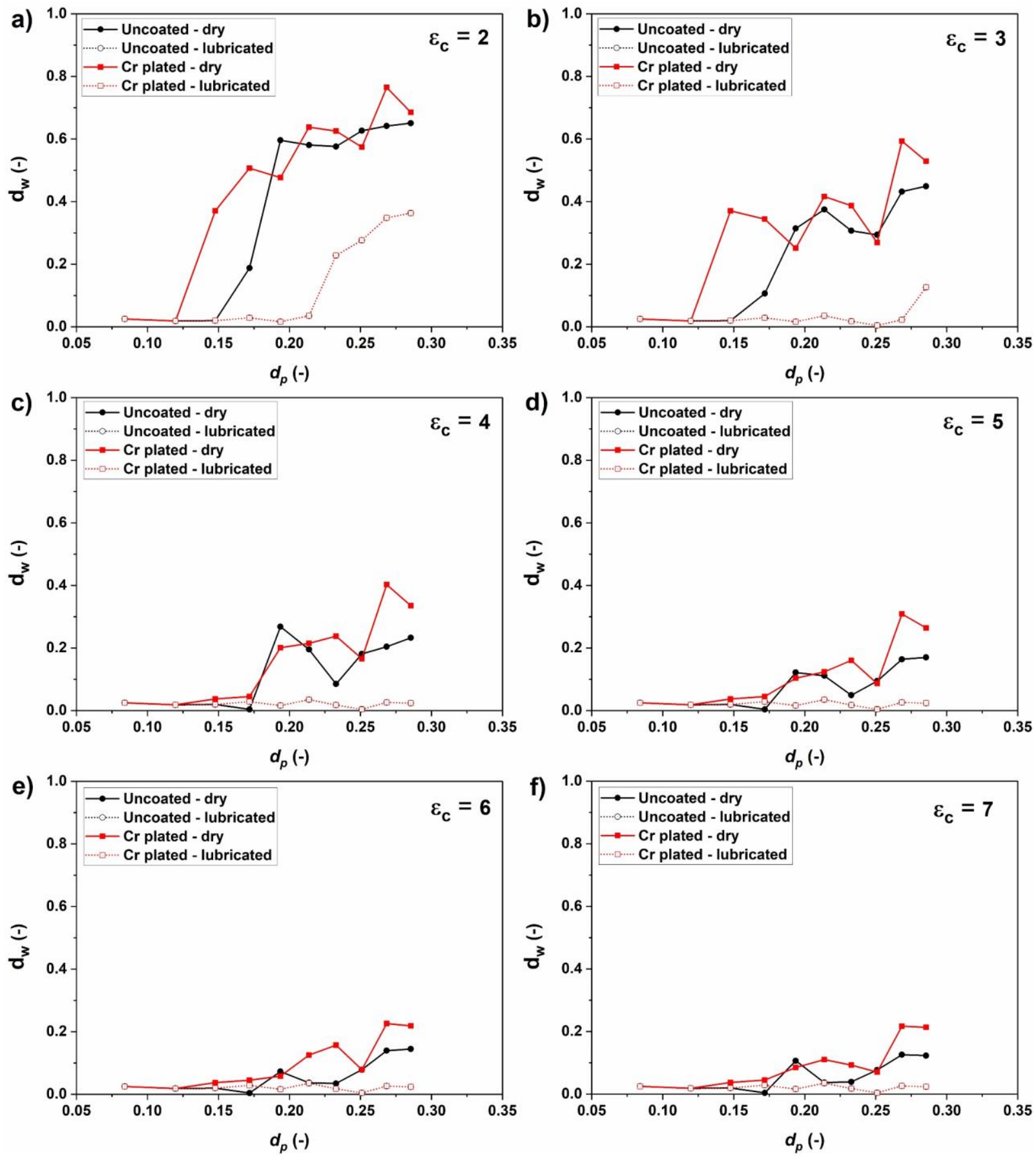

Figure S5: Degree of wear of the material point scratch simulations as a function of degree of penetration for different critical strain $\varepsilon_{c}$ values. It has been observed that a critical plastic strain in the range of 3 to 4 (figure $\mathrm{S} 5 \mathrm{~b}, \mathrm{c}$ ) gives a reasonable agreement with the experiments in terms of predicting the degree of wear. $\varepsilon_{c}$ of 2 greatly overestimates the degree of wear (figure $S 5$ a), whereas $\varepsilon_{c}$ values greater than 5 underestimate the degree of wear (figure $\mathrm{S} 5 \mathrm{~d}$-f) compared to the scratch experiments. 


\section{Paper C}

Mekicha MA, de Rooij MB, Matthews DTA, Pelletier C, Jacobs L, Schipper DJ. The effect of hard chrome plating on iron fines formation. Tribol Int 2020;142: 106003

https://doi.org/10.1016/j.triboint.2019.106003. 



\title{
The effect of hard chrome plating on iron fines formation
}

\author{
M.A. Mekicha ${ }^{a}$, M. B. de Rooij ${ }^{a}$, D.T.A. Matthews ${ }^{a, b}$, C. Pelletier ${ }^{b}$, L. Jacobs ${ }^{a, b}$, D. J. Schipper ${ }^{a}$ \\ a Department of Mechanics of Solids, Surfaces \& Systems (MS ${ }^{3}$ ), Faculty of Engineering Technology, University of Twente, \\ Enschede, The Netherlands. \\ ${ }^{\mathrm{b}}$ Tata Steel, Research \& Development, Ijmuiden, The Netherlands.
}

\begin{abstract}
Scratch tests and reciprocating sliding tests were carried out under lubricated conditions to explore the influence of hard chrome plating on iron fines formation. In the scratch tests, the effect of hard chrome plating on iron fines formation at single asperity contact due to its inherent property have been investigated. In the reciprocating sliding tests, the initial roughness of the substrate and the roughness changes introduced due to the hard chrome coating have been taken into account. It was found that both the tribochemistry of the chromium layer and the smoothening of aggressive roughness features from the grinding process due to chrome plating play an important role in reducing iron fines formation.
\end{abstract}

\section{Keywords:}

Hard chrome plating; Iron fines; Scratch tests; Tribochemistry.

\section{Introduction}

Cold rolled sheet metals are extensively used in many sectors such as automotive, packaging and electronics industries. The surface cleanliness of a rolled sheet is important for the functional and aesthetic properties of many sheet products and their downstream product process performance in forming operations [1,2]. The generation of iron fines due to the ploughing action of the roughness peaks of the roll through the strip surface during cold rolling is one of the main factors that contaminate the strip surface [3]. Iron fines originate mainly from the sheet metal being rolled, which is generally much softer than the roll $[3,4]$. They can cause problems in fouling the cold rolling mill as well as negatively affect downstream processes such as annealing, galvanizing, filtration, forming and painting. For example, the iron fines that remain on the strip can reduce the adherence of zinc coating during galvanizing, and consequently, decrease corrosion resistance [1]. A large amount of wear debris can block the filtration system. Moreover, cleaning the strips to remedy poor surface cleanliness incurs an extra cost and is environmentally undesirable.

The ever-increasing demands on strip quality in terms of surface cleanliness require reducing the generation of iron fines during cold rolling. In order to achieve this, a thorough understanding of the rolling tribological system and the effect of rolling parameters is vital as these parameters play a decisive role in iron fines generation. The thickness reduction, rolling speed, and roll and strip roughness determine the lubrication regime and the ratio of metal to metal contact. The strip and the roll surface chemistry, and the lubricant and its additives define the physical and chemical interaction at the roll bite interface. These macro-scale rolling parameters create the environment at the micro-scale. The micro-scale is the scale where iron fines formation actually takes place. At micro-scale, the roll asperities plough through the strip surface. This ploughing could lead to wear particle formation depending on the wear regime [5]. Methods that can be employed to enhance strip cleanliness include modifying pass schedules (e.g. reduction ratio per mill stand) [6], lubricant properties [7,8], strip properties (e.g. surface roughness resulting from pickling) [4] and/or roll surface (e.g. hard chrome plating) $[9,10]$. The focus of this study is on the influence of hard chrome plating the rolls on iron fines formation.

Chrome plating the rolls has been a common practice in the steel industry for a long time, both to increase the service life of the roll and to improve strip cleanliness. The high hardness of the chromium coating (up to $1200 \mathrm{HV}$ ) provides higher abrasion resistance, which helps to increase roll life time [11]. Additionally, it helps against adhesive transfer for sticky alloys $[9,10,12]$. It is reported that chrome plating could make a 
difference of up to $20 \%$ in reflection tape value, a method used to quantify iron fines generated $[3,13]$. Although its positive influence on strip cleanliness has been known, there are only few studies on the governing mechanisms why this coating improves strip cleanliness.

Jacobs et al. $[3,13]$ performed experiments on a specially designed plate-out tester, using oil in water emulsion, to study the influence of chrome plating on the efficiency of oil adherence to the roll or strip surface. They found out that the amount of oil that adheres to the chrome coated samples is at least twice the amount of oil on the uncoated samples. The authors suggested that the increased oil adherence on chrome plated rolls could be one of the reasons why it results in cleaner strips. Nevertheless, they did not examine the influence of chrome plating on the change of the micro roughness of the asperities. In another study, De Mello et al. [9] investigated the combined influence of surface texturing and hard chromium coating on the wear behavior of cold rolling mill rolls. Their results indicate that the influence of chrome plating on roughness and wear behavior depends on the initial surface condition. The authors emphasize that wear is controlled by the generation and stability of a tribolayer formed during the contact. In their recent work, Montmitonnet et al. [10] studied the effect of chrome plating on strip cleanliness by performing plane strain compression tests under lubricated conditions. In their tests, chrome plated punches exhibited a cleaner strip and lower friction compared to the uncoated punches. The authors attributed the decrease of friction to the formation of a tribolayer on the chrome layer with positive tribological properties. Furthermore, they argue that strip cleanliness is not an intrinsic property of chrome plating but rather depends on the quality of the coating deposited.

In summary, the factors that are proposed in literature to contribute to the improvement of strip cleanliness by chrome plating the rolls are: (i) better adherence of oil to the chrome plated surface than to the steel surface [13]; (ii) the formation of $\mathrm{Cr} / \mathrm{CrO}_{x}$ tribolayer with desirable tribological properties [9]; and (iii) smoothening of the sharp and aggressive features from the grinding process with gentler features [10]. The first two are due to the inherent property of the chromium coating and the last one is due to its influence on the roughness features of the roll surface. In reality, the improvement could be due to some or all of these mechanisms acting simultaneously.

Besides the limited number of studies conducted on the positive influence of chrome plating of the rolls on strip cleanliness, there is a need to find a replacement for this coating due to health and safety regulations. The electrolyte used in the hard chromium plating process contains a hexavalent chromium $\left(\mathrm{Cr}^{6+}\right)$ ion which is hazardous to human health and is environmentally harmful. For example, the products containing $\mathrm{Cr}^{6+}$ are on the list of substances of very high concern and to be progressively eliminated under the REACH (Registration, Evaluation, Authorisation and Restriction of Chemicals) regulation by the European chemicals agency [14]. To systematically develop alternative coatings, a detailed understanding of the fundamental mechanisms behind the positive effects of chrome plating on strip cleanliness is necessary.

In this work, we explore experimentally the influence of chrome plating on iron fines formation. Two experimental techniques, namely scratch tests and reciprocating sliding tests, were carried out for this purpose to simulate the relative sliding of the roll and the strip in the roll bite. In the scratch tests, the influence of chrome plating on iron fines generation at single asperity contact due to its inherent property excluding the roughness changes introduced during coating was investigated. In reciprocating sliding tests, the influence of chrome plating on iron fines formation taking into account the initial roughness of the substrate and the roughness changes caused by the hard chrome plating was studied.

\section{Materials and methods}

Both the scratch and the reciprocating sliding experiments were performed using a multi-purpose tribometer (UMT Tribolab from Bruker). The contacts in the current experiments were designed to resemble the roll-strip contact in the roll bite of cold rolling processes. Typically, in rolling processes the roll surface is prepared by grinding and it is continuously in contact with fresh incoming strip surface. An illustration of a roll-strip contact geometry is provided in figure 1a. In the roll bite, the speed of the strip equals the peripheral speed of the roll only at the neutral point. The roll moves faster than the strip before 
the neutral point and the strip moves faster than the roll after the neutral point. Thus, an asperity on the roll surface slides on the strip surface in the rolling direction before the neutral point and backwards after the neutral point. The sliding length depends on the thickness of the strip, the reduction ratio and the location of the neutral point. Rolling is commonly done with the neutral point kept close to the exit of the roll bite.

\subsection{Scratch tests}

In the scratch tests, a single asperity of a roll sliding on a strip material is simulated. The scratch tests were conducted under lubricated conditions using conical pins with a hemispherical tip. The hemispherical tip has a radius in the order of a single roughness asperity of a roll surface. The pin was fastened to a stage with a linear drive while the strip substrate was kept stationary. Each scratch was made by applying a normal load on the pin and sliding it $10 \mathrm{~mm}$ in the forward direction and $0.5 \mathrm{~mm}$ backward. Then, the pin is lifted and returned to the starting position and moved a distance of $1 \mathrm{~mm}$ perpendicular to the sliding direction to the side, after which the process is repeated (figure $1 \mathrm{~b}$ ). In this way it is ensured that the pin, which represents the roll asperities, is always in contact with a fresh strip surface, which corresponds to the rolling process. The sliding distance of the scratches corresponds to a typical slip distance of the first stand of a tandem cold rolling mill, where iron fines generation is a severe problem.
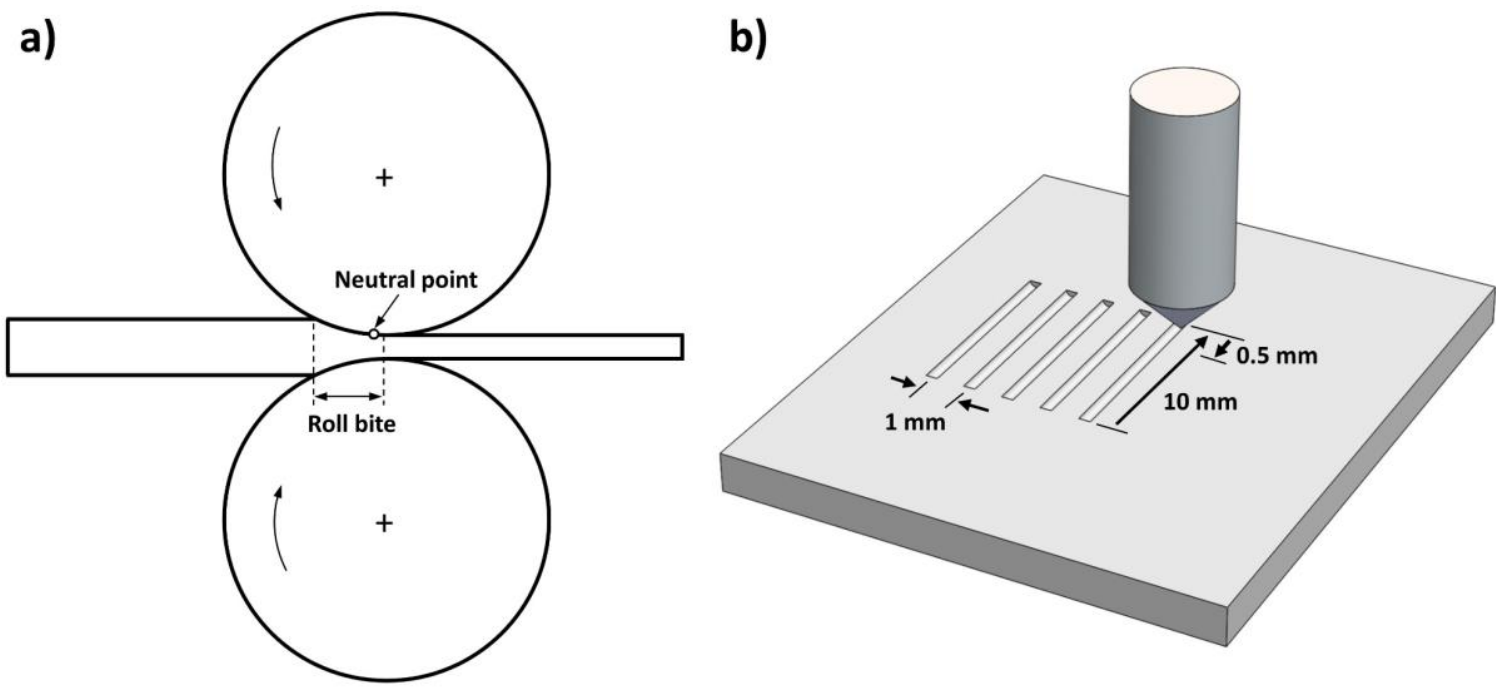

Figure 1: Schematic of (a) the contact geometry of cold rolling and (b) scratch tests (not to scale).

The scratch pins were made of a commercially available medium - alloyed cold work tool steel (Uddeholm Rigor $^{\circledR}$ ) that has similar composition to commonly used roll material. Chemical composition in wt. \%: 1.0 C, $0.3 \mathrm{Si}, 0.6 \mathrm{Mn}, 5.3 \mathrm{Cr}, 1.1 \mathrm{Mo}, 0.2 \mathrm{~V}$, balance Fe; hardness 60 - $62 \mathrm{HRC}$ as supplied by the manufacturer. Three sets of scratch pins with a hemispherical tip radius of 225,265 and $615 \mu \mathrm{m}$, two pins for each radius, were prepared. Half of the pins, one from each radius, were commercially hard chrome plated under usual industrial conditions and half of them uncoated for comparison. The average thickness of the coating is 5 $-10 \mu \mathrm{m}$. Coating thickness measurements were made using a magnetic induction method (DUALSCOPE ${ }^{\circledR}$ FMP20 from Fischer) according to ISO 2178. Prior to chrome plating, the hemispherical tips of all the pins were polished to a mirror like surface finish, see figure $2 \mathrm{a}$. To remove the roughness changes introduced due to chrome plating and ensure that the chrome plated pins have the same surface finish as the uncoated pins, the former were polished again after the coating was applied. A section $(50 \mathrm{~mm} \times 50 \mathrm{~mm} \times$ $3 \mathrm{~mm}$ ) of industrially hot rolled and pickled Titanium-stabilized interstitial-free (Ti-IF) steel strip was used as the counterface. This steel grade was chosen because it is extensively used in automotive applications owing to its high formability. It has also been observed to pose a high risk for poor strip cleanliness while rolling. The strip samples were polished to a mirror like surface finish.

Prior to the tests, the pins and the strip samples were thoroughly degreased and cleaned in isopropanol. Next, a film $\left(1 \mathrm{~g} / \mathrm{m}^{2}\right)$ of a palm-oil based fully formulated industrial cold rolling oil containing anti-wear as 
well as extreme-pressure additives was applied on the polished side of the strip sample by smearing the oil using a clean rubber roller. The amount of oil film per unit area was determined by measuring the weight of the strip before and after applying the lubricant using a high resolution $\left(10^{-2} \mathrm{mg}\right)$ microbalance. The load applied on the pins was selected so that the scratches are either in the wedge forming or cutting mode of abrasive wear in each case. This choice was made because wear debris generation occurs in these two abrasive wear regimes [5]. A normal load of $17 \mathrm{~N}, 25 \mathrm{~N}$ and $50 \mathrm{~N}$ were used for the pin radius of 225 $\mu \mathrm{m}, 265 \mu \mathrm{m}$ and $615 \mu \mathrm{m}$ respectively. A constant sliding speed of $1 \mathrm{~mm} / \mathrm{s}$ was used. A total of 16 scratches were made by each pin. The scratches were done parallel to the rolling direction of the strip. The friction coefficient was measured with a sampling frequency of $1 \mathrm{kHz}$ and the tests were monitored in-situ using a scientific camera to study the scratches. The worn surfaces were analyzed using an optical microscope (Keyence VHX-5000) and a scanning electron microscopy (SEM). In addition, X-ray photoelectron spectroscopy (XPS) analysis was done on the wear scar of the pins after the scratch tests to analyze the chemical nature of the tribolayer formed.

The XPS analysis was performed with Quantera SXM (scanning XPS microprobe) from Physical Electronics. Prior to the XPS analysis, the pins were thoroughly cleaned with acetone followed by 20 minutes ultrasonic cleaning with isopropanol in order to remove residual oil and wear debris. The sampling depth of XPS is generally few nanometers; therefore, the results reflect information on the uppermost pin layer including an adsorption film formed by the lubricant additives. The XPS spectra were acquired using a monochromatic Al Ka source with a spot size of $100 \mu \mathrm{m}$. First, a wide scan survey was done to see the gross overall atomic content of the surface layer. Afterwards, element spectra scans were made with a better energy resolution. Charge correction was done by setting the binding energy of $\mathrm{C} 1 \mathrm{~s}$ peak of aliphatic carbon at $284.8 \mathrm{eV}$. The identification of the tribofilm species is possible by comparing the peak spectra in the tribofilm to the same photon binding energies in the reference spectrum.

\subsection{Reciprocating sliding tests}

Reciprocating sliding tests represent the contact of a strip and a roll surface ground to several roughness values. In these tests, the strip substrate was fastened to a stage with a reciprocating drive while the pin was kept stationary. A self-aligning pin holder was designed to avoid edge scratches. The direction of sliding was along the rolling direction of the strip. Reciprocating sliding tests were carried out using pins with a squared cross section $(5 \mathrm{~mm} \times 5 \mathrm{~mm})$. The tip of the pins on one side was shaped to have a cylindrical shape (diameter $50 \mathrm{~mm}$ ) to resemble a fragment of a roll, see figure 2 . The tips were ground and polished in the sliding direction similar to the grinding process of rolls. Three groups of pins in terms of r.m.s. surface roughness (Sq), approximately $0.03 \mu \mathrm{m}, 0.3 \mu \mathrm{m}$ and $1 \mu \mathrm{m}$ were prepared. Four pins were prepared for each roughness value. Afterwards, two pins from each roughness group were chrome plated. No surface modification was done on the coated pins after the coating was applied, which is different from the scratch tests (section 2.1).

The counterface was a Ti-IF steel strip sample in as pickled surface condition. The strip samples were used in as pickled condition so that the surfaces of the contacting pairs of the tests are similar to that of the first stand of a tandem cold rolling mill. Both the pins and the strip samples were degreased using isopropanol prior to the tests. The tests were carried out under lubricated conditions using the same rolling oil as the scratch tests (section 2.1). The reciprocating sliding tests were done using a constant normal load of 100 $\mathrm{N}$, a stroke length of $25 \mathrm{~mm}$, a frequency of $3 \mathrm{~Hz}$, and a duration of 5000 cycles $(250 \mathrm{~m})$ at room temperature. The friction coefficient was continuously monitored during the tests. The surface of the worn pins were analyzed using SEM.

The surface topography of the pins was measured using a non-contact three dimensional height profiler (Sensofar S-neox confocal microscopy). For the r.m.s. surface roughness analysis, 3 measurements at different locations with a resolution of $0.64 \mu \mathrm{m}$ and a scan area of $877 \mu \mathrm{m}$ by $660 \mu \mathrm{m}$ were taken. The one dimensional (i.e. perpendicular to the grinding direction) power spectral density (PSD) of the pins surfaces was analyzed before and after hard chrome plating. Profile scans for PSD analysis were made with a resolution of $0.142 \mu \mathrm{m}$ and a scan length of $146 \mu \mathrm{m}$. To average out the effects of noise, the PSD was 
obtained as an ensemble average of 30 profile scans at different locations. The PSD calculation was done using Welch's method in MATLAB with a Hamming window.

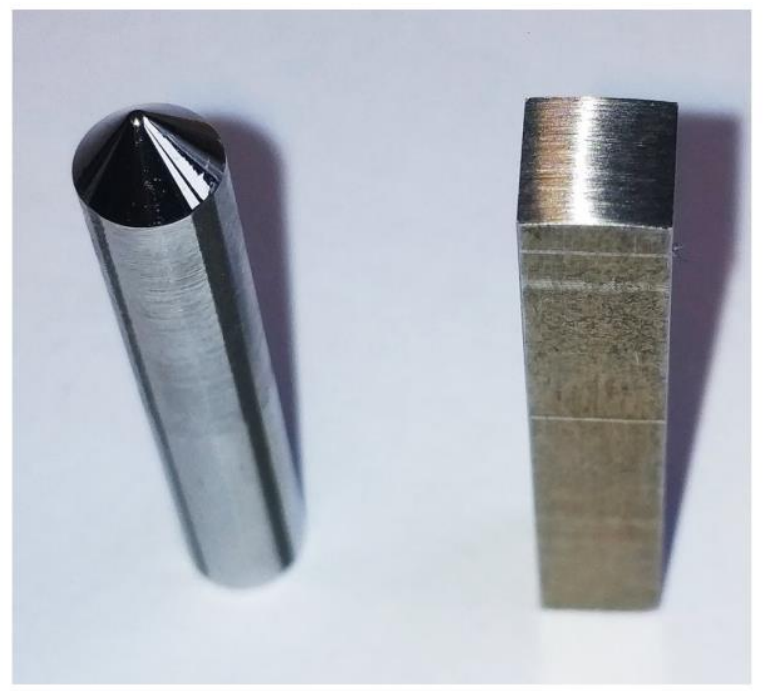

Figure 2: Pins used for the scratch tests (left) and reciprocating sliding tests (right).

The nanohardness of the strip sample, the uncoated and the chrome plated pins were measured using a Berkovich indenter (Nanoindentation tester $\mathrm{NHT}^{2}$ from Anton Paar). The measurements were made using a load of $40 \mathrm{mN}$ (indentation depths less than $0.5 \mu \mathrm{m}$ ) to avoid the effect of the substrate for the coated pins. 20 measurements were made for each sample. The average nanohardness values are $10.7 \pm 0.53 \mathrm{GPa}$ and $12.2 \pm 0.49 \mathrm{GPa}$ for the uncoated and hard chrome plated pins respectively. The average nanohardness value of the strip sample is $2.2 \pm 0.08 \mathrm{GPa}$.

\section{Results and discussion}

\subsection{Scratch tests}

The average steady state friction coefficient of the scratch tests is illustrated in figure $3 a$. The scratches made with the chrome plated pins showed lower friction coefficient on average compared to the scratches made with the uncoated pins. The distinct high friction coefficient of the chrome plated pin with a tip radius of $265 \mu \mathrm{m}$ can be explained by the large amount of cracks observed on the chromium layer of that particular pin (not shown). This indicates that the quality of the coating is very important in terms of strip cleanliness, as has been pointed out by other authors [10].

Factors such as interfacial shear stress, ploughing and asperity deformation all contribute to friction. The contribution of asperity deformation may be considered negligible in the current tests as both the contacting surfaces were polished to a very smooth mirror like finish [15]. Thus, ploughing and interfacial shear stress may be considered as the only two contributing factors to the friction. The ploughing component of friction can be assumed to be the same for both the uncoated and the chrome plated pins, as the pin geometry, the applied load, the surface finish, the lubrication condition and the counterface material are the same. Therefore, the difference in the friction coefficient between the uncoated and the coated scratch tests can solely be attributed to the difference in the interfacial shear stress. This component of friction is sensitive to the material combination and the tribochemistry of the contacting pair. The following two phenomena can explain the low friction coefficient of the scratches made with the chrome plated pins. First, the extreme pressure and polar additives may react with the chromium/chromium oxide layer to form a tribochemical film with low shear, and hence, lower friction. Second, generally lower adhesion is expected between the contact of dissimilar materials (i.e. chromium - steel in the scratch tests with the coated pins) than contact interfaces with similar materials (steel - steel for the uncoated pins) [16]. 
The differences in the friction coefficient value for the different pin radii is related to the differences in the size of the pins and the applied load. The friction curves neither show any substantial difference among the different scratches nor exhibited any particular trend as the number of scratches increases, see figure $3(b, c)$. It seems to be rather dependent on the local wear phenomena happening on each scratch. The large fluctuation of the friction coefficient for the uncoated pins most likely arises from the buildup and breaking of wear particles which was seen by the scientific camera observations.
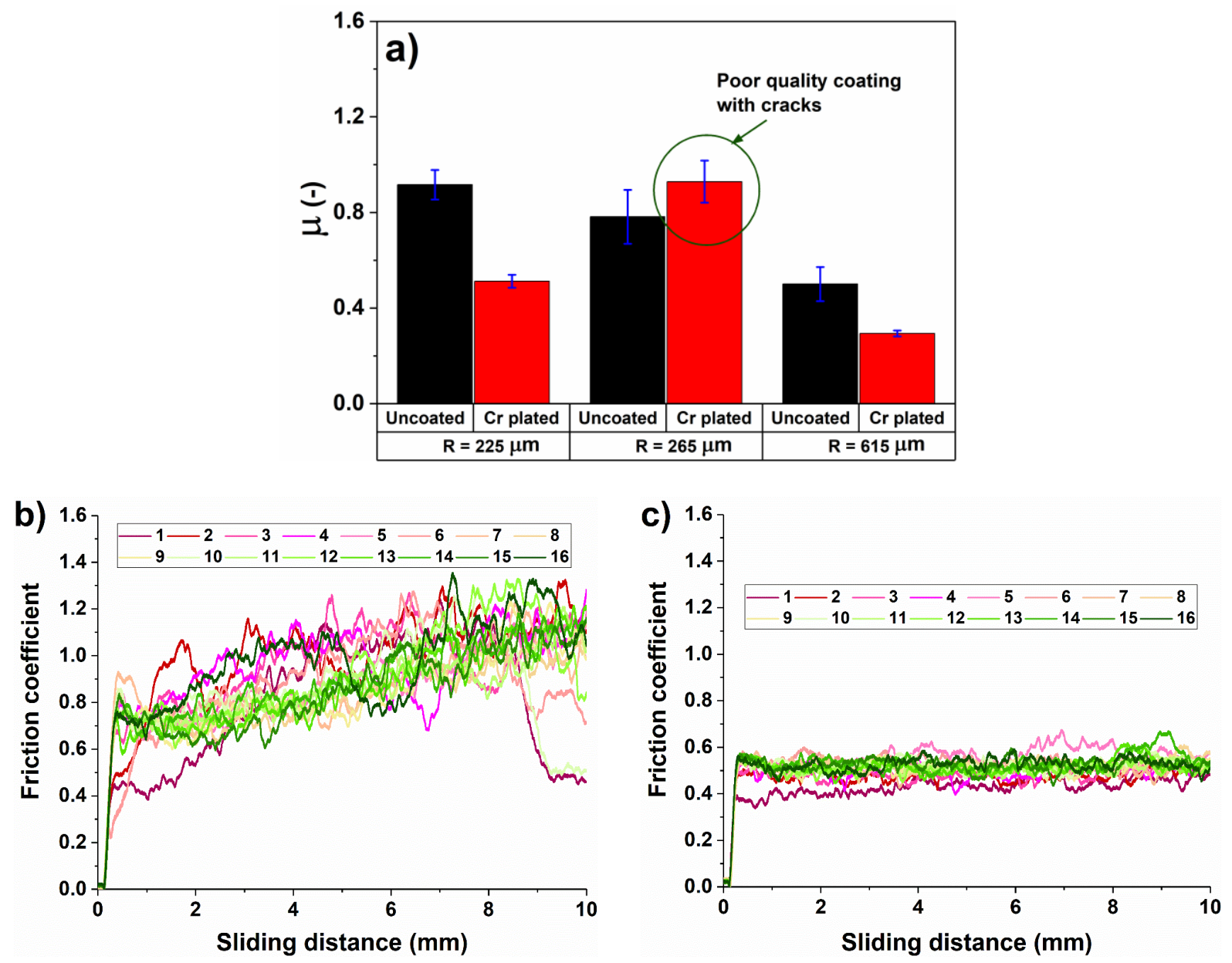

Figure 3: a) average friction coefficient ( $\mu$ ) of the scratch tests; friction coefficient vs sliding distance of the uncoated $b$ ) and hard chrome plated pins c) with a tip radius of $225 \mu \mathrm{m}$.

SEM images of the pins after the scratch tests are provided in figure 4. Although abrasion of the strip is the main wear mechanism, material transfer occurred on the tip of the pins. The uncoated and the chrome plated pins showed different degrees of strip material transfer, corresponding to their friction behavior. The chrome plated pins displayed a qualitatively significantly lower quantity of adhered strip material compared to the uncoated pins. Since all the test conditions are kept the same, the difference in the tribochemistry of the contacting pairs can be considered as the sole cause of this behavior.

For material transfer to happen, there should be a local breakdown of the lubricant film. In the scratch tests, a plastic wave is formed as the pin scratches through the strip surface. Due to the high contact pressure involved, lubricant failure can be expected at the contact spot. Depending on the strength of the boundary lubricant and the surface chemistry of the contacting counterparts, material transfer can happen. In the current tests, the lubricant additives may behave differently, in terms of physical and chemical interaction, towards the chromium layer of the coated pins and the steel surface of the uncoated pins. Probably, a tribolayer consisting chromium oxide(s) with positive effects on the tribological behavior is formed on the chromium surface, delaying the local failure of the lubricant, and subsequently delaying the initiation of adhesive wear. Once adhesive wear initiates, subsequent scratches may lead to build up of the transfer layer and lump growth. It has been shown in literature that the buildup of the transfer layer 
and the formation of big lumps is very sensitive to the material combination [17]. It is highly likely that the dissimilar steel - chromium material combination has a low rate of material transfer compared to the similar steel - steel contact pair.

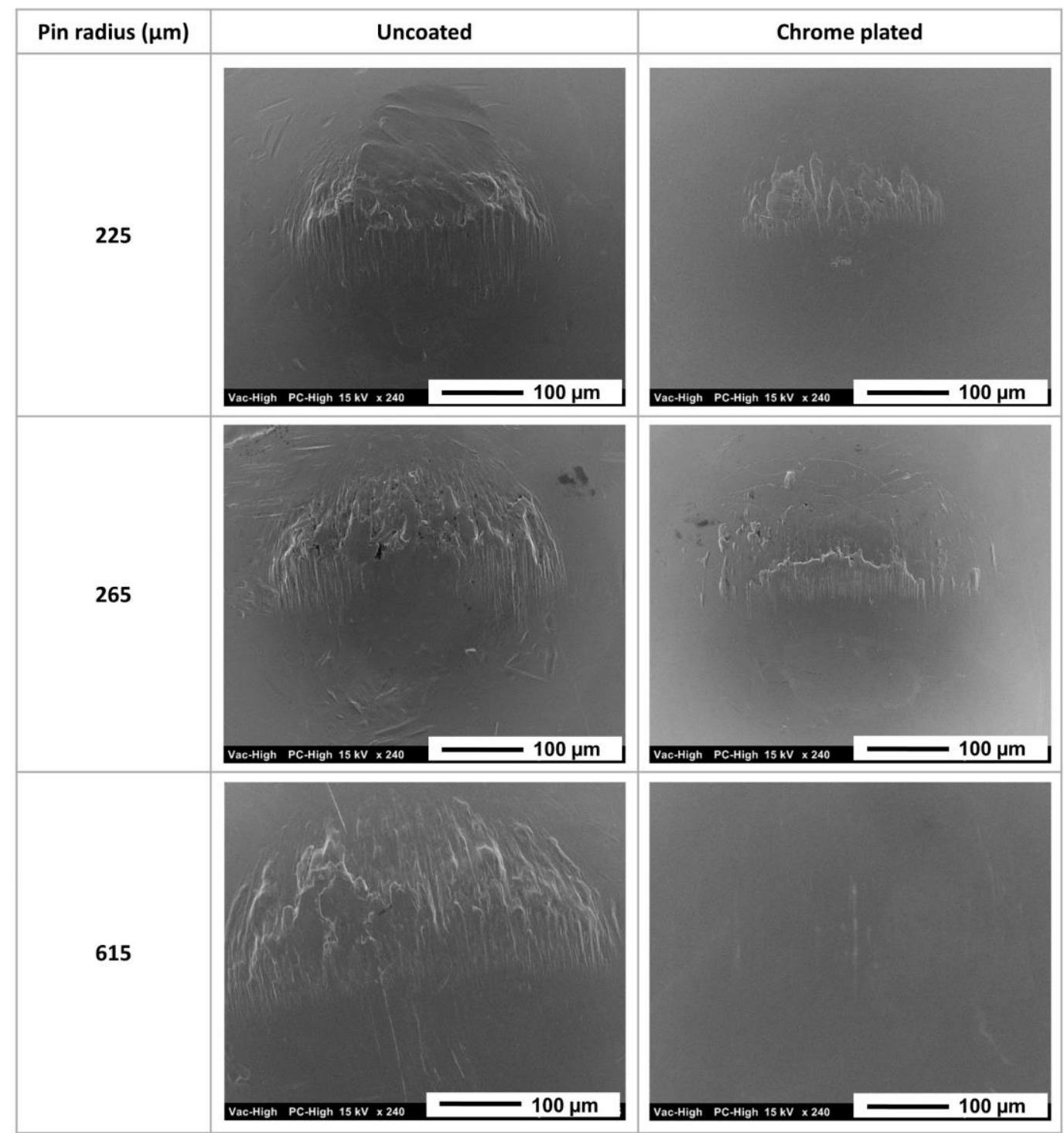

Figure 4: The SEM images of conical pins after the scratch tests. The pin sliding direction is from bottom to top.

Optical microscopy images of the scratch grooves on the strip surface are given figure 5 . The quantity of both loosely detached and adhered iron fines on the strip surface of the scratches made using the chrome plated pins is substantially smaller than the scratches made with the uncoated pins. This corresponds well to the friction measurements. The scratches made with the uncoated pins showed a higher friction coefficient, which means a higher friction shear stress at the contact spots. The increased tangential subsurface stress on the strip material due to the higher friction produces a greater surface damage on the strip. This leads to generation of more wear debris that contaminate the strip (figure 5) and more material transfer on the pin surface (figure 4). The camera observations also revealed that particle generation was accompanied by material transfer. Figure 6 shows a snapshot of the scratch tests at the end of the forward movement of the $16^{\text {th }}$ scratch. It can be clearly seen that more wear debris was generated and loosely adhered to the uncoated pin than the clean hard chrome plated pin. Furthermore, the wear debris showed more adherence to the uncoated pins and were partly carried to the next scratch. On the contrary, the chrome plated pins remained clean with no loosely adhered wear debris at the end of each scratch during the whole duration of the tests. 


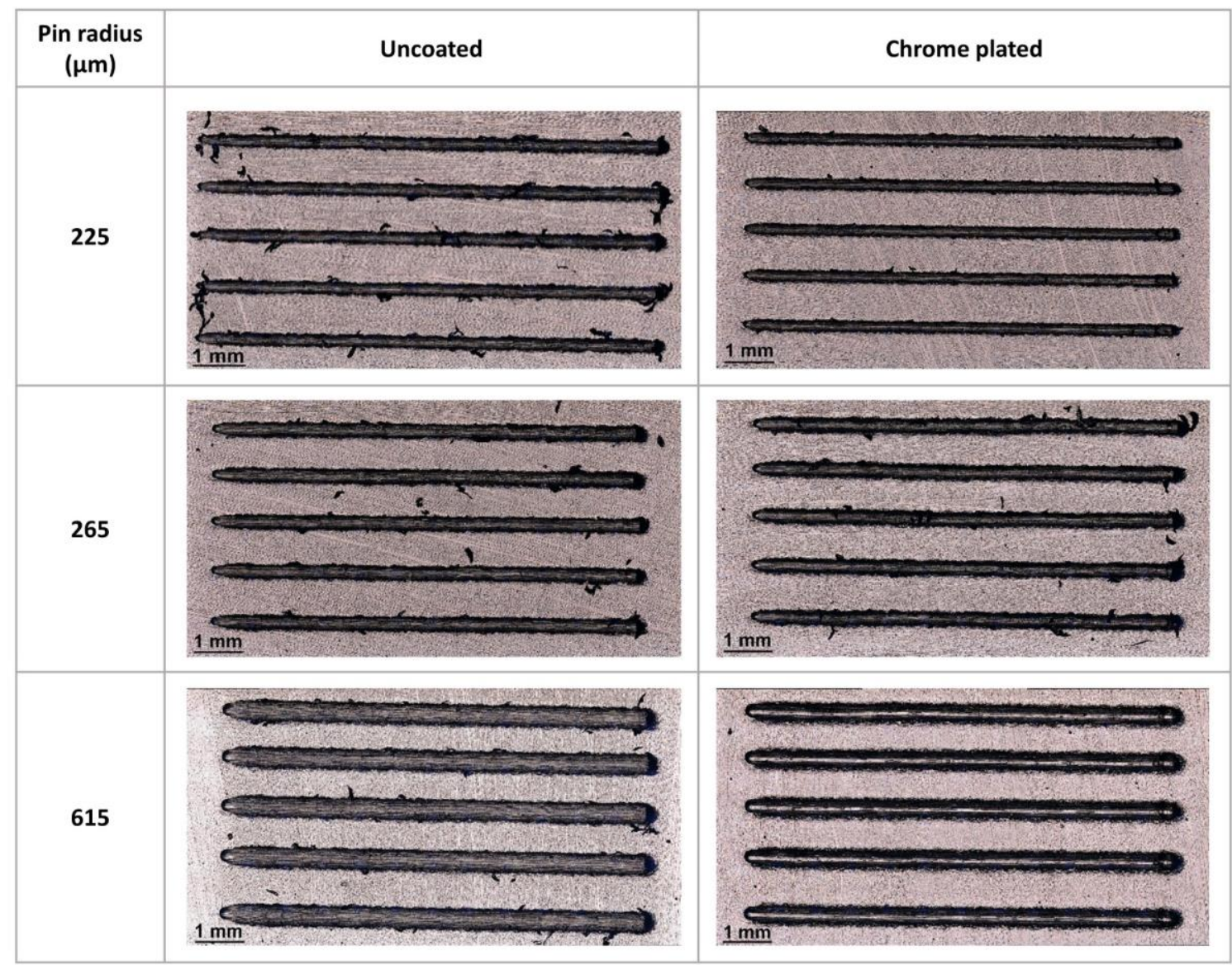

Figure 5: Wear grooves of the scratch tests with various chips. The direction of the scratch is from the left to the right.
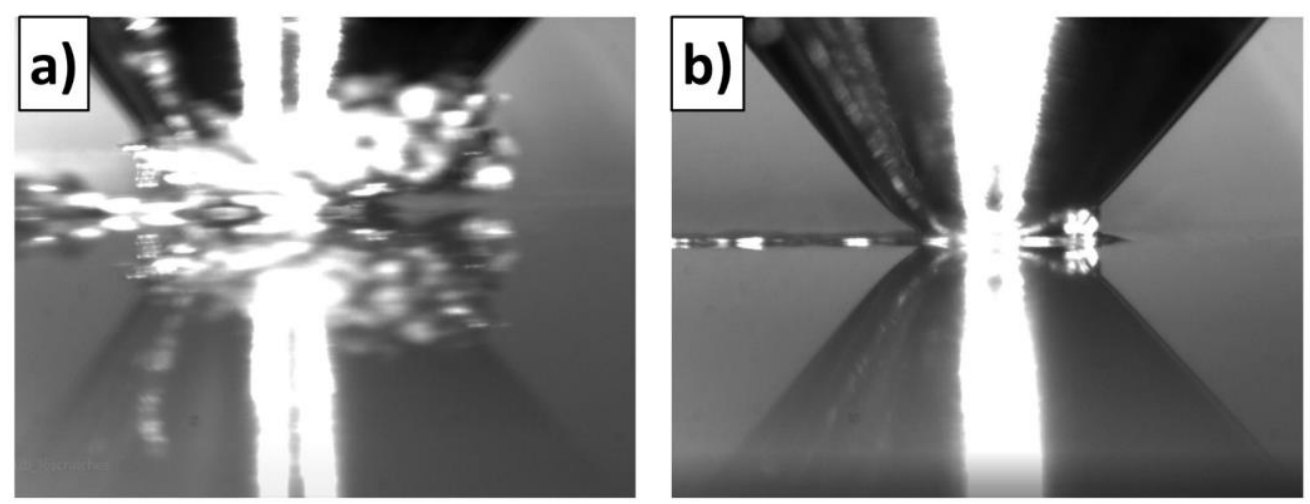

Figure 6: Snapshot of the scratch tests at the end of the 16th scratch (tip radius of $615 \mu \mathrm{m}$ ), (a) uncoated and (b) hard chrome plated.

XPS analysis was done on the worn tip of the pins to characterize the chemical nature of the tribofilm on the surface. The lubricant used in the current tests is a commercial fully formulated oil that contains friction modifiers, antioxidant, extreme pressure and anti-wear additives. The narrow scan XPS spectra of selected elements are provided in figure 7. A peak at $347.5 \mathrm{eV}$ which corresponds to calcium carbonate $\left(\mathrm{CaCO}_{3}\right)$ and calcium phosphates $\left(\mathrm{CaHPO}_{4}\right.$ or $\left.\mathrm{Ca}_{2} \mathrm{P}_{2} \mathrm{O}_{7}\right)$ was observed on the $\mathrm{Ca} 2 \mathrm{p}$ spectra of both the uncoated and the chrome coated pins [18]. However, the intensity of the peak on the chrome plated pin was significantly higher than the uncoated pin suggesting higher concentration (thicker tribofilm) of this species on the former. Overbased calcium sulphonate detergents are employed in industrial oils to act as extreme pressure and anti-corrosion additives. It is known that calcium detergent can interact with the surface and form $\mathrm{a} \mathrm{CaCO}_{3}$ pad like tribofilm that covers the surface [19-21]. In addition, calcium detergent 
and the phosphorus anti-wear agent generally have a synergetic effect and form a reaction film consisting of $\mathrm{CaCO}_{3}, \mathrm{CaHPO}_{4}, \mathrm{Ca}_{2} \mathrm{P}_{2} \mathrm{O}_{7}$ and $\mathrm{Fe}_{3}\left(\mathrm{PO}_{4}\right)_{2}[18,21]$. In the current tests, some calcium carbonate and calcium phosphates are likely to be generated on the worn surface due to the interaction of the calcium based detergents with the contacting surfaces and/or with other additives [18]. The presence of a sharp peak at the binding energy of $288.4 \mathrm{eV}$ of the $\mathrm{C} 1 \mathrm{~s}$ spectra, which is assigned to a $\mathrm{O}-\mathrm{C}=\mathrm{O}$ bond (carbonate and/or carboxylic), in the case of the chrome plated pins but no distinct peak on the uncoated pin supports this claim [22]. The lack of a distinct peak on the P $2 p$ spectra corresponding to the range of phosphates (133.2 $\mathrm{eV}$ ) suggests no presence of calcium phosphates on the surface. Hence, it is reasonable to conclude that calcium carbonate was likely deposited due to the interaction of the calcium detergent with the surface and/or with the other additives. In literature, it has been shown that the thickness of the calcium carbonate film depends on the material combination and the sliding speed [19]. Therefore, it is possible that a thicker protective calcium carbonate tribofilm was formed on the chrome coated surface than on the uncoated steel surface.
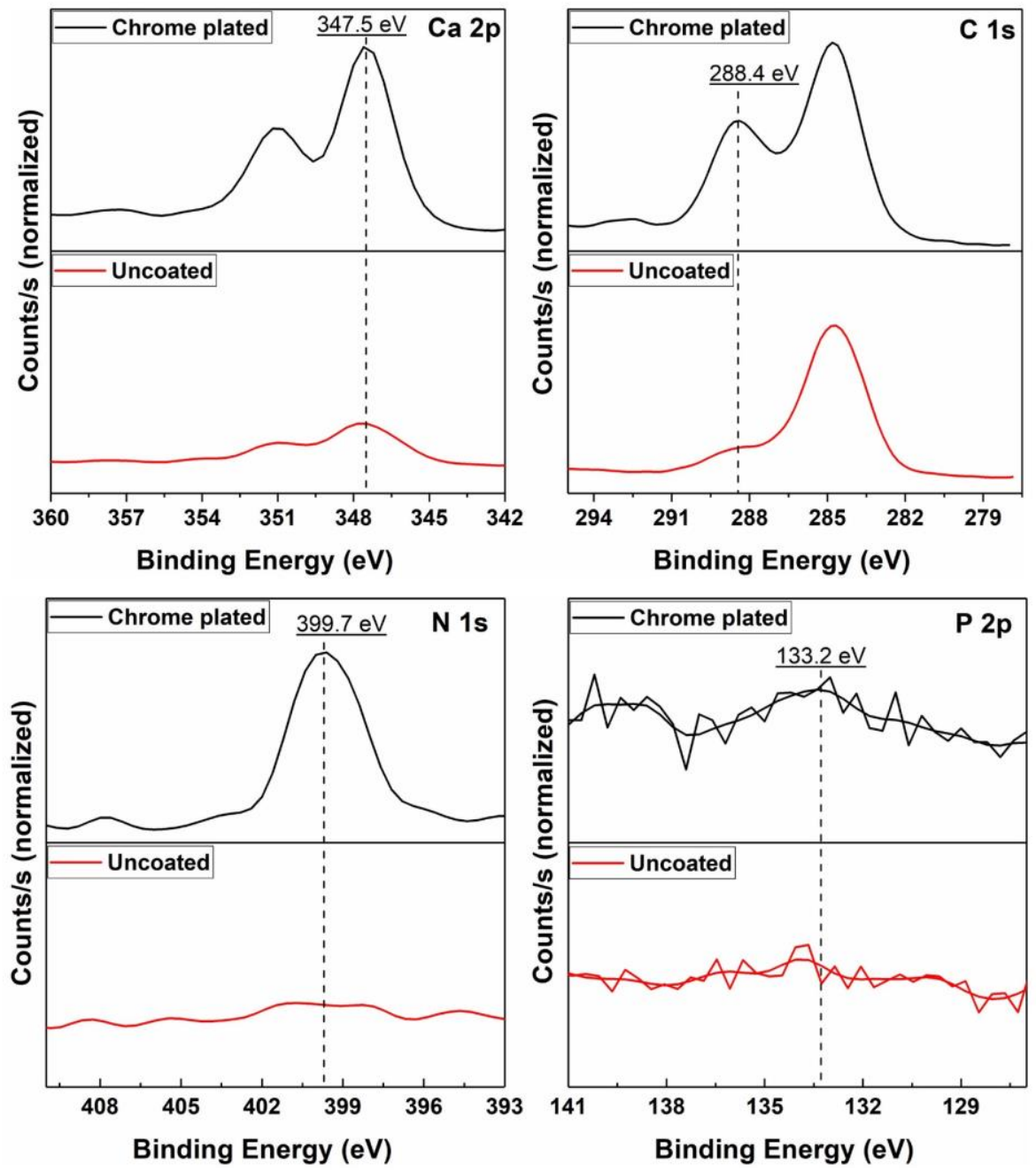

Figure 7: XPS spectra of the tribofilm on the worn pin surface.

Another major difference between the XPS spectra of the uncoated and the chrome plated pins is the $\mathrm{N}$ 1 s peak. A sharp peak at $399.7 \mathrm{eV}$ was observed on the chrome plated pin surface but not for the uncoated one. The binding energies for nitrogen in organic compounds overlap significantly $(399.0-400.6 \mathrm{eV})$ and can be difficult to decipher especially if there are multiple nitrogen containing groups. Nevertheless, this peak can be attributed to the amines species owing to their presence in the current lubricant as a friction modifier [22]. Organic friction modifiers such as amines are in general assumed to reduce friction by adsorbing/reacting on the lubricated contact surface. Friction modifiers can adsorb or chemically react on oxide covered metal surfaces [23]. Furthermore, they show competitive adsorption/reaction against other 
polar additives [24]. The adsorption and friction performance of amine based organic friction modifiers on surfaces has been shown to depend on surface chemistry and composition, its interaction with other additives, the bonding energy of the polar head to the surface, surface roughness and pressure $[22,23]$. The XPS results indicate that the amines adsorbed/reacted better to the chrome plated surface than the steel surface because of the different surface chemistry. This offers a possible explanation for the lower friction coefficient and less material transfer observed on the hard chrome plated pins.

The current tests were performed in the boundary lubrication regime. In this lubrication regime, friction and wear behavior strongly depend on the adsorption and the chemical reaction of the additives on the surface. A tribofilm can be formed in the frictional area through adsorption and/or tribochemical reactions with friction serving as the driving force. Some studies proposed a three layer model to characterize a tribofilm with the metal substrate at the bottom, a metal oxide/metal hydroxide in the middle and a reaction tribofilm on the top layer [25]. The compositional analysis obtained by XPS in the current tests suggested formation of a tribolayer consisting a carbonate and amine species on the chrome plated surface but not on the uncoated steel surface. This demonstrates that the surface chemistry of the chromium layer and its interaction with the additives plays an important role in reducing iron fines formation.

\subsection{Reciprocating sliding tests}

The r.m.s. roughness $(\mathrm{Sq})$, the typical surface topography and the power spectral density (PSD) of the pins are illustrated in figure 8 . Chrome plating did not significantly alter the average roughness of the pins (figure 8a). Nevertheless, a slight smoothening of the rough pins and a slight roughening of the polished samples was observed. Similar observation of roughness changes due to chrome plating is reported in literature $[9,11]$. Although chrome plating did not alter the average roughness value remarkably, the topography of the uncoated and chrome plated pins are visually distinct at sufficiently high magnification, figure $8 \mathrm{~b}$. The uncoated pin surface possesses sharp features from the grinding process which can be aggressive and induce intense abrasive wear on the strip surface during rolling. The sharp features are also the primary location for initiation of galling and a preferential locus for adhesion of fine strip wear debris. Chrome plating covers the sharp features and the prominent peaks from the grinding process with gentler patterns. It smoothens the short wavelengths while preserving the average roughness and the large wavelength of the topography. This was confirmed by the power spectral density analysis of the pins surface (figure 8c). The power spectrum of the pins with Sq of 1.0 and $0.3 \mu \mathrm{m}$ show that chrome plating decreased the power at high spatial frequencies (short wavelengths), confirming that hard chrome plating smoothened the high frequency roughness features. The r.m.s. roughness amplitude (Sq) is mainly determined by the amplitudes at the low spatial frequency regions of the power spectrum [26]. Hence, even though the high-frequency roughness is reduced by chrome plating, the long wavelength feature of the pins surface keeps the magnitude of the roughness height parameters unchanged. On the contrary, hard chrome plating increased the magnitude of the PSD for all the frequencies of the smoothest pins with Sq of $0.03 \mu \mathrm{m}$, indicating that it increased the amplitude of the surface at all frequency ranges of the current measurement. This corroborates the r.m.s roughness measurements (figure 8a). The effect of hard chrome plating is more pronounced at high frequencies. This asymmetry arises from the fact that the smoothing of the higher frequencies relative to the low frequencies. This change in micro roughness can influence the mechanical interlocking and accumulation of material transfer. The typical cracking of hard chromium deposits can also be observed on the coated pins [27]. 

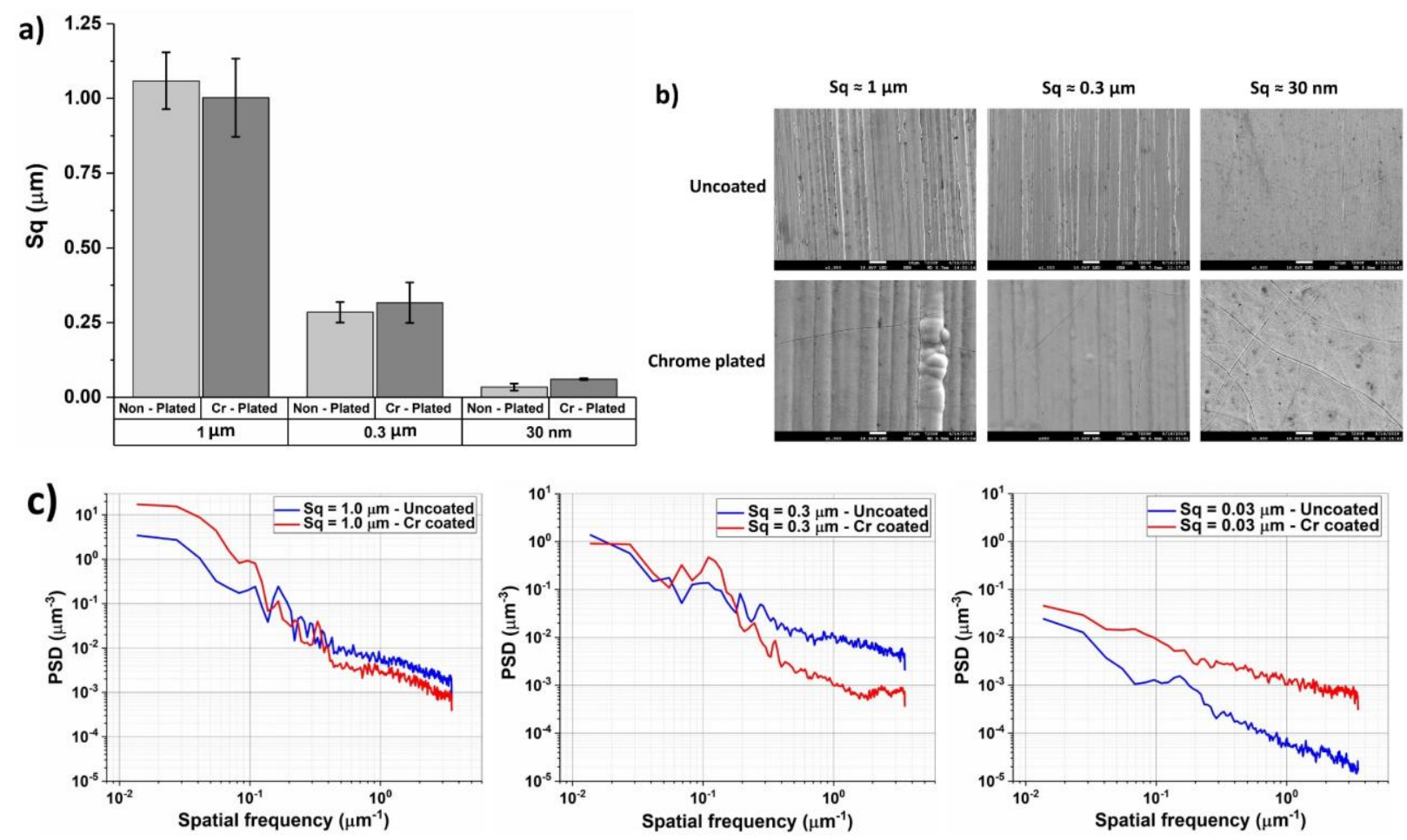

Figure 8: The r.m.s. roughness (a), the typical surface topography (b) and the power spectral density (c) of the uncoated and hard chrome plated pins.

The typical friction curves of the reciprocating sliding tests are presented in figure 9. At approximately a sliding distance of 75 to $100 \mathrm{~m}$ for pins with Sq of $1 \mu \mathrm{m}$ and $175 \mathrm{~m}$ for pins with Sq of $0.3 \mu \mathrm{m}$, a sudden increase of friction coefficient was seen. The sudden increase of friction is generally associated with a transition to severe adhesive wear and gross macroscopic surface damage, also known as galling. This was confirmed by post-test SEM analysis of the pins. For lubricated contacts, like the current tests, local failure of the lubricant is a necessary condition for galling to occur. The local lubricant failure is generally related to frictional heating [28]. No such transition of friction was observed for the tests done using chrome plated pins and pins with Sq of $0.03 \mu \mathrm{m}$. This is similar to previous publications on the influence of roughness on galling behavior, smooth roughness delaying the initiation of galling $[29,30]$.

The minimum sliding distance needed for the transition in friction to occur varies depending on the roughness of the pins. The dependence of the minimum sliding distance to galling on roughness can be attributed to the quantity and severity of defects serving as a spot for the initiation of galling. The rough pins have relatively coarse grooves and surface irregularities from the grinding process which may act as spikes making scratches on the strip surface and serve as a location for the initiation of galling. On the other hand, the surface of the smooth pins is relatively defect free because the coarse protrusions and irregularities are removed by polishing. In literature, it has been shown that surface roughness has a crucial effect on the friction and the ability of a material to prevent pickup of counter material. The rougher the surface the sooner the transition occurs, which is attested by the friction graphs (figure 9). Both substrate polishing and polishing the surface after a coating is applied has been shown to improve the galling resistance of coated surfaces [29].

None of the chrome coated pins showed such a transition in friction. Both the tribochemistry of the chromium layer as well as the smoothening of the aggressive roughness features due to the chrome plating may contribute to this behavior. However, the contribution of each component cannot be isolated in these tests. Scratch tests indicated that tribochemistry plays a big role in terms of material transfer due to the formation of a protective tribolayer on the chrome plated surface. Concurrently, smoothening of the sharp roughness features on the pin surface reduces the number of galling initiation points. For the tests which did not show any sign of galling i.e. the tests with stable friction throughout the whole test duration and no transition, the chrome plating did not alter remarkably the friction. The friction coefficient remained at 
a steady value of approximately 0.05 for all roughness values. These results are in agreement with previous findings $[9,12]$.

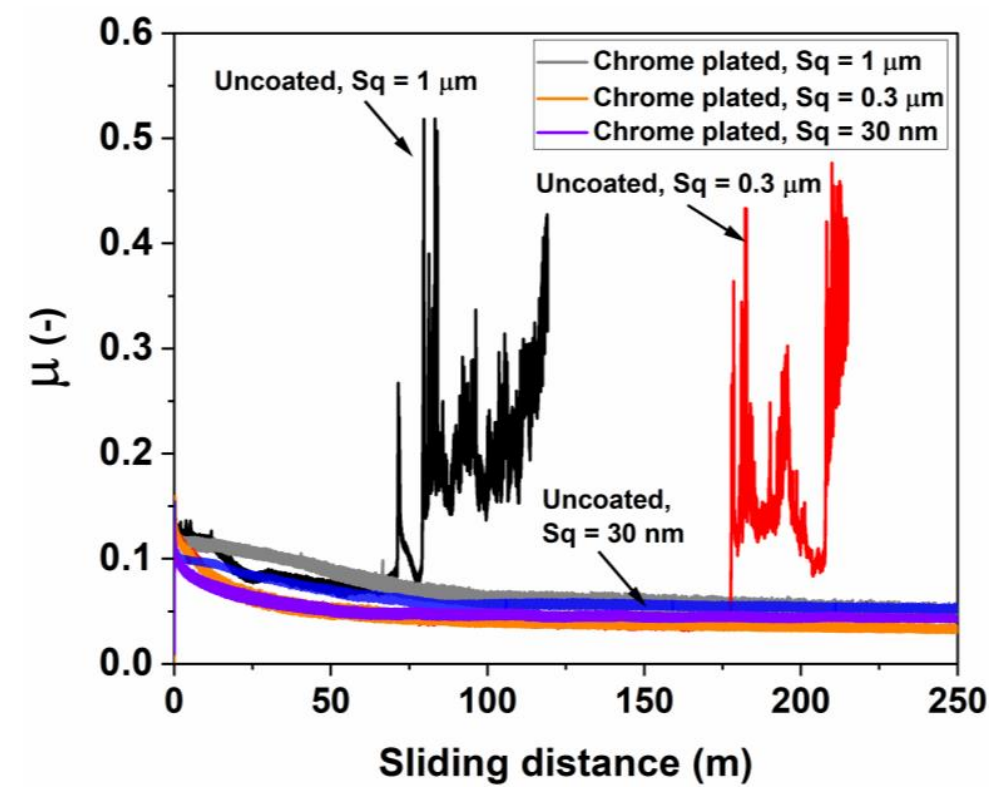

Figure 9: Friction coefficient $(\mu)$ of the reciprocating sliding tests.

The worn surface morphologies of the pins after the reciprocating sliding tests are provided in figure 10. Figure $10(a, b)$ shows the SEM image of the worn pins ground to Sq of $1 \mu \mathrm{m}$. The SEM image of the uncoated pins that showed a transition of friction coefficient revealed a massive strip material transfer (figure 10a). This observation correlates well with the friction measurements. On the contrary, no such material transfer was seen on the chrome plated pins (figure 10b). However, abrasive scratches can be seen on the pin surface. The abrasive scratches are possibly caused by the wear particles generated during the test and remain within the contact area. At some locations, the abrasive scratches led to coating damage. These wear induced defects may act as the initiation point for galling and accelerate material transfer and formation of lumps on the pin surface if the test is continued for longer sliding distance.

Figure 10(c-f) illustrates the worn surface of the pins ground to Sq of $0.3 \mu \mathrm{m}$. In addition to macro galling (figure 10c), SEM analysis of the uncoated pins revealed multiple galling initiation sites with small fragments adhered locally to the pin, see figure 10d. The fragments are situated on the valleys from the grinding process. A collection of fine wear debris are also gathered at these spots, which may promote mechanical interlocking and trigger formation of large lumps [31]. Additionally, coarse abrasive scratches that are originated by detached wear particles are visible on the pin surface (figure 10e). The abrasive particle is seen embedded to the pin surface at the end of a scratch. The hardness of the wear debris that stayed within the contact may increase due to extensive plastic deformation during their formation or as a consequence of repeated plastic working during sliding. They could become even harder than the pin material and act as a third body abrasive and scratch through the pin material with subsequent sliding, such as the one shown in figure $10 \mathrm{e}$. Fine abrasive scratches are seen on the chrome plated pins, see figure 10f. The scratches on the chrome plated pins are milder than the uncoated pins owing to the higher hardness of the chromium coating. Nonetheless, at some locations the abrasion resulted in coating spalling. The brittle nature of the coating wear can be explained by the high degree of residual stress in the coating layer which is indicated by the presence of cracks [27].

The smooth pins with Sq of $0.03 \mu \mathrm{m}$ did not exhibit any material transfer, see figure $10(\mathrm{~g}, \mathrm{~h})$. This can be attributed to the very smooth roughness of the pins. The surfaces of these pins are relatively defect free as the coarse protrusions and irregularities are removed by polishing, reducing the potential initiation sites for strip material transfer. Despite no changes in friction, mild fine abrasive scratches could be seen on the surface of the pins. This might be caused by fine wear particles generated during the test and remain within 
the contact area. The fine scratches are more pronounced for the uncoated pins. This is expected as the hardness of the uncoated pins is lower than the chrome plated pins.

The wear mechanisms for the uncoated pins in the current reciprocating sliding tests resemble the wear mechanisms reported elsewhere for generalized lubricated contacts where adhesive wear is dominant and the influence of roughness of the harder counterpart was demonstrated [32]. The wear process of the tests can be summarized as follows. At the beginning stage of the tests, abrasive scratches are formed on the soft strip surface by the roughness peaks of the hard pin with mild adhesive wear and material transfer on the pins. As the sliding proceeds, the transferred layer builds up on the pin surface. The local contact changes from pin-strip material to a self-mating contact with the strip material in both contacting bodies, which is known to give an unfavorable contact with high adhesion. Further adhesion and mechanical scratches promote accumulation of the transferred material and formation of lumps on some of the initiation points. These lumps act as a protruding abrasive scratching features and create coarse macroscopic scratches on the strip surface. These coarse scratches eventually lead to unstable friction and severe adhesive wear.
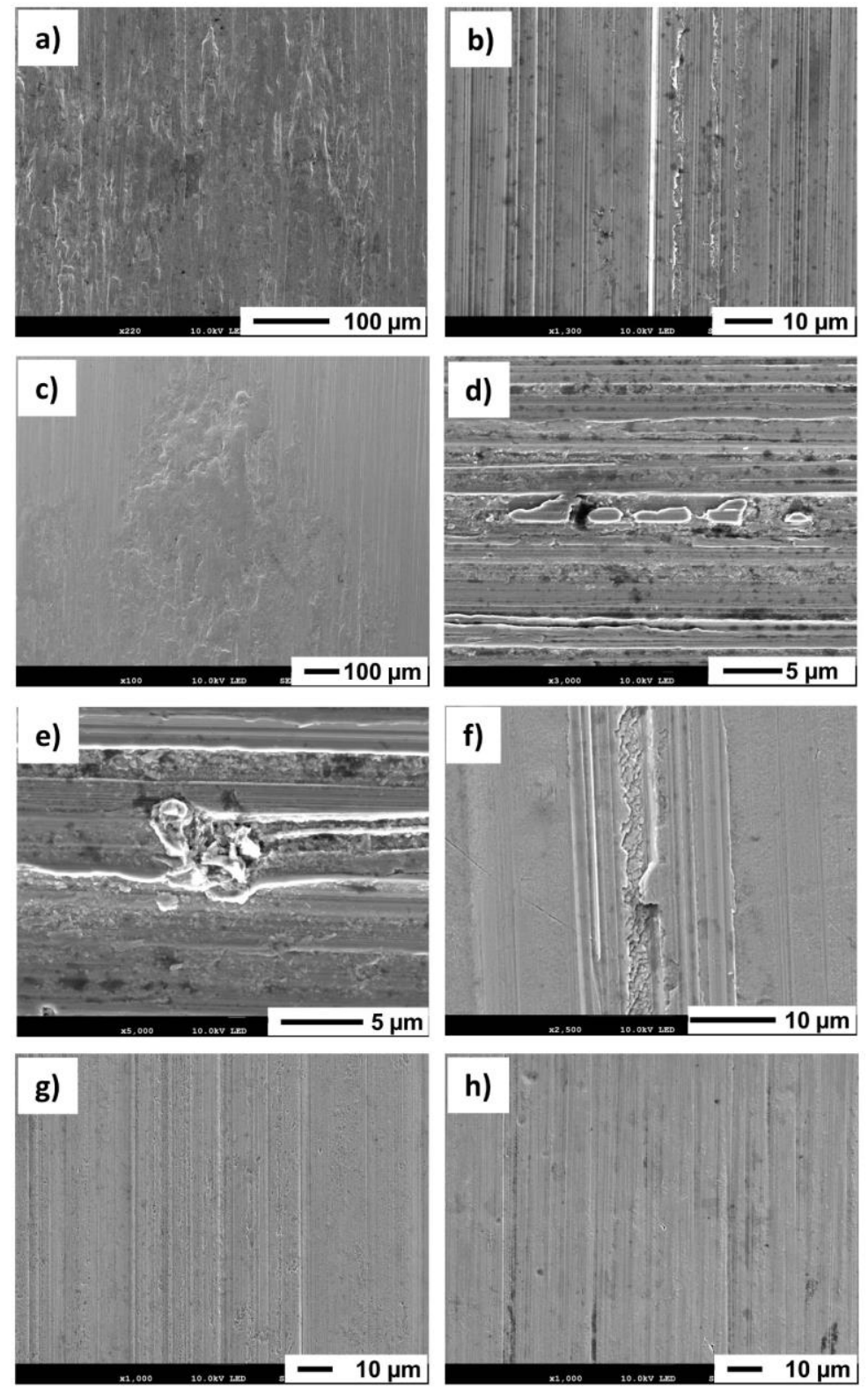

Figure 10: SEM images of the pins after the reciprocating sliding tests; (a) $\mathrm{Sq}=1.0 \mu \mathrm{m}$ uncoated, (b) $\mathrm{Sq}=$ $1.0 \mu \mathrm{m}$ chrome plated, (c, d) Sq $=0.3 \mu \mathrm{m}$ uncoated and (e, f) Sq $=0.3 \mu \mathrm{m}$ chrome plated, (g) Sq $=0.03 \mu \mathrm{m}$ uncoated and $(\mathrm{h}) \mathrm{Sq}=0.03 \mu \mathrm{m}$ chrome plated. 
The wear mechanism for smooth pins is dominated by plastic deformation and flattening of strip asperities with some fine abrasive scratching. The hard smooth pin surface causes plastic deformation and flattening of the soft strip asperities in the initial stage. Repeated sliding leads to concentration of sub-surface shearing strain, fatigue, delamination wear or detachment of oxidized particles. These wear mechanisms can result in wear debris generation. Partly, wear debris are removed from the contact by subsequent sliding movements and some stay within the contact. The hardness of the debris remaining within the contact could possibly increase due to work hardening and oxidation, causing the micro-scratches seen on the pins surface.

In summary, the scratch and the reciprocating sliding tests demonstrated that hard chrome plating delays initiation of galling, reduces the rate of material transfer and improves abrasive wear resistance. This behavior can be attributed to the combined effect of better adsorption/reaction of the additives to the chromium surface providing protection against galling, the smoothening of aggressive roughness features from the grinding process by gentler features due to the chrome plating, and low adhesion of the strip material to the chromium layer. The most important finding of this work is that the tribochemistry of the chrome plated layer plays an important role in reducing iron fines formation. Uncoated pins showed severe galling and material transfer. Galling deteriorates the surface finish of the strip. In rolling processes, this implies that the roll has to be changed by then. Chrome plating and the tribofilm formed act as a protective layer, delaying galling. The improved abrasive wear resistance due to chrome coating implies that the roughness peaks will wear out slowly with a longer rolling distance, and hence, longer roll life. In the search of an alternative for hard chrome coating, in terms of strip cleanliness, the current tests demonstrated that it is important to consider both the tribochemistry and hardness of the coating. No direct comparison between the scratch tests and the reciprocating sliding tests was performed, owing to the different test geometries and scales. Further research is necessary to investigate whether the type of lubricant and additives affect the performance of chrome plating on strip cleanliness.

\section{Conclusion}

Scratch and reciprocating sliding tests were carried out to gain a detailed insight regarding the positive influence of hard chrome plating the rolls on iron fines generation in cold rolling processes. The scratch tests quantitatively confirmed lower friction, lower amounts of iron fines and less material transfer occur when using chrome plated pins than those made using uncoated pins. The scratch tests also confirmed that the tribochemistry of the chromium layer plays an important role on reducing friction and iron fines generation. Furthermore, the current work revealed new insights in the analysis of these contacts as follows:

- XPS results showed that chrome plated surfaces promote the formation of a tribofilm consisting of a carbonate and amine species.

- Scratch tests can be used to evaluate the potential performance of other coatings on strip cleanliness in cold rolling processes.

- Chrome plating did not significantly alter the average roughness of the pins. However, a smoothening effect of the sharp surface irregularities and protrusions from the grinding process is seen.

- In the reciprocating sliding tests, chrome plated pins exhibited reduced scratches, delayed initiation of galling and low rate of material transfer. This indicates that chrome plating has a positive influence in terms of both abrasive and adhesive wear resistance.

- The combined effect of the surface chemistry of the chromium layer and the smoothening of sharp features from the grinding process due to chrome plating contribute to the improved strip surface cleanliness. 


\section{Acknowledgements}

This research was carried out under project number F41.1.14551 in the framework of the Partnership Program of the Materials innovation institute M2i (www.m2i.nl) and the Foundation of Fundamental Research on Matter (FOM) (www.fom.nl), which is part of the Netherlands Organization for Scientific Research (www.nwo.nl).

\section{References}

[1] Fisher TW, lezzi RA, Madritch JM. Theoretical and practical considerations of sheet steel surface cleanliness. Automot. Eng. Congr. Expo., 1980. doi:10.4271/800149.

[2] Pathak, P and Jha, SK and Singh A. Tribological approach for improvement in productivity and quality of flat rolled steel products: a review. Int J Tech Res 2012;1.

[3] Pesci C, Monfort G, Torre V, Van Steden H, Kurzynski J, Vervaet B, et al. Controlling wear and surface cleanliness during cold rolling (LOWWEAR). 2012. doi:10.2777/23177.

[4] Labiapari W da S, de Alcântara CM, Costa HL, De Mello JDB. Wear debris generation during cold rolling of stainless steels. J Mater Process Technol 2015;223:164-70. doi:10.1016/J.JMATPROTEC.2015.03.050.

[5] Hokkirigawa K, Kato K. An experimental and theoretical investigation of ploughing, cutting and wedge formation during abrasive wear. Tribol Int 1988;21:51-7. doi:10.1016/0301-679X(88)901284.

[6] Deltombe R, Dubar M, Dubois A, Dubar L. A new methodology to analyse iron fines during steel cold rolling processes. Wear 2003;254:211-21. doi:10.1016/S0043-1648(03)00005-X.

[7] van Steden G, Neumann W, Suilen F, Bos S, Schoone E. Pilot mill as the key to optimize lubrication and strip cleanliness. Proc. 7th Int. Conf. Steel Roll., Chiba, Japan: 1998, p. $467-472$.

[8] Louaisil K, Dubar M, Deltombe R, Dubois A, Dubar L. Analysis of interface temperature, forward slip and lubricant influence on friction and wear in cold rolling. Wear 2009;266:119-28. doi:10.1016/J.WEAR.2008.06.003.

[9] De Mello JDB, Gonçalves JL, Costa HL. Influence of surface texturing and hard chromium coating on the wear of steels used in cold rolling mill rolls. Wear 2013;302:1295-309. doi:10.1016/J.WEAR.2013.02.006.

[10] Montmitonnet P, Bouadjadja N, Luong LP, Bertrandie JJ, Dietsch H. On the mechanism by which chromium improves strip surface cleanliness in steel strip cold rolling. Key Eng Mater 2018;767:2407. doi:10.4028/www.scientific.net/KEM.767.240.

[11] Simão J, Aspinwall DK. Hard chromium plating of EDT mill work rolls. J Mater Process Technol 1999;92-93:281-7. doi:10.1016/S0924-0136(99)00124-7.

[12] Chiu LH, Yang CF, Hsieh WC, Cheng AS. Effect of contact pressure on wear resistance of AISI H13 tool steels with chromium nitride and hard chromium coatings. Surf Coatings Technol 2002;154:282-8. doi:10.1016/S0257-8972(02)00011-7.

[13] Jacobs L, Vervaet B, Hermann H, Agostini M, Kurzynski J, Jonsson N-G, et al. Improving strip cleanliness after cold rolling. Proc Inst Mech Eng Part J J Eng Tribol 2011;225:959-69. doi:10.1177/1350650111413639.

[14] European Parliament and Council. Regulation Concerning the Registration, Evaluation, Authorisation and Restriction of Chemicals (REACH). Establ a Eur Chem Agency 2006:1-849.

[15] Suh NP, Sin HC. The genesis of friction. Wear 1981;69:91-114. doi:10.1016/0043-1648(81)90315-X.

[16] Stachowiak GW, Batchelor AW. Engineering tribology. Fourth Edition. 2014. 
[17] Schedin E. Galling mechanisms in sheet forming operations. Wear 1994;179:123-8. doi:10.1016/0043-1648(94)90229-1.

[18] Narita K, Priest M. Friction characteristics and topography of tribofilms from anti-wear additives applied to metal v-belt type CVT fluids. Tribol Lett 2009;35:45-56. doi:10.1007/s11249-009-9432-8.

[19] Topolovec-Miklozic K, Forbus TR, Spikes H. Film forming and friction properties of overbased calcium sulphonate detergents. Tribol Lett 2008;29:33-44. doi:10.1007/s11249-007-9279-9.

[20] Kobylyansky E V., Mishchuk OA, Ishchuk YL. Lubricating properties of thixotropic systems based on overbased calcium sulphonate. Lubr Sci 2004;16:293-302. doi:10.1002/Is.3010160308.

[21] Rounds FG. Additive interactions and their effect on the performance of a zinc dialkyl dithiophosphate. ASLE Trans 1978;21:91-101. doi:10.1080/05698197808982864.

[22] Soltanahmadi S, Esfahani EA, Nedelcu I, Morina A, van Eijk MCP, Neville A. Surface reaction films from amine-based organic friction modifiers and their influence on surface fatigue and friction. Tribol Lett 2019;67:80. doi:10.1007/s11249-019-1189-0.

[23] Wood MH, Welbourn RJL, Charlton T, Zarbakhsh A, Casford MT, Clarke SM. Hexadecylamine adsorption at the iron oxide-oil interface. Langmuir 2013;29:13735-42. doi:10.1021/la4018147.

[24] Ratoi M, Niste VB, Alghawel H, Suen YF, Nelson K. The impact of organic friction modifiers on engine oil tribofilms. RSC Adv 2014;4:4278-85. doi:10.1039/C3RA46403B.

[25] Miyajima M, Kitamura K, Matsumoto K. Characterization of tribochemical reactions on steel surfaces. Nippon Steel Sumitomo Met Tech Rep 2017;114:101-7.

[26] Persson BNJ, Albohr O, Tartaglino U, Volokitin Al, Tosatti E. On the nature of surface roughness with application to contact mechanics, sealing, rubber friction and adhesion. J Phys Condens Matter 2005;17:R1-62. doi:10.1088/0953-8984/17/1/R01.

[27] Leisner P, Bech-Nielsen G, Moller P. Current efficiency and crystallization mechanism in pulse plating of hard chromium. J Appl Electrochem 1993;23:1232-6. doi:10.1007/BF00234805.

[28] van der Heide E, Schipper DJ. Galling initiation due to frictional heating. Wear 2003;254:1127-33. doi:10.1016/S0043-1648(03)00324-7.

[29] Podgornik B, Hogmark S, Sandberg O. Influence of surface roughness and coating type on the galling properties of coated forming tool steel. Surf Coatings Technol 2004;184:338-48. doi:10.1016/j.surfcoat.2003.11.002.

[30] Gåård A, Sarih RM. Influence of tool material and surface roughness on galling resistance in sliding against austenitic stainless steel. Tribol Lett 2012;46:179-85. doi:10.1007/s11249-012-9934-7.

[31] Montmitonnet P, Delamare F, Rizoulieres B. Transfer layer and friction in cold metal strip rolling processes. Wear 2000;245:125-35. doi:10.1016/S0043-1648(00)00473-7.

[32] Schedin E, Lehtinen B. Galling mechanisms in lubricated systems: A study of sheet metal forming. Wear 1993;170:119-30. doi:10.1016/0043-1648(93)90358-S. 


\section{Paper D}

Mekicha MA, de Rooij MB, Jacobs L, Matthews DTA, Schipper DJ. Understanding the generation of wear particles in cold rolling processes. Tribol Int 2021;155:106789.

https://doi.org/10.1016/j.triboint.2020.106789. 



\title{
Understanding the generation of wear particles in cold rolling processes
}

\author{
M.A. Mekicha ${ }^{a}$, M. B. de Rooij ${ }^{a}$, L. Jacobs ${ }^{a, b}$, D.T.A. Matthews ${ }^{a, b}$, D. J. Schipper ${ }^{a}$ \\ a Department of Mechanics of Solids, Surfaces \& Systems (MS ${ }^{3}$ ), Faculty of Engineering Technology, University of Twente, \\ Enschede, The Netherlands. \\ ${ }^{\mathrm{b}}$ Tata Steel Nederland Technology BV, IJmuiden, The Netherlands.
}

\begin{abstract}
In this paper, the influence of rolling parameters on the generation of wear particles is studied experimentally using a pilot scale rolling mill. Further, we proposed a multi-scale wear model to predict the amount of wear particles generated in cold rolling processes operating under the boundary lubrication. Rolling experiments revealed that thickness reduction and roll roughness are the two dominant process parameters that control wear particles generation in cold rolling processes. Analysis of the wear particles size distribution showed that most of the wear particles are less than $5 \mu \mathrm{m}$ in diameter. The proposed model captures the trend correctly and give values in the same order of magnitude as the experiments in terms of the volume of wear particles generated.
\end{abstract}

\section{Key words}

Wear modelling; Scratch experiment; Wear particle size; Surface cleanliness

\section{Introduction}

High surface quality is desired for cold rolled sheet metals, particularly for applications in the automotive sector (e.g. outer body parts) and packaging sector (e.g. food and beverage cans). Surface cleanliness, which can be defined as the absence of undesirable material on the surface, is one measure of the surface quality of a cold rolled sheet metal. A cold rolled sheet metal with poor surface cleanliness can have a negative impact on the final product as well as adversely affect subsequent processes such as annealing, galvanizing and forming. For example, it can cause extreme dross inclusions and/or locally weakened zinc coating in hot dip galvanizing lines [1,2]. One of the key factors that decrease sheet metal (strip) cleanness are wear particles, which are generated during cold rolling due to the relative sliding of the roll and the strip in the roll bite [3]. The roll-strip contact in cold rolling is illustrated in figure 1a. The strip metal is drawn into the roll bite by the exit tension and the frictional force between the roll and the strip. The relative speed between the roll and the strip surface varies throughout the roll bite. The peripheral speed of the rolls and the speed of the strip are equal only at the neutral point. The roll moves faster than the strip before the neutral point, whereas the strip moves faster than the roll after the neutral point, as illustrated in figure $1 \mathrm{~b}$. In other words, the roll moves forward and backward relative to the strip before and after the neutral point, respectively. As a result, the roughness peaks of the much harder roll plough through the soft strip material being rolled. This leads to the formation of wear particles, which originate mainly from the sheet being rolled $[2,4]$. 

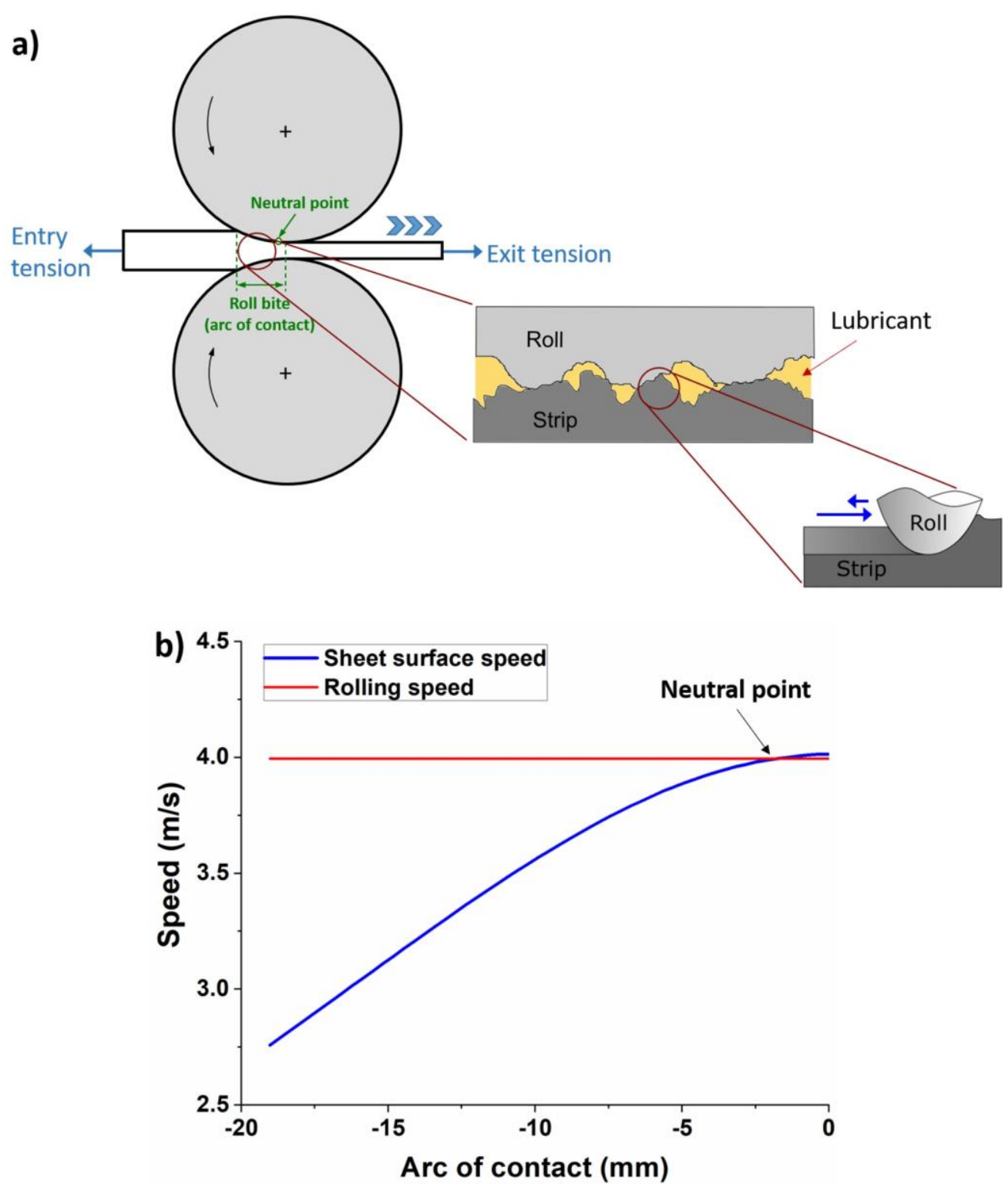

Figure 1: a) schematic of the multiscale contact geometries during cold rolling, and b) an example of the speed differences between the sheet (blue) and roll surface (red) throughout the roll bite as a function of the $\operatorname{arc}$ of contact $(0=$ exit).

Increasing demands in higher surface quality of cold rolled sheet metals requires increased understanding and control of wear debris formation. The whole cold rolling tribological system, which involves a dynamic interaction of the rolls, the sheet metal and the lubricant/coolant, governs the sheet surface cleanliness. Process parameters (such as rolling pressure, pass reduction and rolling speed) as well as the surface roughness of the rolls and the sheet, material properties, surface treatment of the rolls (coated or not), and lubricant type and composition control the tribological behavior and the total amount of wear particles generated. Therefore, a thorough understanding of the rolling tribological system and the main process parameters that influence wear particles generation is crucial to control and tailor the surface cleanliness of a cold rolled sheet metal.

Many experimental studies have been conducted to investigate the wear mechanism and the influence of rolling parameters on the rate of wear particles formation in cold rolling processes. Jacobs et al. [2,3] carried out extensive rolling experiments on pilot rolling mills and studied the origin and composition of wear particles. Moreover, they studied the influence of roll roughness, $\mathrm{Cr}$ plating the rolls, thickness, rolling speed, incoming strip temperature and lubricant composition on strip cleanliness. Dubar and co-workers developed a laboratory experimental setup to simulate cold rolling contact conditions and investigated 
the influence of several rolling parameters such as thickness reduction and stress reversal [5], roughness and lubricant entrapment [6,7], interface temperature [7], and forward slip [5,7] on wear particles formation. Labiapari et al. [4] performed laboratory cold rolling experiments and investigated the influence of thickness reduction ratio, lubricant temperature as well as the hardness, previous annealing and surface finish of the sheet on the formation of wear debris in stainless steel cold rolling.

Although these studies provide an insight on the influence of rolling parameters on the rate of wear particles formation, little or no attempt has been made to develop a wear model for cold rolling processes to estimate the amount of wear particles generated. The dynamic and complex nature of cold rolling with many interacting variables makes it very challenging to develop a wear model. Huart et al. [6] attempted to relate the rate of wear particles formation to the accumulated plastic strain energy in the strip asperities by modelling the plastic behavior of the (strip) asperities using two dimensional finite element method (FEM) simulations in the case of a rigid smooth roll and a deforming rough strip. However, developing a wear model for cold rolling processes has the prerequisite that the macroscale rolling parameters that define the contact conditions at the microscale as well as the microscale wear mechanism at asperity level are both taken into account.

It has been repeatedly shown in literature $[2,8-11]$ that abrasive wear is the dominant wear mechanism and is the main cause of wear particles formation in lubricated cold rolling processes. The total amount of wear particles generated due to abrasive wear in lubricated contacts depends on the real contact area, the geometry of the microscale contacting asperities, the sliding distance, lubricant and material properties, and surface treatment of the interacting surfaces. In cold rolling, the rolling force, thickness reduction and forward slip define the real contact area and the sliding distance. The roughness of the rolls and the strip determine the geometry of the microscale contacting asperities. The strip material, pretreatment of the strip and the rolls (e.g. pickling and coating respectively), roll material and hardness, temperature, and lubricant composition collectively determine the (degree and type of) wear at each micro-contact. Thus, any model that attempts to estimate the rate of wear particles formation in cold rolling should take into account the rolling parameters that have the most influence on the wear debris formation.

In this paper, we propose a multi-scale wear model to predict the severity of wear particles generation due to abrasive wear for cold rolling processes operating under boundary lubrication. The proposed wear model combines a semi-analytical deterministic multi-asperity contact model and wear at microscale single asperity contact. Furthermore, we conducted cold rolling experiments, using a semi-industrial cold rolling pilot mill, to study the influence of rolling parameters on wear particles formation. The rolling experiments were done at several combinations of roll roughness, lubrication condition, rolling speed and exit tension. Finally, the model results are compared with the experimental measurements.

\section{Computational procedure}

The flow diagram of the proposed wear model is illustrated in figure 2 . The inputs to the model are the three-dimensional (3D) strip and roll roughness topography (obtained using confocal microscopy measurements), constitutive equation of the strip material, thickness reduction, rolling speed, forward slip, and entry and exit tension. First, the real area of contact between the roll and the strip surface is calculated by employing a fully plastic contact model, in which the real contact area due to normal loading and bulk deformation of the strip are taken into account. The roll is assumed to be rigid and the strip as rigid-plastic. The details of the contact model and its experimental validation can be found in our previous publication [12]. The mean contact pressure, which is an input to the contact model, is determined from the friction hill calculations made using slab analysis under plane strain conditions [13]. In the friction hill calculations, the rolling force, contact pressure distribution, relative velocity between the roll and the strip, length of arc of contact, and bite angle are determined. The outputs of the contact model are the real contact area ratio, identification of the micro contacts and the surface finish of the rolled strip. Note that the real contact area varies throughout the roll bite as the bulk strain and the contact pressure vary across the roll bite. However, for simplicity and computational speed, the real contact area at the roll bite exit is 
used for wear calculations. This may lead to a slight overestimation of the real contact area, and consequently, the amount of wear particle generated. Similarly, the roll-strip contact is dynamic and the shape and size of micro-contacts may vary throughout the roll bite. Nevertheless, it is reasonable to assume, on average, that the number of micro-contacts and their size distribution remain constant for a given rolling condition.

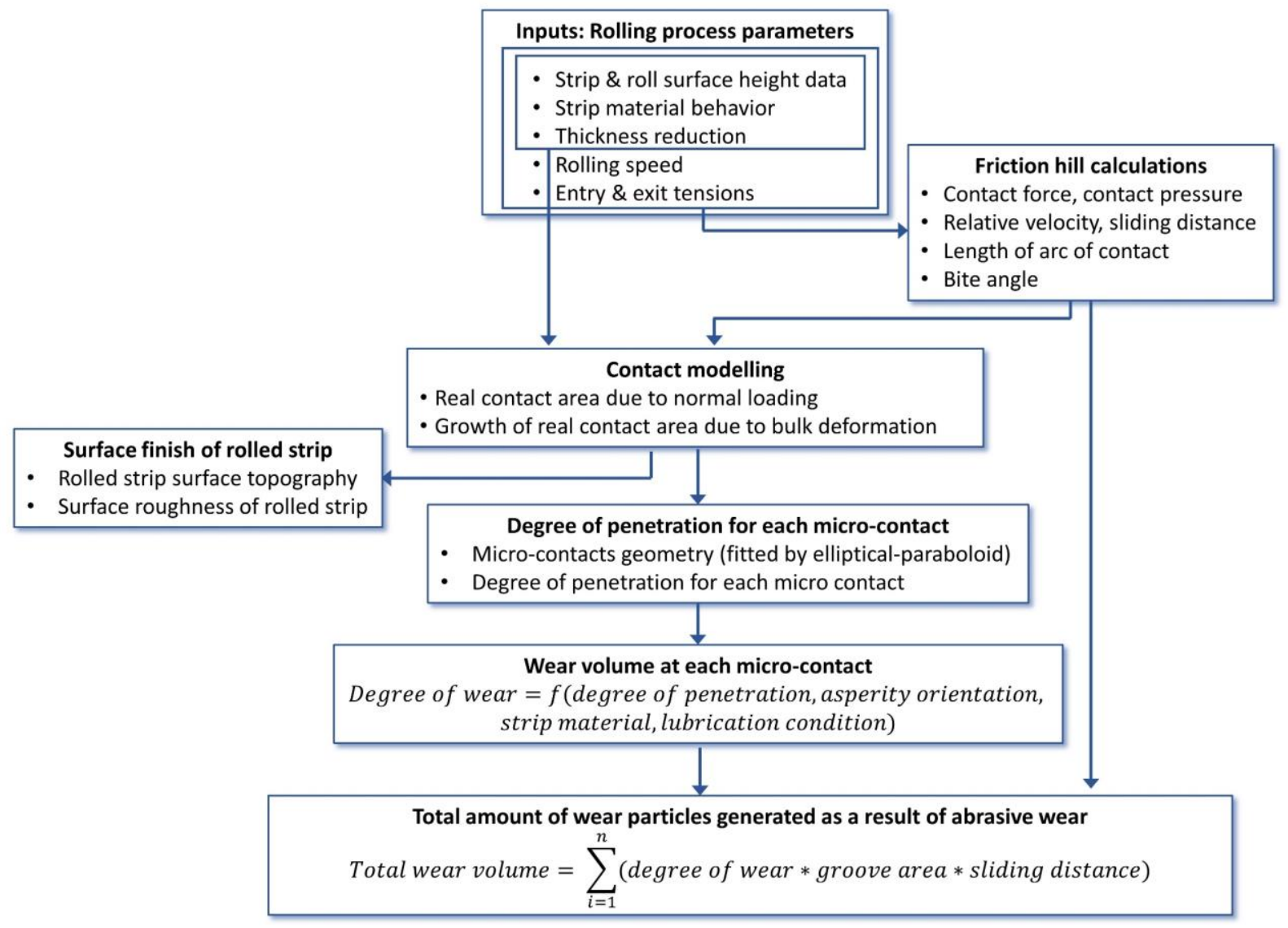

Figure 2: Flow diagram of the computational approach used to model wear in cold rolling.

In the next step, the volume of material removed as wear debris at each micro contact is determined. To attain this objective, each contacting asperity is approximated by an elliptical-paraboloid. The size and shape of the elliptical-paraboloid is determined using the least squares fit through the measured height data of the contacting asperity. Next, the degree of penetration of each micro-contact is computed. The degree of penetration $\left(d_{p}\right)$, which is the ratio of indentation depth $(d)$ and the semi-axis of the contact spot in sliding direction $(a)$ is a commonly used non-dimensional measure of the sharpness of an indenting asperity $[14,15]$. For a spherical indenter, $d_{p}$ is defined by (also see figure $3 a$ ):

$$
d_{p}=d / a
$$

The degree of penetration calculation of the elliptic paraboloid asperities is made by adjusting the value of degree of penetration of a sphere by introducing the shape and the orientation $(\theta)$ of the asperity with respect to the sliding direction as described in [15]. The semi-axis of the contact in the sliding distance is expressed in terms of the orientation of the asperity and the semi-minor and semi-major axis of the contact (see figure $3 b$ ) as:

$$
a_{x}^{\prime}=\sqrt{\left(a_{x}^{2} \cdot a_{y}^{2}\right) /\left(a_{x}^{2} \cdot \sin ^{2} \theta+a_{y}^{2} \cdot \cos ^{2} \theta\right)}
$$

with this, Eq.(1) becomes:

$$
d_{p}=d / a_{x}^{\prime}=d /\left(a_{x}^{2} \cdot a_{y}^{2} /\left(a_{x}^{2} \cdot \sin ^{2} \theta+a_{y}^{2} \cdot \cos ^{2} \theta\right)\right)
$$


a)

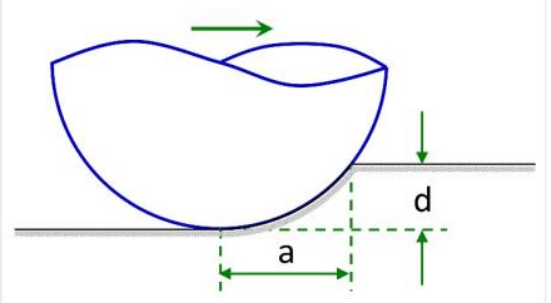

b)

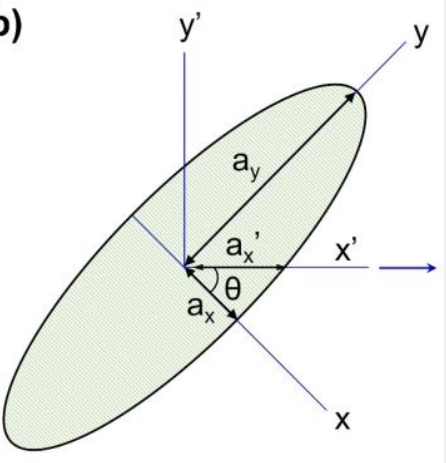

c)

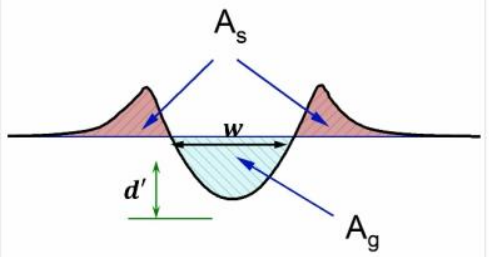

Figure 3: a) degree of penetration for a spherical indenter, b) an elliptic micro-contact: $x^{\prime}$ is the sliding direction, $a_{x}$ and $a_{y}$ are the semi-minor and semi-major axis, respectively, and c) cross section of a scratch wear scar.

Next, the proportion of material removed as wear debris, denoted by the degree of wear $\left(d_{w}\right)$, at each micro contact is evaluated. The degree of wear for a given contact geometry and normal load depends on material properties and surface treatment of the interacting surfaces, surface chemistry, contact temperature and lubricant composition. Because $d_{w}$ depends on many variables, the values are obtained in this work by performing scratch experiments using an indenter made from a tool steel, having a similar composition as commonly used work roll material, sliding against a polished strip material surface. The details of the scratch experiments are discussed in section 3.2. $d_{w}$ can be calculated from the average twodimensional scratch cross section (illustrated in figure $3 \mathrm{c}$ ) by:

$$
d_{w}=\left(A_{g}-A_{s}\right) / A_{g}
$$

The volume of material removed due to wear at each micro contact is the product of the degree of wear, frontal area of the groove $\left(A_{g}\right)$, and the sliding distance $(L)$. The sliding distance is determined in the friction hill calculations from the relative sliding speed of the roll and the strip surface in the roll bite. The frontal area of the groove $A_{g}$ can be approximated by eq. (5) [16], see also figure 3c:

$$
A_{g}=\frac{2}{3} \cdot w \cdot d^{\prime}+d^{\prime 3} /(2 \cdot w)
$$

Finally, the total volumetric wear $(V)$ caused by all asperities is calculated as the sum of the volume of material removed due to abrasive wear at each micro contact:

$$
V=\sum_{i=1}^{N}\left(L \cdot d_{w} \cdot A_{g}\right)
$$

where, $N$ is the number of micro-contacts.

\section{Materials and experiments}

\subsection{Rolling experiments}

The objective of the rolling experiments was to validate the proposed wear model and to investigate the effect of rolling parameters such as roll roughness, thickness reduction, lubrication, entry/exit stresses and rolling speed on strip cleanliness. The rolling experiments were carried out on a two-high configuration, semi industrial rolling mill in Tata Steel, The Netherlands. An illustration of the rolling mill configuration is presented in figure 4. Two sets of work rolls with r.m.s. roughness (Sq) of $0.2 \mu \mathrm{m}$ ('smooth' rolls) and 1.2 $\mu \mathrm{m}$ ('rough' rolls) were prepared to study the effect of roll roughness on wear particles generation. The roughness peaks of a freshly ground roll wear off quickly in the beginning of its service life. To avoid this undesired roughness change, dummy rolling experiments were conducted before the main experiments. The diameter of the rolls is $400 \mathrm{~mm}$. The strip material was an industrially hot-rolled and pickled Titaniumstabilized interstitial-free (Ti-IF) steel, a steel grade widely used in automotive outer body part applications. The entry strip was $3 \mathrm{~mm}$ thick and $100 \mathrm{~mm}$ wide. A fully formulated industrial rolling (mineral) oil that 
contains anti wear and extreme pressure additives was used in the rolling experiments. Pure oil was used instead of an emulsion, which is a common practice in industrial production, to avoid the influence of undesired oil concentration variation and emulsion contamination during circulation. The lubricant was applied on the strip before entering the roll bite using a direct application unit (figure 4). The oil temperature was maintained between $43^{\circ} \mathrm{C}-45^{\circ} \mathrm{C}$. There was no oil circulation. The rolling force, torque, thickness, rolling speed, entry and exit strip speeds, and entry and exit tension forces were measured during the experiments.

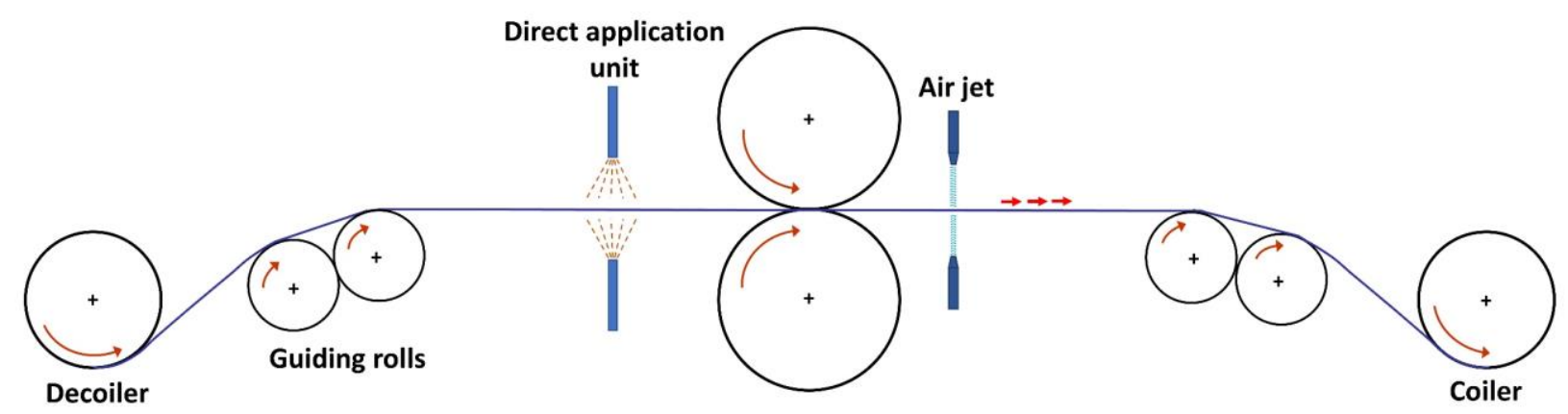

Figure 4: Schematics of the pilot-mill used for the rolling experiments.

The effect of thickness reduction was examined by performing rolling experiments at $5 \%, 10 \%, 20 \%$ and $35 \%$ thickness reduction. The rolling speed was varied between 0.5 and $2.0 \mathrm{~m} / \mathrm{s}$. The experiments were carried out both in lubricated and dry (non-lubricated) conditions. The effect of forward slip was studied by varying the exit tension between 10 and $40 \mathrm{kN}(83-167 \mathrm{MPa})$ while keeping the entry tension constant at $20 \mathrm{kN}(67 \mathrm{MPa})$. Varying the entry and exit tension affects the location of the neutral point, and thereby, the forward slip [13]. Forward slip $\left(S_{f w d}\right)$ is defined as the relative difference between the peripheral roll speed $\left(V_{r}\right)$ and strip exit speed $\left(V_{\text {exit }}\right)$, and is given by:

$$
S_{f w d}=\left(V_{\text {exit }}-V_{r}\right) / V_{r}
$$

Prior to the rolling experiments, the coils were degreased and cleaned using a commercial cleaner (3\% concentration) to remove oil residues from previous processes, using a direct application unit. The cleaner was applied using a flat jet nozzle at the entry side of the mill. The cleaner is then blown off with an air knife while moving at a speed of $0.2 \mathrm{~m} / \mathrm{s}$ on the exit side of the mill. A summary of the process parameters of the rolling experiments are presented in table 1 . A total of $400 \mathrm{~m}$ of strip was rolled, $10 \mathrm{~m}$ for each rolling experiment.

Table 1: Process parameters of the rolling experiments.

\begin{tabular}{|c|c|c|c|c|c|}
\hline $\begin{array}{c}\text { Experiment } \\
\text { No. }\end{array}$ & $\begin{array}{c}\text { Roll roughness, } \\
\text { Sq }(\mu \mathrm{m})\end{array}$ & $\begin{array}{c}\text { Lubrication } \\
\text { condition }\end{array}$ & $\begin{array}{c}\text { Thickness } \\
\text { reduction (\%) }\end{array}$ & $\begin{array}{c}\text { Rolling } \\
\text { speed }(\mathrm{m} / \mathrm{s})\end{array}$ & $\begin{array}{c}\text { Exit tension } \\
(\mathrm{kN})\end{array}$ \\
\hline $1-4$ & \multirow{6}{*}{0.1} & \multirow{3}{*}{ Dry } & $5,10,20,35$ & 0.5 & 10 \\
\hline $5-7$ & & & 20 & 0.5 & $20,30,40$ \\
\hline $8-10$ & & & 20 & $1.0,1.5,2.0$ & 10 \\
\hline 11-14 & & \multirow{3}{*}{ Lubricated } & $5,10,20,35$ & 0.5 & 10 \\
\hline $15-17$ & & & 20 & 0.5 & $20,30,40$ \\
\hline $18-20$ & & & 20 & $1.0,1.5,2.0$ & 10 \\
\hline $21-24$ & \multirow{6}{*}{1.2} & \multirow{3}{*}{ Dry } & $5,10,20,35$ & 0.5 & 10 \\
\hline $25-27$ & & & 20 & 0.5 & $20,30,40$ \\
\hline $28-30$ & & & 20 & $1.0,1.5,2.0$ & 10 \\
\hline 31-34 & & \multirow{3}{*}{ Lubricated } & $5,10,20,35$ & 0.5 & 10 \\
\hline $35-37$ & & & 20 & 0.5 & $20,30,40$ \\
\hline $38-40$ & & & 20 & $1.0,1.5,2.0$ & 10 \\
\hline
\end{tabular}

The 3D surface roughness of the strip before and after rolling as well as the rolls was measured using a Sensofar S-neox confocal microscope. The surface roughness of the rolls was measured by replicating the 
roll surface using a surface replicating compound. Form removal was performed on the roughness measurements to remove tilt and eliminate the long-range wavelengths associated with lack of flatness.

The surface cleanliness of the rolled strip was evaluated using two widely used methods in the steel industry. The first one is the "reflection tape" method. In this method, an adhesive tape is applied on the surface of the rolled strip (with a thumb). The tape is then removed and it is taped on a white paper. Afterwards, a light source is directed to the tape on the paper and the reflected light is measured. The fraction of the reflected light is a measure for the degree of cleanliness of the strip. The reflection is $100 \%$ for an entirely transparent tape and $0 \%$ for an entirely black one. The better the surface cleanliness of the strip, the higher the reflection value. Typical reflection values for steel rolling are between $40 \%$ and $80 \%$ [3]. The second method, known as "iron tape method", involves measuring the weight of (iron) wear particles per unit area. Wear particles in steel cold rolling consist mostly of iron [2]. The wear debris are removed from the rolled strip surface using an ash-less adhesive tape. The tape is burnt afterwards and the weight of the remaining wear debris is measured.

Both the reflection tape and iron tape method do not provide information about the size and shape of wear particles. Hence, analysis of the quantity and size distribution of the wear particles was performed using image processing. This was done first by taking a color microscopy image of the wear particles collected on a transparent adhesive tape, which is placed over a black sample holder to facilitate particle identification and extraction, at high magnification. The images are then converted into a gray scale image. The wear particles are extracted from the image based on contrast information by removing the background. Next, the area and size of each particle is measured. Finally, particle size distribution analysis is carried out.

\subsection{Scratch experiments}

Scratch experiments were performed to evaluate the volume of material removed as wear debris at each micro contact when a roll asperity ploughs through the strip surface. The scratch experiments were designed to resemble the roll asperity-strip contact in the roll bite of cold rolling processes. The experiments were executed using a Multi-purpose tribometer (Bruker's UMT Tribolab). The experiments were conducted using conical indenters with a hemispherical tip under lubricated conditions, which represents the roll asperity, sliding against a polished flat strip substrate, as depicted in figure 5 . The hemispherical tip has a radius in the order of a single roughness asperity of the roll $(175 \mu \mathrm{m})$. The strip samples were polished to a mirror like surface finish with an average r.m.s. roughness of less than $20 \mathrm{~nm}$. The scratch indenters were made of a hardened and tempered medium cold working tool steel (60- 62 HRC) that has similar composition to a commonly used work roll material. The substrate was a piece of strip obtained from the hot rolled and pickled Ti-IF steel coil used in the rolling experiments. The same oiltype used in the rolling experiments was used in the scratch experiments.

The strip sample and the indenters were degreased and cleaned using acetone and isopropanol prior to the scratch experiments. Next, an oil film was applied on the strip sample. Each scratch was made by applying the desired normal load under load-controlled conditions. The load needed to obtain the intended $d_{p}$ was determined on the basis of the radius of the indenter tip and hardness of the strip material. The scratches were performed using a constant normal load, ranging between 3 and $39 \mathrm{~N}$. The sliding speed was kept constant at $1 \mathrm{~mm} / \mathrm{s}$. The length of each scratch is $15 \mathrm{~mm}$. The normal force, the tangential force and the friction coefficient were measured during the experiments. 


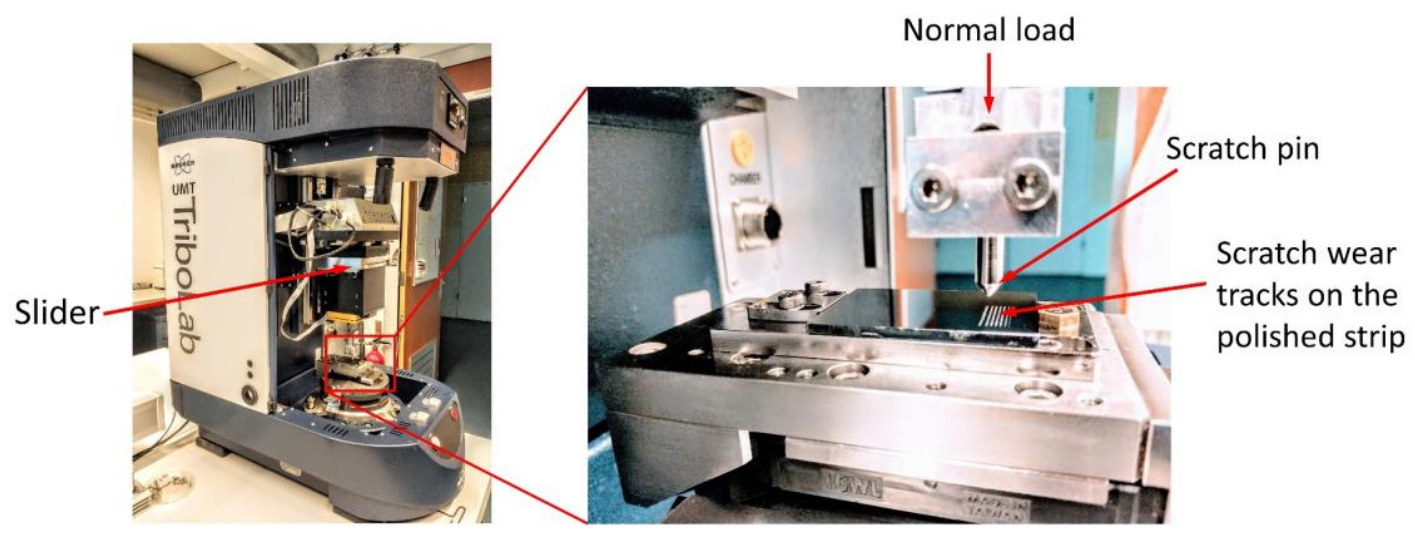

Figure 5: Scratch experiment setup.

The three-dimensional height profile of the scratches was measured using confocal microscopy (S neox 3D Optical Profiler from Sensofar). Tilt correction and shifting the reference plane to $z=0$ was carried out employing the flat section away from the wear track which is unaffected by the scratches. The amount of material removed as wear debris, for each individual scratch, was measured from the wear groove profile by calculating the degree of wear $\left(d_{w}\right)$ from the ratio of the groove volume and shoulder volume, see Eq. (4).

\section{Results \& discussion}

\subsection{Rolling experimental results}

\subsubsection{Roughness changes}

The surface roughness topographies of the rolled strip are presented in figure 6 and figure 7. The r.m.s. roughness (Sq) of the strip after cold rolling is plotted in figure 8 . The following points can be noted from these figures: (i) thickness reduction is the predominant rolling parameter that determines the real contact area, and hence, the roughness of the rolled strip (figure 6 and figure 8); (ii) rolling speed and exit tension had little impact on the rolled strip roughness for a given thickness reduction, both in the lubricated and dry experiments (figure 7 and figure 8); (iii) the real area of contact is much higher in the case of dry rolling experiments than the lubricated ones for a given thickness reduction, see figures $6-8$. These observations are preliminary indicators of which rolling parameters may potentially have major influence on wear particles formation (strip cleanliness).

The roll marks become predominant and the strip asperity flattening and/or indentation intensify with an increase in the thickness reduction. This translates to a higher real contact area ratio (i.e. the ratio of the real contact area to the apparent contact area) and more conformity of the strip to the roll surface with an increase in thickness reduction. It is known that bulk deformation dramatically increases asperity flattening and indentation $[12,17]$. The roughness topography of the incoming strip is completely obliterated at $20 \%$ thickness reduction in the dry rolling experiments, indicating full contact between the strip and the roll. On the other hand, roughness features of the strip from the pickling process, particularly the cavities, are still clearly visible in the lubricated rolling experiments at $35 \%$ thickness reduction. This is even more pertinent on the strip rolled using smooth rolls. Rolling speed is expected to have no or little impact on the real area of contact for a rolling process that operates under the boundary lubrication regime, as there are basically no velocity dependent effects. The little impact of the rolling speed on the rolled strip roughness confirms that the current lubricated rolling experiments were indeed operating mainly under boundary lubrication conditions. Similarly, the variation of the exit tension did not affect the roughness of the rolled strip. This is expected as the thickness reduction was kept constant. 


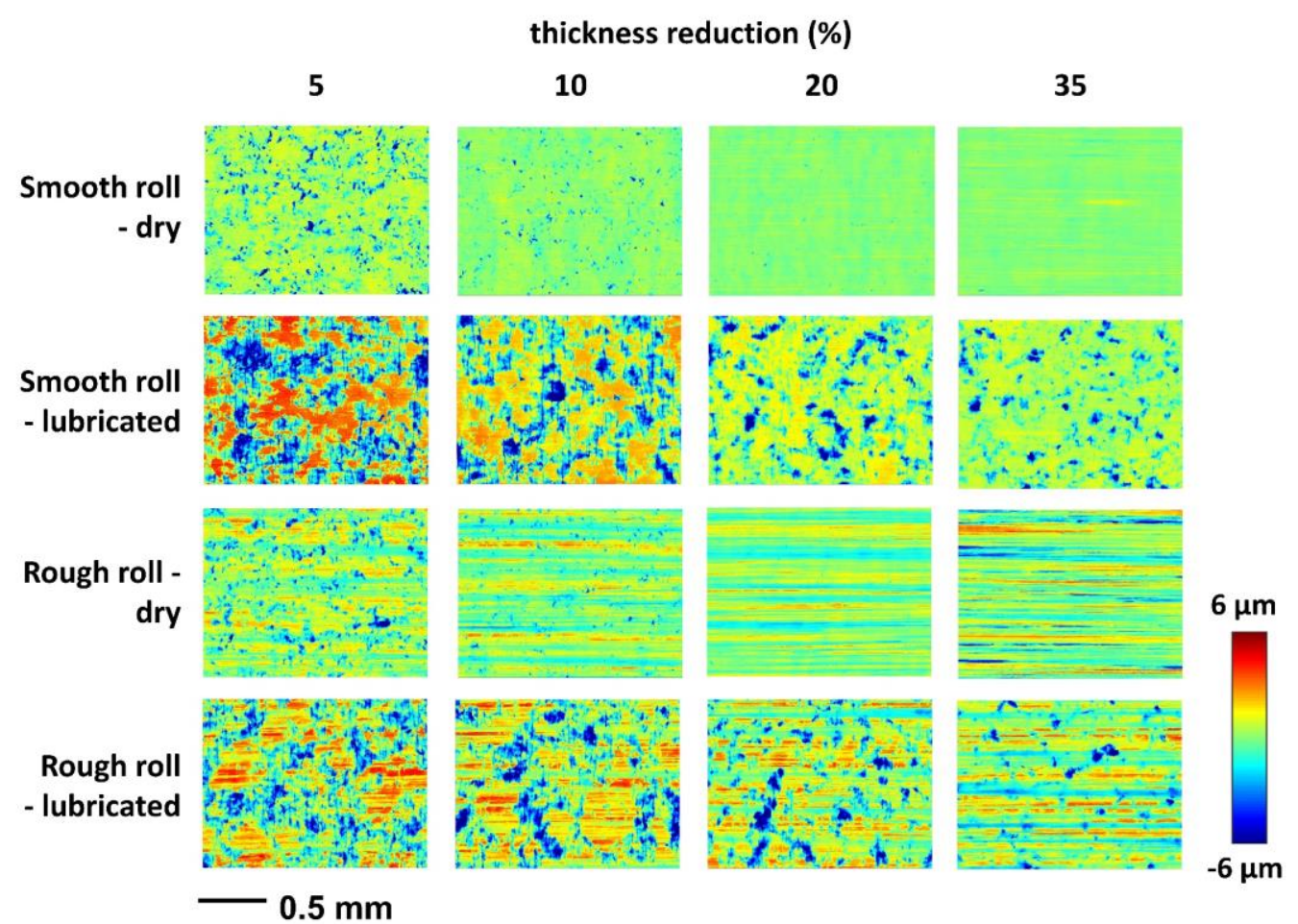

Figure 6: Roughness topography of the rolled strip as a function of thickness reduction in dry and lubricated conditions, using smooth and rough rolls.
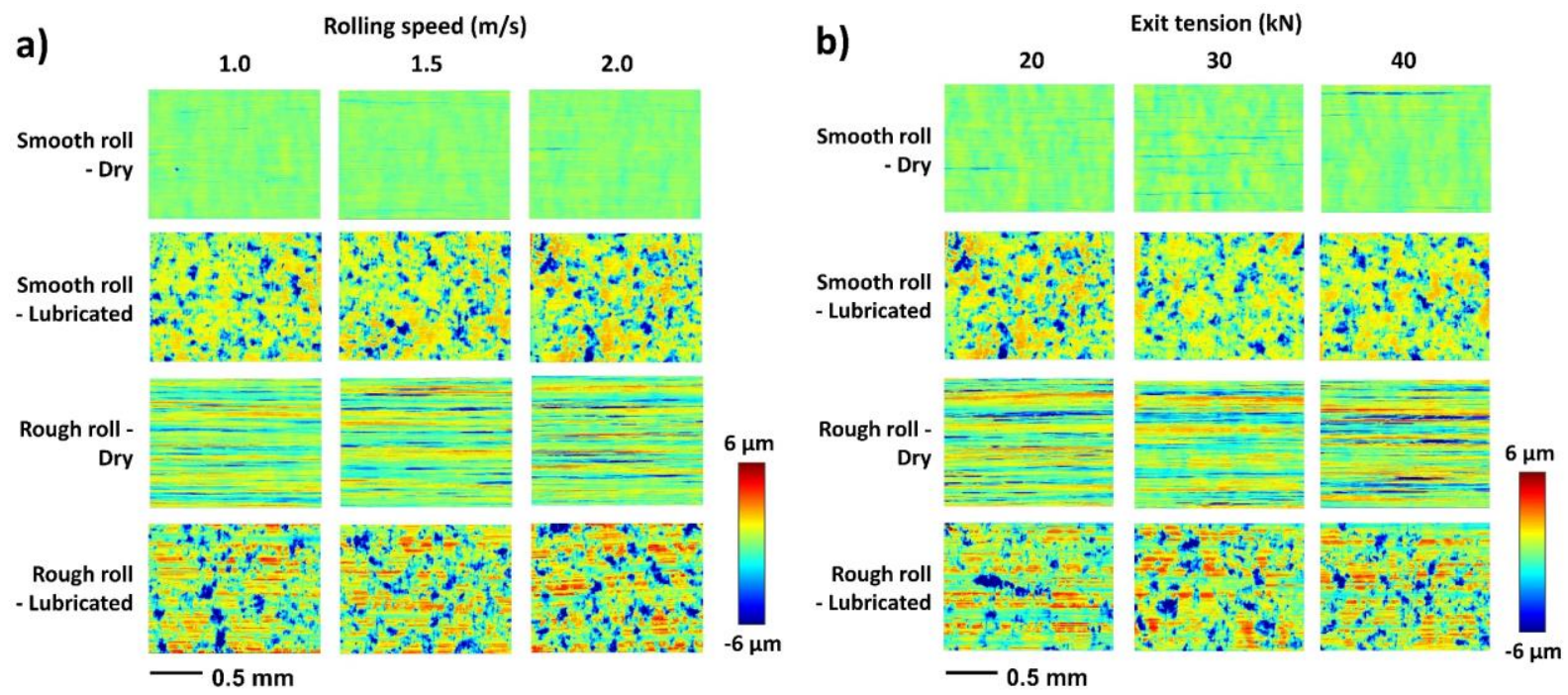

Figure 7: Roughness topography of the rolled strip as a function of: a) rolling speed (at $20 \%$ thickness reduction and $10 \mathrm{kN}$ exit tension) and b) exit tension (at $20 \%$ thickness reduction and $0.5 \mathrm{~m} / \mathrm{s}$ rolling speed).

One factor that plays an important role in the real contact area ratio difference between the dry and the lubricated experiments is the lubricant trapped in the cavities [18,19]. Huart et al. [6], using two dimensional FEM simulations, demonstrated that a trapped lubricant avoids the total flattening of asperities and limits the real contact area ratio. With the roll-strip relative motion, lubricant may be trapped in a closed volume at the entry of the roll bite, particularly for smooth rolls. It is squeezed and dragged into the roll-strip interface resulting in the so called micro-plastohydrodynamic lubrication (MPHL) [19-22]. MPHL is the trapping of lubricant in closed surface cavities and the subsequent permeation of the trapped lubricant into the neighboring real contact area due to deformation. This lubricant film prevents direct metal to metal contact and allows the conservation of the cavity geometry. Due to the strong directionality on the roughness, lubricant trapping can be expected to be negligible in the rolling 
experiments when rough rolls are used, as the squeezed lubricant can escape through the grooves created by the roll roughness [23]. This is clearly visible at the highest thickness reduction, where a relatively low number of cavities are seen on the strip surface rolled using rough rolls (figure 6). Another contributing factor that explains the difference in the real contact area ratio between the dry and the lubricated experiments is junction growth. Tabor [24] has demonstrated that the real area of contact increases as the tangential force is increased. Junction growth continues until the tangential shear stress reaches the interface shear strength, where macroscopic sliding onsets. Obviously, a higher tangential force is needed for macroscopic sliding to occur in the dry rolling experiments than the lubricated ones. Hence, the real contact area is higher in the dry rolling experiments.

Another characteristic of the dry rolling experiments is the material pickup that occurred for the rolling experiments with rough rolls at $35 \%$ thickness reduction. This is evidenced by the "scratches" that started to appear on the rolled strip surface topography at 35\% thickness reduction (figure 6) and the increase of the Sq value (figure 8a). Once full contact is reached, which is already achieved at $20 \%$ thickness reduction, the $\mathrm{Sq}$ is expected to stay constant. However, the Sq increased at $35 \%$ thickness reduction. This can only be attributed to the increase of the roll roughness due to material pickup. This roughness change is also reflected in the subsequent experiments, see figure 7. Deep scratches, although few, that indicate material pickup by the roll are also seen on the strips rolled using smooth rolls (figure 7). This observation may be explained by the fact that rough rolls provide much more surface irregularities and surface defects that serve as an initiation point for material transfer (galling) than the smooth rolls [25]. This indicates that a combination of rough roll and high thickness reduction are not favorable in terms of strip cleanliness as this may lead to galling and more wear.
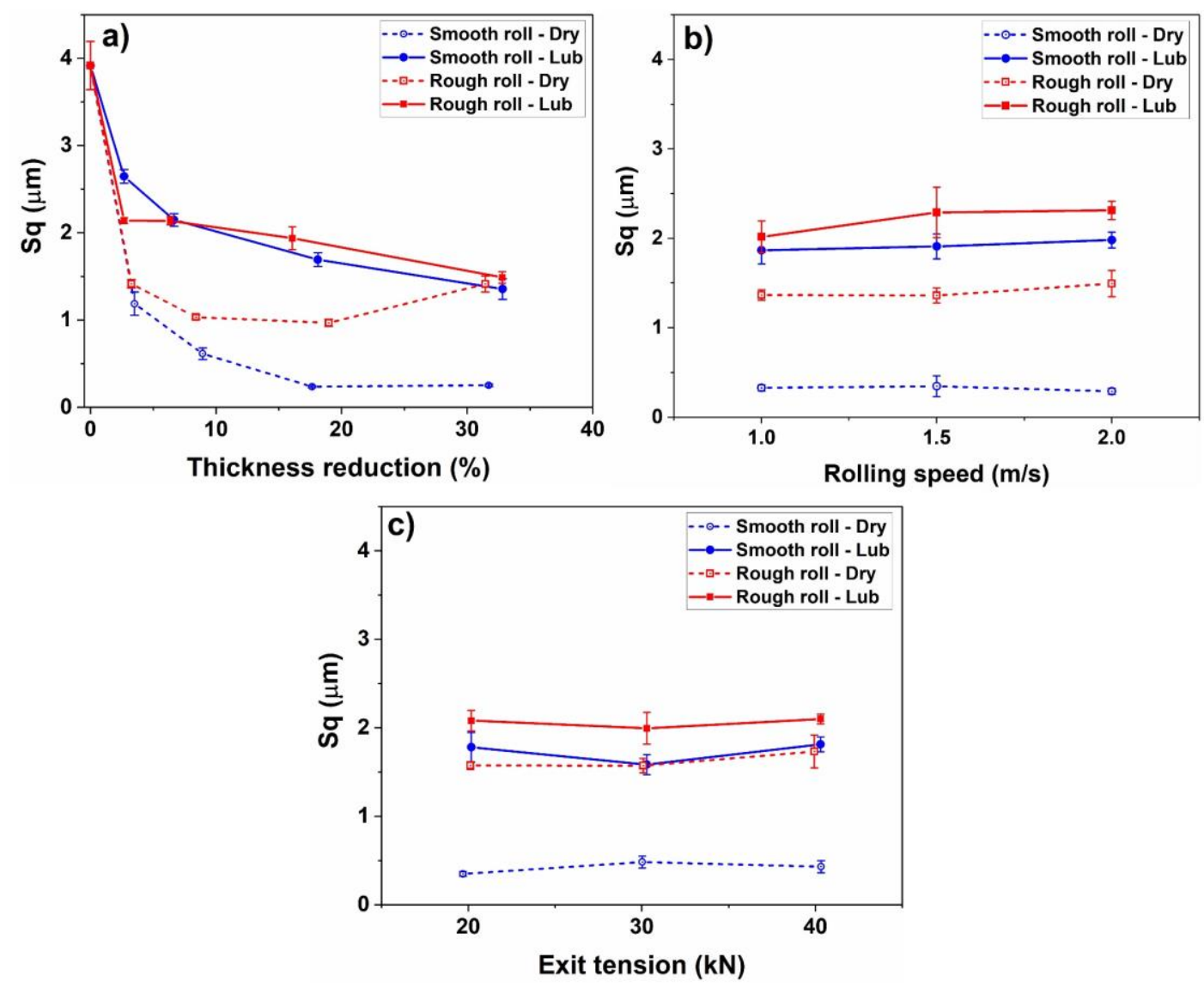

Figure 8: R.m.s. surface roughness of the rolled strip as a function of: a) thickness reduction, b) rolling speed, and c) exit tension. 


\subsubsection{The effect of rolling parameters on wear particles formation}

\subsubsection{Thickness reduction, roll roughness and lubrication}

The plots of iron tape and reflection tape values, indicating surface cleanliness of the sheet material after the rolling experiments, as a function of thickness reduction are provided in figure 9 . The amount of material removed as wear particles increases with the thickness reduction; higher thickness reduction leading to higher wear and dirtier strip. Higher thickness reduction means harsher contact conditions, i.e. higher rolling forces (figure 10a) and higher contact stresses (figure 10b), higher real area of contact, increased length of the arc of contact, higher sliding lengths, higher interfacial temperature, and higher depth of indentation by roll asperities. In addition, high thickness reduction increases the roll bite angle which may reduce the amount of trapped lubricant [6]. These contact conditions promote higher rate of wear particles formation. Furthermore, higher thickness reduction may result in more material pickup as it increases the sliding length, normal stress and contact time which promote adhesion and adhesive wear [10]. This was manifested in the roughness profiles of the rolled trip, particularly for the dry rolling experiments, as discussed earlier in section 4.1.1.
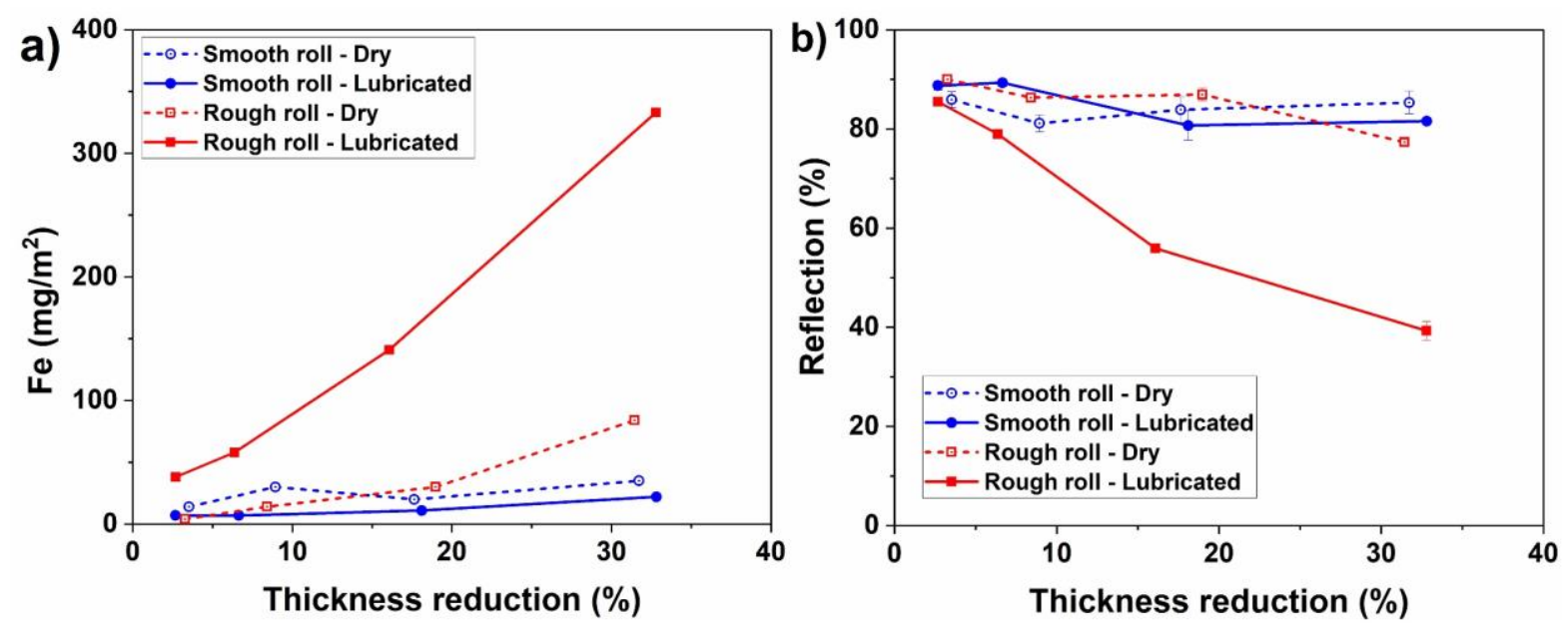

Figure 9: Iron tape a) and reflection tape b) values as a function of thickness reduction.

The impact of thickness reduction on strip cleanliness is far greater for the rolling experiments using rough rolls than for smooth rolls. When the thickness reduction was increased from $5 \%$ to $35 \%$ in the lubricated experiments, the amount of wear particles $\left(\mathrm{mg} / \mathrm{m}^{2}\right)$ increased by approximately 9 times for the rough rolls while it increased only 3 times for the smooth rolls, see figure $9 a$. Likewise, the amount of wear increased by 7.5 times for the rough rolls and by only 2.5 times for smooth rolls in the dry experiments. The amount of wear at 35\% thickness reduction in the case of rough rolls is 15 times higher than in the case of smooth rolls in the lubricated experiments, while it is only 2.4 times in the dry ones. These results clearly demonstrate that roll roughness has a major influence on wear particles formation and strip cleanliness in particular. The smoother the work roll, the better is the strip cleanliness. The asperities of rough rolls plough deeper into the strip material, increase the frictional stress [26] and result in more wear. These results corroborate with earlier studies $[3,4]$ which demonstrated that strip cleanliness strongly deteriorates when the roll roughness is increased. The proportion of asperities operating in the cutting and wedge forming abrasive wear regimes (i.e., the wear regimes which lead to wear particles generation) increases with the increase in the roughness of the rolls. This is related to an increase in the average degree of penetration $\left(d_{p}\right)$ of the roughness asperities as the roughness of the rolls increases. A schematic representation of the different abrasive wear modes as a function of $d_{p}$ and interfacial shear strength ratio $f$ (i.e. ration interface shear strength over shear strength of the softer material) is depicted in figure 11. 

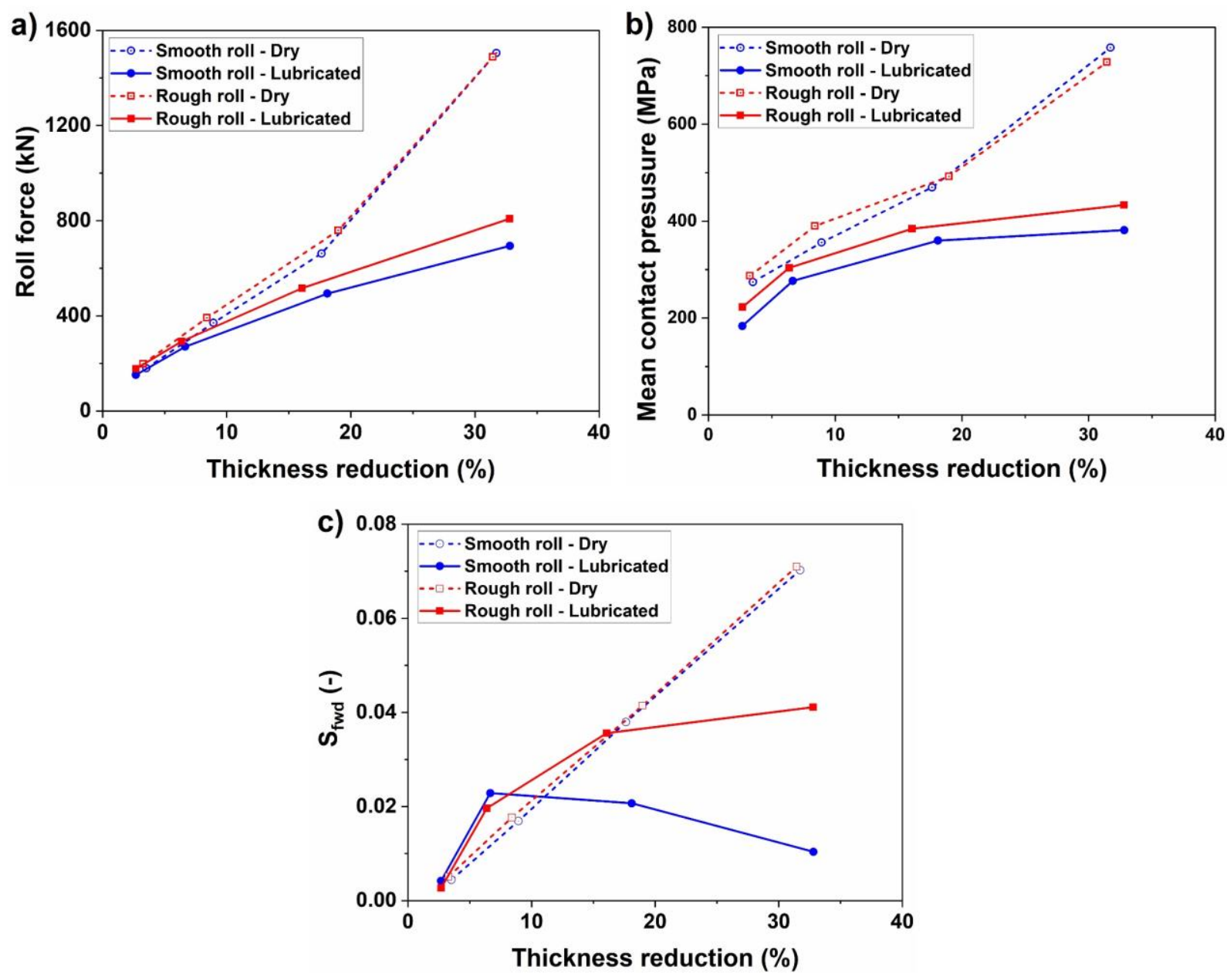

Figure 10: Relation between: (a) thickness reduction and rolling force, (b) thickness reduction and mean contact pressure and (c) thickness reduction and forward slip.

Although it is sometimes possible to roll without lubrication, in general lubricant is applied during cold rolling (in the form of an emulsion) to act as a coolant, to prevent surface damage and to control friction. Nevertheless, the deformation of surfaces under unlubricated conditions provides a useful starting point for lubricated rolling, and points up the key features in the mechanics of asperity deformation. The influence of lubrication on strip cleanliness is also clearly seen in figure 9. The strips rolled under lubricated conditions have a lower surface cleanliness than those in dry conditions at a given thickness reduction for the rolling experiments using rough rolls. On the contrary, the strips rolled using smooth rolls in lubricated experiments are cleaner than the dry ones. This can be explained by the differences in the active abrasive wear modes in dry and lubricated conditions, the effect of lubrication on the real contact area, and the average degree of penetration of the roughness asperities of the rough and smooth rolls. 


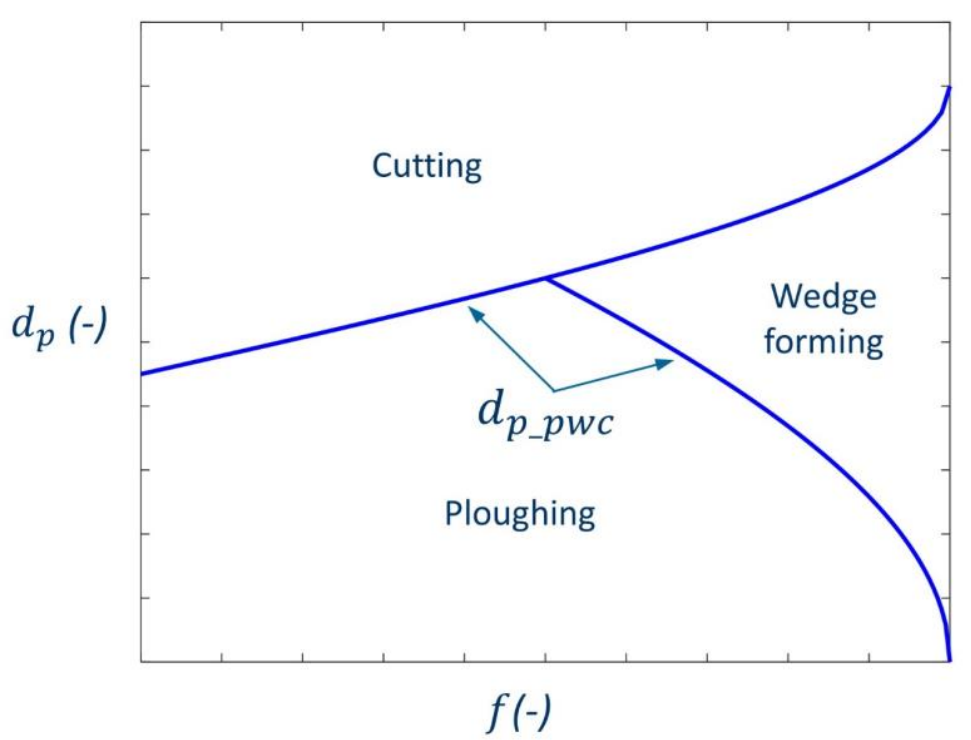

Figure 11: Schematic representation of abrasive wear mode diagram, after Hokkirigawa and Kato [14,27].

Under dry rolling the friction is high, and therefore $f$ is high, and as a result mainly wedging and cutting takes place, see figure 10 [14]. Lubrication reduces the shear strength at the contact interface. The reduced interfacial shear strength results in the transition of the wear mode from wedge forming to cutting for the asperities with $d_{p}$ higher than the critical degree of penetration corresponding to the transition from ploughing to wedge forming/cutting $\left(d_{p_{-} p w c}\right)$. For asperities with $d_{p}<d_{p_{-} p w c}$, lubrication has little influence on the wear mechanism and they stay in the ploughing wear mode [27]. Thus, the roll asperities operate primarily either in ploughing or cutting regime in the lubricated rolling experiments. A higher proportion of the wear groove volume is removed as wear particles in the cutting wear mode than in wedge forming $[14,27,28]$. Owing to the higher average $d_{p}$ of the rough roll asperities than the smooth ones, more asperities will transition from wedging to cutting in the former as a result of the lubrication. This explains the higher wear of the lubricated experiments compared to the dry ones when using rough rolls. In contrast, a small proportion of asperities are expected to have a $d_{p}$ greater than $d_{p_{-} p w c}$ in the smooth rolls, hence little increase in wear particles is expected as a result of the lubrication. The decrease of the wear particles in the lubricated experiments compared to the dry ones when rolling using smooth rolls can be explained by the reduction in the real area of contact due to lubricant entrapment, see section 4.1.1. More lubricant trapping is expected when smooth rolls are used compared to the rough rolls, as the lubricant can easily escape on the deep ridges created by the rough roll asperities. Moreover, the lubrication regime of the smooth rolls will be more towards the mixed lubrication regime, resulting in less real contact area between the roll and the strip, and hence, less friction and wear. This is attested by the lower rolling force (figure 10a) and lower forward slip (figure 10c) of the rolling experiments using smooth rolls. Low forward slip is commonly associated with low friction coefficient [29].

\subsubsection{Rolling speed}

Reflection tape and iron tape values as a function of the rolling speed are plotted in figure 12 . The thickness reduction was kept constant at $20 \%$. Rolling speed did not show any substantial influence on the strip cleanliness. In literature [3], a positive influence of a high rolling speed on surface cleanliness is reported. This influence can be expected for a very large increase in the rolling speed for lubricated cold rolling. As this may result in thicker oil film in the roll bite and affect the lubrication regime (possibly change from boundary lubrication to mixed lubrication) and therefore reduce the real contact area. The fact that the rolling speed did not significantly affect the strip cleanliness in the current experiments affirms that the rolling was indeed carried out in boundary lubrication regime and the variation of the rolling speed was not big enough to considerably influence the film thickness and the lubrication regime. Both the rolling force and forward slip were not influenced notably by the rolling speed (figure 13), corroborating the strip cleanliness measurements. The small increase in the rolling force as the rolling speed is increased (figure 
13a) is probably caused by the strain rate hardening behavior of the strip material. The slight decrease of the forward slip observed in figure 13b, particularly for the lubricated rolling experiments with smooth rolls, indicates that there might be a marginal increase in film thickness.
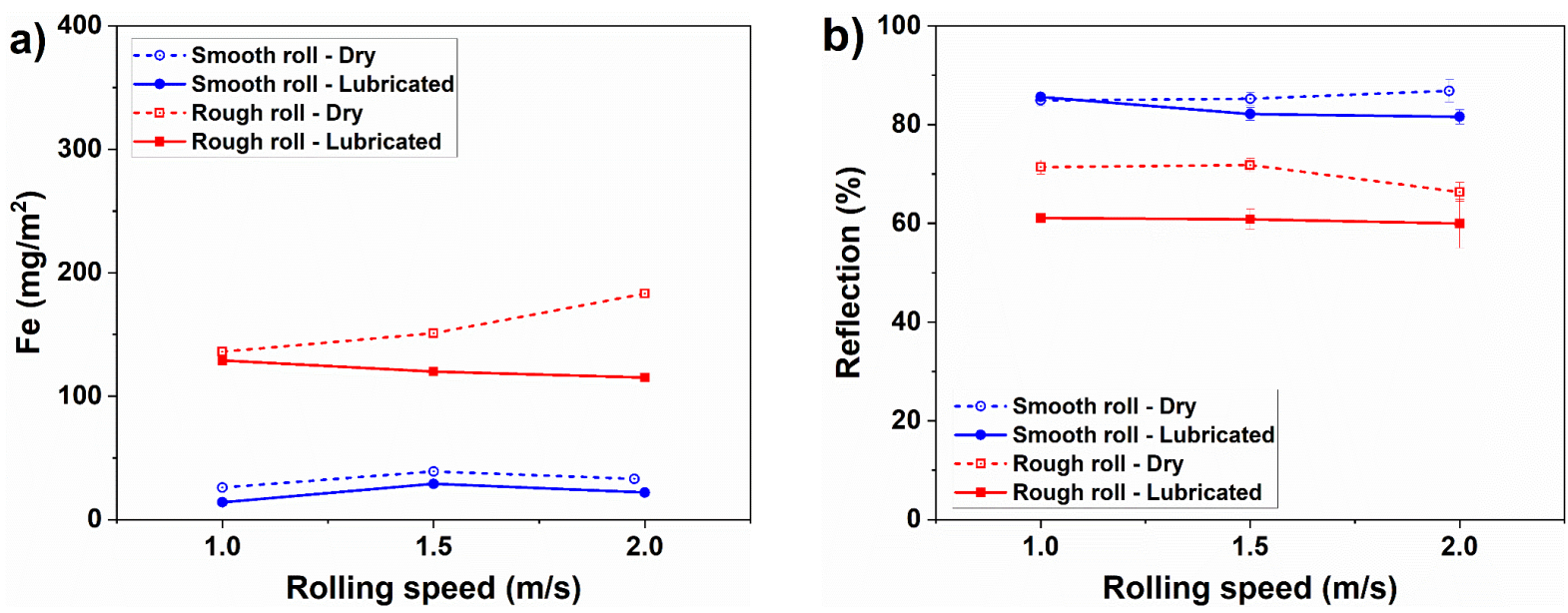

Figure 12: Iron tape a) and reflection tape b) values as a function of the rolling speed.
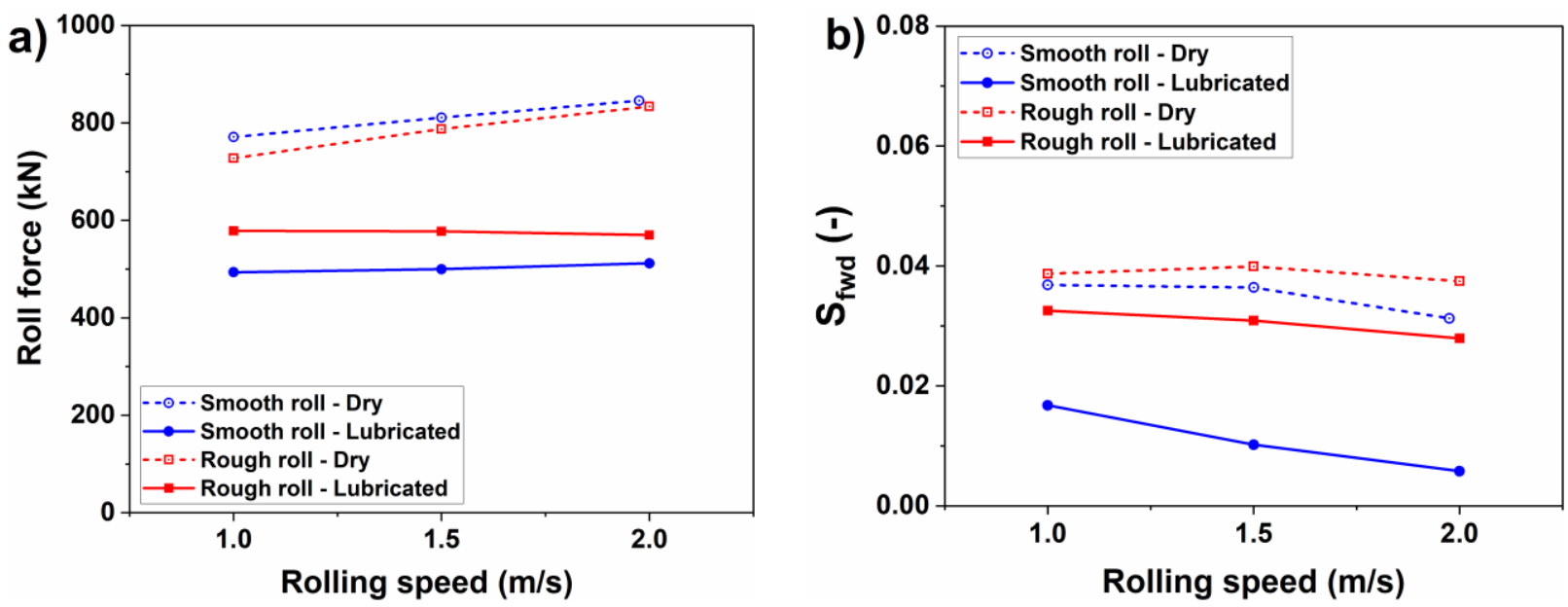

Figure 13: Influence of rolling speed on: a) rolling force and b) forward slip.

\subsubsection{Exit tension}

The exit tension was varied, keeping the entry tension constant, to investigate the influence of forward slip on strip cleanliness. Increasing the exit tension moves the neutral point towards the roll entrance and increases the forward slip [13]. One effect of varying the forward slip is on the sliding length before and after the neutral point. The strip asperities are deformed by the ploughing roll asperities in the rolling direction before the neutral point. Strip asperities are deformed opposite to the rolling direction after the neutral point, as the relative velocity of the roll asperities relative to the sheet surface is reversed. The effect of changing the exit tension on forward slip is illustrated in figure 14. The rolling speed and thickness reduction were kept constant at $0.5 \mathrm{~m} / \mathrm{s}$ and $20 \%$ respectively. As expected, the forward slip increased with an increase in the exit tension. Besides, the increase in forward slip is much higher for the lubricated rolling experiments than the dry ones. This can be ascribed to the lower friction coefficient of the lubricated experiments which allows easy slip between the roll and the strip surface. 


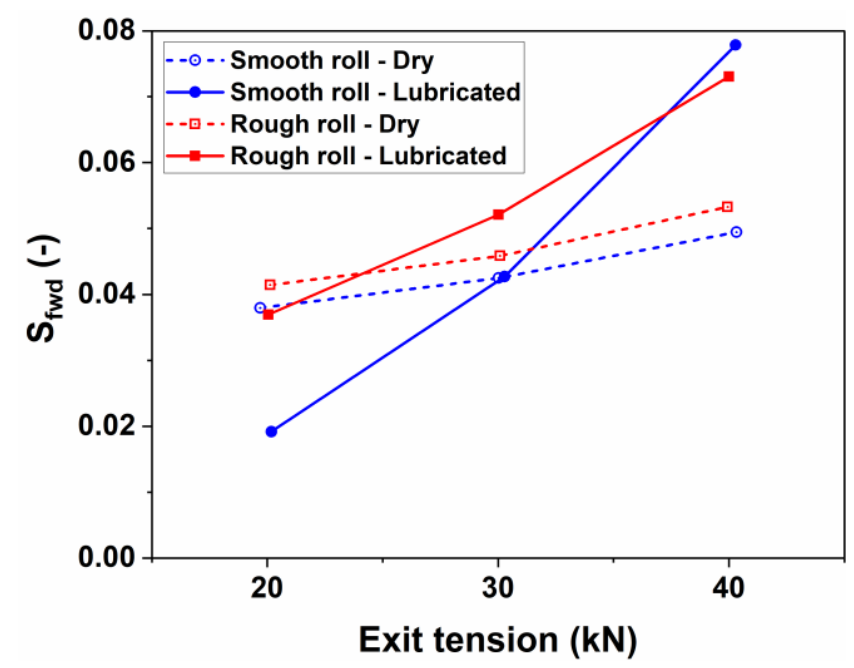

Figure 14: Influence of exit tension on forward slip.

The amount of wear debris produced as a function of the forward slip is plotted in figure 15 . No clear influence of the forward slip on the rate of wear particles formation is witnessed in the current experiments. Contradicting results are reported in literature on the influence of forward slip on strip cleanliness. Some studies $[5,6]$ reported increasing the forward slip increases the amount of wear particles generated. Others $[3,7]$ reported no influence of forward slip on the quantity of wear particles. The current result agrees with the latter. Deltombe et al. [5] and Huart et al. [6] claimed that increasing the forward slip contributes to the increase in quantity of wear particles produced, with its influence being more pronounced at high thickness reductions and high forward slip. This was attributed to the large sliding distance in the backward direction. However, the forward slip in their study is much higher (>0.1 and > $0.2)$ than the one experienced in the current experiments $(<0.08)$.
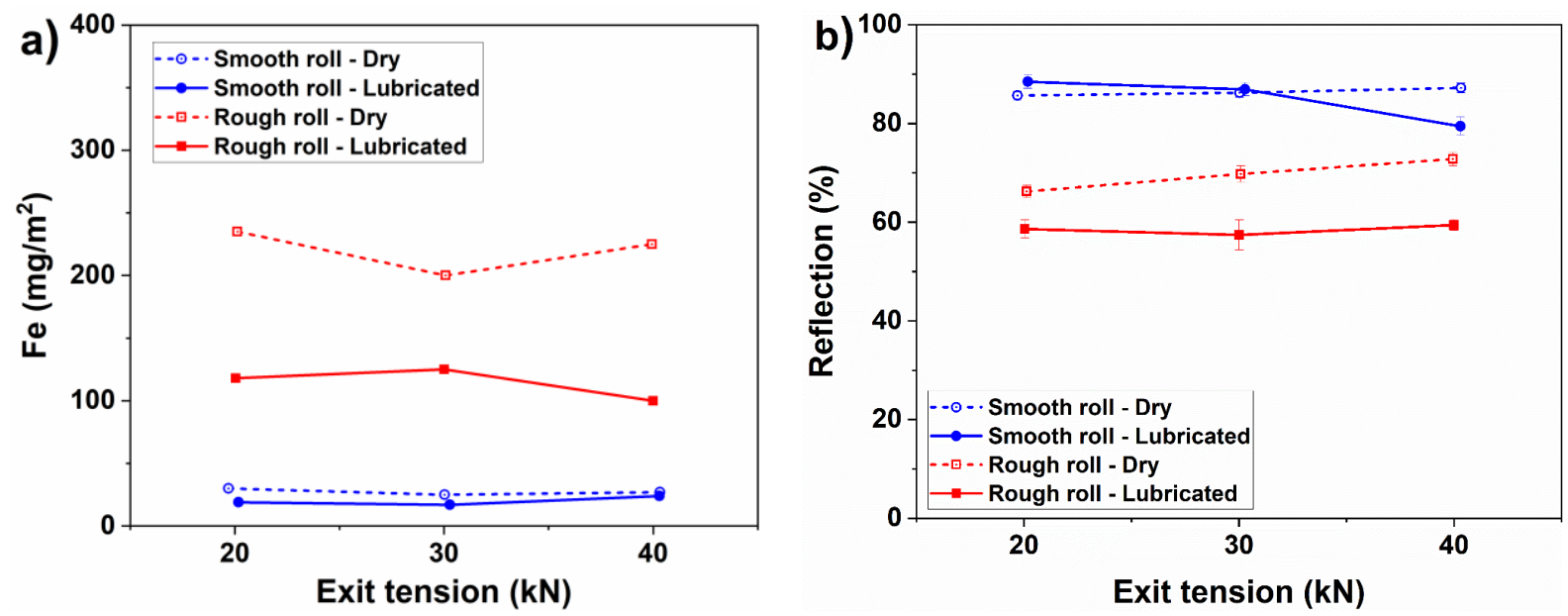

Figure 15: Strip cleanliness as a function of exit tension.

\subsubsection{Reflection tape vs iron tape}

In order to study the reproducibility and suitability of the two strip cleanliness characterization techniques, the relationship between the reflection tape and iron tape measurement values is plotted in figure 16. They seem to show an exponential relationship. The exponential relationship can be linked to the fact that overlapping wear particles cannot be measured in reflection tape measurements, whereas all the particles are measured in the iron tape measurements. One effect of this relationship is that the reflection tape is less sensitive for unclean strips. Note that the lubricated and the dry experiments do not lie on the same curve. The reflection tapes of the lubricated experiments are darker than the dry ones for the same amount of iron tape value. This is expected as the lubricant makes the tape darker in the lubricated 
experiments. Jacobs et al. [3] has evaluated the accuracy of the reflection tape and iron tape method. They showed a linear relationship between these two methods in a semi-logarithmic scale.

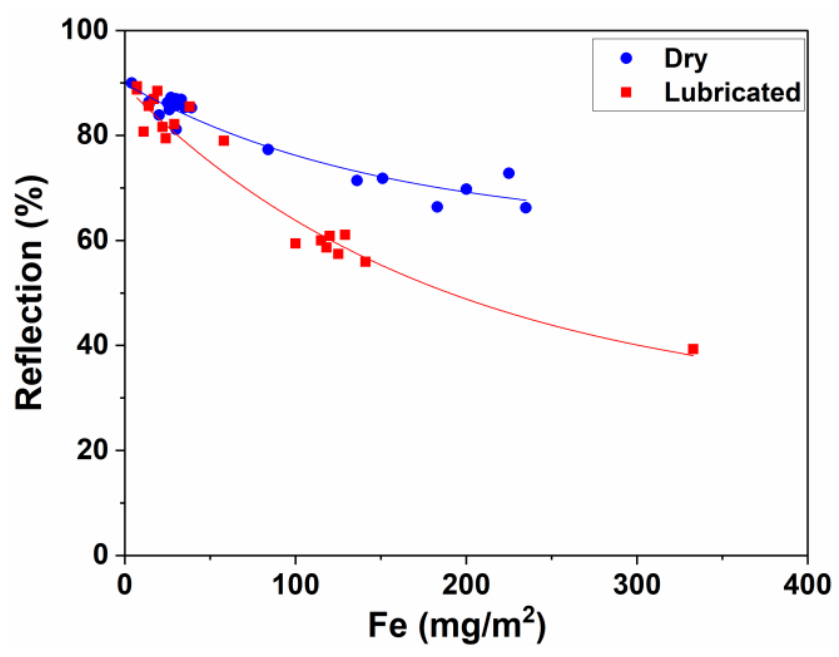

Figure 16: Reflection tape vs iron tape values.

\subsubsection{Wear particle size distribution}

Analysis of the size distribution of wear particles has been done using microscopy imaging and image segmentation. This allows to visualize of the shape and/or size of the wear particles, and to study how the characteristics of the particles change (if any) with process parameters. The typical acquired color images are presented in figure 17a. The wear particles are clearly brighter than the background. After converting the color image into gray scale, the wear particles are extracted from the image based on contrast information by thresholding to remove the background. It is necessary to know the distribution of the pixel values to obtain an appropriate threshold. The histogram of the image in figure 17a is shown in figure 18. The distribution of the background is concentrated around and below the highest peak of the histogram distribution. The distribution of the pixel values in all the images taken show a peak approximately in the same range as in figure 18 because the background luminescence is adjusted during image acquisition. Consequently, the pixels corresponding to the wear particles can be distinguished from those belonging to the background by the following condition:

$$
\text { Pixel value }>\zeta
$$

where, $\zeta$ is the appropriate threshold.

a) Original color image
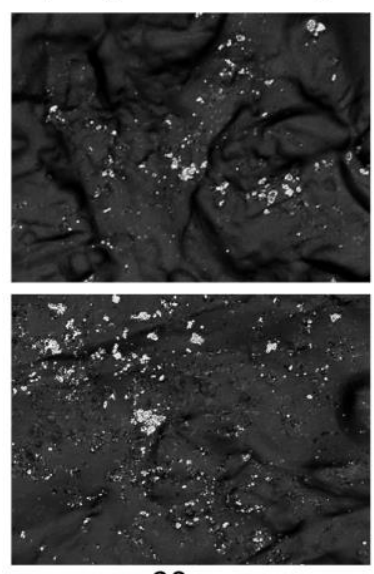

$30 \mu \mathrm{m}$ b) $\zeta=77$
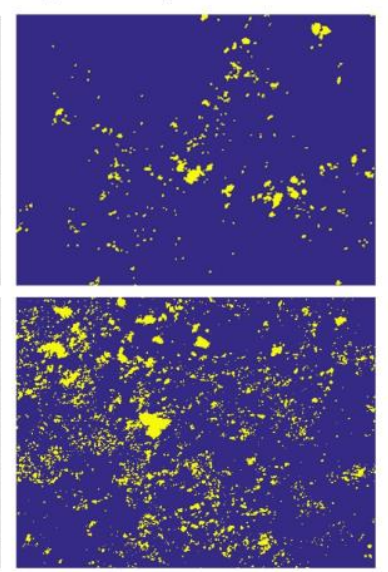

c) $\zeta=102$
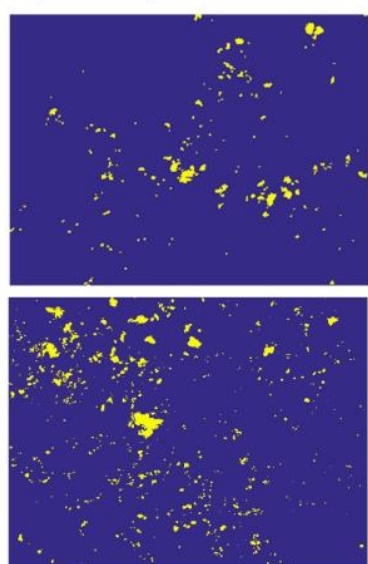

d) $\zeta=128$
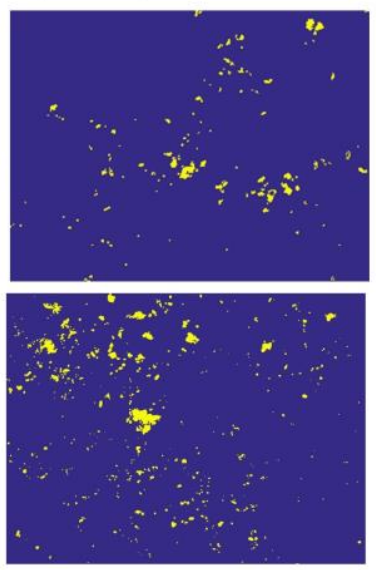

Figure 17: a) typical color microscopy images of the wear particles of the rolling experiments, and b-d) the corresponding images after wear particle extraction (represented by light yellow) by applying several threshold (ろ) values. 
The wear particles can be extracted by selecting the pixels which satisfy the conditional expression in Eq. (8). Figure 17(b-d) shows the result when the wear particles are extracted from the images in figure 17a for several $\zeta$ values. A closer look of the images shows that part of the background is falsely identified as a wear particle at $\zeta=77$ (30\% of the maximum pixel value) (figure 17b) and some wear particles (mainly contaminated small wear particles) are falsely identified as background at $\zeta=128$ (50\% of the maximum pixel value). A threshold value of $\zeta=102$ (which is $40 \%$ of the maximum pixel value) was chosen for further analysis as this value appears to minimize false interpretation of the background as a wear particle and vice versa. After the particles are identified from the input image, the size (area and equivalent diameter) of each particle and the number of particles on each image is determined. The image processing was executed in MATLAB.

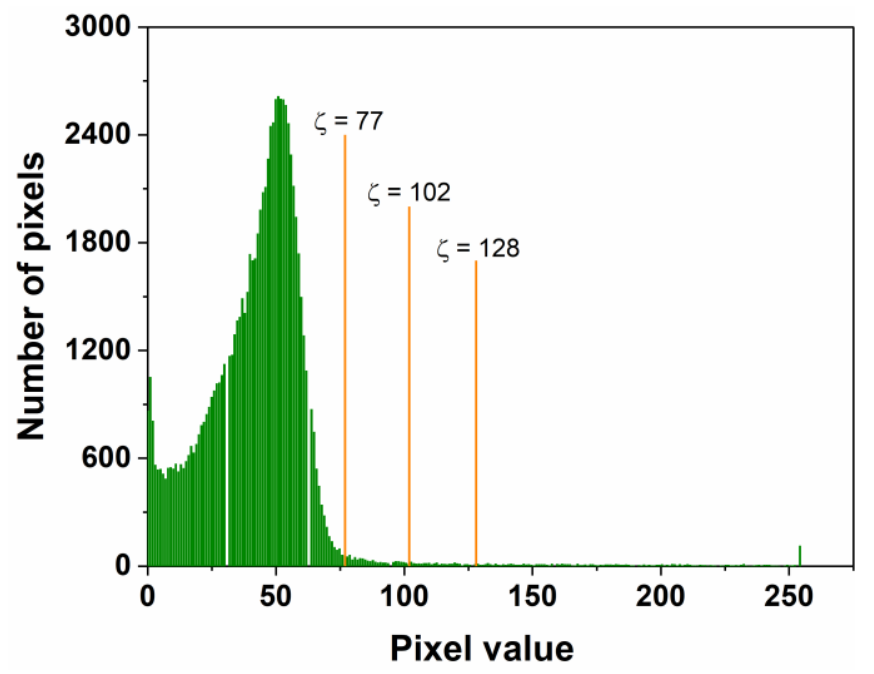

Figure 18: Histogram of pixel values of the image in figure 17a (top).

Figure 19 illustrates the spread of wear particles on the adhesive tape at several thickness reductions, roll roughness and lubrication condition. A lot of small and a few big wear particles are seen dispersed throughout the tape. Previous study [2] has shown that these particles consist mostly of iron. The size and quantity of wear particles increase as the thickness reduction increases. This is consistent with the iron tape and reflection tape measurements. The increase in the size of wear particles as the thickness reduction is increased can be ascribed to the roll asperities ploughing deeper and sliding longer distance. Many more particles are formed when rough rolls are used, in agreement with the iron tape and reflection tape measurements. Moreover, it can be seen that the proportion of small wear particles is larger in the lubricated experiments than the dry ones. The two factors that may contribute to this difference are: (i) the difference in the predominant abrasive wear mode in lubricated and dry contact and (ii) the small wear particles can easily disperse in the oil in the lubricated experiments. Cutting is expected to be the dominant abrasive wear mechanism in the lubricated experiments and wedge forming in the dry ones (see figure 11). Cutting promotes formation of a small size flake-type wear particles [14]. Whereas, in wedge forming, wear debris are detached when the wedge growing ahead of the ploughing asperity reaches a critical size, see for example [27]. 


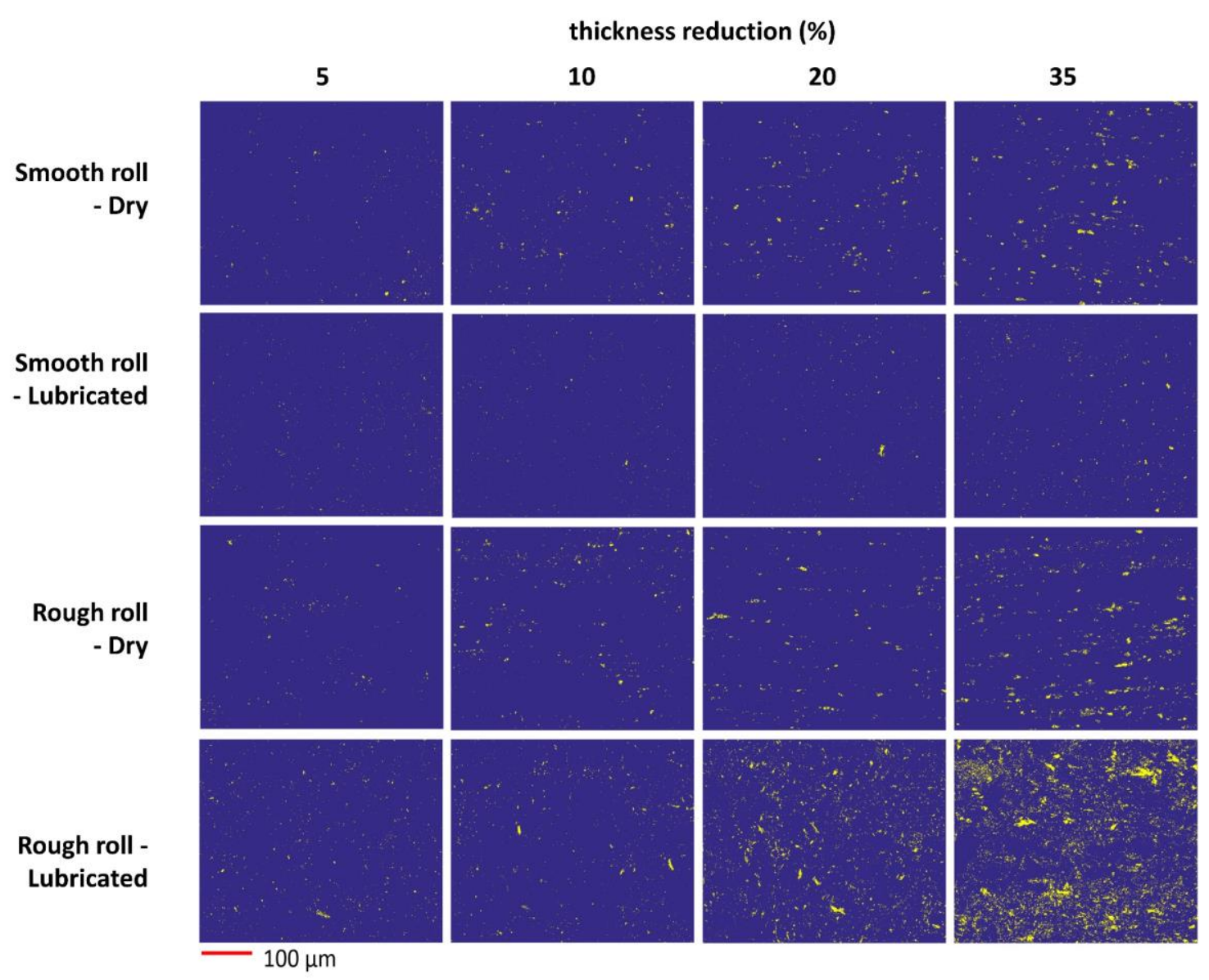

Figure 19: The variation of wear particle distribution as a function of thickness reduction, roll roughness and lubrication.

The statistical results of the size and quantity distribution of the wear particles is presented in figure 20. The microscopy images were taken at four different locations (for every rolling condition), each covering an area of $473 \mu \mathrm{m} \times 356 \mu \mathrm{m}$, to get a representative distribution of the particles. The size of the wear particles is defined by an equivalent diameter, which is the diameter of a circle with the same area as the particle. The wear particles with $<5 \mu \mathrm{m}$ in diameter constitute nearly $99 \%$ of the total number of wear particles and $80 \%$ to $97 \%$ of the total area covered by wear particles. In contrast, particles bigger than 10 $\mu \mathrm{m}$ constitute only a very small fraction, less than $2 \%$ and $7 \%$ of the total area in the lubricated and dry experiments, respectively. The amount of big wear particles $(>5 \mu \mathrm{m})$ increases with thickness reduction from about $5 \%$ of the total area at $5 \%$ thickness reduction to $19 \%$ at $35 \%$ thickness reduction. The roll asperities plough deeper into the strip surface and slide larger distance as the thickness reduction is increased, leading to the formation of bigger wear particles observed at high thickness reductions.

Figure 21 compares the proportion of the surface area of the adhesive tape (strip) covered by wear particles. It exhibits good agreement with the iron tape measurements (figure 9). Less than $2 \%$ of the strip area is covered by wear particles when smooth rolls were used, irrespective of the thickness reduction. On the contrary, the wear particles cover an area as high as $7.5 \%$ of the strip surface at high thickness reduction when rough rolls were used under lubricated conditions. 

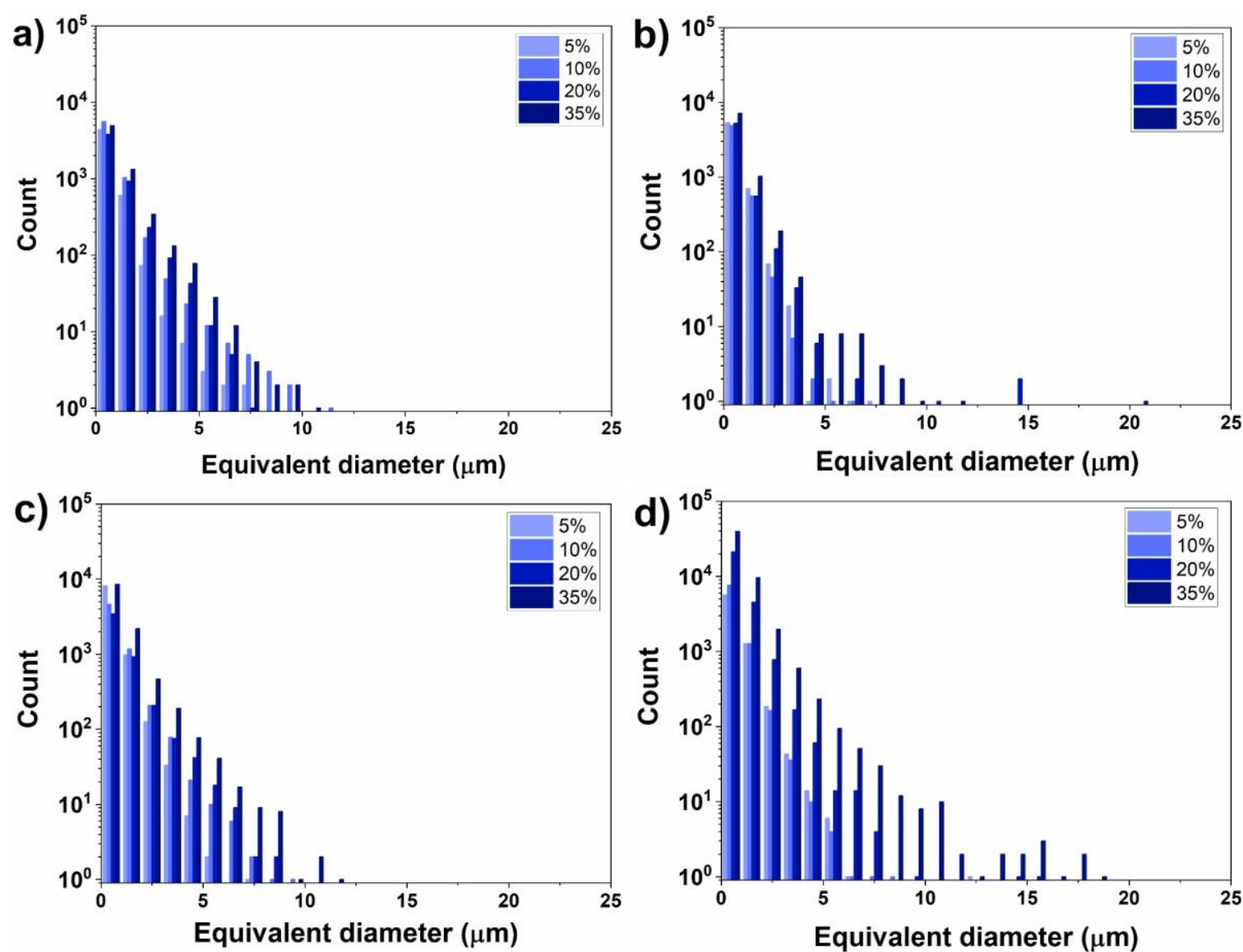

Figure 20: Wear particle size distribution of the rolling experiments at several thickness reductions (5\%, $10 \%, 20 \%$ \& 35\%): a) smooth roll - dry, b) smooth roll - lubricated, c) rough roll - dry, d) rough roll lubricated.

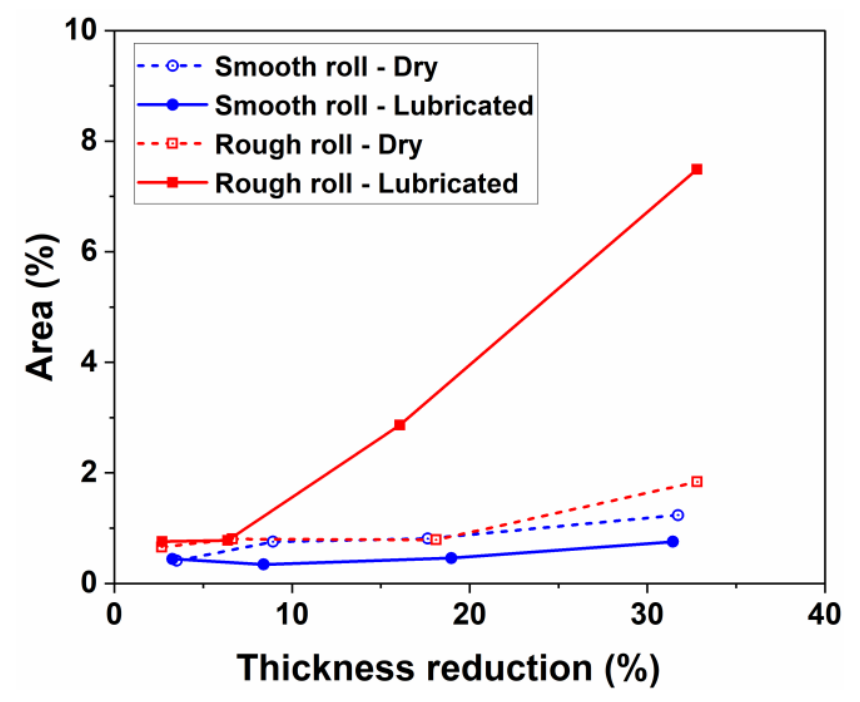

Figure 21: The percentage area of the strip surface covered by wear particles.

\subsection{Scratch experimental results}

Modelling wear in cold rolling requires relating the influence of rolling parameters on the macroscale contact behavior and the microscopic wear mechanism at asperity level. The scratch experiments provide information about the microscopic wear mechanism and the volume of material removed as wear debris at single asperity contact. The fraction of material removed $\left(d_{w}\right)$ as a function of the degree of penetration $\left(d_{p}\right)$ in the scratch experiments is graphed in figure 22. As expected, the degree of wear increases with 
increasing $d_{p}$. However, $d_{w}$ starts to fluctuate heavily with increasing $d_{p}$. This is due to the high ductility of the material under investigation (Ti-IF steel), where the formed chips (sometimes) do not break off but remain next to the wear track, resulting in this fluctuation. Similar observation is reported in [15].

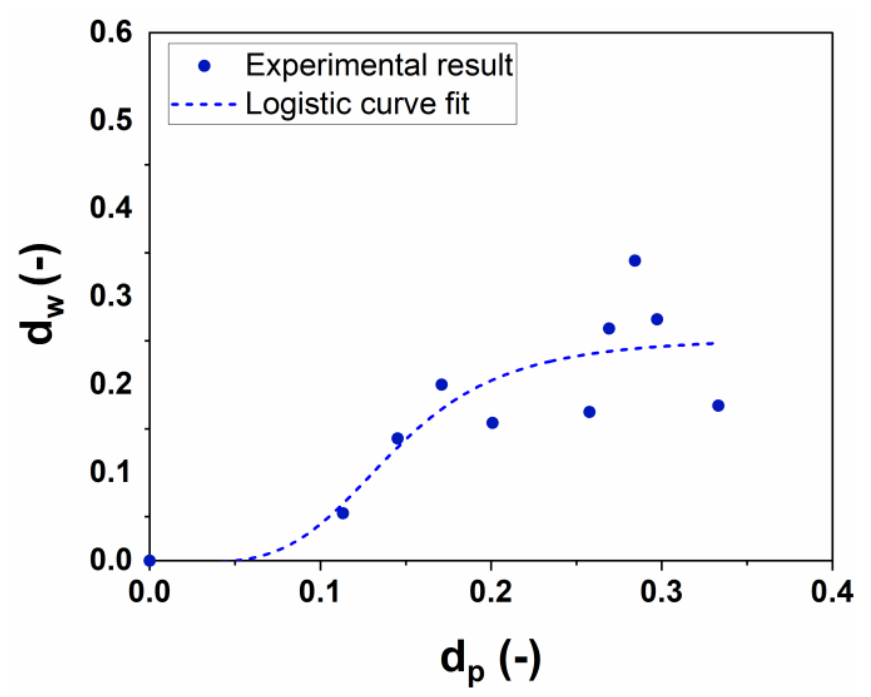

Figure 22: Degree of wear as a function of degree of penetration.

It is necessary to define the relationship between $d_{w}$ and $d_{p}$ in a mathematical equation to incorporate the scratch experiment results into the wear model (see section 2). Referring to Hokkirigawa et al. [28] experimental results obtained by sliding a spherical indenter on various heat treated steels, the degree of wear is expected to increase from 0 to a maximum value following an S-shaped curve, in which the maximum value depends on the material being scratched. Considering this, the experimental results are fitted by a logistic function, which has a characteristic S-shaped curve, following a least squared method curve fitting approach. The resulting equation is given by Eq. (9) and is plotted as a dashed line in figure 22.

$$
d_{w}=0.253-0.253 /\left(1+\left(d_{p} / 0.143\right)^{4.348}\right)
$$

\subsection{Model results}

Comparison of the measured amount of wear and the model results for the lubricated rolling experiments are provided in figure 23 . The model results presented here are an average of 18 simulations. Dissimilar surface roughness measurements $(1.6 \mathrm{~mm} \times 1.2 \mathrm{~mm}$, lateral resolution $0.52 \mu \mathrm{m})$ of the roll and the strip were used for each simulation. The model results confirm that roll roughness and thickness reduction are the predominant rolling parameters that determine the amount of wear particles formation, rough roll and high thickness reduction giving the most wear. The observed higher wear when using rough rolls than smooth rolls is attributed to the higher $d_{p}$ of asperities in the former. Figure 24 illustrates an example of the $d_{p}$ distribution at $20 \%$ thickness reduction for smooth and rough rolls. When smooth rolls are used, most asperity contacts will be in the ploughing regime and wear will occur only for relatively small number of asperity contacts which are sufficiently sharp enough to operate in cutting or wedge forming wear mechanism. The high rate of wear particles formation at high thickness reductions is due to the increased severity of contact, i.e. the increased real area of contact and sliding distance at high thickness reduction. The high standard deviation of the model results suggests that the variation of the local roll roughness significantly influences the amount of wear. This can be, however, improved by utilizing surface roughness measurements covering a bigger area. 


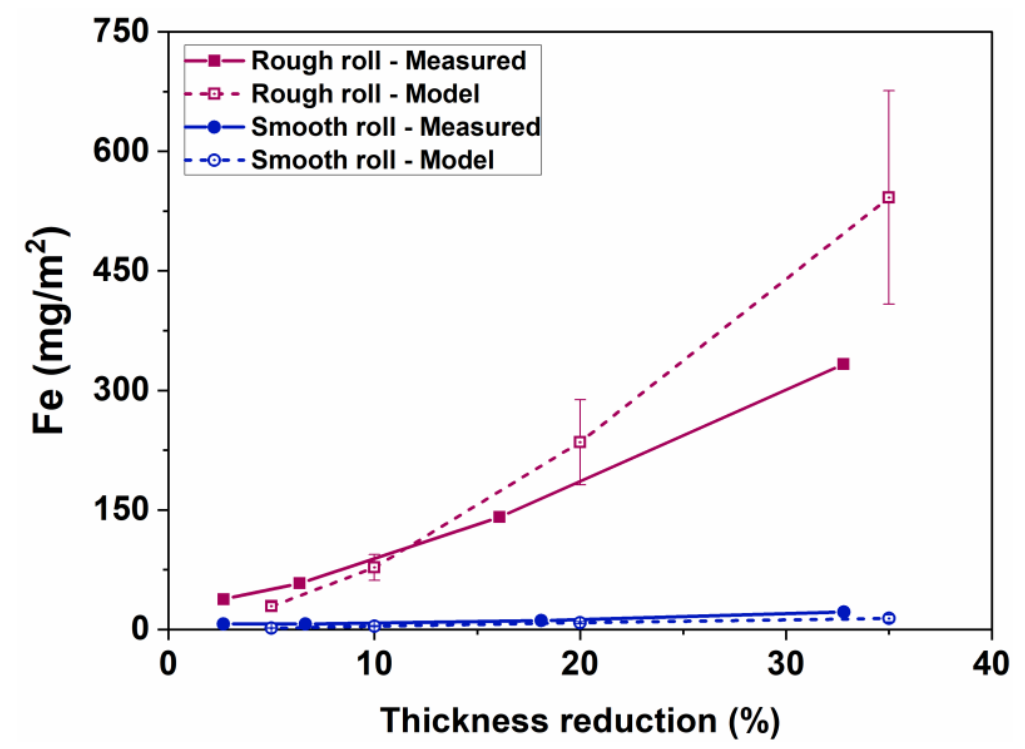

Figure 23: Wear as a function of thickness reduction for the lubricated rolling experiments: Measured vs Model.
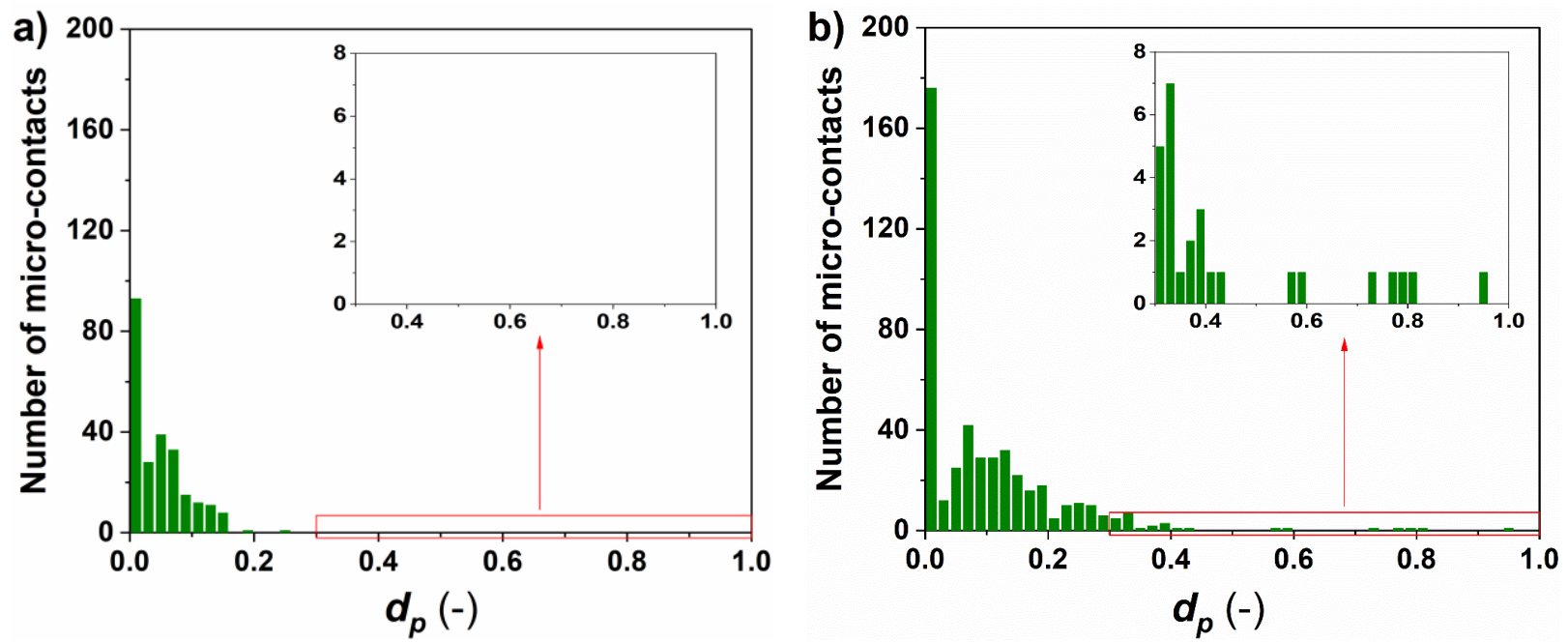

Figure 24: The distribution of degree of penetration of roll asperities in contact with the strip at $20 \%$ thickness reduction for $a$ ) smooth roll and $b$ ) rough roll.

The model captures the trend correctly and give values in the same order of magnitude as the experiments. Nevertheless, noticeable differences are observed in terms of the exact amount of wear between the measured and the model results. The model underestimates the wear volume when using smooth rolls at all thickness reductions and at low thickness reductions when using rough rolls. Conversely, the model overestimates the wear volume when using rough rolls at high thickness reductions. In the current model, only abrasive wear is considered. Although abrasive wear can be regarded as the prime wear mechanism, it has to be emphasized that usually several wear mechanisms act simultaneously and the wear mechanisms interact. Adhesive, fatigue, corrosive and erosive wear are the potential other wear mechanisms may also contribute to wear in cold rolling operations [9]. Additionally, third body abrasive wear, caused by the hard oxide particles/hard phases like carbides from the strip which are broken away and drag long the rolls also influence the mechanics, dynamics and chemistry of the sliding surfaces. Plus, the scratch experiments were done for spherical asperities. However, the roughness asperities are irregular and this shape may affect the wear mechanism and the degree of wear. Kayaba et al. [30] studied the three dimensional shape effect on abrasive wear (both wear mode and wear rate) as a function of the attack angle and the dihedral angle. They showed that wear rate is sensitive to the change of both attack angle and dihedral angle. It has also to be noted that the influence of other rolling parameters such as roll 
diameter and lubricant temperature cannot be neglected as it affects the lubricant film thickness and performance of lubricant additives $[4,7]$.

The slight underestimation of the wear volume by the model when using smooth rolls at all thickness reductions and at low thickness reductions when using rough rolls is most likely caused by the fact that hard oxide particles and carbides from the strip, which can break away, are not modelled. The overestimation of the model at high thickness reductions when using rough rolls is probably caused by the use of the real contact area at the exit of the roll bite, which is an overestimation of the actual real contact area. Another aspect of the varying relative speed throughout the roll bite is that a roll asperity that is directly behind the one ahead along the rolling direction will catch up and slide already created wear groove by the latter. This reduces the effective degree of penetration, and consequently, the wear volume. Besides, the degree of wear was measured in the scratch experiments for an ideal asperity, an approximate of the real shape of asperities.

In summary, the model covers the main physical phenomena related to wear particle generation and showed a good agreement with the experimental results. It can be developed further by including the influence of several other rolling parameters and influencing factors. For example, it can be extended for different material grades and cold rolling processes operating in the mixed lubrication regime.

\section{Conclusion}

Cold rolling experiments were conducted in dry and lubricated conditions at several thickness reductions, rolling speed and exit tension using smooth and rough rolls to investigate the effect of rolling parameters on the quantity of wear particles. Moreover, a wear model that combines macroscale contact model and wear at single asperity contact is proposed. Rolling experiments revealed that thickness reduction and roll roughness are the two dominant process parameters that control strip cleanliness/wear particles generation in cold rolling processes operating under boundary lubrication regime. The combination of rough rolls and high thickness reduction under lubricated contact resulted in the worst strip cleanliness. Rolling speed and exit tension (forward slip) exhibited little influence on strip cleanliness in the current experiments. Analysis of the wear particles size distribution showed that most of the wear particles are less than $5 \mu \mathrm{m}$ (in diameter), constituting nearly $99 \%$ of the total number of the wear particles and $80 \%$ to $97 \%$ of the total area covered by wear particles.

The proposed wear model covers the main physical phenomena related to wear particle generation. Furthermore, it captures the trend correctly and give values in the same order of magnitude as the experiments in terms of the volume of wear particles generated.

\section{References}

[1] Fisher TW, lezzi RA, Madritch JM. Theoretical and practical considerations of sheet steel surface cleanliness. SAE Trans 1980;89:923-35. doi:10.2307/44632465.

[2] Pesci C, Monfort G, Torre V, Van Steden H, Kurzynski J, Vervaet B, et al. Controlling wear and surface cleanliness during cold rolling (LOWWEAR). 2012. doi:10.2777/23177.

[3] Jacobs L, Vervaet B, Hermann H, Agostini M, Kurzynski J, Jonsson N-G, et al. Improving strip cleanliness after cold rolling. Proc Inst Mech Eng Part J J Eng Tribol 2011;225:959-69. doi:10.1177/1350650111413639.

[4] Labiapari W da S, de Alcântara CM, Costa HL, De Mello JDB. Wear debris generation during cold rolling of stainless steels. J Mater Process Technol 2015;223:164-70. doi:10.1016/J.JMATPROTEC.2015.03.050.

[5] Deltombe R, Dubar M, Dubois A, Dubar L. A new methodology to analyse iron fines during steel cold rolling processes. Wear 2003;254:211-21. doi:10.1016/S0043-1648(03)00005-X.

[6] Huart S, Dubar M, Deltombe R, Dubois A, Dubar L. Asperity deformation, lubricant trapping and iron 
fines formation mechanism in cold rolling processes. Wear 2004;257:471-80. doi:10.1016/J.WEAR.2004.01.012.

[7] Louaisil K, Dubar M, Deltombe R, Dubois A, Dubar L. Analysis of interface temperature, forward slip and lubricant influence on friction and wear in cold rolling. Wear 2009;266:119-28. doi:10.1016/J.WEAR.2008.06.003.

[8] Hui Z, Manxing W. A study of wear mechanisms in the cold rolling of aluminium strip. J Mater Process Technol 1992;31:235-43. doi:10.1016/0924-0136(92)90024-M.

[9] Turner $\mathrm{CH}$. Tribology - understanding the cost of quality in cold rolling. Steel Times Iternational 1995;223:s6-7.

[10] Montmitonnet P, Delamare F, Rizoulieres B. Transfer layer and friction in cold metal strip rolling processes. Wear 2000;245:125-35. doi:10.1016/S0043-1648(00)00473-7.

[11] Montmitonnet P, Bouadjadja N, Luong LP, Bertrandie JJ, Dietsch H. On the mechanism by which chromium improves strip surface cleanliness in steel strip cold rolling. Key Eng Mater 2018;767:2407. doi:10.4028/www.scientific.net/KEM.767.240.

[12] Mekicha MA, de Rooij MB, Jacobs L, Matthews DTA, Schipper DJ. Experimental validation of contact models for cold-rolling processes. J Mater Process Technol 2020;275:116371. doi:10.1016/j.jmatprotec.2019.116371.

[13] Dieter GE, Bacon DJ. Mechanical metallurgy. London: McGraw-Hill; 1988.

[14] Hokkirigawa K, Kato K. An experimental and theoretical investigation of ploughing, cutting and wedge formation during abrasive wear. Tribol Int 1988;21:51-7. doi:10.1016/0301-679X(88)901284.

[15] Masen MA, de Rooij MB, Schipper DJ. Micro-contact based modelling of abrasive wear. Wear 2005;258:339-48. doi:10.1016/J.WEAR.2004.09.009.

[16] Masen MA, de Rooij MB. Abrasive wear between rough surfaces in deep drawing. Wear 2004;256:639-46. doi:10.1016/j.wear.2003.10.006.

[17] Wilson WRD, Sheu S. Real area of contact and boundary friction in metal forming. Int J Mech Sci 1988;30:475-89. doi:10.1016/0020-7403(88)90002-1.

[18] Lenard JG. Metal Forming Science and Practice. Elsevier; 2002. doi:10.1016/b978-0-08-044024$8 . \times 5000-0$.

[19] Azushima A, Yoneyama S, Yamaguchi T, Kudo H. Direct observation of microcontact behavior at the interface between tool and workpiece in lubricated upsetting. CIRP Ann - Manuf Technol 1996;45:205-10. doi:10.1016/S0007-8506(07)63048-0.

[20] Azushima A, Uda M, Kudo H. An interpretation of the speed dependence of the coefficient of friction under the micro-phl condition in sheet drawing. CIRP Ann - Manuf Technol 1991;40:227-30. doi:10.1016/S0007-8506(07)61974-X.

[21] Bay N, Bech JI, Andreasen JL, Shimizu I. Studies on micro plasto hydrodymic lubrication in metal forming 2002:115-34.

[22] Bech J, Bay N, Eriksen M. Entrapment and escape of liquid lubricant in metal forming. Wear 1999;232:134-9. doi:10.1016/S0043-1648(99)00136-2.

[23] Patir N, Cheng HS. An average flow model for determining effects of threedimensional roughness on partial hydrodynamic lubrication. J Tribol 1978;100:12-7. doi:10.1115/1.3453103.

[24] Tabor D. Junction growth in metallic friction: the role of combined stresses and surface contamination. Proc R Soc London Ser A Math Phys Sci 1959;251:378-93. doi:10.1098/rspa.1959.0114. 
[25] Gåård A, Sarih RM. Influence of tool material and surface roughness on galling resistance in sliding against austenitic stainless steel. Tribol Lett 2012;46:179-85. doi:10.1007/s11249-012-9934-7.

[26] Mizuno T, Hasegawa K. Effects of die surface roughness on lubricating conditions in the sheet metal compression-friction test. J Tribol 1982;104:23-8. doi:10.1115/1.3253160.

[27] Kayaba T, Hokkirigawa K, Kato K. Analysis of the abrasive wear mechanism by successive observations of wear processes in a scanning electron microscope. Wear 1986;110:419-30. doi:10.1016/0043-1648(86)90115-8.

[28] Hokkirigawa K, Kato K, Li ZZ. The effect of hardness on the transition of the abrasive wear mechanism of steels. Wear 1988;123:241-51. doi:10.1016/0043-1648(88)90102-0.

[29] Lenard JG. Primer on Flat Rolling. 2nd edition. Elsevier; 2014. doi:10.1016/C2012-0-06474-5.

[30] Kato K, Hokkirigawa K, Kayaba T, Endo Y. Three dimensional shape effect on abrasive wear. J Tribol 1986;108:346-9. doi:10.1115/1.3261193. 

